Transformaciones en territorios de interfase. Un aporte a la planificación de Sierras Chicas en Córdoba desde los socio-ecosistemas

Tesista: Arq. Yuliana Céliz

Directora: Dra. Arq. Beatriz Giobellina

Co-Director: Lic. Geografía H. Luis Adriani

La Plata - Buenos Aires

12 de febrero de 2020 


\title{
Transformaciones en territorios de interfase
}

\section{Un aporte a la planificación de Sierras Chicas en Córdoba desde los socio- ecosistemas}

\section{Arq. Yuliana Céliz}

\author{
Directores \\ Dra. Arq. Beatriz L. Giobellina \\ Lic. Geografía H. Luis Adriani
}

Director en metodología SIG y Teledetección

Dr. Biol. Diego Pons

El tribunal para esta tesis estuvo conformado por

Dr. Ramiro Sarandón

Dra. María Amalia Lorda

Dra. Evangelina P. Velazco

\section{ccreative co (1) (-)}

This work is licensed under the Creative Commons Attribution-NonCommercial-ShareAlike 4.0 International License. To view a copy of this license, visit http://creativecommons.org/licenses/by-nc-sa/4.0/ or send a letter to Creative Commons, P0 Box 1866, Mountain View, CA 94042, USA. 
En realidad, el hombre es un actor recién llegado al escenario ambiental del que se quiere apropiar: Ios mamíferos, género al cual pertenece, existen en la Tierra desde mucho antes, los animales en general desde todavía antes y la vida, como manifestación biológica, desde todavía más atrás en el tiempo. Y todas estas formas de vida se desarrollaban también en "su" ambiente. Está bien que podemos decir que el hombre tiene una particular capacidad para modificar algunos de los factores que forman el ambiente y también de agregarle nuevos elementos. Pero esto no le da necesariamente derecho de propiedad exclusiva sobre ese ambiente del cual forma parte (Reboratti 2000). 


\section{Agradecimientos}

A la arquitecta Isabel López, por confiar en que esto sería posible desde el primer día, infinitamente agradecida. A todos los que forman parte de la maestría, docentes y compañeros, por hacerlo tan feliz. A Licia por la palabra y la sonrisa cariñosa cada vez que llegaba después de un largo viaje desde casa.

A mi directora Beatriz, por ser una guía y una mujer incansable, por abrir puertas y ser inmensamente compañera. A Diego por la paciencia, por compartir su conocimiento conmigo desde la humildad y la más grande generosidad. A Luis por la confianza y las palabras que hacían siempre ver un horizonte al que llegar.

A Fede y Griselda por ser la familia que elegí y que, desde el amor más hermoso me acompañaron en este camino. A Lady Newlls por estar a mi lado inmensa y sabia mientras escribía esta tesis. A Lu por escuchar todas mis crisis, por ser la mejor amiga y la mejor profe de metodología.

A la arquitecta Carolina Peralta porque su tesis fue necesaria y aún es vanguardia. Porque es urgente que las arquitectas como ella sean visibilizadas y reconocidas en espacios como los que disputamos.

A Patricio, Adrián, Fredy, Pablo y al Guille, que me enseñaron que la lucha del ambiente es una de las más difíciles que nos quedan por dar, que es profunda y conlleva una entrega inmensa... que es obrera y socialista.

A mis compañeros de la AER Córdoba por hacer muy alegre este recorrido. A Charo que, sin saberlo, me enseñó a defender mi trabajo en una ronda y por bulerías. 


\section{Índice General}

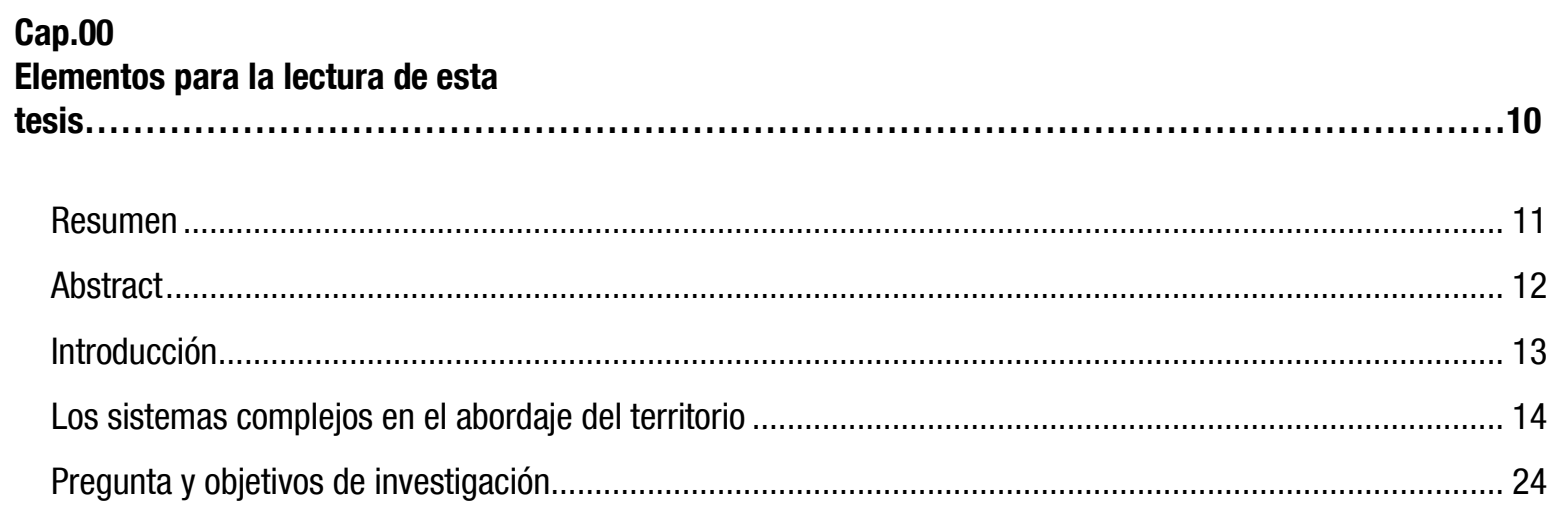

Cap.01

El crecimiento urbano en un contexto de cambio global.................................................................. 26

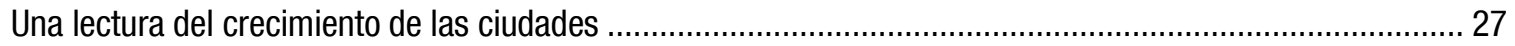

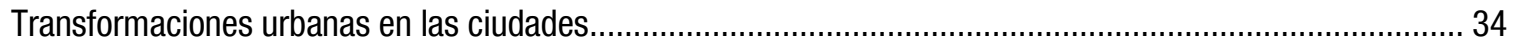

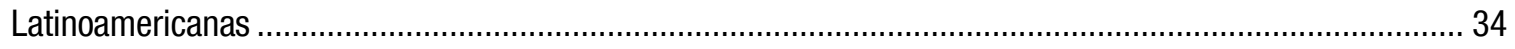

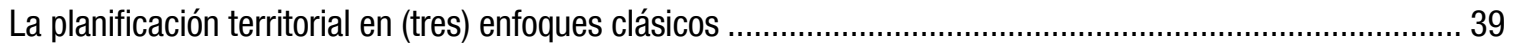

La mirada ecosistémica del territorio o la urgencia de comprender los procesos biofísicos ............................ 55

Planificar la interfase: una mirada compleja para la definición de variables................................................... 65

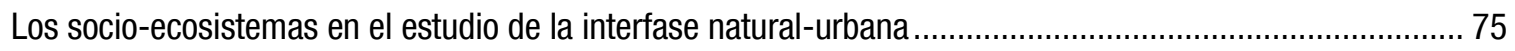

Servicios ecosistémicos ¿Por qué operativizarlos para la planificación territorial? ......................................... 78

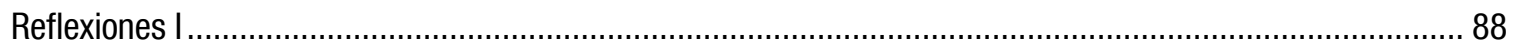

Cap.02

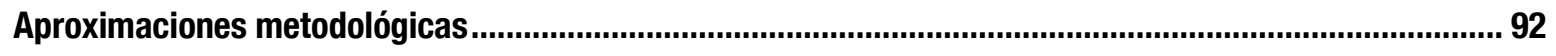

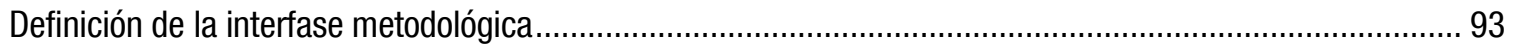

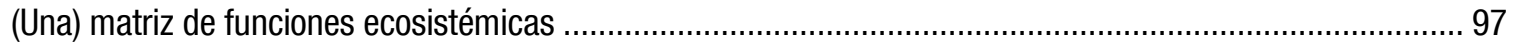

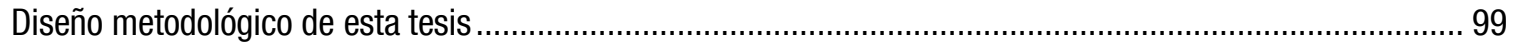

\section{Cap.03}

Córdoba al pie del monte (el) caso de estudio 


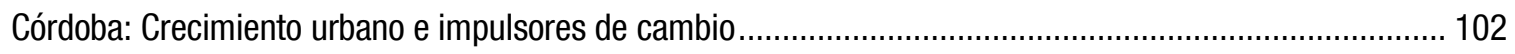

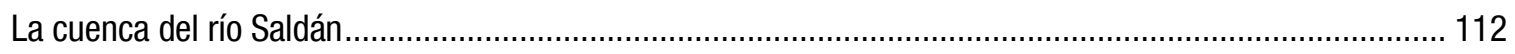

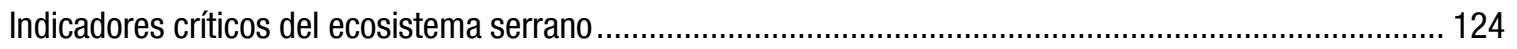

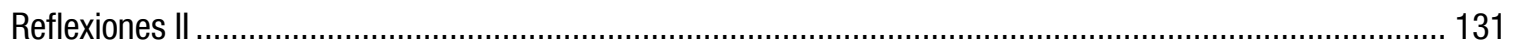

\section{Cap.04}

Sierras Chicas: de los planes a los socio-ecosistemas.

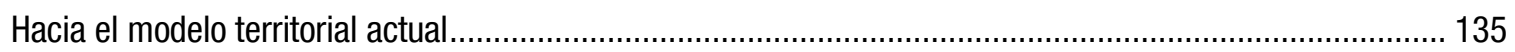

La interfase crítica y el aumento de superficie impermeabilizada .......................................................... 150

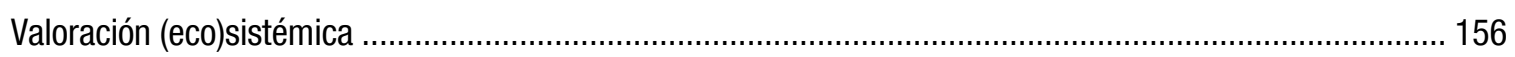

Áreas críticas de interfase 0 el avance de la impermeabilización del suelo .................................................. 167

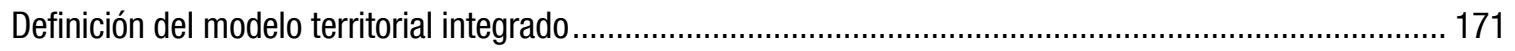

\section{Cap.05}

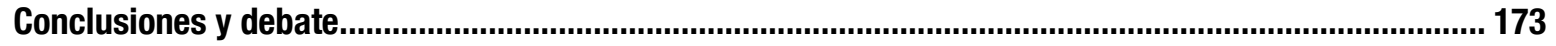

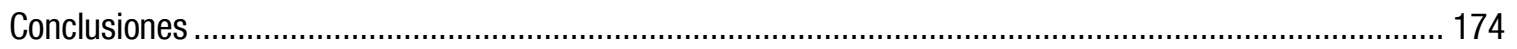

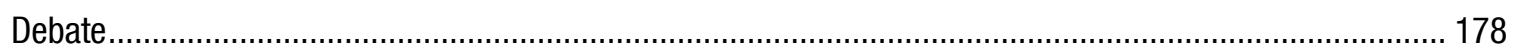

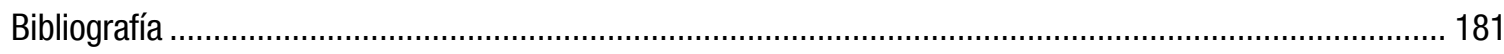




\section{Índice de figuras}

Figura 1. Esquema conceptual de abordaje territorial de esta investigación.................................................... 19

Figura 2 . Desarrollo estructural y proceso de expansión de la ciudad latinoamericana: de la ciudad colonial a la

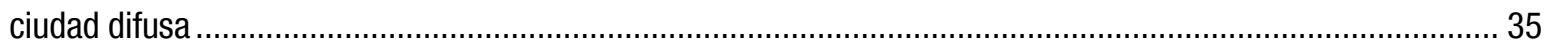

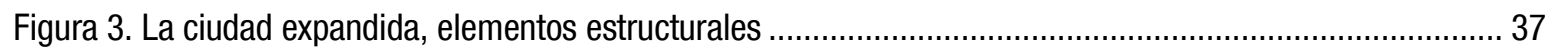

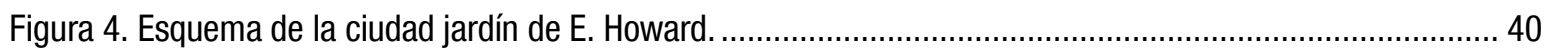

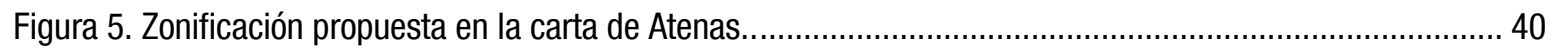

Figura 6. The diagram transect. Una versión de DPZ Architects \& Planners, 2008. ......................................... 46

Figura 7. Esquema clásico de interacciones para el desarrollo sostenible....................................................... 47

Figura 8. Evolución de la planificación sectorial, plurisectorial y territorial en América Latina y la influencia del

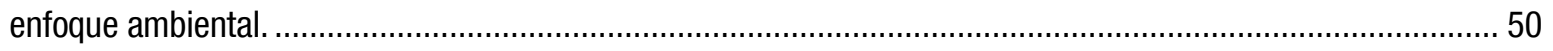

Figura 9. Uno de los modelos presentados en Los límites del crecimiento. World 3: Relación entre los sistemas

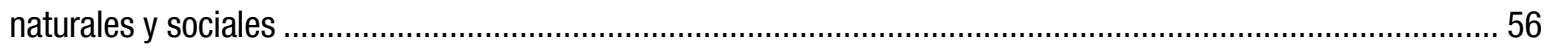

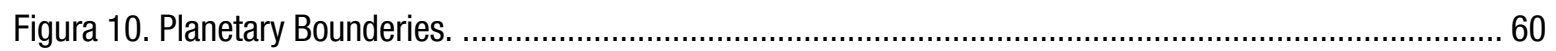

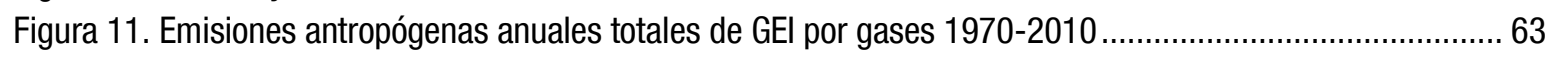

Figura 12. Esquema de interacción en la dinámica de interface urbano-rural ................................................... 65

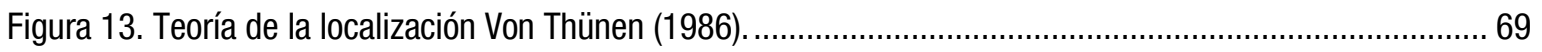

Figura 14. Organización de las distintas coronas periurbanas según Bryant y Russwurm. .............................. 70

Figura 15. Proceso de intercambio de servicios en la interfase.................................................................. 73

Figura 16. Contribución de los servicios ecosistémicos al bienestar humano................................................... 83

Figura 17. Modelo de cascada. Relación entre biodiversidad, funciones ecosistémicas y bienestar humano....... 86

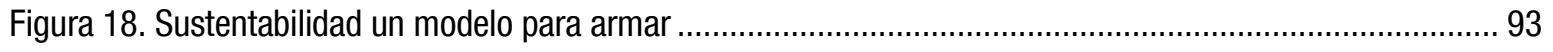

Figura 19. Etapas de proyecto de gestión del paisaje ............................................................................... 95

Figura 20. Escalera ascendente de integración de procedimientos de evaluación y mapeo de SE y su capacidad

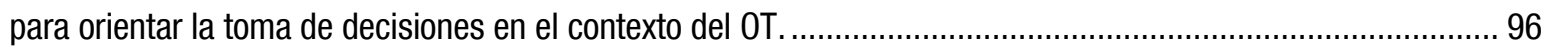

Figura 21. Ubicación de Córdoba respecto a regiones metropolitanas en el corredor bioceánico Mercosur ....... 102

Figura 22. Mapa de usos del suelo del área metropolitana de Córdoba...................................................... 104

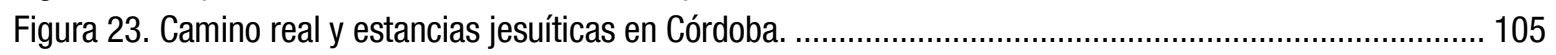

Figura 24. Sistema vial del AMC al año 2012. Sistema vial a escala regional propuesto por IPLAM (2012)....... 107

Figura 25. Comparación intercensal crecimiento demográfico de las principales ciudades de Sierras Chicas.

Relación demográfica censo nacional 1947 ......................................................................................... 108

Figura 26. Comparación intercensal crecimiento demográfico de las principales ciudades de Sierras Chicas.

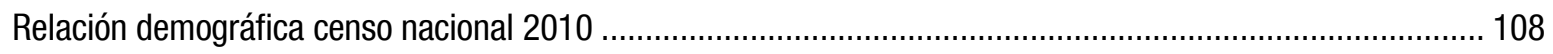

Figura 27. Antigua área de producción hortícola bajo riego sobre área urbanizada al año 2016.................... 109

Figura 28. Cursos, cuerpos de agua y canales de riego AMC .................................................................. 110

Figura 29. Superficies de producción hortícola en el AMC. Cinturón Verde ................................................... 111

Figura 30. Esquema de ubicación de la cuenca de estudio respecto la ciudad de Córdoba y las principales relaciones

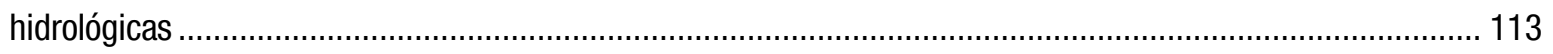

Figura 31. Ubicación de la cuenca Saldán dentro del AMC. .................................................................... 114

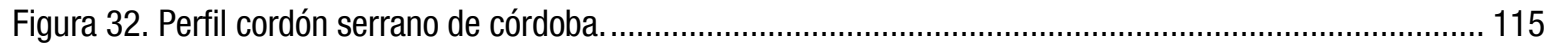

Figura 33. Perfil de la distribución altitudinal de la vegetación nativa en las Sierras Chicas .............................116

Figura 34. Síntesis gráfica de etapas de ocupación y consolidación del sistema urbano SS.CC. 1900-1985 ..... 118 


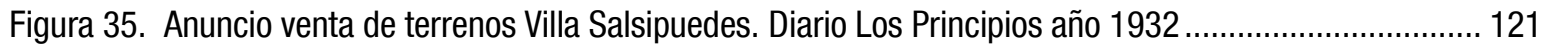

Figura 36. Principales localidades de la cuenca y sus ejidos municipales..................................................... 122

Figura 37. Unidades ambientales en la cuenca Saldán ........................................................................... 123

Figura 38. Deforestación 1970-1987-1997. Sierras Chicas. Las localidades mapeadas son desde Salsipuedes hasta

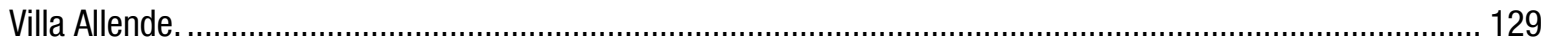

Figura 39. Diagrama síntesis del sistema natural-urbano de Sierras Chicas .............................................. 133

Figura 40. Diagrama de conectividad: nodos y redes ampliados ............................................................ 137

Figura 41. Ley 9814 de ordenamiento territorial de bosques nativos de Córdoba. Recorte del área cuenca Saldán

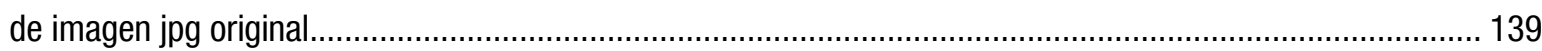

Figura 42. Mapa de la propuesta COTBN 2010. Área cuenca Saldán ............................................................. 141

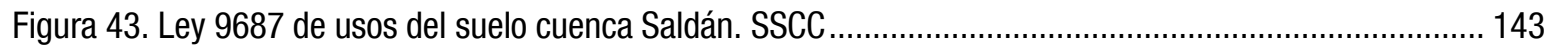

Figura 44. Porcentajes de ocupación del suelo en la cuenca según IPLAM 2012 ........................................... 144

Figura 45. Mapa de riesgo de inundaciones en la cuenca Saldán ............................................................. 146

Figura 46. Modelo territorial actual de SS CC. .................................................................................... 148

Figura 47. De izquierda a derecha tipos de ocupación por manzana identificados en la cuenca....................... 150

Figura 48. Avance del área urbana en la cuenca Saldán...................................................................... 152

Figura 49. Relación entre el aumento de superficie urbanizada y lluvias históricas en relación a la superficie de la

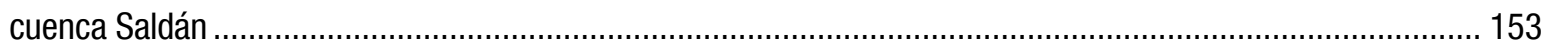

Figura 50. Clasificación supervisada. Cobertura de suelo para la cuenca Saldán. ............................................ 154

Figura 51. Perfil de altimetría de la cuenca. Unidades ambientales en interfase compatibilizadas con clasificación supervisada de usos y coberturas de suelo de la cuenca sobre datos de altimetría de Google Earth................ 155

Figura 52. Mapa de biomasa (NDVI) para el año 2017, cuenca Saldán......................................................... 159

Figura 53. Mapa de variación anual de biomasa para el año 2017 en la cuenca Saldán ................................... 160

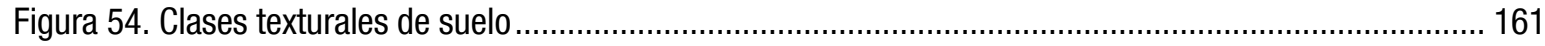

Figura 55. Mapa de capacidad de infiltración de suelo suelo según textura, drenaje e infiltración..................... 162

Figura 56. Mapa de precipitaciones máximas media en mm para la cuenca Saldán en año 2017..................... 164

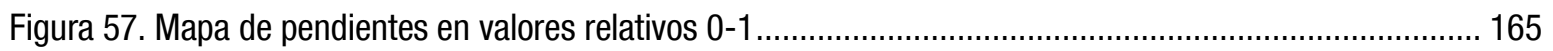

Figura 58. Modelo de retención de excesos de precipitación por cobertura vegetal para el año 2017 en la cuenca

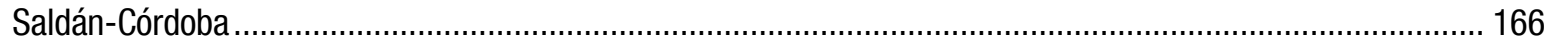

Figura 59. Modelo de retención de excesos de precipitación por cobertura vegetal para el año 2017 en la cuenca

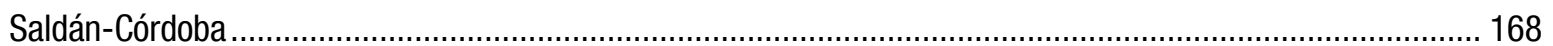

Figura 60. Interfase crítica y afectación por impermeabilización urbana y prospectiva de áreas a urbanizar según

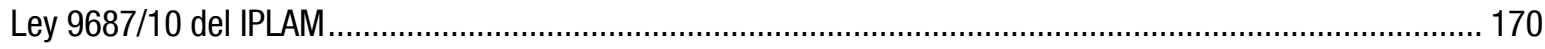

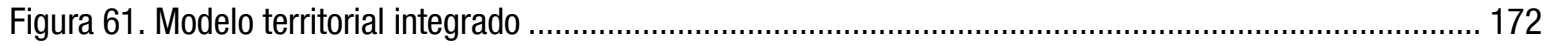




\section{Índice de tablas}

Tabla 1. Evolución de políticas urbanas económicas y territoriales, ciclos y puntos de ruptura .......................... 41

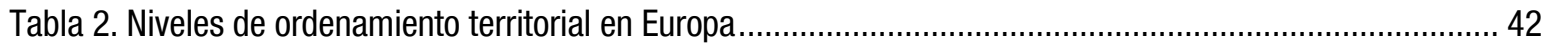

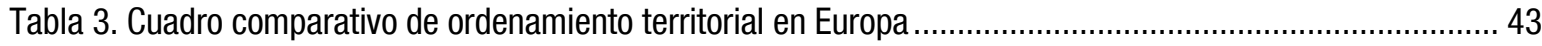

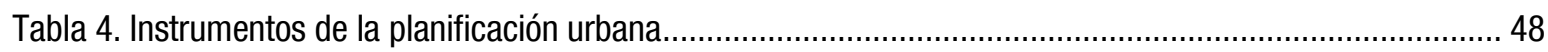

Tabla 5. Análisis comparado de los planes estratégicos en las principales ciudades latinoamericanas ............... 52

Tabla 6. Síntesis sobre los tres principales enfoques del ordenamiento territorial occidental ............................ 54

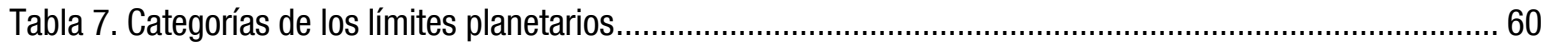

Tabla 8. Una tipología de servicios ecosistémicos y sus características (posterior a Kremen 2005) ................... 85

Tabla 9. Criterios para la selección de servicios ecosistémicos .................................................................. 99

Tabla 10. Variación de la superficie agrícola (2002-2004 contra 2008-2010) ............................................... 112

Tabla 11. Síntesis de las etapas de consolidación del sistema urbano en Sierras Chicas ................................. 117

Tabla 12. Crecimiento demográfico en las principals ciudades de las Sierras Chicas.................................... 120

Tabla 13. Superficie deforestada por período analizado en área de Sierras Chicas y subregiones.................... 129

Tabla 14. Área ocupada en el año 1997 por coberturas que reemplazaron a superficies originalmente cubiertas por

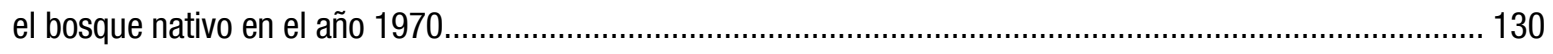

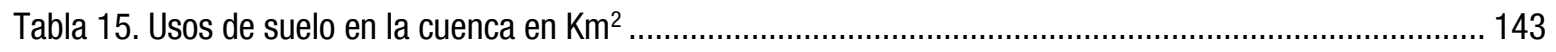

Tabla 16. Muestras para definición de manzanas urbanas consolidadas ................................................... 151

Tabla 17. Identificación de SSEE en la cuenca Saldán ................................................................................ 155

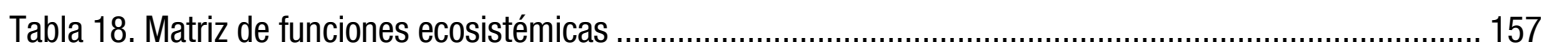

Tabla 19. Ponderación de textura de suelo para determinar capacidad de infiltración..................................... 162

Tabla 20. Precipitaciones máximas media para el año 2017 en la cuenca Saldán ........................................... 163

Tabla 21. Comparación del impacto de superficie impermeabilizada (Céliz, 2017) y área de uso de suelo urbano

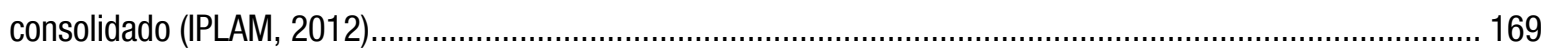




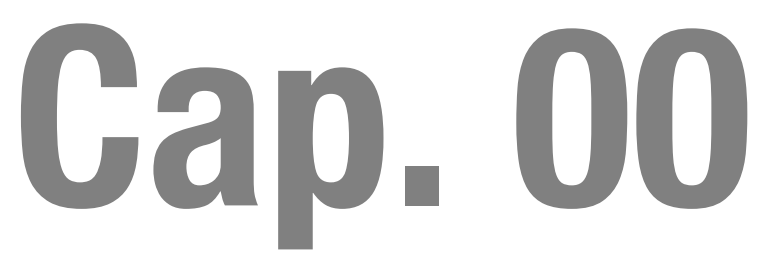

Elementos para la lectura de esta tesis 


\section{Resumen}

El crecimiento de las ciudades latinoamericanas durante los últimos treinta años, en un contexto de cambio global implicó complejas transformaciones territoriales. El desequilibrio relacional entre sistemas naturales y rurales con la ciudad -entre otros factores-, ha provocado la pérdida de condiciones ambientales a escala global. En este punto se localiza el problema teórico de este trabajo que plantea incorporar el enfoque de sistemas complejos para el abordaje territorial. Este marco teórico implica la necesidad de una construcción transdisciplinar de instrumentos de ordenamiento territorial.

El caso de estudio en donde se aplicaron las articulaciones teórico-metodológicas se definió como la cuenca del río Saldán en el área metropolitana noroeste de la ciudad de Córdoba, Argentina. La observación de la dinámica territorial fue observada y entre el año 1987-2017 como recorte temporal asimilable al proceso de intensificación del crecimiento urbano de las principales ciudades latinoamericanas.

Esta tesis se organiza en cuatro capítulos. El primero establece la relación entre el crecimiento urbano y el proceso de globalización del fenómeno metropolitano en un contexto de cambio climático. Este análisis plantea la necesidad de conocer aquellos aspectos del estado de salud terrestre y se pregunta en qué medida cuantificar aquellos límites ecosistémicos que aún no han sido sobrepasados. En este contexto la interfase se presenta como área de transformación dinámica necesaria de ser abordada; por lo que se ensaya en este apartado la construcción de la idea de interfase desde la complejidad.

El segundo capítulo es ubica estratégicamente como articulador del problema teórico y el caso de estudio, dado que se construye aquí la articulación teórico-metodológica. En este apartado se revisan los antecedentes metodológicos que alimentan este trabajo, por un lado; y por el otro, se construye el diseño metodológico cuantitativo basado en la articulación disciplinar. El modelo metodológico se estableció de tipo cuantitativo con fuerte utilización de teledetección y sistemas de información geográfica. En el tercer capítulo se procedió a la operativización del concepto de servicios ecosistémicos desde el caso de estudio, haciendo énfasis en las dinámicas de interfase.

El cuarto capítulo responde al diagnóstico, donde se establecen los parámetros para la construcción del modelo territorial actual a escala de cuenca como unidad de abordaje ambiental. Posteriormente se realizó la valoración socio-ecosistémica desde una matriz de identificación de funciones ecosistémicas y la cuantificación mediante el modelado de funciones ecosistémicas. Este modelo incorpora a la lectura territorial, variables ecológicas de diagnóstico. Se planteó la incorporación de procesos de regulación hidrológica como insumo estratégico en la construcción de las líneas de ordenamiento territorial sostenible en un contexto de avance urbano. En un apartado final entonces, se abordan los resultados obtenidos y el debate final interpela al enfoque territorial tradicional y la necesidad de incorporar la lectura compleja a espacios dinámicos que demandan una intervención transdisciplinar. 


\section{Abstract}

The growth of Latin American cities over the last thirty years in a context of global change has led to complex territorial transformations. The imbalance between natural and rural systems and the city, among other factors, has led to the loss of environmental conditions on a global scale. At this point the theoretical problem of this work is located, which proposes to incorporate the approach of complex systems for the territorial approach. This theoretical framework implies the need for a transdisciplinary construction of territorial planning instruments.

The case study in which the theoretical-methodological articulations were applied was defined as the Saldán river basin in the northwestern metropolitan area of the city of Córdoba, Argentina. The observation of territorial dynamics was established between 1987 and 2017 as a temporary cutback similar to the process of intensifying urban growth in the main Latin American cities.

This thesis is organized into four chapters. The first one establishes the relationship between urban growth and the process of globalization of the metropolitan phenomenon in a context of climate change. This analysis raises the need to know those aspects of the state of terrestrial health and asks to what extent to quantify those ecosystem limits that have not yet been exceeded. In this context, the interface is presented as an area of dynamic transformation that needs to be addressed; therefore, this section tests the construction of the idea of an interface from the perspective of complexity.

The second chapter is strategically located as an articulator of the theoretical problem and the case study since the theoretical-methodological articulation is constructed here. This section reviews the methodological background that feeds this work, on the one hand; and on the other hand, it constructs the quantitative methodological design based on the disciplinary articulation. The methodological model was established on a quantitative basis with strong use of remote sensing and geographic information systems. In the third chapter, the concept of ecosystem services was operationalized from the case study, with emphasis on interface dynamics.

The fourth chapter responds to the diagnosis, which establishes the parameters for the construction of the current territorial model at the basin scale as a unit of environmental approach. Subsequently, the socio-ecosystemic assessment was carried out from an identification matrix of ecosystem functions and quantification through the modeling of ecosystem functions. This model incorporates ecological diagnostic variables into the territorial reading. This model proposed the incorporation of hydrological regulation processes as a strategic input in the construction of sustainable land management lines in a context of urban progress. A final section then deals with the results obtained and the final debate challenges the traditional territorial approach and the need to incorporate complex reading into dynamic spaces that demand transdisciplinary intervention. 


\section{Introducción}

El fenómeno de la expansión urbana en las ciudades argentinas da cuenta de un país casi en su totalidad urbano, más del $90 \%$ de la población vive en ciudades. La ciudad de Córdoba no es la excepción, donde el crecimiento urbano desde el año 1976 al 2014 ha duplicado la superficie de la mancha urbana, aumentando en 6.697,54 ha (Mari and Pons 2015). El proceso por el cual se ha constituido la interfase urbano-rural-natural actual de Córdoba en su área metropolitana, especialmente sobre el eje nor-noroeste da cuenta de este proceso, ya que los asentamientos humanos se localizan sobre sistemas naturales (los faldeos de Sierras Chicas), impactados en la transformación del territorio a partir de una dinámica dada principalmente por el valor del suelo, la búsqueda de mejor calidad de vida derivada de una mejor calidad ambiental y una buena conectividad con el área central de la ciudad.

Estos sistemas naturales, dentro de un sistema socio-ecológico, cumplen funciones estratégicas para la sostenibilidad de los asentamientos humanos. Numerosos estudios y planes de ordenamiento han sido propuestos para el sector, especialmente luego de las últimas inundaciones ocurridas en febrero de 2015. Sin embargo, no ha habido una articulación ni sistematización de la información producida. Una revisión reciente por parte de la Coordinadora Ambiental y de Derechos Humanos de Sierras Chicas da cuenta de un sinnúmero de reservas naturales creadas desde la normativa, pero que no han sido implementadas.

Las Sierras Chicas -SS CC-, son proveedoras de procesos ambientales críticos para la sostenibilidad del sistema metropolitano: regulación del ciclo hídrico, regulación de desastres naturales, mantenimiento de biodiversidad, hábitat de polinizadores e insectos benéficos, regulación de plagas y enfermedades, etc. En este contexto los sistemas serranos son valorados por su oferta natural-paisajística. Las condiciones ambientales descriptas configuran ecosistemas de interfase entre lo natural y lo urbano, en gran mayoría configurados por el bosque nativo.

La reducción de la superficie de bosque y su reemplazo por el uso de suelo urbano no ha sido contemplada en la planificación desde los desequilibrios ecosistémicos. Este proceso se agrava si se tienen en cuenta los escenarios de cambio global proyectados por expertos para el área que implican: aumentos de temperaturas máximas y mínimas medias anuales, aumento del porcentaje de precipitaciones, como así también el aumento de la duración de los períodos secos (Barros et al. 2015).

La visión de estos procesos, expresados en las dinámicas urbanas que se observaron en este trabajo utilizan a lo largo de su desarrollo un concepto síntesis: "crítico". Este trabajo entenderá la criticidad como el punto a partir del cual el avance lineal en las transformaciones, generalmente asociadas a la creación de suelo de urbano, implicaría 
consecuencias negativas para los asentamientos humanos. Asimismo, la criticidad de estos procesos impacta en sistemas, tanto naturales como antrópicos, generando efectos asociados que en algunos procesos no son reversibles, para lograr una nueva situación o estado de equilibrio. Esta idea de relaciones sistémicas se desarrolla con mayor profundidad a partir de la teoría de la complejidad o la lectura de los sistemas complejos como teoría central a la hora de explicar las transformaciones territoriales.

\section{Los sistemas complejos en el abordaje del territorio}

Antes del desarrollo específico de esta tesis, consideré fundamental explicitar este enfoque dado que es la idea central a partir del cual se realizó el proceso de aproximación como el estudio en sí mismo del fenómeno. Estas teorías no sólo permitieron el abordaje del caso, sino que, uno de los principales objetivos de este trabajo radica en la necesidad de articular saberes de diferentes disciplinas para estudiar los procesos territoriales.

\section{La teoría sistémica: el conocimiento fenomenológico desde la interdisciplina}

La configuración del pensamiento científico y sobre todo la dispersión y especialización de saberes han llevado a profundizar la distancia entre los descubrimientos y aportes disciplinares. Esta separación ha generado importantes avances en cada campo del conocimiento y, por otro lado, el desconocimiento de estos aportes por parte de investigadores de áreas relacionadas y con ello, la posibilidad de potenciar transdiciplinariamente esas ideas.

El enfoque sobre el territorio, objeto de estudio de este trabajo, es una excelente oportunidad para articular conocimientos en los procesos de investigación y gestión. Las ciencias del territorio plantean este desafío a la luz de la velocidad de las transformaciones territoriales y las dinámicas de antropización que implican.

Esta investigación parte entonces, desde la teoría de los sistemas complejos e implica un compromiso con la articulación de saberes y la permeabilidad de diversos actores en la construcción del conocimiento territorial.

La palabra complejidad proviene del término "complexus" y significa "lo que esta interrelacionado", o "tejer junto". Reflexionar sobre el mundo que nos rodea, entrelazándolo. Esta idea reclama la rearticulación de saberes disgregados del pensamiento científico tradicional concebido principalmente en las teorías del pensamiento cartesiano ${ }^{1}$ (Morin 1997). La rearticulación de conocimientos es fundamental en la comprensión de la dinámica de los procesos actuales.

\footnotetext{
${ }^{1}$ La base del pensamiento científico de Descartes, Bacon y Galileo entre otros, plantea en términos generales la linealidad en la construcción de cuerpos teóricos. El paradigma cartesiano indica que el mundo funciona a partir de leyes simples y que, por
} 
Muchos científicos del siglo XX desde diversas disciplinas han contribuido en la construcción del pensamiento de la complejidad: la teoría general de los sistemas de Karl Ludwig von Bertalanffy (1969), desde el enfoque de la biología, plantea la organización del mundo que nos rodea a partir de sistemas determinados posibles de relacionarse entre sí. Werner Heisenberg (1925), enuncia el principio de incertidumbre que establece las limitaciones de la física clásica en la determinación de la posición exacta (tiempo-espacio) de una partícula determinada, exponiendo que esto no siempre es posible en la relación observador-objeto observado y estableciendo, por tanto, existe un margen de incertidumbre en estas afirmaciones. Maturana y Varela (1973) por su parte, incorporan el concepto de "autopoiesis" que explica las relaciones de un sistema vivo. A partir de este concepto fundamental se entiende que, la red que establecen los componentes a partir de la intensidad de sus relaciones no sólo define estas interacciones, sino que define a cada parte en interacción tanto como a la totalidad con la que interactúan (Maturana and Varela 2003). Esto es, en síntesis, una característica intrínseca a los seres vivos en continua producción de sí mismos. Es posible recurrir a la autopoiesis para definir entidades que reproducen internamente las diferencias con las cuales se constituyen (Luhmann 1998). Para ello, define tres grandes tipos de sistemas:

- Los sistemas vivos,

- Los sistemas psíquicos y

- Los sistemas sociales

En síntesis, podemos decir que la observación del sistema es, necesariamente la observación de las operaciones relacionales que mantienen y caracterizan el sistema que se estudie y las principales fuerzas relacionales que lo definan. Se reconocen entonces, tres indicadores del pensamiento complejo, que serán necesarios para interpretar el caso de la realidad en el proceso de investigación. i) La idea de orden-desorden, que indica que el producto de las interacciones entre ambos procesos 0es la auto-organización que permite al sistema generar nuevos patrones, jerarquías, incluso nuevas interacciones que volverán a obtener un equilibrio dado. Este orden será siempre circunstancial y cualquier modificación iniciará un nuevo estado de desorden. En tanto el sistema sea capaz de auto-organizarse cada vez que entre en estado de alteración, podrá sobrevivir. Es definido este como el principio de "entropía" -o proceso de desorden interno-, y "negentropía" entendida como la presión ejercida sobre el sistema para conservar el orden alcanzado una vez superado el proceso de auto-organización.

Otro principio fundamental es el de azar e incertidumbre, que determina que para la complejidad las interacciones entre sistemas y elementos del sistema son azarosas. No hay predictibilidad en la ocurrencia de ciertos fenómenos,

tanto, es necesario fragmentar el conocimiento para explicar el fenómeno, para después integrarlo y comprenderlo finalmente. Esta lógica es la base de la educación tradicional disciplinar. 
que ocurrirán con una importante cuota de incertidumbre que lleva adelante la naturaleza. Estos principios son asociables tanto a sistemas naturales como sociales, sin embargo, algunos son más reconocibles en unos que en otros. El desafío es interpretar los flujos que producen estas interacciones entre el sistema natural y el humano asociados.

Como se ha mencionado brevemente, el pensamiento complejo es una construcción de muchas disciplinas y teorías que lo alimentan. No existe una definición acabada, sino que, a través de la experiencia, se ha construido, por lo que no existe una teoría única. Esto implica la posibilidad de releer la complejidad en cada proceso que se pretenda estudiar no como metodología en sí misma, sino, como se ha mencionado anteriormente; un enfoque teórico general para abordar un problema que no es posible acotar a limites jurídicos y procesos endógenos como es el territorio en su relación con los asentamientos humanos.

Se definirán entonces los principios de los que se derivan las herramientas principales a considerar por este trabajo. El principio dialógico como fundamental para entender el diálogo entre dos lógicas que se definirán mutuamente a partir de contribuir a un mismo objeto de abordaje (Morin 1997). El principio de recursividad organizacional permitirá introducir la idea de que aquello que es producido vuelve a aquello que le dio origen convirtiéndose en productor. Esto significa que lo que definimos como objeto de estudio es a la vez causa y productor de aquello que lo ha definido. Esta es la idea de auto-organización y autoproducción que el pensamiento complejo establece en contradicción a la tradicional imagen lineal causa-efecto y producto-productor. Por último, el principio hologramático -y no holístico-, es fundamental para comprender que aquello que es adquirido como conocimiento de las partes sirve para entender el todo, al que regresa -teniendo en cuenta el principio anterior-. Es decir, es un conocimiento alimentado y retro-alimentado el que se construye.

Estos principios sustentan la visión ecológica del pensamiento complejo, en tanto todo fenómeno es autónomo, autorganizador, autoproductor, autodeterminado en su relación con el entorno, definido este por el ecosistema 0 por una determinada cantidad de intensidad de relaciones en cualquier escala observada. Esto se define como la “auto-eco-organización”(Morin 2005)

A través de la auto-regulación, el sistema se alimenta de su entorno, en el caso de la ciudad consumiendo "bienes y servicios" de su entorno natural y rural. Estos inputs pueden ser materias primas como maderas, áridos para construcción, alimentos, o medicinas, entre otros. A su vez utiliza servicios que no son percibidos directamente como la amortiguación climática que da la vegetación, la regulación hídrico-hidrológica, etc. Este proceso se intensifica, a medida que el sistema ciudad crece con mayor capacidad de impacto sobre su entorno. Esto se denomina complejo autonomía-dependencia (Morin 2005) 
Diremos entonces que la ciudad es un sistema complejo dinámico ya que ha manifestado características asociadas a los sistemas complejos y que durante el necesario proceso de entropía que realiza para incorporar las alteraciones propias de sus transformaciones sociales, políticas, económicas, ambientales -si se quiere-, y morfológicas, realiza procesos autogeneradores de sí misma y a la vez autoproductores, esta dualidad de procesos se encuentran contenidos en la idea de bucle recursivo (Morin 2005).

Este proceso de entropía en que el sistema incorpora las alteraciones que se producen buscando un nuevo estado de orden -transitorio-, puede ser superado por el proceso de negentropía; en el que el sistema cambia de estado dada la imposibilidad de continuar incorporando las alteraciones producto de nuevas o distintas interacciones. La negentropía otorgará un nuevo estado de orden a la organización, nuevamente transitorio.

La ciudad como organismo vivo, y sistema complejo no se limita a su competencia como tal, es decir su abordaje no termina en los límites jurídicos. Sino que se encuentra dentro de un contexto mayor con el que interactúa y mediante el cual se establecen determinadas interacciones: el territorio. El proceso de aproximación al territorio será un proceso de carácter complejo y al mismo tiempo implica un proceso de alejamiento de la visión disciplinar como especificidad (Morin 1997).

Ahora bien, a partir de caracterizar de la complejidad como postura del abordaje territorial, es necesario establecer líneas que aborda este enfoque. Algunas de ellas son:

- La identificación de patrones y regularidades como una transacción entre el sistema y sus relaciones pero que no implica una estabilidad, sino más bien, la posibilidad de una ruptura. Esto significa que los patrones son estables hasta que nuevas interacciones conduzcan a un nuevo patrón que implica otra categorización.

- Compresión del orden y los patrones, esto no es más que admitir el enfoque dialógico entre ordendesorden. En tanto el desorden es la respuesta necesaria al carácter simplificador del orden (Morin 1997). Esto implica necesariamente a los modelos para entender la dinámica sistémica. Recurrir al estudio de modelos para avanzar sobre la compresión sistémica.

- La interrelación de los conceptos, a partir de la necesidad de interrelacionar conceptos aprendidos y arribar a macro-conceptos a partir de ello. Cualquier fenómeno tiene un contexto independiente de la escala a la que sea observado, esta condición será parte de su explicación.

- La teoría de los sistemas como nuevo enfoque. Esto implica la premisa de no sustituir un reduccionismo por otro, tampoco abordar el holismo. Es, sobre todo, la importancia de las partes y su individualidad alimentando al sistema. 
Para García, ninguna investigación particular integra diferentes disciplinas, ya que los procesos de integración disciplinaria significan replanteos fundamentales y no se limitar a "poner juntos" los conocimientos de diferentes áreas. De igual manera considera que esto no es necesario "puesto que el análisis histórico de la ciencia permite poner en evidencia que las diferentes disciplinas científicas se van integrando a lo largo de su desarrollo"(García 2006, p.24).

La integración disciplinaria es un hecho histórico y característico del desarrollo científico que no es resultado de la voluntad de un grupo de investigación y que, por tanto, no puede constituir una pretensión metodológica. Esto mismo implica que ningún sistema estará dado en el punto de partida de la investigación, pero es definible. Esta definición se realizará durante el proceso de investigación y para cada caso particular (García 2006). Para cada caso entonces se reconocerán componentes básicos para la construcción del caso de estudio: i) limite, ii) elementos $y$, iii) estructura.

Los elementos dentro del sistema también pueden constituir unidades complejas: los subsistemas -en interacción. Estas relaciones entre subsistemas son de vital importancia ya que no sólo determinan la estructura del sistema, sino que además son sistemas en otra escala que pueden estudiarse con sus propias lógicas. Se entiende esto como el intercambio de flujos que caracterizan tanto a los sistemas como a los subsistemas. Como los componentes del sistema adquieren características a partir de su determinación mutua -interdefinibilidad-, tienen igual importancia el caso de estudio como las relaciones que lo definirán. Como la estructura está determinada por este conjunto de relaciones, el sistema incluirá los elementos que establezcan las relaciones más significativas [subrayado propio]. Las interrelaciones entre ellos y los elementos que quedan dentro pueden establecer condiciones definibles o los límites. Los límites estarán dados a partir de las relaciones y elementos que otorguen estructura al sistema haciendo comprensible su organización.

\section{El territorio como construcción del conocimiento}

Es fundamental entender que la primera mirada hacia el objeto de estudio se realiza en términos complejos en tanto y en cuanto no se abordan delimitaciones jurídico-municipales para entender las lógicas del crecimiento urbano como antropización del territorio.

La elección del enfoque territorial supone una mirada integradora de los conceptos tradicionales que disocian campo y ciudad como sistemas independientes uno del otro (Figura 1). Tanto el urbanismo como las ciencias naturales han observado al hecho urbano y al entorno natural como sistemas aislados que no son interpelados mutuamente. 
El concepto de territorio como superador de una división arbitraria en la dinámica de intercambio entre sistemas naturales y antrópicos, plantea un desafío fundamental no sólo en términos teóricos de articulación disciplinar sino también, metodológicos para el desarrollo de esta investigación.

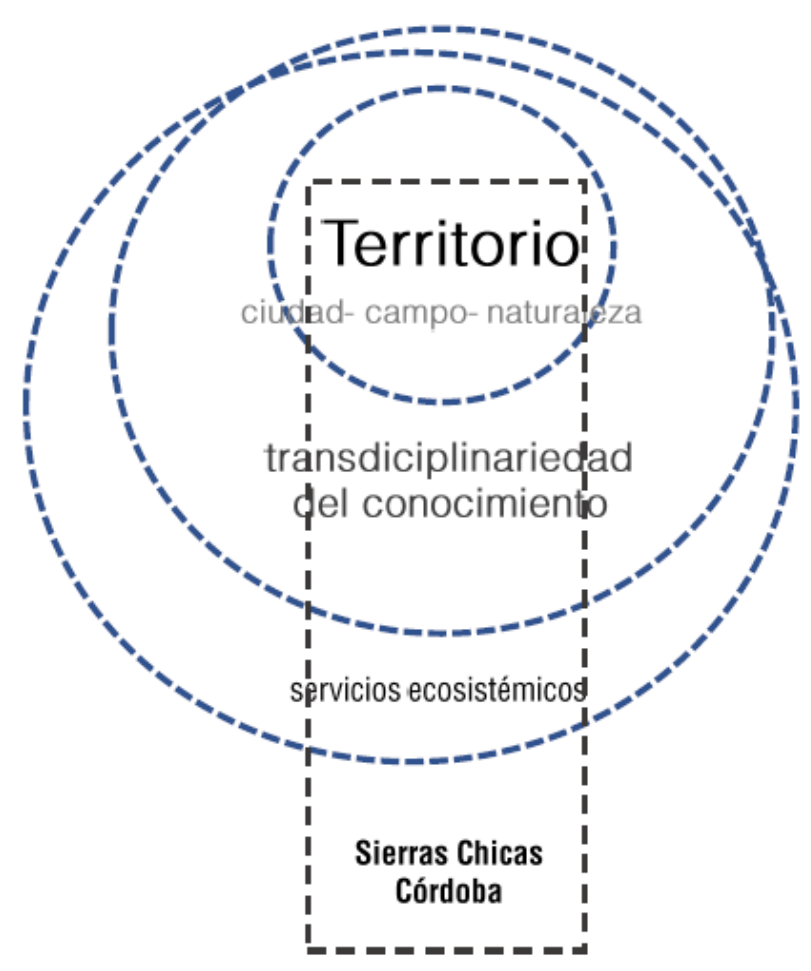

Figura 1. Esquema conceptual de abordaje territorial de esta investigación. Fuente: Céliz, 2018.

Para la construcción de un concepto de territorio interdisciplinar, se recurrió a diferentes autores que desde sus enfoques y contextos particulares arribaron a una definición clarificadora. La lectura crítica de los procesos que llevaron a definir esta idea, se constituye como el punto de partida para observar los procesos territoriales objeto de esta tesis.

A los efectos de diferenciar el punto de partida de la observación del territorio se organizaron 3 enfoques a partir de los cuales los diferentes autores realizaron sus aportes. Estos enfoques son el resultado del aporte de líneas precedentes cuyos principales referentes se resumen a continuación.

La primera aproximación, está vinculada a la geopolítica clásica, articulando la lógica jurídico-política y la naturalista. A partir de aquí el territorio se concibe como la porción de superficie terrestre sobre la cual ejerce soberanía un Estado. Hacia 1870 la Biología realiza un aporte fundamental desde la Zoología, la Botánica y la Ecología: la noción biogeográfica del Estado (Cataia 2009, citado en Benedetti and Souto 2011); que define al 
“espacio vital”. Este será entendido como la porción de superficie terrestre apropiado para la realización de un ser político. Existe una lectura entre el Estado como desarrollo político de los asentamientos humanos y el suelo en el que este se desarrolla como entidad natural sobre la que se ejerce control. Posteriormente, autores franceses como Paul Vidal de la Blache, incorporan las nociones de género: vida, paisaje, medio y región. De todos ellos, el término región fue ampliamente desarrollado por la geografía francesa. En esta concepción naturalista del territorio, es posible reconocer tres elementos: i) un agente: el Estado, ii) una acción: la apropiación, el control o dominio y, iii) una porción de superficie terrestre: la realidad material determinada. Para otros geógrafos franceses como Gottman (1973), el territorio a pesar de ser una entidad material, medible y concreta, es producto y expresión de las características psicológicas de los grupos humanos que lo habitan; y por tanto es un espacio definido por las leyes y la unidad de gobierno de un estado.

Hacia 1980, el historiador suizo André Cordobz, introduce la variable temporal a la definición territorial. Define al territorio como un "palimpsesto", lo que implica su conocimiento a partir de una construcción histórica. Desde el momento en que una población ocupa un territorio establece una relación que implica necesariamente modificaciones. Esta acción estará guiada de alguna forma por el indicio de ordenación sobre la interpretación de las modificaciones sucesivas y la información que otorgan (Corboz 1980).

Otro de los lineamientos más importantes en la concepción de territorio proviene de las ciencias naturales en un contexto global en el que acababa de desarrollarse la Cumbre ambiental de Río (1992), el concepto de huella ecológica había sido enunciado en el mismo año por William Rees y el discurso de la Biodiversidad y el Desarrollo Sostenible ponía el foco en el territorio como clave en los procesos de apropiación productiva de la naturaleza. Por lo tanto, la relación más importante estaba puesta en la manera en que una determinada sociedad utiliza los recursos de los que dispone en su organización productiva y, por tanto, en la relación entre sistemas sociales y ecológicos (Berkes and Folke 1998b). Esta concepción señala que existen sistemas fuera del económico-político que también se ponen en juego, aunque no constituyan las definiciones prioritarias de los sistemas sociales. La relación entre sistemas naturales y sistemas sociales se producen en un determinado territorio para definirlo a partir de sus intereses y producción, identificar estas relaciones es fundamental para la construcción compleja del concepto territorio.

Es entonces que el territorio se transforma en un concepto integrador, por lo que se delimitan los enfoques más relevantes mediante los cuales una configuración compleja define su determinación.

El primer enfoque se denomina geo-crítico y desde su inspiración marxista estudia las relaciones entre geografía y economía en su carácter espacial. Taylor (1993) enuncia que no todos los territorios son soberanos, planteando así las principales líneas de este enfoque. En Latinoamérica esta mirada es llamada también "concepción 
materialista histórica del territorio" (Benedetti, 2011) y remite particularmente a la producción de M. Santos $(1978,1988,1996,2000)$. Santos establece una relación espacial entre fijos y flujos: mientras que los fijos son lugares donde se acumula el capital, los flujos son el movimiento que explica el fenómeno de distribución (1978). En esta línea el autor define la configuración territorial como la reunión entre materialidad y la vida que la anima. Esto implica que son las relaciones sociales las que otorgan realidad al soporte territorial. Aparecen aquí elementos de la teoría de la localización (Von Thunen, 1826) y el análisis espacial es reemplazado por el análisis territorial (Benedetti and Souto 2011). El geógrafo Peter Taylor (1993, originalmente publicado en 1983), pone el énfasis en las relaciones espaciales entre centros, periferias y semi-periferias. Algunos de los autores relevantes influenciados por esta línea son D. Harvey (1982), M. Santos (1996), S. Sassen (1991, 2001, 2007) (Benedetti and Souto 2011). Esta lectura crítica de la configuración territorial es alimentada por otras como la (nueva) ciencia regional, que pone el acento en las transformaciones metropolitanas, las estrategias empresariales, las formas flexibles de la organización de la producción.

El segundo enfoque se denomina relacional ya que recupera elementos de la teoría de la estructuración perspectivas humanistas, posmodernas y eclécticas-. Este enfoque es ordenado por dos obras claves: Por un géographie du pouvoir (Raffestin, 1980) y Human territoriality (Sack, 1986). En esta perspectiva de geografías del poder, Raffestin (1980), resalta los aspectos políticos del territorio en tanto y en cuanto el territorio es una producción del espacio dada por las relaciones sociales que implica. A su vez, Sack (1986) le otorga al territorio una cualidad netamente humana, definiéndolo como tal siempre y cuando existe una motivación específica por un grupo específico que va a establecer sus límites y ejercer el control sobre dichos límites. Ambos trabajos parten de la consideración de un concepto previo al de territorio: la territorialidad. Este concepto surge de estudios naturalistas es explicitado en las primeras décadas del siglo XX por la etología (Raffestin 1980). A partir de allí, el territorio es entendido como un área delimitada que es defendida por uno o más individuos, sea a través del ataque directo, la intimación o la vocalización en procura de (Cardoso y Alves, 2009). Esto implica que la territorialidad es la conducta adoptada por un organismo para tomar posesión de un área y defenderla frente a posibles agresores. Se consolida la idea de que el territorio nace de las estrategias para controlar áreas, necesarias para la vida social. Aquí la territorialidad es una acción consciente orientada al control sobre la acción de otros. Este concepto incorpora la noción de temporalidad que desnaturaliza al agente de control y al terreno que es controlado (Benedetti and Souto 2011).

Para Lopes de Sousa (2003), el territorio es algo flexible que puede ser construido y deconstruido en las escalas que fuera posible por un determinado período de tiempo. Por esto mismo les asigna a las territorialidades infinitas variedades espacio-temporales. En la misma línea, Haesbaert (2004) retomando el concepto de territorio como recurso y refugio de Gottman (1973), plantea la cuestión temporal compleja territorial. El elemento red constituye 
Ios territorios conectando discontinuidades. Se define entonces, a los territorios zona -como mosaico de unidades de áreas-, a los territorios red -como la fragmentación articulada; construyendo así la idea de multiterritorialidad. Esta perspectiva relacional introduce un cambio de gran relevancia: el territorio no es un soporte material sobre el que se desarrollan los procesos: el territorio mismo es un proceso, constitutivo del entramado de relaciones sociales.

El enfoque regional, como tercera mirada, plantea la idea de la institucionalización regional, entendiendo a las regiones como entidades geo-históricas que surgen, se transforman y desaparecen en un período determinado de tiempo, y que son producidas y reproducidas a través de una serie de instituciones (Paasi 1986). A su vez dentro de este enfoque, existen variable diferentes que definen una región. Algunos criterios utilizados se basan en criterios ambientales, paisajísticos o naturales (Benedetti and Souto 2011). Otra forma de definirla refiere a la categoría práctica como la comunidad de habitantes, a partir del espacio vivido (Haesbaert 2010). La institucionalización de estos territorios estará dada entonces por el proceso de surgimiento de la unidad territorial como sistema socio-espacial, la identificación en la acción y conciencia social como ratificación de dicho territorio (Paasi 2003). Esta idea se basa en que las identidades regionales están asociadas a la movilidad, las redes y las interacciones en espacios blandos y fronteras difusas (Raco, 2006; Tewdwr-Jones y Allmendinger,2006; Haughton et al.,2010; Allen, 1998 y otros, en Paasi, 2012).

En el campo del urbanismo -y los estudios regionales- se abordan conceptos desde la modernidad líquida (Bauman 1999), la ciudad de los flujos (Castells 1989), la ciudad genérica (Koolhaas 1995) y la ciudad hojaldre (García Vázquez 2008), entre otros. Todas líneas que abonan la idea de que relaciones -0 intercambios- políticoeconómicos van a condicionar desarrollos socio-culturales territoriales y se definirán mutuamente en estos procesos locales y globales.

Las relaciones conceptuales hasta aquí expuestas, dan cuenta de la construcción compleja de la que parte el estudio de las dinámicas territoriales. El énfasis está puesto entonces, en entender al enfoque territorial como superador en la necesidad de articular contenidos disciplinares en la lectura del territorio en sus variables naturales-temporales-antrópicas con la dificultad que ello implica.

Este territorio observado en tanto sistema, incluye a su vez subsistemas de gran complejidad como la ciudad y los intercambios que realiza con su entorno sea este igual de antropizado, poco antropizado como lo es un sistema productivo rural o nada antropizado en el caso de un bosque, un desierto 0 un área protegida. Una aproximación inicial indica que las construcciones conceptuales sobre las cuales se basan estos estudios son cambiantes, así como el agente principal que determina transformaciones en el sistema territorio es en gran medida el ser humano, es también afectado por las transformaciones que lleva adelante en su medio. 
Este trabajo se plantea ante todo el desafío de trascender la comodidad disciplinar e indagar en las posibles transdisciplinariedades que aporten a la construcción del fenómeno, entender sus causas y poder identificar las relaciones más importantes que, en este caso y para cada caso en particular, lo determinan.

"El estudio de un ecosistema natural que ha sufrido la acción del hombre, ya sea por medio de la explotación de sus recursos, renovables o no renovables (...), o bien por la instalación de asentamientos humanos de diversos tipos, incluyendo las grandes urbanizaciones y las obras de infraestructura, supone la consideración del conjunto de los elementos que intervienen en tales procesos (...), de sus partes o factores constitutivos, sus interrelaciones y sus interacciones con otros fenómenos o procesos. Es decir, supone concebir el objeto de estudio como un sistema complejo". Rolando García (2006) 


\section{Pregunta y objetivos de investigación}

\section{Pregunta de investigación}

¿Cuáles son las consecuencias ecosistémicas críticas de la expansión urbana sobre áreas naturales proveedoras de servicios ecosistémicos en el área de Sierras Chicas en Córdoba?

\section{Objetivo principal de investigación}

Definir herramientas transdiciplinarias que posibiliten una valorización ecosistémica de la interfase urbano-natural de Sierras Chicas en Córdoba, durante el período de consolidación metropolitana; tendientes a ser incorporadas a la planificación territorial.

\section{Objetivos particulares de investigación}

1. Integrar la información producida sobre el territorio del piedemonte noroeste de la ciudad de Córdoba a los efectos de identificar áreas de vacancias en la planificación territorial-ambiental para el área.

2. Construir una matriz de valoración de servicios ecosistémicos a los efectos de establecer criticidades en la afectación de procesos ecosistémicos para el área de interfase urbano-natural.

3. Proponer un modelo territorial ambiental integrado a partir de la incorporación de funciones ecosistémicas críticas al ordenamiento territorial

\section{Aporte al conocimiento}

Este trabajo se plantea desde una interfase teórico-metodológica y, por lo tanto, disciplinar. Se buscó superar la fragmentación disciplinar en la construcción del conocimiento. Dado que desde lo discursivo esto tiene muchas interpretaciones y aplicaciones, esta instancia es fundamental como ensayo de abordaje transdisciplinario. De esta manera el enfoque territorial se planteó desde los sistemas complejos. La incorporación de las Ciencias Naturales al Ordenamiento Territorial permite incorporar una variable temporal a partir de la necesidad de una aproximación a los procesos ecológicos territoriales. Esto permite determinar que han sido ensayadas herramientas por otras disciplinas que aplicadas a etapas diagnósticas y prospectivas construyen un enfoque territorial complejo: la noción 
de socio-ecosistemas (re)significan el territorio habitado. A partir de allí, estas metodologías pueden transferirse a diversos procesos de planificación y finalmente, aportan información de base de gran relevancia para decisores políticos. Si estos procesos son concebidos desde el principio con una mirada socio-ecosistémica, es posible establecer prognosis respecto a diversas transformaciones territoriales. Al final de este trabajo se incorpora una línea en este sentido, a partir de la información provista por organismos de planificación y la posibilidad de trabajar con modelos, se plantea la pregunta: ¿Cómo serían afectados los procesos ecológicos de mayor valor para los asentamientos humanos, si la ciudad sigue creciendo en forma horizontal? 


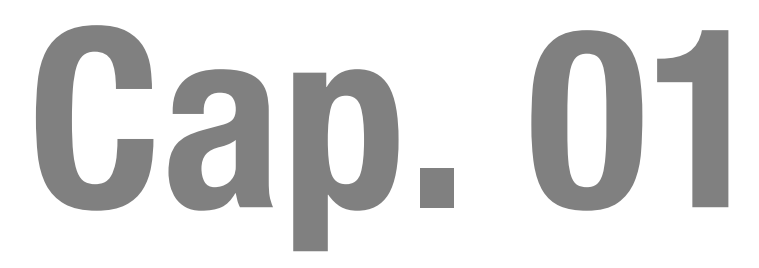

\section{El crecimiento urbano en un contexto de cambio global}

"Nada puede crecer indefinidamente en un medio finito" [Informe al club de Roma]. Donella Meadows, 1972. 


\section{Una lectura del crecimiento de las ciudades}

\section{El crecimiento revolucionario de las ciudades}

Diversos autores han caracterizado al crecimiento de las ciudades, a partir del análisis de procesos socioeconómicos en el territorio. De aquellos más relevantes en los estudios urbanos, Ascher (2004) y Soja (2008) los han sistematizados en etapas que definidas como revoluciones. Los puntos de inflexión en la lectura de la urbanización occidental fueron identificados por los autores a partir de hechos y procesos radicales en que implicaron transformaciones decisivas en la configuración urbana.

"Hacia el año 7.000 a.C. ya se habian desarrollado en Jericó métodos simples de irrigación con el fin de ampliar la escala y el alcance del cultivo agrícola, al menos en el valle del río Jordán. A partir de entonces, el espacio urbano de Jericó comenzó a ser definido, confinado y simbolizado en términos materiales a través de la construcción de aquellos famosos muros" (Soja 2008).

Soja (2008) pone en crisis el orden cronológico, particularmente los orígenes del urbanismo y atribuye la primera revolución urbana a Jericó y Çatal Hüyük, en el suroeste de Asia. Para Soja, las ciudades en su configuración se remontan al menos 10.000 años atrás, lo que da lugar a la invención inicial de base urbana de la agricultura a gran escala. El autor enuncia "las ciudades primero", sintetizando la idea que ilustra tanto con Jericó como con Çatal Hüyük, a través de la observación de los descubrimientos arqueológicos respectivos, que muestran como estas urbanizaciones de gran escala precedieron la especialización de los asentamientos humanos que tradicionalmente se atribuye a la adopción de la agricultura.

La segunda revolución urbana de Soja (2008), puede ubicarse en las tierras bajas aluviales del Creciente Fértil 5000 años después de Jericó y Çatala Hüyük-, y está caracterizada por una revolución política que dio lugar a la formación de ciudades-estado y a los imperios basados en la ciudad, la monarquía, la organización de clases sociales y el poder social patriarcal. Ascher (2004) va a caracterizar este período como la primera modernidad². Esta es la caracterización de la ciudad clásica en donde el poder estatal se refleja en la monumentalidad. Se trazan las avenidas que re-organizan el espacio urbano. Las huertas separan lo público de lo privado terminando con la ambigüedad de esta dualidad. El espacio público ocupa un lugar significativo y se sectoriza a partir de criterios sociales y funcionales. Esta modernidad coincide con la de la arquitectura que se atribuye nuevas libertades sin dejar de lado el legado de la antigüedad.

\footnotetext{
2 "La modernización es un proceso que surge mucho antes de la época que conocemos como Edad Moderna. Fue el resultado de la interacción de tres dinámicas socio-antropológicas cuyas huellas encontramos en distintas sociedades pero que, al entrar en resonancia con Europa durante la Edad Media, dieron lugar a las sociedades modernas: Ia individualización, la racionalización, y la diferenciación social" (Ascher, 2004). La primera modernidad está definida por el autor entonces, desde fines de la Edad Media hasta principios de la Revolución Industrial.
} 
Para Ascher (2004), esta nueva ciudad explica la instauración del Estado-Nación y con este la expansión territorial, las ciencias, las nuevas técnicas y la autonomía de los individuos. Ahora el futuro es proyectado y controlado, aquí es donde el proyecto de una sociedad llegará a su forma última: la utopía. Esta etapa también es definida como Paleourbanismo en donde es posible identificar los elementos principales que configurarán al urbanismo, es decir el cuestionamiento de cómo organizar los espacios para la creciente población, la definición de sus necesidades y desplazamientos.

Después de otros cinco o seis milenios, el urbanismo ${ }^{3}$ entra en una nueva fase con la tercera revolución urbana, cuya antesala es la revolución agrícola ${ }^{4}$ que aumenta la producción de alimentos, pero expulsa del campo gran cantidad de agricultores. Este es considerado el inicio del capitalismo específicamente urbano-industrial. Es posible leer un doble proceso: por un lado, el crecimiento demográfico de las ciudades que suponía la primera expansión espacial acelerada de la ciudad y que, al mismo tiempo generó la pauperización de una parte de las poblaciones urbanas (Ascher 2004)

Este urbanismo comenzará a organizar la ciudad con la misma lógica que se organiza la industria (Ascher,2004). La noción fundamental es la especialización: el taylorismo, la sistematizará en la industria, en la que tratará de separar y simplificar las tareas para hacer su ejecución más rentable. El urbanismo moderno pondrá en práctica estas nociones desde finales del siglo xix bajo la forma de zonificación, esta lógica encuentra su mayor expresión en Le Corbusier y la carta de Atenas.

Durante la ciudad de la revolución Industrial la prioridad era adaptar las ciudades a las exigencias de la producción, del consumo y de los intercambios mercantiles. Fue decisivo el papel de los transportes urbanos para hacer posible la dilatación de los territorios y su recomposición a gran escala. Se consolidaban las primeras estructuras del llamado estado de bienestar. red de líneas de transporte, colegios, hospitales, baños públicos, oficinas postales, equipamientos deportivos, etc. Son producto de esta revolución la mirada simplificada de una realidad que podría

\footnotetext{
${ }^{3}$ La palabra "urbanismo" aparece bajo formas diversas a finales del siglo xix y principios del xx.

${ }^{4}$ El autor señala a la revolución agrícola inglesa del siglo XVIII -antesala de la revolución industrial-, como el proceso que detona la segunda revolución urbana como motor primero de los procesos de tecnificación que llevaron, finalmente a la influencia de los procesos del capitalismo en la organización y transformación territorial y específicamente de las ciudades. Existen discusiones y algunas concepciones no acabadas respecto los enfoques de la revolución agrícola inglesa, "la versión convencional de la revolución agrícola se puede reducir a un organigrama que va desde los terratenientes emprendedores a los cercamientos -o cierre de los tejidos comunales-, y a las grandes explotaciones, para pasar posteriormente a una mayor producción y a una reducción de la mano de obra y, finalmente a la Revolución Industrial propiamente dicha. Arthur Young en el siglo XVIII, posteriormente extendida por Marx en el siglo XIX y formulada definitivamente por Ernle en 1912 y los Hammonds en 1911" (Robert Allen, 2002).
} 
definirse por las zonificaciones monofuncionales y las estructuras urbanas jerárquicas, que Ascher (2004) define como un "urbanismo fordo-keynesiado-corbusiano". Aquí se verifica la idea de ciudad como palimpsesto que se transforma en una superposición de intervenciones que reflejan la lectura socio-económica del momento en que se llevan a cabo.

El comienzo de la cuarta revolución, ubicada tras los últimos treinta años de intensa reestructuración urbana (Soja, 2008) y que se cuenta en tiempo presente (Ascher, 2004), será definida como la posmetrópolis. Este fenómeno posterior a la expansión urbana dispersa sobre sus periferias es explicado a partir de 6 enfoques: i) la metrópolis industrial posfordista flexiblemente especializada; ii) la región urbana globalizada o Cosmópolis;iii) la exópolis postsuburbana o la megaciudad; iv) la ciudad fractal que intensifica las desigualdades a partir de la polarización social; v) un archipiélago carcelario de ciudades fortificadas o la explosión de los barrios cerrados; vi)una colección de simcities hiperreales, "donde la vida diaria se juega de forma creciente como si fuera un juego de ordenador" (Soja, 2008). A estos aspectos planteados por Soja, sumaremos: vii) las nuevas relaciones de riesgo como idea transversal a la configuración de los territorios y la construcción de la noción de riesgo. Asimismo, la generalización del segundo automóvil resignificando el territorio-región. Por último: viii) la mirada hacia la naturaleza y el patrimonio como un retorno. Este proceso estará asociado a la valorización del suburbio y fenómenos asociados a la necesidad -individual, sobre todo- de habitar-en-la-naturaleza. Diversos autores de diferentes disciplinas, en este contexto están poniendo en crisis la idea de progreso asociada a la expansión de las ciudades. Las lógicas del avance urbano, se cuestionan a partir de la lectura de los procesos de dispersión urbana y la fragmentación social que llevaban implícitas estas lógicas.

Ambos autores coinciden en afirmar que estamos transitando la cuarta revolución y que las dinámicas urbanas siguen desarrollándose no sólo en términos de expansión horizontal- por extensión de la periferia inmediata, por absorción de ciudades y pueblos-, sino al interior de las ciudades -por densificación o resignificación simbólica y funcional de los centros-. Los límites y la diferenciación entre el binomio campo-ciudad son prácticamente inexistentes y un debate obsoleto en esos términos. Esta última etapa a diferencia de las revoluciones anteriores, ha significado la aceleración del proceso de urbanización y la intensificación de las dinámicas de producción de suelo urbano.

La difusión de las nociones de la complejidad en diversos campos de conocimiento generó procesos de renovación en las formas de representación y construcción de modelos. Desde la planificación, el urbanismo ecológico y los estudios de prospectiva urbana y territorial, son las aproximaciones más difundidas. Ambos enfoques tienen en común la lectura de la dispersión y expansión urbana sobre un determinado territorio, produciendo nuevo suelo 
urbano sin considerar la baja densidad como una oportunidad, o incluso infraestructuras de soporte dentro del espacio urbano existente. Dichos procesos de urbanización en este contexto generan nuevos debates respecto las morfologías territoriales.

Según datos del Banco Mundial el 54\% de la población vive en ciudades (Banco Mundial 2016). Para América Latina ese porcentaje es del 80\% (CEPAL 2010) y en el caso de Argentina, asciende a un 90\% (Banco Mundial 2016). La velocidad del incremento de estos datos, demuestra la clara atención puesta en el crecimiento de la ciudad. En este contexto, y a los efectos de establecer estos intercambios de distinta intensidad resulta fundamental diferenciar la naturaleza de las dinámicas. En una primera aproximación, se identificaron aquellas que producen suelo urbano nuevo y las que no. Enumeraré a continuación los más relevantes en términos de literatura occidental y latinoamericana.

\section{La primera dispersión urbana. Ciudad compacta vs. ciudad difusa}

La ciudad europea pos-revolución industrial manifestó una clara diferencia entre la forma de implantación y la expansión física de la ciudad: por un lado, las germanas y anglosajonas del centro y norte del continente, y las latinas del sur mediterráneo (Dematteis 1998). Las primeras con una morfología dispersa y difusa y las segundas de tipo compactas. Hacia 1960, se produce una convergencia entre ambos patrones urbanos. En el caso de Estados Unidos -de tendencia anglosajona-, se produce la dispersión a partir del crecimiento y consolidación de los suburbios. Este proceso se acentúa a partir de 1930 con la generalización del automóvil para las clases media y alta (Josép Luis Sert, 1942 en Dematteis, 1998). Algunos autores coinciden en señalar la industrialización y el proceso de migración campo-ciudad como el primer impulsor del crecimiento periférico continuo, aunque variable en su magnitud. Este proceso puede ser entendido como la primera dispersión urbana, en donde dominaba la ocupación irregular de terrenos y la auto-construcción de viviendas precarias por sectores migrantes campesinos -migración campo-ciudad-, o de trabajadores ya urbanizados, la denominada urbanización popular (Duhau, 1998 en Pradilla Cobos, 2015).

A mediados de los años 70 en Estados Unidos se verifica una tendencia regresiva en el proceso de crecimiento de las ciudades. En Inglaterra y Estados Unidos este proceso se denominó contraurbanización y consistió en el retorno de flujos poblacionales a zonas rurales (Ávila Sánchez 2001). En el Reino Unido a partir de los años 50 se detectó un incremento de la población rural, la localización de población en zonas periurbanas y rurales alrededor de los principales núcleos urbanos. En los años 70 la población rural creció notablemente en zonas de Escocia, Gales y el norte del Reino Unido (Buller 1991). 
La ecología urbana pone especial atención al debate ciudad compacta-ciudad difusa bajo la hipótesis de que el protagonismo de estas cuestiones urbanas no solo estaba asociado al avance de los suburbios sino también a la sensibilización respecto los efectos que la ciudad dispersa traía consigo en calidad de vida y consecuencias ambientales (Monclús 1999). Para Monclús, cuando se enfatizan este tipo de dinámicas territoriales son identificables con los procesos de spraw/ ${ }^{5}$. Sin embargo, la acepción generalizada del término inglés que puede ser traducido como "desparramamiento" urbano no coincide con aquellas dinámicas que pueden poner el foco en la dimensión morfológico-paisajística y que refieren a la disolución de la ciudad compacta tradicional con la ocupación discontinua del territorio.

Los sistemas urbanos aumentan su organización y complejidad conforme crecen pero, sin embargo; esto no maximiza la recuperación de entropía ${ }^{6}$ en términos de información. La explotación de los recursos se hace, en la mayoría de los casos sin tener en cuenta los límites de la capacidad de carga de los sistemas (Rueda,2002). El sistema urbano es asociado entonces, a los organismos vivos, pero con niveles de eficiencia reducidos. La búsqueda de la sostenibilidad social, económica y ambiental será entonces la búsqueda de la reducción de disfunciones de la ciudad dispersa? ${ }^{7}$.

El modelo de ciudad compacta y densa se presenta a su vez como multifuncional y con alto grado de heterogeneidad por tanto diversa. Esto permite el aumento de la complejidad al mismo tiempo que ahorra suelo,

\footnotetext{
${ }^{5}$ El sprawl puede ser entendido como el crecimiento disperso en los espacios periurbanos y que se observa tanto en regiones metropolitanas como en núcleos medianos y menores, con cierto dinamismo económico.

${ }^{6}$ La entropía puede definirse en el campo de los sistemas, como la medida que calcula la probabilidad de que ocurran cambios en el sistema en función de la probabilidad de sus micro-estados. Es decir que la coexistencia de diferentes micro-estados de energía es compatible al estado general del sistema. En el contexto del urbanismo ecológico de Rueda (2002) el estado de entropía apunta a la máxima heterogeneidad del sistema que disminuya el gasto energético debido al aumento de heterogeneidades presentes en dicho sistema, es decir la cercanía de entradas necesarias para satisfacer el sistema.

${ }^{7}$ La ecuación de sostenibilidad propuesta por Rueda (2002) se base en los análisis de diversidad (H) para sistemas compuestos de partes heterogéneas. Una $\mathrm{H}$ diversificada como índice de organización se complejiza con la noción de persistencia y el espectro. La primera relacionada con el tiempo y la segunda con el espacio (Margalef R., 1986 en Rueda 2002). Los análisis de $\mathrm{H}$ entonces, permitirán la aproximación a la idea de mixtura y densidad de usos y funciones intercambiadoras de información de un espacio concreto. La mixtura de personas y actividades es entonces, la garantía de pervivencia del sistema a partir del aumento de oportunidades. si se relaciona la diversidad $(H)$ con la energía consumida $(E)$ a través de un consiente $E / H$, su aumento $^{7} 0$ disminución, en el espacio georreferenciado, puede convertirse en una función que sirve para determinar la eficiencia energética de un sistema -urbano-, además de su grado de organización, donde la organización será la el flujo diferente por unidad de información adquirida o conservada (Rueda, 1995). Si se entiende al desplazamiento mecanizado como la actividad de mayor consumo energético, la reducción de la distancia y la velocidad para mantener el mismo número de contactos e intercambios significa una reducción de la energía consumida por el sistema.
} 
energía y recursos materiales. Por consiguiente, reduce la dispersión preservando los sistemas naturales y agrícolas. Uno de los impulsores de cambio de la ineficiencia urbana estará definido por la segregación espacial de las funciones de la vida cotidiana urbana y que en las ciudades latinoamericanas también implica la segregación social explícita. Esto conlleva a la homogeneización, contrarrestada por la diversidad concentrada en una superficie menor compacta que disminuya trayectos de circulación y por ende consumo energético.

Según Baker et al. (2000), la alta densidad de ocupación puede favorecen la localización de servicios, equipamientos y comercio porque esto es económicamente posible, beneficiando la "sostenibilidad social" ya que esta densidad de usos favorece la ocupación del espacio público y por tanto la interacción social. Por otro lado, la ciudad compacta puede convertirse en un lugar hacinado y perder calidad urbana, reduciendo el espacio público, aumentando la congestión y la contaminación. Desde el punto de vista económico, la relación entre la compactación y la demanda de suelo urbano haría menos accesible este modelo para la gente de menores recursos, de esta manera tampoco es sustentable desde el enfoque social.

No obstante, críticas a favor y en contra, el modelo de ciudad compacta es un planteo genérico al cuál es necesario dotar de herramientas relativas a un contexto socioeconómico, político y cultural determinado. En cualquier caso. las perspectivas que analizan estos fenómenos convergen en la lectura de rasgos característicos y comunes de procesos de dispersión urbana bajo la lógica de la: i) ciudad europea, ii) la ciudad latinoamericana y, iv) la ciudad estadounidense. Esto nos permite inferir que si bien los procesos de expansión o compactación del hecho urbano adquieren particularidades asociadas a la forma en que el territorio es ocupado. A su vez es condicionado por factores sociales, económicos, geográficos y políticos en un contexto global de mayor o menor influencia.

\section{La segunda dispersión urbana: edge cities y ciudades dormitorios, la dispersión especializada}

Durante los años 80 el proceso se vuelve no-lineal: en Estados Unidos, Dinamarca y Suecia la desconcentración urbana se revierte. En Holanda el fenómeno de periurbanización siguió su curso mientras que, en Bélgica, Francia y Alemania aumentó (Courgeau, 1991). En los países periféricos, los años 80 implicaron el acelerado crecimiento urbano, pero a partir de otro tipo de procesos. La expansión de las ciudades se daba fundamentalmente por la migración rural hacia las ciudades por lo que la periferia era ocupada legal o ilegalmente por esta población dado el bajo costo de la tierra (Ávila Sánchez, 2001).

Las ciudades norteamericanas definirán al fenómeno Edge City. Este término es acuñado en una publicación: "Edge city; life on the new frontier", por el periodista Joel Garreau (1991), su traducción literal es la de "ciudad borde" y 
en esta publicación el autor cuantifica alrededor de 123 ciudades borde y 77 emergentes en todo Estados Unidos. Esta forma urbana puede asociarse a la década de los ochenta para este lugar y, posteriormente se traslada a Europa, Asia y América Latina. A diferencia de las ciudades dormitorios que tienen un origen muy diverso según cada contexto, las Edge cities son el resultado de la planificación basada en el desarrollo de oficinas para corporaciones -tanto nacionales como extranjeras-, en donde el contacto real resultaba primordial. Obedecen a la carencia de espacio disponible en el área periurbana para el desarrollo de los distritos financieros 0 -Central Business District (CBD)-. Estas configuraciones urbanas son apoyadas en las autopistas, aeropuertos y centros comerciales mediante la movilidad privada.

Esta forma de expansión urbana, representa una clara segregación socio-espacial determinada por ingresos económicos. Sumado a eso, son configuraciones más densas que la ciudad que la contiene 0 a la cual se encuentran próximas. No poseen una identidad fundacional y su antigüedad máxima se ubica hace aproximadamente treinta años (Garreau, 1991). Se establecen alrededor de corporativos empresariales que se relocalizan a las afueras del CBD. Henderson y Mitra mencionan que el fenómeno de las Edge Cities no es descentralización ni expansión urbana si no son "la creación estratégica controlada hecha por grandes desarrolladores a través de proyectos de planeación urbana" (J. Vernon Henderson y Arindam Mitra, 1996). En las edge cities la superficie destinada a áreas de trabajo es mayor que la que está dedicada a las áreas de habitaciones.

Las ciudades dormitorio por el contrario son principalmente habitaciones. Ya que se consolidan alrededor de grandes centros metropolitanos donde trabaja la población de la ciudad dormitorio y que, por diversos motivos, asociados al valor del suelo de la ciudad capital o la oferta inmobiliaria emergente en estos centros urbanos próximos se transforman en el lugar "para dormir" luego de la jornada laboral. Son la residencia principal de sus habitantes núcleo en lugares que en general, han tenido tradición de segunda residencia, como el caso de algunas ciudades turísticas cercanas a grandes áreas metropolitanas. Ambas configuraciones comparten la cercanía a los centros económicos -en general no superan distancias de 50 kilómetros-. Las Edge cities además se consolidan en torno a tres tipos de centros atractores: los asentamientos de fábricas de autos, en nodos de autopistas y cercano a centros comerciales y la Edge city producto de un plan maestro hecha por un desarrollador inmobiliario específico (Vazquez Roldán, 2015). 


\section{Transformaciones urbanas en las ciudades}

\section{Latinoamericanas}

La configuración de las ciudades latinoamericanas merece un apartado particular no sólo en términos de contexto regional de trabajo sino, dadas las condiciones en que se han expandido sobre el territorio que las diferencian de otras ciudades del mundo. En la mayoría de los casos han tenido una fuerte imposición en su configuración actual durante el período de "fundación". Esto implica que la relación de las sociedades con el territorio fue condicionada por un modelo urbano capaz de contener todas las actividades acordes al momento de su configuración morfológica colonial.

Hasta la segunda mitad del siglo XIX, fue posible identificar generalidades en la configuración de la ciudad latinoamericana producto del asentamiento colonial y su expresión en el trazo y estructura interna (Bahr and Riesco 1981). Estas configuraciones cuya base obedecía a las ordenes reales de construcción urbana hispánica: las leyes de indias, implicaron ciertos patrones que en la mayoría de los casos pueden verificarse en las principales ciudades -luego metrópolis- latinoamericanas: la imposición de la cuadrícula por sobre la realidad del territorio -topografía, por ejemplo-, el espacio central de plaza cívica y la tipología de vivienda similar a la del mar Mediterráneo orientada al patio interno-, entre otras. Estas características definieron la estructura urbana colonial hispánica como altamente compacta, en contraposición al entorno rural-natural. Esta diferencia entre la ciudad y el área circundante algunas veces era acentuada por la construcción de una muralla (Bahr and Riesco 1981). Hacia la periferia se localizaban barrios de clases bajas, negociantes y artesanos. Esta segmentación social, se mantuvo en la mayoría de las ciudades latinoamericanas (Figura 2).

De los patrones comunes al primer proceso de configuración urbana de las ciudades latinoamericanas, el trazado urbano es el que evidencia una persistencia a lo largo de distintos períodos. Otra característica que no sólo se mantuvo, sino que se potenció fue la lógica de las vías de circulación como retícula organizadora del espacio, el ensanche del espacio público y las diagonales en la intensificación del flujo vehicular. 


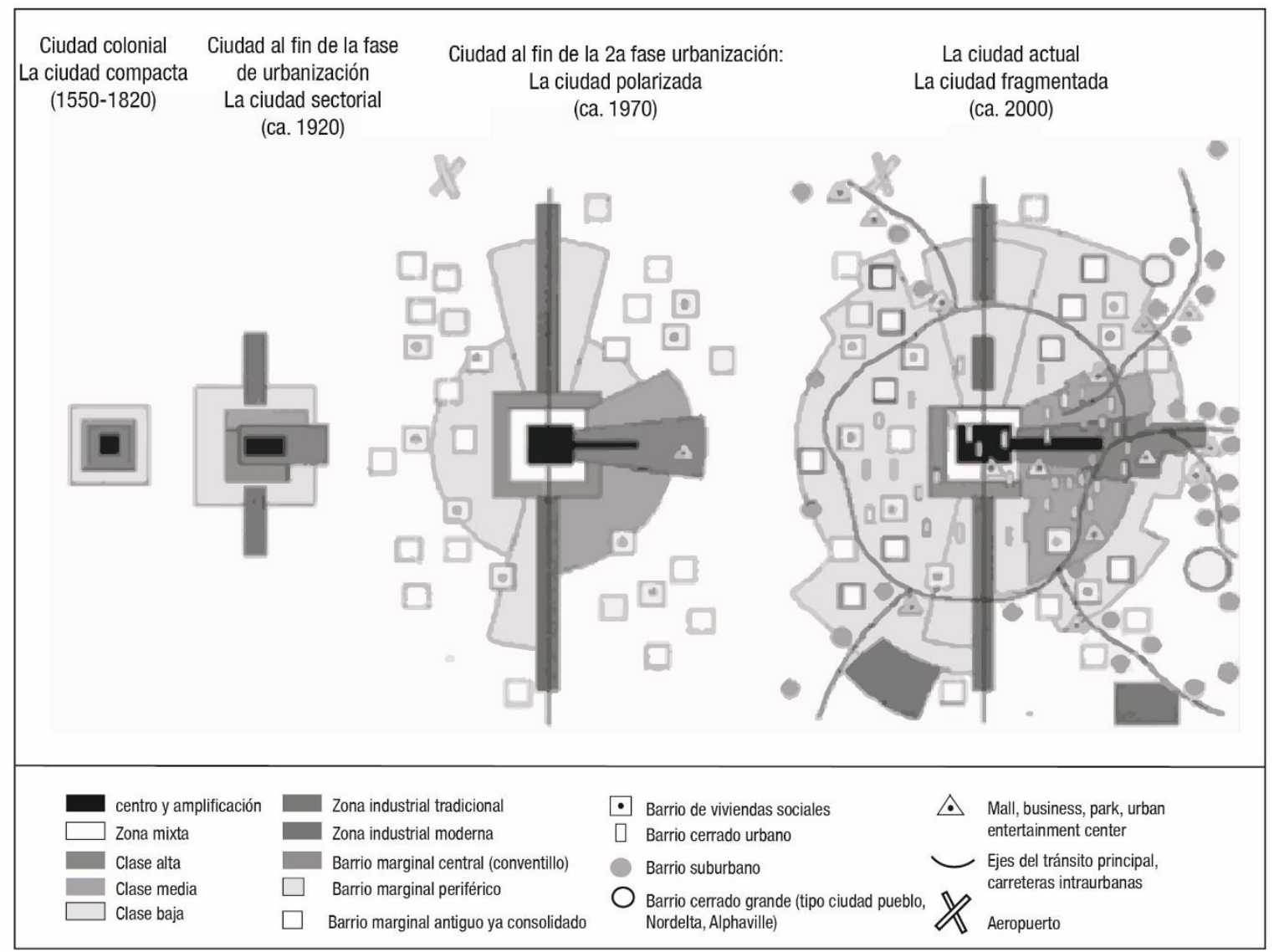

Figura 2 . Desarrollo estructural y proceso de expansión de la ciudad latinoamericana: de la ciudad colonial a la ciudad difusa (Janoshcka 2010). Redibujo Céliz 2020.

Durante un determinado período de tiempo, este crecimiento demográfico no originó una expansión significativa de la superficie urbanizada, sino más bien un aumento de la densidad en las superficies ya construidas ${ }^{8}$. Se trataba principalmente de un área habitacional de condiciones muy variadas. Convivían barrios acomodados, cerrados, con áreas marginales 0 de altos índices de pobreza. Actividades informales, de cierto grado de tecnificación. Durante los años 60-70 el crecimiento urbano se dio por población rural sobre superficies con baja vocación agrícola (Collin 1993).

Durante los años 80' hubo desplazamientos temporales sobre zonas rurales vinculadas a la reconversión productiva por labores estacionales o prácticas agrícolas itinerantes de campesinos sin tierra en zonas de alto riesgo ecológico. Este proceso se intensificó en la década de los 90 así como la movilidad "intrametropolitana" (CEPAL-ILPES,2000,

\footnotetext{
${ }^{8}$ Un ejemplo de ello lo constituyen las poblaciones obreras que surgieron a comienzos de siglo al margen del antiguo centro de la ciudad y que en algunas metrópolis latinoamericanas se han conservado en parte hasta la actualidad (Bahr and Riesco 1981).
} 
citado en Ávila Sánchez 2001). El crecimiento urbano tomó la forma de ampliaciones desconectadas del centro para luego establecer su unión y comunicación como una nueva lógica dominando la ciudad latinoamericana. La periferia de las grandes ciudades muta de una estructura compacta a una de tipo celular. El movimiento centrífugo de la población fue iniciado por miembros de los estratos superiores en el período entre la Primera y Segunda Guerra Mundiales (Bahr and Riesco 1981). Se abandonaron barrios céntricos y se trasladaron a villas en la periferia urbana. Estos procesos se desarrollaron en un marco similar a lo que se definió como la primera dispersión urbana, pero de características latinoamericanas, y un recambio de configuración del centro. El traslado de población que generó modelos urbanos tipo celular es construido mayormente por acción del Estado, a lo que se suman los asentamientos informales, villas y barriadas populares.

Varios autores coinciden en determinar que desde mediados de los años 70 (Ciccolella, 1999; Janoschka, 2002) y principios de los años 80 (Abramo 2012), las ciudades latinoamericanas han sufrido importantes transformaciones. Este proceso asociado a un cambio en la lógica de la producción urbana es considerado como la institucionalización de la ciudad neoliberal (Moulaert, Rodríguez, and Swyngedouw 2003). La mayoría de estos procesos están asociados a la disminución del acelerado crecimiento demográfico -a partir de una disminución de las migraciones campo/ciudad-, y a ciertas transformaciones socio-políticas. En este sentido, las reformas económicas de los años 90' en Argentina, apuntaron a contraer al Estado mediante privatizaciones de empresas públicas y el desmantelamiento del sistema social limitaron en gran medida la capacidad de gestión estatal (Janoschka 2002).

Estos procesos de sustitución del actor público por el actor privado -y sus intereses-, provocaron la aparición de nuevas formas urbanas comerciables, redituables y con valoración inmobiliaria de gran impacto para el mercado. Este nuevo proceso de transformación fue conquistado por las formas de la globalización: los shoppings malls, centros de entretenimiento, escuelas privadas, complejos residenciales cerrados y de acceso restringido. La segregación espacial de la ciudad hispánica se acentuaba y se expandía a través de grandes autopistas. Este predominio del mercado como regulador de las decisiones en torno al uso del suelo es el rasgo característico más relevante de la ciudad neoliberal, en contraste con el período del fordismo urbano: en donde el papel del mercado en la producción de la ciudad estaba fuertemente mediado por el Estado a través de la definición de las reglas en el uso del suelo, pero también de las características que debía tener esa producción urbana. Se consolida de esta manera el proceso de dispersión y expansión horizontal de la ciudad latinoamericana (Figura 3), generando áreas de especulación, vacancias urbanas, áreas de sobrevalorización, áreas de exclusión, especialización y resignificación del mercado de suelo a partir de infraestructuras expandidas sobre el área rural y natural. 


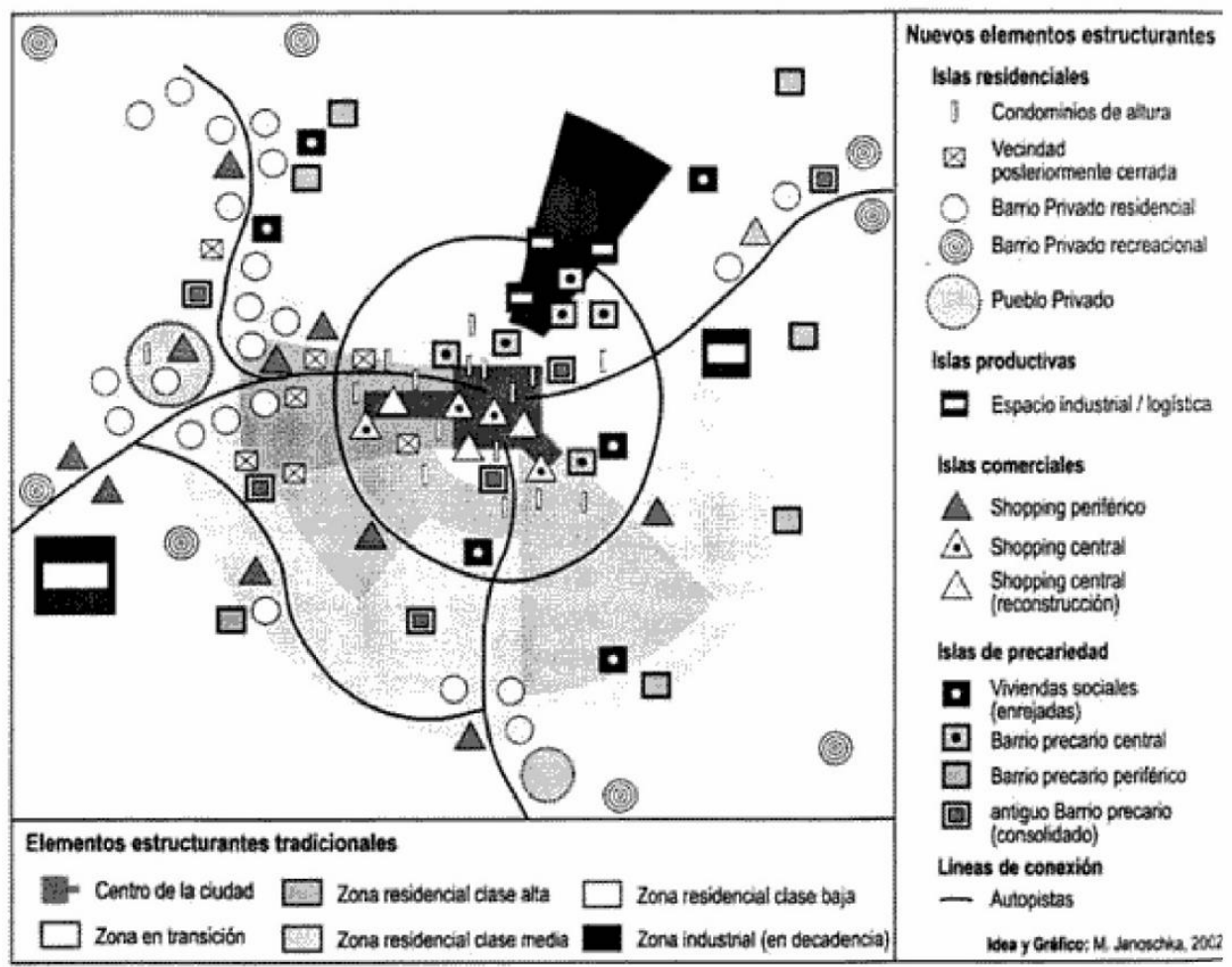

Figura 3. La ciudad expandida, elementos estructurales (Janoschka, 2002).

de Mattos (2006), considera un quiebre decisivo en la transformación urbana de las principales ciudades latinoamericanas al momento de la reestructuración productiva. Este hecho entre otros, resalta la relevancia de los factores político-económicos como impulsores de cambio en la configuración urbana.

De las diferentes expresiones de los procesos de intensificación metropolitana, algunos elementos comunes están asociados a la homogeneización de los actores económicos, presentes con las mismas lógicas en todos los países, en la mayoría de las ciudades y, la diferenciación en la competencia interurbana, donde rige la competitividad y la disputa por la especialización (Ascher 2004). Estas dinámicas pueden observarse en la extensión de la infraestructura de transporte. El clásico centro urbano deja de ser el lugar accesible por excelencia, se multiplican las polaridades y la expansión se acentúa. Se multiplican las polaridades y los centros financieros. Los barrios de vivienda cerrados en un contexto de espacialidad exclusiva potenciados por el automóvil.

A su vez, para Ascher (2004), las ciudades del mundo que se han definido desde el comienzo de la revolución industrial están sufriendo un cambio de patrón territorial que implica, no sólo el cambio de la tendencia de crecimiento urbano, sino también en las relaciones urbano-rurales. Frente a este escenario, plantea que el foco está en las nuevas dinámicas de reestructuración productiva que resultan del posfordimo y como configuran una ciudad cada vez más compleja en sus interacciones. En esta misma línea Ciccolella (2012), retoma la idea de 
revolución urbana señalando que en los últimos 30 años la difusión universal del suburbio, se constituye como el último fenómeno revolucionario. La expansión del suelo urbano en las antiguas ciudades europeas y en las de América del Norte y del Sur a partir del modelo de Los Ángeles, permitió la profusión de urbanizaciones privadas en segundas y terceras periferias es prueba de esta dinámica.

Complementariamente, tanto Duhau (1998) como Pradilla Cobos (2015), coinciden en señalar el paralelo entre el proceso tardío de industrialización y, la configuración del patrón de crecimiento periférico de la ciudad latinoamericana. Los rasgos más relevantes de este proceso es resumido a partir del cuantitativo ${ }^{9}$ de la urbanización popular, caracterizada por la ocupación irregular de terrenos viables -necesariamente dispersos en la periferia- y la autoconstrucción de viviendas precarias (Pradilla, 1987, Duhau, 1998). La presencia de fraccionamientos dispersos de clase media y alta, desarrollados por fraccionadores privados. La implantación de grandes empresas y zonas industriales públicas o privadas dispersas en las periferias sucesivas, que atraían implantaciones obreras a sus alrededores, la construcción periférica de algunas unidades de vivienda pública; y lo que es más importante y específico, el posterior y sucesivo relleno de los intersticios desocupados por nuevas implantaciones de los distintos sectores de acuerdo con los costos diferenciales de los terrenos, incrementados por las nuevas rentas del suelo generadas por la urbanización inicial y la construcción de infraestructuras en la presencia de procesos especulativos.

"El resultado de las transformaciones territoriales metropolitanas en América Latina, desde los años noventa, sobre una estructura socioeconómica-territorial históricamente desigual, parece ser el agravamiento de la misma. La estructura metropolitana emergente combina la residencia en "barrios privados" o urbanizaciones cerradas, el consumo y la recreación a través de los shoppings, hipermercados y mega-centros de esparcimiento y la educación, la salud y la seguridad a través de servicios privados." (Ciccolella 2006, p.305)

En la medida que el capital privado comienza a ordenar el territorio, a partir de la obtención de ventajas competitivas según la locación de que se trate, se expulsan sectores populares y medios de los núcleos históricos a la periferia y más allá, donde las problemáticas cambian e incluso se agudizan. La transformación de grandes ciudades en centros financieros globales como Nueva York, Londres, Tokio, Frankfurt y, en un futuro próximo seguramente también San Pablo, Santiago, México, Buenos Aires, Shangai, Mumbai, El Cairo, etc., son algunos ejemplos.

\footnotetext{
${ }^{9}$ Se calcula que durante este período más de la mitad de la superficie de las ciudades latinoamericanas fueron urbanizadas mediante la ocupación irregular de terrenos y la autoconstrucción.
} 
El proceso de transformación de la ciudad latinoamericana es planteado en este capítulo a los efectos de identificar elementos comunes que definen en este caso, ciudades mestizas producto de la no resolución de tendencias metropolitanas. Esto se verifica en la convivencia conflictiva en la mayoría de los casos. Para Ciccolela y Mignaqui (2004) en algunos casos, los cambios constituyen la aceleración de las tendencias del proceso desarrollista. En otros casos, las transformaciones más estructurales implican la ruptura radical con la ciudad antecesora desarrollista latinoamericana. La globalización arrasa con formas y estructuras espaciales previas modelando la ciudad global, la escala cambia radicalmente también lo que significa que territorios naturales y rurales son reemplazados en algunos casos, completamente.

La primera conclusión indica que, las lógicas de crecimiento urbano entre las ciudades europeas y estadounidenses no pueden leerse de la misma manera en la ciudad latinoamericana. Esto implica necesariamente, que los instrumentos a partir de los cuales se ha desarrollado el ordenamiento del territorio difieran.

Esta lectura del crecimiento de las ciudades establece los principales elementos que permitirán entender las lógicas de construcción de los planes, programas y proyectos que define el ordenamiento territorial (OT) según cada una de las lógicas analizadas. De esta manera se organizaron los enfoques de las principales líneas de planificación territorial desde su concepción geopolítica y como a partir de aquí, se define la relevancia de los instrumentos clásicos que ordenan el territorio.

\section{La planificación territorial en (tres) enfoques clásicos}

Es posible identificar al menos tres enfoques en la planificación asociados a los procesos descriptos en las revoluciones urbanas, su alcance y la adaptación que cada territorio hacia a los procesos históricos que dictaban la forma urbana. Estos enfoques determinaron tres lógicas para ordenar el territorio: i) la mirada europea, ii) la mirada estadounidense y, iii) la mirada latinoamericana.

"La actual planificación urbana sigue reflejando, en muchas instancias, los principios del funcionalismo expuestos en la Carta de Atenas, una teoría de la planificación surgida en los años cuarenta, que también se encuentra en el anterior movimiento inglés de ciudades jardín (...). Ello significa que la vivienda, la industria, las zonas comerciales, los espacios verdes, etc., se separan físicamente enlazándolas mediante una extensa red de calles y transportes."

(Monclús, 1999, p.8) 
¿Qué principios rigen la planificación de la ciudad en la posmetrópolis? ¿Ha superado el urbanismo estos dos grandes paradigmas? ¿Las ciudades latinoamericanas han transferido estos modelos como una receta que no se cuestiona?

Las ideas de la ciudad jardín (Figura 4) del libro "Ciudades jardín del mañana" (Howard, 1902), eran parte del movimiento de las utopías urbanas del siglo XX. Planteaban el control del crecimiento urbano a partir de anillos concéntricos que contuvieran cierta cantidad de habitantes en una determinada superficie, que al momento de ser excedida añadiría una nueva unidad jardín a modo radial, este límite estaría dado por un cinturón verde que contendría a la ciudad central y luego la ciudad industrial.

Por su parte, La carta de Atenas en el IV Congreso internacional de arquitectura moderna (CIAM, 1933), preveía una ciudad masivamente construida que debía ser zonificada de acuerdo a funciones rígidas en su definición, separando unos usos de otros: una zona para vivir, una para trabajar y una zona para el ocio determinadas por las áreas para circular de uno a otro punto (Figura 5). Para Monclús, "si bien el auge de estas -primeras- ciudades dormitorio puede explicarse en parte como respuesta de las autoridades públicas a una necesidad acuciante, obedece también a una doctrina surgida de la primera guerra mundial que veía un ideal de la ciudad jardín".

Desafortunadamente, este intento de proporcionar a los habitantes de la ciudad aire, calma y espacio ha dado lugar a procesos de dispersión planificada ( Monclús, 1999).
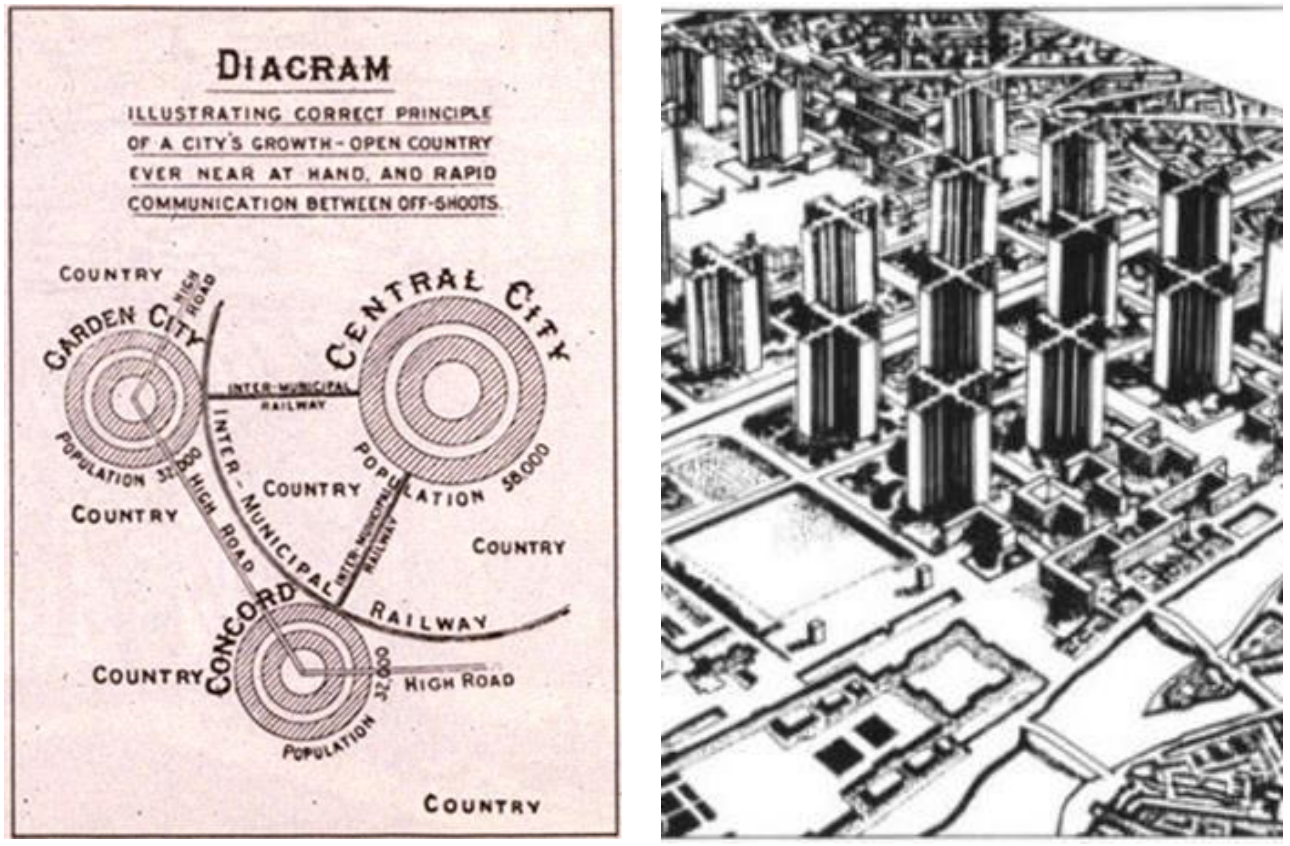

Figura 4. Esquema de la ciudad jardín de E. Howard. Fuente: Garden City Movement a concept in Urban Planning by Sir Ebenzer Howard.

Figura 5. Zonificación propuesta en la carta de Atenas. Fuente: Le Corbusier. Principios del Urbanismo. La Carta de Atenas. 


\section{La mirada europea}

Hasta comienzos de la década de los ochenta, las ciudades tenían como únicas preocupaciones urbanas la regulación del crecimiento urbano, la rehabilitación y renovación de áreas centrales y la gestión de áreas cada vez más extensas. A partir de la crisis energética -1973-, tanto el sistema productivo como el urbano entraron en fase de reestructuración (Precedo Ledo, Orosa González, and Iglesias 2010). En muchas ciudades, actuaciones de renovación física de los centros se orientaron a recuperar posiciones anteriores 0 a mejorar su posicionamiento en el nuevo sistema de ciudades. Precedo analiza la evolución de las políticas urbanas económicas y territoriales resumidas en la Tabla 1 y, establece que es posible identificar los síntomas necesarios para un nuevo diagnóstico urbano en la ciudad europea:

"la ruptura de la relación lineal entre crecimiento de la población, dinamismo y jerarquía urbana; la reestructuración del mercado de trabajo y la formación de bolsas de pobreza urbana; la reducción de la natalidad y del crecimiento vegetativo endógeno; sustituido por la creciente aportación inmigratoria, el transvase sectorial del sector secundario -la industria- al terciario productivo y al cuaternario especializado y tecnológico, el incremento de rentas familiares y el aumento del tiempo libre con nuevas demandas de ocio, los cambios en la movilidad urbana y la internacionalización de las economías locales" (Precedo, 1996 citado en Precedo et. al 2010, p.8).

Tabla 1. Evolución de políticas urbanas económicas y territoriales, ciclos y puntos de ruptura

\begin{tabular}{|c|l|l|l|}
\hline & \multicolumn{1}{|c|}{ Industrial } & \multicolumn{1}{c|}{ Postindustrial } & \multicolumn{1}{|c|}{ Globalización } \\
\hline Actividades motrices & $\begin{array}{l}\text { Industrial, terciario } \\
\text { comercial }\end{array}$ & $\begin{array}{l}\text {-Terciario avanzado } \\
\text {-Sistema financiero } \\
\text {-Comunicaciones }\end{array}$ & $\begin{array}{l}\text {-Nueva economía } \\
\text {-Tiempo libre } \\
\text {-Cultura } \\
\text {-Formación } \\
\text {-Salud } \\
\text {-Oficinas globales }\end{array}$ \\
\hline Forma urbana & $\begin{array}{l}\text { Áreas metropolitanas con } \\
\text { gravitación central }\end{array}$ & Red urbana dispersa & Red Urbana Policéntrica \\
\hline Política urbana & $\begin{array}{l}\text { Equidad (zoonning, } \\
\text { desequilibrios, } \\
\text { segregación, sociedad } \\
\text { del bienestar) }\end{array}$ & $\begin{array}{l}\text { Mercado (gestión } \\
\text { público-privada, } \\
\text { dirección, competitividad) }\end{array}$ & $\begin{array}{l}\text {-Calidad urbana } \\
\text {-Atractividad } \\
\text { Internacionalización }\end{array}$ \\
\hline Planificación & Planes de urbanismo & Planificación estratégica & Marketing urbano \\
\hline Gobernabilidad & Tecnoestructura pública & Asociacionismo público & $\begin{array}{l}\text {-Control ciudadano } \\
\text {-Participación social }\end{array}$ \\
\hline
\end{tabular}

Fuente: Precedo et al., 2010 
El compendio de la Unión Europea sobre políticas y sistemas de planificación espacial distingue cuatro tradiciones: la planificación regional; la planificación integral comprehensiva; la gestión de usos de suelo; y la del urbanismo. Esta última tiene un fuerte componente arquitectónico y preocupación por al diseño urbano, el paisaje y el control de los edificios (Cárdenas, 1999).

El consejo de Europa definió la planificación regional/territorial como la expresión geográfica de las políticas económicas, sociales, culturales y ecológicas de la sociedad (Consejo de Europa 1983). Posteriormente, la Carta Europea de Ordenación del Territorio (CEMAT 1999) suscrita por todos los países de la Comunidad Europea, se define como una guía del ordenamiento territorial europeo. La última CEMAT se celebró en Grecia en 2014.

El enfoque del CEMAT define líneas que fueran influenciadas por grandes corrientes del ordenamiento: i) el modelo alemán "Raumordnung", que entiende al concepto como la ordenación física del territorio sin tener en cuenta las vinculaciones con la planificación económica, cultural o de los recursos naturales. Por otro lado, el modelo francés 0 "Aménagent du territorie", desvinculado del urbanismo que se orienta al aprovechamiento global del territorio y sus recursos naturales. Bajo estas influencias la CEMAT define al territorio para la Unión Europea -UE- como:

“la expresión espacial de las políticas económicas, sociales, culturales y ecológicas de la sociedad".

Entiende que el ordenamiento territorial es una disciplina científica, una técnica administrativa y una política de carácter interdisciplinar y global que busca un desarrollo equilibrado entre las regiones que constituyen la UE y la organización física del espacio según estas directrices. Según (Bengoetxea Urizu 2001) en el ordenamiento territorial -europeo-, inciden cuatro niveles de poder con sus correspondientes estatus jurídico-políticos: i) entidades locales, ii) comunidades autónomas, iii) estado y iv) la unión europea (Tabla 2).

Tabla 2. Niveles de ordenamiento territorial en Europa

\begin{tabular}{|c|c|}
\hline Unión & Macro-ordenación del territorio \\
\hline Estado miembro & Política regional \\
\hline Comunidad autónoma & Ordenación del territorio (en sentido estricto o alemán) \\
\hline Entidades locales & Urbanismo (tutelado por las comunidades autónomas) \\
\hline
\end{tabular}

Fuente: Bengoetxea Urizu ,2001

Estos niveles actúan en función de competencias -cada uno en su campo-, pero de cualquier forma que incidan en una única materia, el escalón superior tiene primacía sobre el inferior, en los tres niveles con potestad legislativa, y sobre el inferior al que sólo le compete potestad reglamentaria, rige el principio de jerarquía legal. De esta manera la UE, dentro de determinados ámbitos ha restringido soberanía a estados miembros a pesar de requerir de las herramientas de los sistemas de cada uno de estos.

La Tabla 3 resume las relaciones entre la configuración del ordenamiento territorial (en adelante 0T), el grado de consideración ambiental en el proceso de planificación y la figura que rige la organización territorial de cada país. 
Tabla 3. Cuadro comparativo de ordenamiento territorial en Europa

\begin{tabular}{|c|c|c|c|c|}
\hline Estado & $\begin{array}{l}\text { Organización } \\
\text { territorial }\end{array}$ & $\begin{array}{l}\text { Entidad territorial } \\
\text { competente }\end{array}$ & Concepto de OT & $\begin{array}{l}\text { Valoración } \\
\text { ecosistémica }\end{array}$ \\
\hline Reino Unido & $\begin{array}{l}\text { Sin regiones } \\
\text { políticas- } \\
\text { administrativas. } \\
\text { Constituida por: } \\
\text { Inglaterra, Gales, } \\
\text { Escocia e Irlanda }\end{array}$ & Gobierno central & $\begin{array}{l}\text { Política económica } \\
\text { dirigida a corregir } \\
\text { los desequilibrios } \\
\text { económicos } \\
\text { regionales } \\
\text { (Regional planning) }\end{array}$ & $\begin{array}{l}\text { Estrecha relación } \\
\text { entre la política de } \\
\text { ordenación y el } \\
\text { medio ambiente }\end{array}$ \\
\hline Francia & Estado unitario & Estado & $\begin{array}{l}\text { Política de } \\
\text { desarrollo regional, } \\
\text { centrada en el } \\
\text { desarrollo } \\
\text { económico y la } \\
\text { planificación de } \\
\text { infraestructura y } \\
\text { equipamiento }\end{array}$ & Poco protagonismo \\
\hline Alemania & $\begin{array}{l}\text { Federal: Federación } \\
\text { y Länder }\end{array}$ & Länder & Planificación física & $\begin{array}{l}\text { Figuran temas } \\
\text { ambientales en los } \\
\text { planes territoriales. } \\
\text { Enfoque paisajista } \\
\text { en la planificación. } \\
\text { Cumplimiento de } \\
\text { evaluación de } \\
\text { impactos } \\
\text { ambientales y } \\
\text { territoriales }\end{array}$ \\
\hline Italia & $\begin{array}{l}\text { Estado unitario, } \\
\text { fundado en } \\
\text { Estados, Regiones, } \\
\text { Provincias y } \\
\text { Municipios. }\end{array}$ & Regiones & Planificación física & $\begin{array}{l}\text { Estrecha relación } \\
\text { entre la } \\
\text { planificación } \\
\text { paisajística y } \\
\text { territorial. }\end{array}$ \\
\hline España & $\begin{array}{l}\text { Estado unitario, } \\
\text { constituido por } \\
\text { Municipios, } \\
\text { Provincias y } \\
\text { Comunidades } \\
\text { Autónomas }\end{array}$ & $\begin{array}{l}\text { Comunidades } \\
\text { Autónomas }\end{array}$ & $\begin{array}{l}\text { Planificación } \\
\text { económica }\end{array}$ & $\begin{array}{l}\text { Estrecha relación } \\
\text { entre la política de } \\
\text { ordenamiento } \\
\text { territorial y el medio } \\
\text { ambiente. }\end{array}$ \\
\hline
\end{tabular}

Fuente: Reelaborado por Céliz, 2018 en base a Hildenbrand, A. (2000) y Parejo, T. (2003) citado en Sanabria Pérez (2014).

Cabe destacar que la relación entre el enfoque del OT en países como los del Reino Unido o Francia y los sistemas naturales, es casi nula. Tanto en Alemania como en Italia se utilizan términos de paisaje que dan cuenta de la superación del enfoque "ambientalista": el sistema natural no es un escenario es un conjunto de procesos considerados en su totalidad. Puede que la acepción de paisaje aquí utilizada no se remita literalmente a esta idea, 
sin embargo existe una amplia biblioteca referente a estos países y el estudio del Paisaje: El convenio europeo del Paisaje (Consejo de Europa 2000), la declaración de los sitios Natura 2000( UE, 2000), etc.

El modelo urbano europeo, posee altos niveles de urbanización-84\%- y un crecimiento demográfico bajo, nulo 0 negativo donde existe un predominio de población vieja -mayor a 60 años promedio-. La prospectiva que indica la emergencia de las ciudades medias arroja que la población se concentrará en estas ciudades de menos de 500.000 habitantes (Precedo Ledo 2004). La problemática urbana del siglo xxi estará caracterizada por el aumento de las bolsas de pobreza y la inmigración ocupando las bases erosionadas de la pirámide demográfica. (Precedo Ledo 2004). De las treinta ciudades más grandes del mundo en 1950, doce eran europeas, es decir, casi la mitad, mientras que a principios del siglo xxi sólo una. París, estará en ese grupo, lo cual evidencia la estabilidad de la dinámica urbana europea en términos comparativos. En síntesis en Europa, además de las grandes regiones metropolitanas, las redes de pequeñas y medias ciudades se consolidaron como sistema estratégico de articulación territorial (Precedo Ledo 2004).

\section{La mirada norteamericana}

En los años sesenta diversos movimientos surgieron en contra de "la modernidad funcionalista". Jane Jacobs, se destaca con su argumento de la destrucción del tejido social y urbano por estas tendencias de "tabla rasa" del modernismo (Jacobs 1962). Posteriormente la línea urbana da nacimiento al master plan -o plan maestro- y los planes reguladores, como instrumentos de la planificación urbana que pretendían guiar y controlar el crecimiento físico urbano. Los componentes principales eran: la zonificación, los usos del suelo, la red vial estructurante, el tamaño de la parcela, las densidades de ocupación y los códigos arquitectónicos o condiciones de edificación tales como el índice de construcción -0 FOT-, el coeficiente de ocupación del suelo -o FOS-, las distancias a los límites de la propiedad y las alturas de edificación, entre otros.

Según la forma en que la planificación norteamericana respondió al crecimiento de sus ciudades se identificaron cuatro líneas (Cárdenas Jirón 2005): i) los modelos matemáticos, ii) los planes-proyecto de urbanismo, iii) los sistemas espaciales informáticos, y iv) la sustentabilidad urbana.

El primer enfoque son los modelos matemáticos que tuvieron origen en los años cincuenta en Estados Unidos con motivo de planificar las inversiones en la infraestructura de transporte. Sin embargo, al cabo de un par de décadas de funcionamiento fueron objeto de duras críticas por parte de los planificadores urbanos, por lo que pierden validez. En los años setenta se incorporaron modificaciones de usos del suelo y edificación a fin de mejorar estos modelos con el objetivo de hacerlos aplicables. Es así como en los ochenta y noventa resurgen los modelos de usos de suelo y transporte. 
El segundo enfoque tiene relación con las respuestas de diseño arquitectónico y urbanístico frente al crecimiento de los suburbios y su desintegración espacial por las vías de transporte en las ciudades norteamericanas. Esta metodología pretende dar organicidad, identidad comunitaria y estructura espacial unitaria a los planos de nuevas urbanizaciones que se ubican en la periferia, y que usualmente se adicionan al tejido urbano existente sin la concepción de un proyecto integral. Esta corriente de pensamiento es conocida como el "Nuevo Urbanismo “, L. Mundford (1953) utiliza la expresión "viejas formas para nuevas ciudades"10 para hablar de las prácticas que ya venían desarrollándose pero que a partir de aquí se incorporan como un conjunto de principios a una forma de hacer urbanismo. Las problemáticas urbanas que se abordaron tenían que ver con la zonificación segregacionista, la disminución de peatones y el uso del transporte público, la desaparición del espacio público, el abandono de las áreas centrales y el avance en la degradación de las áreas naturales.

En 1929, C. A. Perry publicó The Neighborhood Unit, abordando el concepto de unidad barrial que consistía en la aplicación de un modelo diagramado para la disposición ideal de un barrio para una cantidad determinada de población. Se planteó el desarrollo de viviendas de baja densidad y se pensó en términos de traslados peatonales y cortos para la satisfacción de diferentes niveles de servicios y necesidades.

Si bien el concepto de un barrio peatonal no resulta innovador, hace aproximadamente 50 años esto implicó romper zonificaciones aisladas, un avance en la configuración de ciudades para ciudadanos. Muchos urbanistas actuales han rescatado la lógica del "vecindario y la caminata de cinco minutos" como la forma de planificar los espacios de la ciudad actual, resignificando algunas cuestiones, pero planteando su plena vigencia ${ }^{11}$ (Steuteville 2017). Este planteo de cambio de escala a partir de concebir a la región dese el barrio, consolida un enfoque de transición a partir de la utilización y posterior difusión del "diagrama de transecto" como representación esquemática de los diferentes entornos en los que se desarrolla la vida de los asentamientos humanos.

El diagrama de transecto incluía -en la mayoría de sus representaciones-, seis categorías desde lo rural a lo urbano (Figura 6). Este esquema, es el resultado de una lectura territorial compleja, no sólo al adaptar una herramienta de las ciencias naturales a la planificación, sino que el particular valor, es la transición espacial gradual en la

\footnotetext{
${ }^{10}$ El autor se refería a que muchas ideas del Nuevo urbanismo ya existían y bajo esta corriente se condensaron. Algunas son: i) Garden City [convivencia del campo y la ciudad, pero definiendo territorios específicos]. Le Corbusier con su Ville Contemporaine, Frank Lloyd Wright ensayando el Broadacre City. Jane Jacobs [mezcla de usos, edades de edificios y niveles de ingreso]. Aldo Rossi [ elementos primarios, barrio, estructura organizativa basada en monumentos, polos y tensiones, punto de partida: la sociedad]. Kevin Lynch [ imagen de la ciudad analizada desde el punto de vista del individuo y su percepción: en nodos, hitos, barrios, senderos, bordes]. Leon Krier [espacio público].

${ }^{11}$ Congress of The New Urbanism -CNU 25- Seattle. Mayo de 2017. https://www.cnu.org/publicsquare/2017/02/07/great-idea-pedestrian-shed-and-5-minute-walk
} 
antropización del espacio. Se planteaban aquí, soluciones estructurales, habitaciones y de espacios abiertos para cada categoría transitiva. Se considera a este modelo como una base fundamental en la construcción compleja de la interfase que pretende esta investigación.

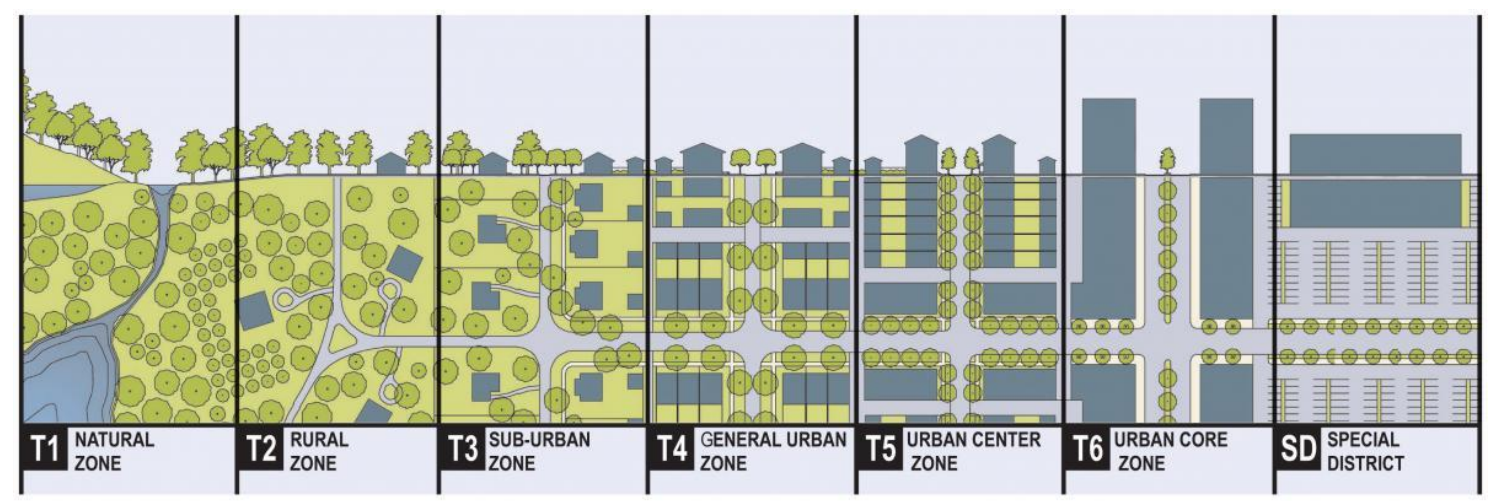

Figura 6. The diagram transect. Una versión de DPZ Architects \& Planners, 2008.

Esta lógica para planificar no ha sido traslada a los modelos subsiguientes de la planificación estadounidense y la utilización de la teoría del transecto fu simplificada a las zonificaciones de áreas en términos de regulación de usos del suelo y no se verificó aún en las adaptaciones a otros enfoques.

El tercer enfoque empleado en la planificación urbana y del transporte son los sistemas espaciales informáticos que constituyen herramientas de apoyo metodológico. Entre los más frecuentes figuran los Sistemas de Información Geográfica (GIS Geographical Information System); Ios Sistemas de Diseño Asistido por Computador (CAD Computer Assisted Design), y recientemente la modelación espacial tridimensional mediante programas computacionales de realidad virtual (VR Virtual Reality). Para conformar un nuevo concepto denominado el Sistema de Apoyo a las Decisiones (DSS) (Decisions Support Systems) El conjunto de opciones presentadas no son excluyentes, sino complementarias entre sí.

El cuarto enfoque, aparece a principios del siglo XXI a través del concepto de sustentabilidad aplicado a distintos campos y con distintos énfasis así, por ejemplo, se habla de sustentabilidad ambiental, sustentabilidad económica y sustentabilidad social, todo lo anterior se puede englobar en otro concepto más amplio conocido como el desarrollo sustentable. El desarrollo sustentable es una modalidad que pretende balancear las tres vertientes clásicas de desarrollo, la social, la económica y la ambiental en forma explícita (Figura 7). Para ello surgen también estudios y propuestas metodológicas que puedan medir el grado de sustentabilidad alcanzado en el desarrollo, a través de los llamados "indicadores de sustentabilidad". Para el caso específico de la ciudad, nace una base teórica conocida como la Ciudad Compacta que relaciona la forma urbana con el sistema de transporte y el uso eficiente de la energía., teniendo como objetivo final el logro de una ciudad sustentable. 


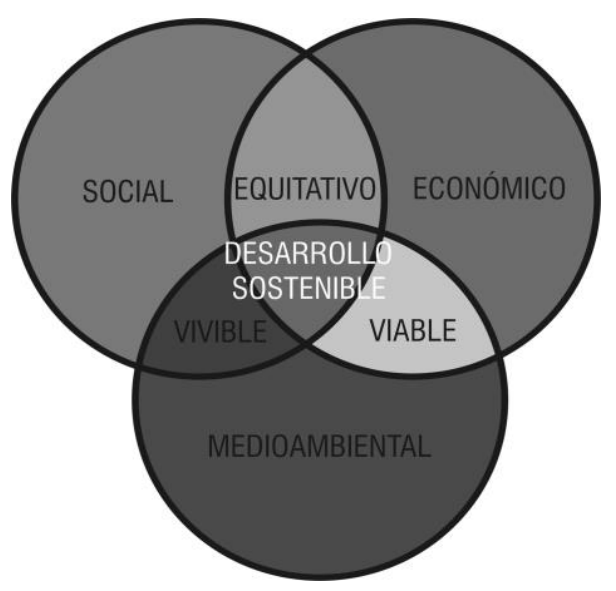

Figura 7. Esquema clásico de interacciones para el desarrollo sostenible. Fuente: recuperado de https://www.desarrollosustentable.co/2013/04/que-es-el-desarrollo-sustentable.html

El modelo norteamericano, presenta niveles de urbanización en el orden del $76 \%$ con mayor dinamismo que el europeo. Esto se debe a un porcentaje de crecimiento urbano de 1.2\% y un crecimiento demográfico del $0.9 \%$ (Precedo Ledo 2004). Tanto en el modelo norteamericano como en el latinoamericano, crecimiento urbano y crecimiento demográfico no son sinónimos. Aquí la relevancia cae en las grandes aglomeraciones metropolitanas que en cantidad son menos que en Europa, pero la distancia entre ellas mayor.

Las problemáticas incluyen el aumento significativo de bolsas de pobreza. Los procesos de descentralización de estas ciudades indican un aumento en el número de habitantes urbanos que viven y trabajan fuera de la metrópolis, generando mayor difusión en la distinción entre la ciudad y el espacio rural.

En1950 la mayor ciudad del mundo era Nueva York y la tercera de Tokio, quedando otras cinco -Chicago, Los Ángeles, Filadelfia, Detroit y Boston- entre las treinta mayores. En la primera década del siglo xxi, Los Ángeles formará parte de este grupo. A excepción de estas grandes metrópolis mundiales, para Precedo Ledo (2004), el crecimiento demográfico de las áreas metropolitanas norteamericanas fue lento durante los últimos años.

Hasta aquí, se subrayan dos conceptos claves y que muchas veces aparecen como sinónimos. Estos son los de planificación territorial y ordenamiento territorial. Por un lado, el enfoque europeo utiliza la figura de OT para referir a los procesos territoriales normativos, organizativos y de regulación de usos del suelo. En este sentido, cabe destacar la concepción europea de ordenar lo que existe, teniendo en cuenta las limitaciones a la hora de ocupar espacios nuevos o la creación de suelo urbano. Por otro lado, el concepto de planificar antecede al hecho, es decir que implica la posibilidad de establecer las pautas de una futura existencia. Este concepto más asociado a la planificación regional o estratégica es más visible en procesos urbanos estadounidense en los que la dispersión y creación del suelo urbano es más notoria. A continuación, se sintetizaron los instrumentos más comunes de este 
tipo de planificación (Tabla 4). Algunos elementos de estos enfoques son reconocibles en las formas de diagnóstico y estrategias actuales del urbanismo de la ciudad latinoamericana.

Tabla 4. Instrumentos de la planificación urbana

\begin{tabular}{|l|l|}
\hline Instrumentos & \\
\cline { 1 - 1 } & Sistema físico \\
\hline \multirow{4}{*}{ Planificación regional } & -topografía y modelo territorial \\
& -clima y vegetación \\
& -recursos naturales \\
& -paisaje \\
\hline \multirow{5}{*}{ Planificación sub-regional } & -espacios protegidos \\
\hline & -gestión de residuos \\
& -riesgos naturales \\
\hline & Sistema productivo \\
\hline & -actividades económicas básicas \\
& -actividades económicas secundarias \\
& -equipamientos \\
& -recursos humanos \\
& -localización de la actividad \\
& -zonificación \\
\hline & Sistema relacional \\
\hline & -estructura interna y articulación \\
& -integración con el exterior \\
& -accesibilidad \\
& -transporte público \\
& -telecomunicaciones \\
\hline & Sistema urbano \\
\hline & -lugares centrales y jerarquías \\
& -sistemas urbanos \\
& -ejes de desarrollo \\
\hline
\end{tabular}

Fuente: Céliz, 2018 en base a Hidenbrand, 1996

\section{La mirada latinoamericana. Desde el enfoque territorial al "ordenamiento territorial"}

En el caso latinoamericano, es frecuente enunciar que la planificación viene por detrás de los hechos consumados. Como en muchos otros aspectos la tradición en la planificación del territorio latinoamericano adquiere particularidades que la diferencian de los anteriores enfoques. Las razones están fuertemente ligadas a la forma en que se extendieron las ciudades, sumada a la lógica de los impulsores de estas transformaciones en los últimos 30 años. Diversos esquemas fueron adaptados a una selectiva demanda de planificación. Se desarrollarán brevemente, los más representativos en orden cronológico. 
Antes de la implementación de políticas de planificación, los intentos de ordenar el territorio se sucedieron desde la planificación regional, el urbanismo, la planificación económica, la planificación ambiental o el desarrollo sostenible y finalmente, el ordenamiento territorial. La planificación regional se apoyaba en planes económicos de ocupación del suelo a gran escala. Implicó grandes problemas de implementación, ya que los instrumentos planteados no constituían una herramienta concreta de ordenamiento. Massiris Cabeza (2002), define la primera de las estrategias de la planificación de cuencas hidrográficas de la década de los años cuarenta, según el modelo estadounidense de la Tennessee Valley Authority ${ }^{12}$ basada en la necesidad de control hidroeléctrico de cuencas.

De Mattos (1984), enumera los proyectos de desarrollo regional de la Corporación del Santa -Perú 1943-, la Comisión de Papaloapan y la de Tepalcatepec -México 1947-, la Comisión del Valle de San Francisco -Brasil 1948, la Comisión Nacional del Río Negro -Uruguay-, la Comisión del Grijalva -México 1951-, la Corporación del Valle del Cauca -Colombia 1954-, la Comisión del Río Balsas -México 1960- y la Corporación Nacional del Chocó Colombia 1968-. Otras estrategias de desarrollo regional utilizadas estuvieron asociadas a políticas de regionalización, polos de desarrollo o crecimiento y desarrollo rural integrado, entre otras (Massiris Cabeza 2002).

A partir de los años cincuenta la planificación urbana comienza a ocupar un lugar en las agendas de los países latinoamericanos, asociada a la preocupación por el acelerado crecimiento de las ciudades y el reconocimiento del sistema urbano como la posibilidad de ordenar el territorio. Hacia los años setenta ya existían planes y normas reguladoras de los usos del suelo en algunos países como Colombia, Cuba y Argentina. En el caso de México se regulan los asentamientos a partir de la Ley General de Asentamientos Humanos en 1976. El enfoque del "ecodesarrollo" llegó a los países latinoamericanos en la década de 1980. Sin embargo, no tuvo gran impacto ya y superado rápidamente por el concepto de desarrollo sustentable -enunciado en la mirada norteamericana-.

La planificación estratégica urbana por su parte, es un proceso que permite articular las iniciativas de los actores públicos y privados para potenciar el desarrollo de una ciudad. Diversos autores coinciden en algunas líneas principales:

- Una metodología adaptable, no rígida, para la cual la flexibilidad es una condición indispensable.

- Una herramienta para el desarrollo local, teniendo como horizonte las intervenciones estratégicas que garanticen calidad de vida urbana, y un proceso económico y social.

\footnotetext{
${ }^{12}$ La Autoridad del Valle del Tennessee es una agencia del New Deal creada para generar energía eléctrica y controlar las riadas del río Tennessee en una región que abarca siete estados de los Estados Unidos. El presidente Franklin Delano Roosevelt firmó la Tennessee Valley Authority Act por la que se creaba la TVA el 18 de mayo de 1933. La agencia todavía existe y ha crecido hasta convertirse en la mayor compañía pública de energía de América.
} 
- Un mecanismo para avanzar hacia formas progresivas de gobernabilidad, profundizando substantivamente la democracia a través de una colaboración real entre los actores públicos y privados.

- Una forma moderna, participativa y democrática de pensar y organizar el desarrollo de una ciudad, que permite establecer un marco de referencia para que todos los agentes económicos y sociales puedan acomodar sus propias estrategias de acuerdo con el escenario que se desee para la ciudad y el territorio.

En el caso latinoamericano el OT está unido a la planificación a partir del surgimiento de normas, planes, ámbitos y escalas prestablecidas. Se entiende entonces, como una respuesta a figuras públicas: el urbanismo y la planificación socioeconómica regional. Pérez Andrés, (1998) plantea que el OT surge como respuesta a la falta de planificación física de los planes socioeconómicos y, como consecuencia de la incoherencia económica de planes urbanos y en especial, su componente espacial.

La relación de algunos países latinoamericanos con el OT puede observarse como una progresión surgida de la planificación urbana (Figura 8), aunque en muchos casos aún existe una difusa diferenciación entre la zonificación de usos del suelo -como política de ordenamiento territorial-, y un enfoque integrador de 0T, como se verificó en el caso europeo, por ejemplo.

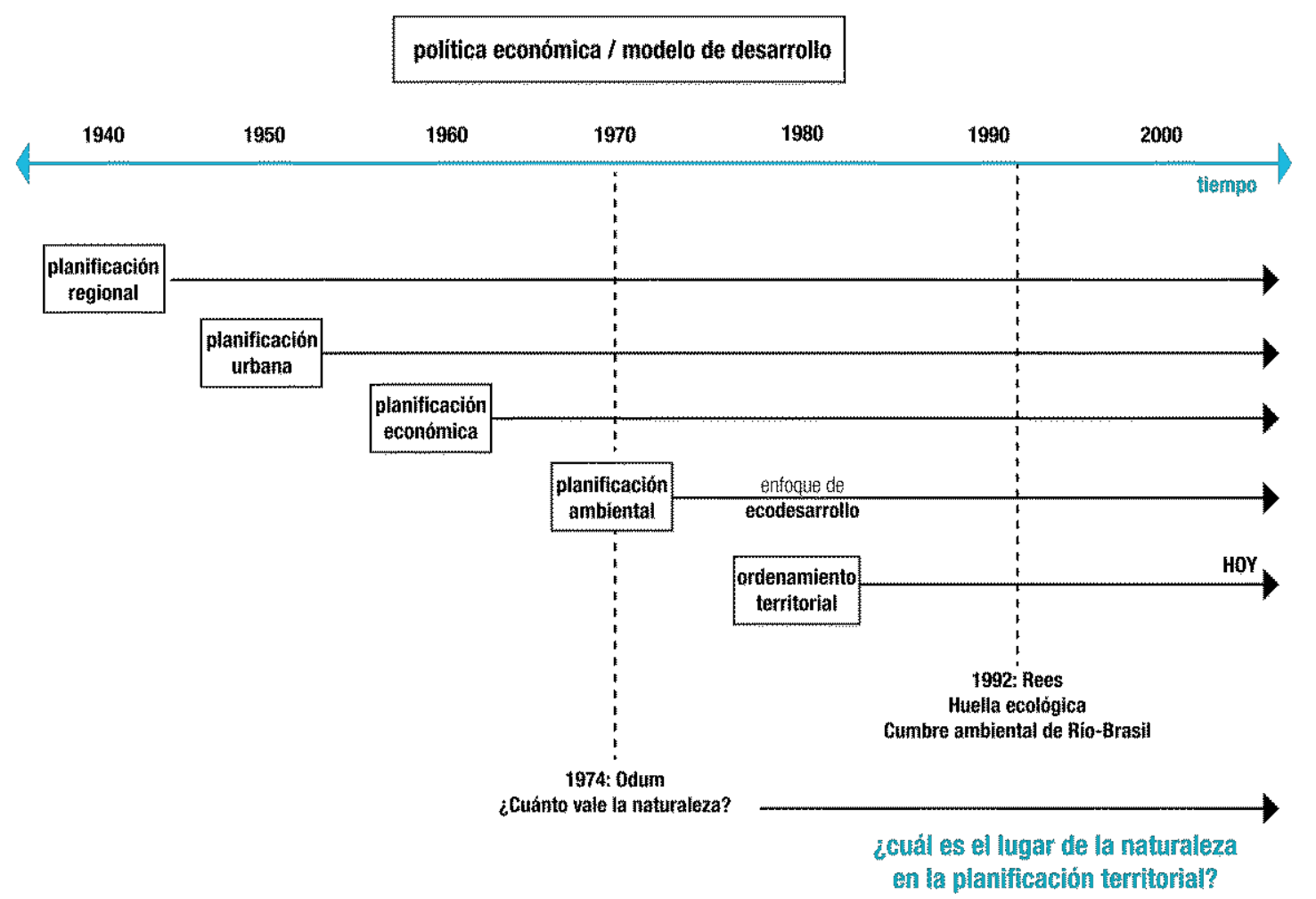

Figura 8. Evolución de la planificación sectorial, plurisectorial y territorial en América Latina y la influencia del enfoque ambiental. Fuente: Céliz, 2018 en base a Massiris Cabeza,2002. 
En el caso argentino, en 1977 se promulgó la ley de ordenamiento territorial y usos del suelo en la provincia de Buenos Aires. En el caso cubano a partir de 1978, el ordenamiento territorial estaba asociado a la planificación física y el urbanismo. En Colombia la planificación de usos del suelo se adoptó legalmente en 1979 (Massiris, 1999).

El enfoque territorial fue difundido por organismos multilaterales encargados de diseñar políticas de desarrollo: el BID, el BM, la FA0, el IICA, la CEPAL-ILPES y la GTZ. En el caso argentino particularmente, estas políticas se manifiestan tempranamente en el Programa Social Agropecuario (Benedetti and Souto 2011). En este contexto se difunden las acciones relacionadas a todo aquello que fuera "territorializable" (Io territorial, lo socio-territorial, etc.) sobre todo, en lo relativo a políticas orientadas a sectores pobres de la sociedad. En esta línea el desarrollo territorial rural (DTR) es según Benedetti \& Souto (2011), un aggiornamento de las ideas clásicas sobre el desarrollo. Este esquema primario de OT es propuesto por el Centro Latinoamericano para el Desarrollo Rural (RIMISP) de Chile.

EI DTR tiene como base el desarrollo económico local -rural-, aunque el enfoque es de escala regional. Este marco busca a partir de conceptos de clústeres y economía de escala, apoyar los ejes del desarrollo rural en la medida que identifica, delimita y busca actuar sobre áreas específicas. Se orienta a escalas intermedio-locales de actuación, definidas por la proximidad de productores y por la presencia de lazos sociales consolidados. Esta forma de OT no se limita al entorno rural ya que incorpora líneas como el eco-turismo o los servicios o la producción artesanal. Se apoya sobre la consolidación de gobernanza territorial y la construcción de redes de actores municipios, equipos técnicos, organizaciones sociales, ONGs, etc-. Para Benedetti (2011), este enfoque promueve la competitividad en el mercado capitalista como base, desconociendo particularidades sociales y culturales locales (Manzanal, 2009 citado en Benedetti \& Souto 2011).

Por otro lado, el plan de acción regional de América Latina y el Caribe define para los países de la región la necesidad de adoptar mecanismos de gestión y ordenamiento territorial para la protección y reconstitución de sistemas biofísicos mediante acciones coordinadas que faciliten el manejo integral del medio ambiente y los recursos naturales (CEPAL, 2001: 21). En esta línea se desarrollan los programas como ciudades resilientes (ONUUNIDSR, 2010), Ciudades emergentes y sostenibles (BID, 2001,2016), entre otros.

Actualmente, la planificación estratégica rige la mayoría de los planes territoriales que se abordan en muchas ciudades latinoamericanas (Tabla 5). Si bien existen metodologías alternativas y experiencias en donde se han llevado a delante procesos en base a la planificación participativa y gestión asociada -PPGA- (Poggiese 2011) por ejemplo, en el caso argentino, aún siguen siendo aislados y la participación de los actores de la comunidad en la elaboración de los planes y programas y la utilización de los recursos, sigue siendo una deuda pendiente, que demanda investigación y articulación entre las diferentes áreas del conocimiento, técnicos y decisores políticos. 
Tabla 5. Análisis comparado de los planes estratégicos en las principales ciudades latinoamericanas

\section{Ciudades y características \\ Los planes estratégicos \\ Trascendencia del caso}

\section{(evolución)}

Córdoba, Argentina: segunda

Plan estratégico de Córdoba -PEC-

ciudad del país. Importancia

entre 1996 y 1999. Abandonado

industrial y comercial

por cambio de gobierno local.

El PEC fue uno de los primeros

casos de implementación.

Leyes del IPLAM. 2012 a la fecha.

Zonificación de usos del suelo del

La conformación del IPLAM como

instancia de planificación

metropolitana.

área metropolitana

Rosario, Argentina: segunda

ciudad del país. Fuerte actividad

Plan estratégico de Rosario -PER-.

Innovación en diseño y ejecución

En ejecución desde 1998.

del plan en una ciudad intermedia.

portuaria. Importante centro de

exportación del agro y desarrollo industrial.

\begin{tabular}{|c|c|c|}
\hline $\begin{array}{l}\text { Buenos Aires, Argentina: capital } \\
\text { del país con supremacía respecto } \\
\text { al resto de las ciudades. Área } \\
\text { metropolitana conformada por } \\
\text { varios municipios, de gran } \\
\text { relevancia. AMBA. }\end{array}$ & $\begin{array}{l}\text { Proceso de consolidación del Plan } \\
\text { estratégico Buenos Aires (año } \\
\text { 2002). Plan estratégico Buenos } \\
\text { Aires 2010. Plan estratégico } \\
\text { Buenos Aires } 2016 \text { con estrategia } \\
\text { metropolitana. }\end{array}$ & $\begin{array}{l}\text { El caso del año 2002: retrasos } \\
\text { producto del escenario político que } \\
\text { condicionaron fuertemente el plan. } \\
\text { Conformación del consejo de } \\
\text { planeamiento estratégico CoPE. La } \\
\text { perspectiva metropolitana del plan } \\
2016 \text {. }\end{array}$ \\
\hline $\begin{array}{l}\text { Bogotá, Colombia: capital del país } \\
\text { y principal innovador en asuntos } \\
\text { urbanos. Bogotá tiene } \\
\text { administración metropolitana en el } \\
\text { distrito capital. }\end{array}$ & $\begin{array}{l}\text { El plan estratégico de Bogotá al } \\
2000 \text { del año } 1997 \text { fue } \\
\text { abandonado en } 1998 \text { con el } \\
\text { comienzo de una nueva } \\
\text { administración y se introdujo el } \\
\text { plan de ordenamiento territorial - } \\
\text { POT-, para el } 2018 .\end{array}$ & $\begin{array}{l}\text { El caso constituye una ejemplar } \\
\text { concentración de fuerzas sociales } \\
\text { y económicas. La principal deuda } \\
\text { del POT de Bogotá es la } \\
\text { desigualdad. }\end{array}$ \\
\hline $\begin{array}{l}\text { Santiago, Chile: capital del país, } \\
\text { forma parte de una amplia zona } \\
\text { metropolitana que incluye } 37 \\
\text { comunas. No posee gobierno } \\
\text { metropolitano. }\end{array}$ & $\begin{array}{l}\text { El plan estratégico de la comuna } \\
\text { de Santiago al } 2010 \text { fue } \\
\text { abandonado en } 2000 \text { por decisión } \\
\text { del nuevo gobierno municipal. En } \\
\text { ese año se publica el plan }\end{array}$ & $\begin{array}{l}\text { El caso demuestra la importancia } \\
\text { de la coyuntura política y el } \\
\text { impacto que implica la falta de } \\
\text { respaldo. }\end{array}$ \\
\hline
\end{tabular}




\begin{tabular}{|c|c|c|}
\hline & $\begin{array}{c}\text { estratégico para Santiago -PES } \\
2020-.\end{array}$ & \\
\hline $\begin{array}{l}\text { La Paz, Bolivia: ciudad capital que } \\
\text { forma parte de una gran } \\
\text { conurbación con El Alto en el } \\
\text { Altiplano. La Paz es el caso de una } \\
\text { metrópoli de rápido crecimiento }\end{array}$ & $\begin{array}{c}\text { El plan de desarrollo municipal } \\
\text { sostenible -PDMS- al } 2010 \text { del año } \\
2000 \text { se consolidó con el Plan } \\
\text { Quinquenal y el Plan Anual } \\
\text { Operativo del } 2002 .\end{array}$ & $\begin{array}{l}\text { El caso demuestra las ventajas de } \\
\text { un sistema nacional de } \\
\text { planificación municipal } \\
\text { participativa de corto, mediano y } \\
\text { largo plazo. }\end{array}$ \\
\hline $\begin{array}{l}\text { Trujillo, Perú: tercera ciudad del } \\
\text { país, con problemas de tipo } \\
\text { industriales y en proceso de } \\
\text { consolidación en el país. }\end{array}$ & $\begin{array}{l}\text { El plan estratégico -La Agenda } 21 \\
\text { Local- se implementó, sin } \\
\text { embargo, sin aprobación oficial } \\
\text { durante los dos primeros años } \\
\text { (1999-2001). }\end{array}$ & $\begin{array}{c}\text { El caso demuestra como la } \\
\text { planificación estratégica se articula } \\
\text { como una Agenda de gobierno. La } \\
\text { institucionalización se dio en el } \\
\text { marco de una nueva coyuntura } \\
\text { política en el año } 2001 \text {. }\end{array}$ \\
\hline $\begin{array}{l}\text { Lima -Distrito de Comas, Perú: } \\
\text { Lima capital y más dominante } \\
\text { ciudad del país. Zona } \\
\text { metropolitana con } 43 \text { municipios } \\
\text { autónomos. }\end{array}$ & $\begin{array}{l}\text { El plan integral de Comas al } 2010 \\
\text { del año 2000, fue uno de los más } \\
\text { logrados de Lima. }\end{array}$ & $\begin{array}{l}\text { El caso demuestra las iniciativas } \\
\text { de un distrito grande, con limitados } \\
\text { recursos que avanzó en } \\
\text { importantes espacios de } \\
\text { concertación. }\end{array}$ \\
\hline $\begin{array}{l}\text { La Habana, Cuba: la capital de } \\
\text { Cuba se encuentra en proceso de } \\
\text { recuperación económica, su } \\
\text { crecimiento ha sido controlado. }\end{array}$ & El plan estratégico de La Habana & $\begin{array}{l}\text { El caso es relevante en su } \\
\text { configuración político-social con } \\
\text { características socialistas. } \\
\text { Participación ciudadana en crisis } \\
\text { económica. }\end{array}$ \\
\hline
\end{tabular}

Fuente: Actualizado por Céliz, 2018 en base a Steinberg, 2001.

El modelo urbano latinoamericano, incluye al menos a 25 de las 30 mayores ciudades del mundo. Su estructura urbana se caracteriza por una marcada desarticulación y agudización de macrocefalia (Precedo Ledo, 2004). Más del $60 \%$ de la población urbana mundial reside allí. El ritmo de crecimiento demográfico es mucho más acelerado que en los modelos anteriores. La población se concentra en mega-ciudades que absorben grandes cantidades de energía del sistema urbano, agudizando problemas de hacinamiento, pobreza, desempleo, carencia de servicios básicos entre otros factores. Esto configura una dualidad global ya que muchas de las regiones metropolitanas latinoamericanas forman parte de la red global de ciudades. 
A continuación y a modo de cierre de una lectura sobre el ordenamiento territorial occidental se sintetizaron en la Tabla 6 los principales enfoques aquí revisados.

Tabla 6. Síntesis sobre los tres principales enfoques del ordenamiento territorial occidental

\begin{tabular}{|c|c|c|c|c|}
\hline $\begin{array}{l}\text { Modelo } \\
\text { urbano }\end{array}$ & OT/planif & OT y valoración ecosistemica & $\begin{array}{c}\text { Principales instrumentos } \\
\text { del OT }\end{array}$ & $\begin{array}{c}\text { Estructura } \\
\text { general }\end{array}$ \\
\hline $\begin{array}{l}\text { Modelo } \\
\text { europeo }\end{array}$ & OT & $\begin{array}{l}\text { Progresiva incorporación del } \\
\text { concepto ambiental. Temas } \\
\text { ambientales }>\text { enfoque paisajista }> \\
\text { informe de impacto ambiental. } \\
\text { Influencia francesa y alemana. } \\
\text { Fondos relativos al ambiente> } \\
\text { Natura 2000, convenio europeo del } \\
\text { paisaje }\end{array}$ & $\begin{array}{ll}\text { - } & \text { Zonificación } \\
\text { ecológica y } \\
\text { económica } \\
\text { - } & \text { Planes de } \\
\text { ordenamiento } \\
\text { territorial } \\
\text { - } & \text { Planes de } \\
\text { acondicionamiento } \\
\text { territorial } \\
\text { - Planes de desarrollo } \\
\text { urbano } \\
\end{array}$ & $\begin{array}{c}\text { PLANES Y } \\
\text { PRGROAMAS } \\
\text { NORMAS } \\
\text { ORGANIZACIÓN } \\
\text { INSTITUCIONAL }\end{array}$ \\
\hline $\begin{array}{l}\text { Modelo } \\
\text { EEUU }\end{array}$ & Planificación & $\begin{array}{l}\text { El territorio natural es el soporte de } \\
\text { expansión de los suburbios de la } \\
\text { ciudad extendida. Planificación } \\
\text { desde el objeto arquitectónico. } \\
\text { Urbanismo de arquitectos. Avances } \\
\text { significativos a partir del "nuevo } \\
\text { urbanismo". El barrio como unidad } \\
\text { funcional. Teoría de transecta. } \\
\text { Desarrollo sostenible, indicadores de } \\
\text { sustentabilidad. }\end{array}$ & $\begin{array}{l}\text { - Planificación } \\
\text { regional } \\
\text { - } \begin{array}{l}\text { Planificación sub- } \\
\text { regional }\end{array}\end{array}$ & $\begin{array}{l}\text { SISTEMA FISICO } \\
\text { SISTEMA } \\
\text { PRODUCTIVO } \\
\text { SISTEMA } \\
\text { RELACIONAL } \\
\text { SISTEMA URBANO }\end{array}$ \\
\hline $\begin{array}{c}\text { Modelo } \\
\text { Aca.Latina }\end{array}$ & $\begin{array}{c}\text { Planificación } \\
\text { primero } \\
\text { luego OT }\end{array}$ & $\begin{array}{l}\text { Países biodiversos, ciudades } \\
\text { extendidas en el territorio, baja } \\
\text { densidad conviviendo con grandes } \\
\text { metrópolis. El ambiente es soporte. } \\
\text { Plan de desarrollo rural primer } \\
\text { antecedente. El } \\
\begin{array}{l}\text { sustentable. No se registran } \\
\text { enfoques de valoración }\end{array} \\
\text { ecosistémico, salvo el Buen Vivir. El } \\
\text { enfoque de paisaje es estético. La } \\
\text { mayor cantidad de iniciativas son } \\
\text { marcos internacionales como BID, } \\
\text { Banco Mundial, etc. El plan } \\
\text { estratégico rige el OT. }\end{array}$ & $\begin{array}{ll}\text { - } & \text { Política nacional, } \\
\text { - } & \text { Plan nacional } \\
\text { - } & \text { Plan regional } \\
\text { - } & \text { Plan municipal- } \\
& \text { departamental }\end{array}$ & $\begin{array}{c}\text { PLAN } \\
\text { PROGRAMA } \\
\text { PROYECTO }\end{array}$ \\
\hline
\end{tabular}

Fuente: Céliz, 2018 


\section{La mirada ecosistémica del territorio o la urgencia de comprender los procesos biofísicos}

Luego de sintetizar las principales líneas teóricas a partir de procesos e instrumentos de 0T, se plantea la necesidad de establecer los principales elementos del enfoque ecosistémico. Esto radica en la necesidad de articular estos elementos con los instrumentos de la planificación tendientes a evaluar las posibilidades de interacción conjunta. Como se expresó en los análisis previos, tanto en los principales procesos de crecimiento urbano como en las estrategias de ordenar el territorio, la mirada tradicional -urbanista, sobre todo- no incluye a los ecosistemas y sus procesos como factores relevantes a tener en cuenta.

Las consecuencias de los procesos de antropización analizados son expresadas a continuación a través del análisis cronológico de la relevancia de las alteraciones antrópicas en los trabajos más influyentes en relación a las disciplinas ambientales y las ciencias naturales.

En el año 1972 un equipo de trabajo del Instituto Tecnológico de Massachussets -MIT-, liderado por Donella Meadows presenta al Club de Roma un detallado informe basado en el estudio de la dinámica de sistemas. Este informe es conocido como The limits to growth -Los límites del crecimiento en español-. El informe de Meadows et al. enfatiza las consecuencias tanto del crecimiento de la población mundial como de la explotación de los recursos naturales para abastecerla y la posibilidad de que estas interacciones sobrepasen los límites absolutos que es capaz de soportar el planeta en los próximos cien años -desde su publicación-. Si bien existen numerosos posicionamientos respecto a las principales ideas producto de la investigación de este informe, el mismo ha resultado en una alerta poniendo en entre dicho las nociones de crecimiento y desarrollo utilizadas en economía, así como la visión de "inagotable" que las sociedades tenían de su medio (Figura 9).

"Si la industrialización, la contaminación ambiental, la producción de alimentos y el agotamiento de los recursos mantienen las tendencias actuales de crecimiento de la población mundial, este planeta alcanzará los límites de su crecimiento en el curso de los próximos cien años. El resultado más probable sería un súbito e incontrolable descenso, tanto de la población como de la capacidad industrial." (Meadows et al. 1972, p.23) 


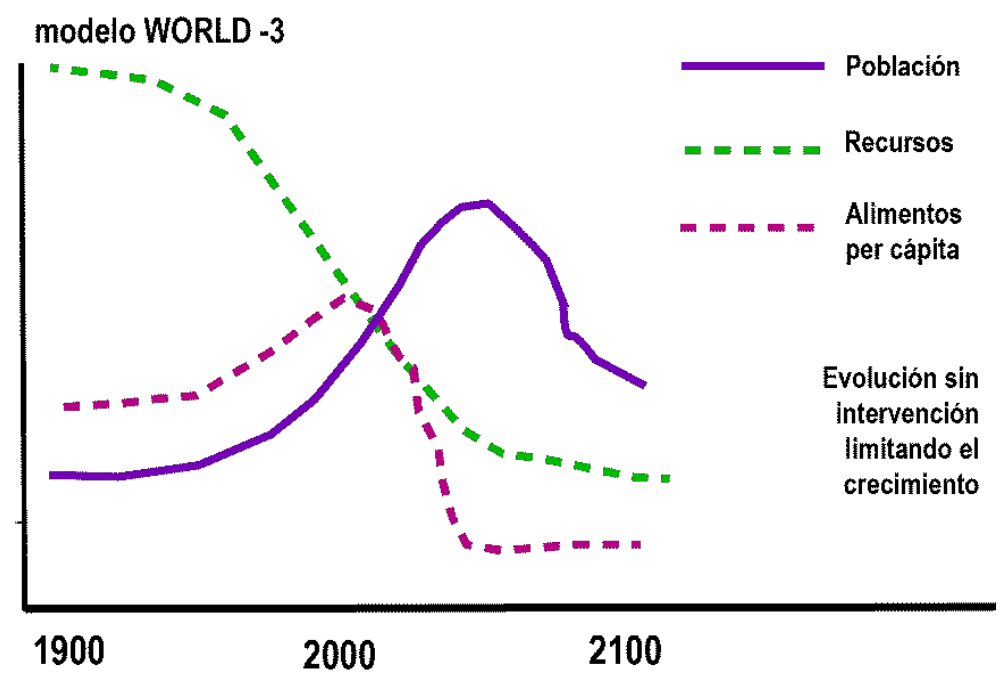

Figura 9. Uno de los modelos presentados en Los límites del crecimiento. World 3: Relación entre los sistemas naturales y sociales. Fuente: Redibujo de Céliz 2017 de Meadows et al. 1972.

Este informe ha sido reseñado y criticado de igual manera por numerosos autores. Las ideas principales sobre los datos que aporta se relacionan con la relevancia de las restricciones cuantitativas del medioambiente terrestre y las consecuencias que tendría una extralimitación (Aizpuru 2003). Esto deja en relieve la presión demográfica en el mundo y su desigual distribución. Según datos del año 2000 (ONU HABITAT), el 80.7\% de la población se concentra en las regiones del mundo menos desarrolladas a pesar de que solamente tiene acceso al $20 \%$ de los recursos. Más de la mitad de la población del mundo vive en ciudades. Al día de hoy estos porcentajes se intensifican, pero siguen demostrando esta relación.

"No tenemos ninguna duda de que, si la humanidad va a emprender un nuevo rumbo, serán necesarias medidas internacionales concertadas y una planificación conjunta a largo plazo a una escala y alcance sin precedentes."

(Meadows et al. 1972, p.194).

Otro aspecto fundamental es aquel que vincula directamente al desarrollo global y la relación conflictiva de los seres humanos con su medioambiente. Este informe indica que hay nociones de base que no están siendo consideradas por el llamado progreso de la humanidad. Sobre el final, afirman que cualquier intento deliberado de alcanzar un estado de equilibrio racional y duradero a través de la planificación, más que a través del azar o la catástrofe, debe hallar su fundamento en un cambio de valores y objetivos no sólo a nivel individuo, sino también nacional y mundial.

45 años después de su publicación, Los límites del crecimiento, han abierto y consolidado líneas de pensamiento crítico sobre la forma en que los asentamientos humanos ocupan el planeta e incluso han derivado en importantes 
investigaciones. Las relaciones presentadas entre ecología y "desarrollo" son de gran relevancia en su posicionamiento y constituyen un antecedente fundamental a la hora de establecer patrones sobre las acciones u omisiones que generan los desequilibrios 0 alteraciones entre los sistemas sociales y naturales.

\section{La huella ecológica humana....urbana}

La escala de los procesos en los que ejerce influencia el ser humano implica transformaciones globales. No es posible comprender los procesos locales relativos a los socio-ecosistemas si no se comprende el contexto en el cual se llevan adelante las transformaciones del medio terrestre. Estas transformaciones son atendibles a escala de biósfera ya que incluyen alteraciones en la composición y funcionamiento de los ecosistemas. Teóricos e investigadores han definido a esta etapa como un nuevo período geológico: el Antropoceno ${ }^{13}$. Este concepto incluye a los tiempos recientes en los que el ser humano se ha convertido en una fuerza dominante en la transformación de la tierra (Zamora et al.,2016).

En el contexto global-temporal de estas transformaciones, el cambio de escala se asocia al impacto directo en el territorio de este proceso de injerencia de las actividades humanas en los procesos biofísicos globales. A partir de la lectura de estas dinámicas desde el enfoque de las ciencias naturales se explican procesos de interacción entre los sistemas naturales y los sistemas sociales-urbanos.

"La ecología define la capacidad de carga como la población de una especie dada que puede ser mantenida indefinidamente en un hábitat dado sin dañar permanentemente el ecosistema del que depende. (...) Para los seres humanos $^{14}$, la capacidad de carga puede interpretarse como la tasa máxima de consumo de recursos y de descarga de desechos que puede mantenerse indefinidamente en una región dada, sin perjudicar progresivamente la integridad funcional y la productividad de los ecosistemas pertinentes." (Rees 1992, p.125)

El concepto de huella ecológica, buscó delimitar la totalidad del territorio como usos del suelo, que es requerido para sustentar una región urbana determinada. Esto es, al menos en términos de magnitud, mayor que la superficie contenida dentro de los límites o jurisdicciones de los municipios o incluso el área de expansión urbana asociada. Esto, sumado a la dinámica de los flujos que se dan a través del comercio, intercambios de bienes y servicios

\footnotetext{
${ }^{13}$ Se proponen tres fases para una posible caracterización del Antropoceno: a) la Era industrial (1800-1945), b) la Gran aceleración (1945-2015), luego de la Segunda Guerra Mundial en la que la población, el consumo y la tecnología se han convertido en los factores dominantes que incrementan el impacto ambiental humano (Steffen et al., 2011) y, c) una posible conducción del sistema terrestre (2015-actualidad).

${ }^{14}$ la población humana correspondiente es una función de las tasas per cápita o consumo de recursos y producción de desechos (es decir, producción sostenible dividida por la demanda per cápita), esta formulación es una simple reafirmación de la "tercera ley de la ecología humana" de Hardin: (impacto humano total en la ecosfera) = (población) x (impacto per cápita). Traducción propia. "Ecological footprints and appropriated carrying capacity: what urban economics leaves out." William E. Rees 1992
} 
ecológicos, deja claro que todas las ciudades se apropian de la capacidad de carga de lugares que las exceden, incluso distantes. Estas relaciones de dependencia que se crean en el territorio generalmente no son ecológicamente sostenibles, ni siquiera estables, y dependerán en muchos casos de "la oferta" del territorio. Para el autor, esta idea puede verificarse en la relación que establecen los países o naciones ricas en su apropiación de extensas superficies del planeta asociadas a la competencia mundial por los remanentes de capital natural ${ }^{15}$, y su capacidad productiva disponible. Se establece una acumulación de excedentes potenciales, idea asociada a la de finitud de los recursos disponibles por lo que resulta fundamental contar con capitales naturales no solo para disponer en caso de ser necesario sino para explotación de dichos recursos naturales en lugares distantes, generalmente asociado a la extracción de materias primas.

En términos de organización y desarrollo de ciudades ¿Cuáles son los límites de aquello que es apropiable por el hecho urbano? ¿Puede establecerse una relación directa entre aquello que no deberíamos sobrepasar y la forma en que los asentamientos humanos se localizan y consumen dicho territorio?

El razonamiento que Rees plantea apunta a pensar cuanta tierra en sus diferentes usos -urbano, rural productivo, paisaje, etc.-, es necesaria para mantener a una población indefinidamente bajo un determinado estándar de demanda-consumo. En este mismo sentido, Roberto Fernández (2000) se aproxima a la idea urbana de la huella ecológica, relacionando este concepto a la expansión urbana y la inequidad de una teórica distribución de los recursos naturales respecto el conjunto de demandas de los asentamientos humanos, es decir que como plantea Rees; no todas las ciudades disponen de la misma capacidad de apropiación de recursos naturales independientemente de la localización y área de influencia directa de las mismas. Este mercado de huellas ecológicas define una condición estructural en la problemática ambiental urbana de las ciudades llamadas en vías de desarrollo -aquellas que no pueden mejorar sus condiciones de acumulación de capital, información y poder-a pesar de contar con las condiciones "teóricas" de control sobre sus sistemas naturales y ecosistemas. Fernández (2000) clarifica este concepto a partir de tres casos:

- Las asimetrías territoriales en la utilización de recursos naturales demandados por concentraciones poblacionales: el caso de los trasvases hidráulicos (...) el trasvase chino de agua sur-norte -proyecto Tres Gargantas, año 2009-, que proporcionaría un total de 44.800 millones de metros cúbicos anuales de agua, provocó

\footnotetext{
${ }^{15}$ Se define al capital natural como todo stock que genera un flujo de bienes y servicios útiles o renta natural a lo largo del (Costanza et Daly 1992). Esta definición se encuentra dentro del paradigma de la economía y la ecología a partir del momento en que comienza a explicitarse esta relación y la idea de tener un stock de la naturaleza. No obstante, desde la ecológica, el capital natural no puede ser concebido como un simple stock o agregación de elementos. A parte de estos componentes (estructura del ecosistema), el capital natural engloba todos aquellos procesos e interacciones entre los mismos (funcionamiento del ecosistema) que determinan su integridad y resiliencia ecológica (Gómez-Baggethun et de Groot, 2007)
} 
el desahucie de 400.000 personas ${ }^{16} \mathrm{y}$ la pérdida de casi $400 \mathrm{~km} 2$ de áreas de agricultura intensiva, "en nombre del progreso".

- El trasvase del río San Francisco, iniciado en el año 2007 que contemplaba la construcción de 720 kilómetros de canales para irrigar una extensa región árida del noroeste de Brasil. Este proyecto fue denunciado por los pescadores y campesinos de la ribera del río San Francisco alertando sobre los posibles costos ambientales de la obra y los beneficios exclusivos para las grandes empresas agrícolas que fueran los beneficiarios directos ${ }^{17}$.

- El caso de Santiago de Chile: entre los años 1970 y 1990 se registró la desafectación de usos agrícolas para absorber el crecimiento urbano de unas 12000 hectáreas -equivalente al total de la superficie urbana para el año 1940-, a razón de unas 800 hectáreas/por año en el período más reciente con más de un 90\% de tierras fértiles en una ciudad instalada en una región de baja disponibilidad de recursos naturales para la obtención de abastecimiento primario de los asentamientos humanos.

- El caso de Lima, Perú: entre 1970 y 1980 se ocuparon para usos urbanos -en muchos casos ocupaciones ilegales y pueblos jóvenes- más de 14000 hectáreas de tierra irrigada del área del valle del Rimac, que en la época del dominio incaico constituía un área extremadamente fértil.

Clarificando factores o flujos que se establecen en la relación entre la demanda por parte de los asentamientos humanos hacia los ecosistemas en los cuáles se insertan, es posible establecer la condición de límite, necesario para mantener las condiciones de habitabilidad tanto en el presente como para las generaciones futuras.

La idea de límite ya fue planteada por Meadows et al. (1972) explayándose en la idea de que "nada puede crecer indefinidamente en un medio finito". Algunos años después el equipo de Rockström et al (2009), del Centro de Resiliencia de Estocolmo, cuantificaron un grupo de fronteras denominadas Planetary Bounderies -Los límites planetarios en español-, como aquellos indicadores biofísicos que no debieran sobrepasarse a los efectos de evitar cambios ambientales irreversibles, por lo que la posibilidad de respetarlos implicaría la reducción de riesgo para Ios asentamientos humanos. Los autores identificaron nueve límites planetarios que debieran ser tenidos en cuenta, y para siete de ellos proponen cifras como umbrales que deben respetarse (Tabla 7).

\footnotetext{
${ }^{16}$ Elmundo.es. "El megatrasvase de agua del sur al norte de China". http://www.elmundo.es/elmundo/2009/03/15/ciencia/1237139061.html

$17 \mathrm{https}$ :/www.lainformacion.com/economia-negocios-y-finanzas/construccion-pesada/brasil-relanzara-obras-paralizadasde-un-polemico-trasvase-impulsado-por-Iula_BtQ4UPj3VVxTulGHrbtxZ3/
} 
Tabla 7. Categorías de los límites planetarios

\begin{tabular}{|c|c|c|}
\hline $\begin{array}{c}\text { Carácter delimitador } \\
\text { Escala del proceso }\end{array}$ & $\begin{array}{c}\text { procesos con umbrales a escala } \\
\text { global }\end{array}$ & $\begin{array}{c}\text { procesos lentos sin umbrales } \\
\text { conocidos a escala mundial }\end{array}$ \\
\hline $\begin{array}{c}\text { Procesos sistémicos a escala } \\
\text { planetaria }\end{array}$ & Cambio climático & Acidificación oceánica \\
\hline & \multicolumn{2}{|c|}{ Ciclos globales de P y N } \\
\hline & \multicolumn{2}{|c|}{ Carga atmosférica de aerosoles } \\
\hline & \multicolumn{2}{|c|}{ Uso del agua dulce } \\
\hline & \multicolumn{2}{|c|}{ Cambios de uso del suelo } \\
\hline & \multicolumn{2}{|c|}{ Pérdida de biodiversidad } \\
\hline
\end{tabular}

Fuente: Rockström et al., 2009, traducción Céliz,2018.

Para Rockström et al. (2009) tres de estos límites ya fueron sobrepasados: cambio climático, pérdida de biodiversidad y ciclo de nitrógeno (Figura 10). A su vez destacan la interconectividad e interdependencia de todos los límites por lo que la extralimitación de uno traerá aparejado consecuencias y posibles aumentos de los otros.

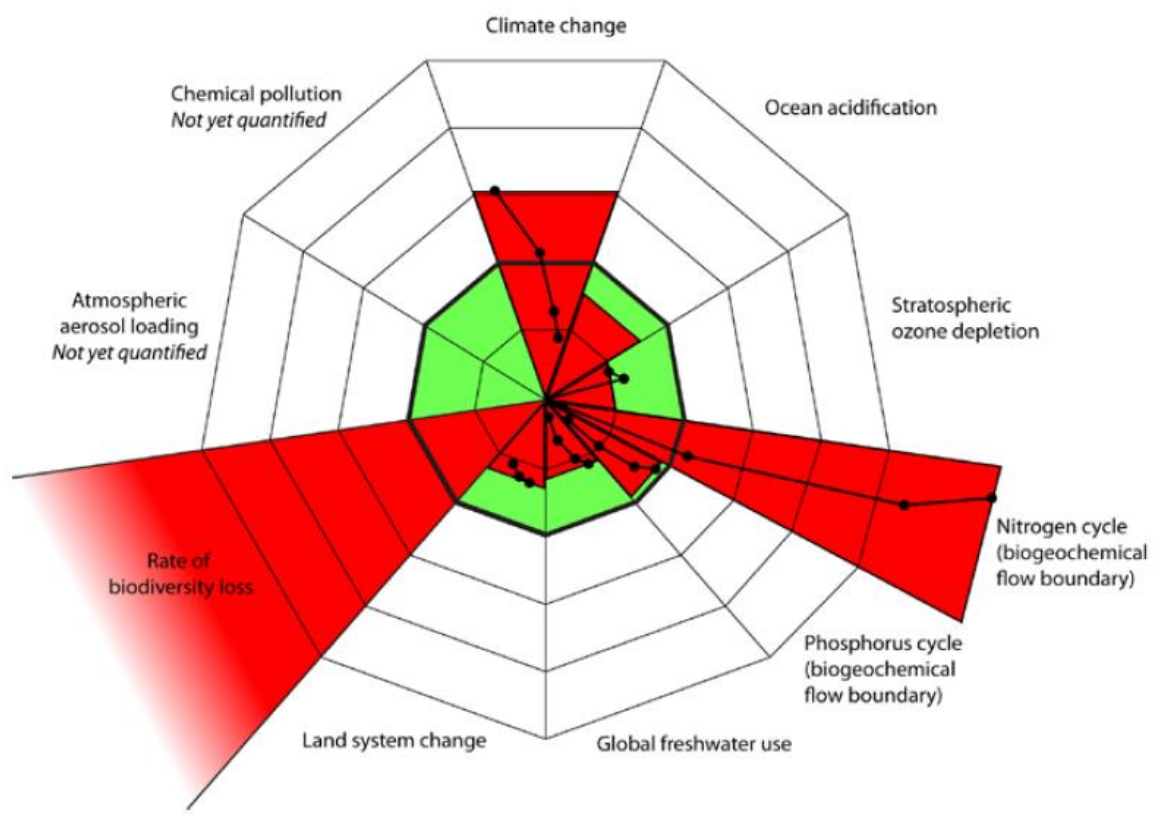

Figura 10. Planetary Bounderies. Rockström et al.2009 
El gráfico araña muestra la estimación de la evolución cuantitativa de las variables de control para siete límites planetarios desde el período preindustrial hasta el presente. El área en verde representa el espacio operativo seguro con los niveles de límites propuestos en su contorno exterior. La extensión de las cuñas para cada límite muestra la estimación de la posición actual del control. Los puntos muestran la trayectoria temporal reciente estimada (1950-al presente) de cada variable de control. En cuanto a la pérdida de biodiversidad, los autores aclaran que el nivel límite actual estimado de >100 extinciones por millón años-especie, excede el espacio disponible en el gráfico. Aunque el cambio climático, la acidificación de los océanos, el agotamiento de la capa de ozono estratosférica, el cambio de uso de la tierra, el uso de agua dulce y la interferencia con el fósforo son límites definidos como el estado de una variable (concentración de C02 atmosférico, aragonito, estado de saturación y concentración de ozono estratosférico, porcentaje de tierra cultivada, máximo cantidad de uso anual global de agua dulce, carga acumulativa de $\mathrm{P}$ en los océanos, respectivamente), los restantes la pérdida de biodiversidad y el componente del límite biogeoquímico relacionado con el ser humano. La interferencia con el ciclo $\mathrm{N}$ se define por las velocidades de cambio para cada variable de control respectiva (extinciones por millón de especies al año, tasa de eliminación de N2 de la atmósfera para uso humano).

Aquí, los umbrales son definidos como una transición no lineal en el funcionamiento de los sistemas humanoambientales acoplados - coupled human environmental systems- (Schellnhuber 2002, Lenton et. al. 2008). Para Rockström et al. (2009) algunos procesos del sistema terrestre como el cambio de uso de la tierra, no están asociados con umbrales conocidos a escala continental y mundial, pero pueden estar directamente asociados a la disminución de funciones ecológicas claves que pueden causar colapsos funcionales que aumenten la probabilidad de establecer un umbral global en otros procesos. Poder establecer umbrales a escala mundial a ciertos procesos no significa que estos no puedan desencadenar dinámicas no lineales a menor escala y de gran impacto: por ejemplo, el mismo cambio del uso de la tierra puede generar el cruce de umbrales en lagos o bosques. Actualmente, el Centro para la Resiliencia de Estocolmo -Stockholm Resilience Centre- (2015), desarrolla y actualiza esta investigación.

Estas transformaciones del uso del suelo natural, los recursos y la consecuente alteración de fenómenos y procesos naturales como se ha dicho tiene impactos de gran relevancia para los mismos asentamientos humanos implicados en esta dinámica. Este impacto a su vez, puede identificarse en el marco del Cambio Global, cuyo componente visible es el Cambio Climático (Stocker et al. 2013).

\section{El contexto de cambio global}

Como se ha mencionado antes, la actividad industrial, el transporte masivo, los fertilizantes, la deforestación, la quema de bosques para agricultura y ganadería, la producción de energía, -y en menor medida la urbanización- 
han sido los principales responsables en el aumento de los llamados "gases de efecto invernadero -GEI-. El dióxido de carbono, junto con otros gases como el óxido nitroso y el metano producen este efecto. De la misma forma en que los cristales del invernadero mantienen además de la humedad y el calor en su interior, la atmósfera gracias a determinada concentración de estos gases mantiene la temperatura del planeta en rangos habitables.

"Los rayos del sol que llegan a la tierra en parte son reflejados al espacio por las nubes y otra parte penetra hasta llegar a la superficie, para luego ser reflejados en longitudes de onda correspondientes al infrarrojo y en forma de calor irradiado desde la tierra. Esta energía es atrapada por los gases de efecto invernadero, manteniendo la temperatura del planeta. Sin dichos gases, la Tierra tendría en promedio $35^{\circ} \mathrm{C}$ menos. ” (Pons \& Céliz 2018, p.230) Este comportamiento ha llevado a la humanidad a transformaciones radicales del planeta y sus ambientes, dando lugar a lo que se conoce como "Cambio Global", aunque su componente más visible debido a su escala, es el cambio climático. La Convención Marco de las Naciones Unidas sobre el Cambio Climático (CMNUCC), lo define como

"el cambio de clima atribuido directa o indirectamente a la actividad humana, que altera la composición de la atmósfera global y que se suma a la variabilidad natural del clima observada durante períodos de tiempo comparables"(CMNUCC 1992, p.3).

Para el Panel Intergubernamental de Expertos sobre el Cambio Climático -IPCC en sus siglas en inglés-, el cambio climático es la,

"variación del estado del clima identificable (por ejemplo, por un análisis estadístico) a raíz de un cambio en el valor medio y/o en la variabilidad de sus propiedades, y que persiste durante un período prolongado, generalmente cifrado en decenios o en períodos más largos. (...) puede deberse a procesos internos naturales 0 a forzamientos externos (...) o cambios antropógenos persistentes de la composición de la atmósfera o del uso del suelo." (IPCC 2013, p.188)

Ambos conceptos difieren entre sí respecto a la relatividad de los impulsores del cambio climático, sea este inducido por la acción humana o por condicionantes naturales que no dependen de ello. Lo que es innegable es que las alteraciones del ambiente asociadas a causas distintas, sean estas de origen geológico, climático, astronómico, así como las transgresiones y regresiones marinas, glaciaciones, clima árido cambios en la órbita de la tierra, impacto meteórico y períodos de gran actividad volcánica han sido registrados y comprobadas sus relaciones (Wignall,2005), aunque aún la naturaleza de estos procesos no este resulta en términos científicos. Aquello en lo que los autores coinciden a pesar de sus diferentes enfoques y conclusiones al respecto es que no hay registro de antecedentes geológicos a la capacidad de una sola especie para alterar a gran escala los procesos planetarios como lo está haciendo el ser humano actualmente (Zamora et al., 2016) 
Emisiones antropógenas anuales totales de GEl por gases, 1970-2010

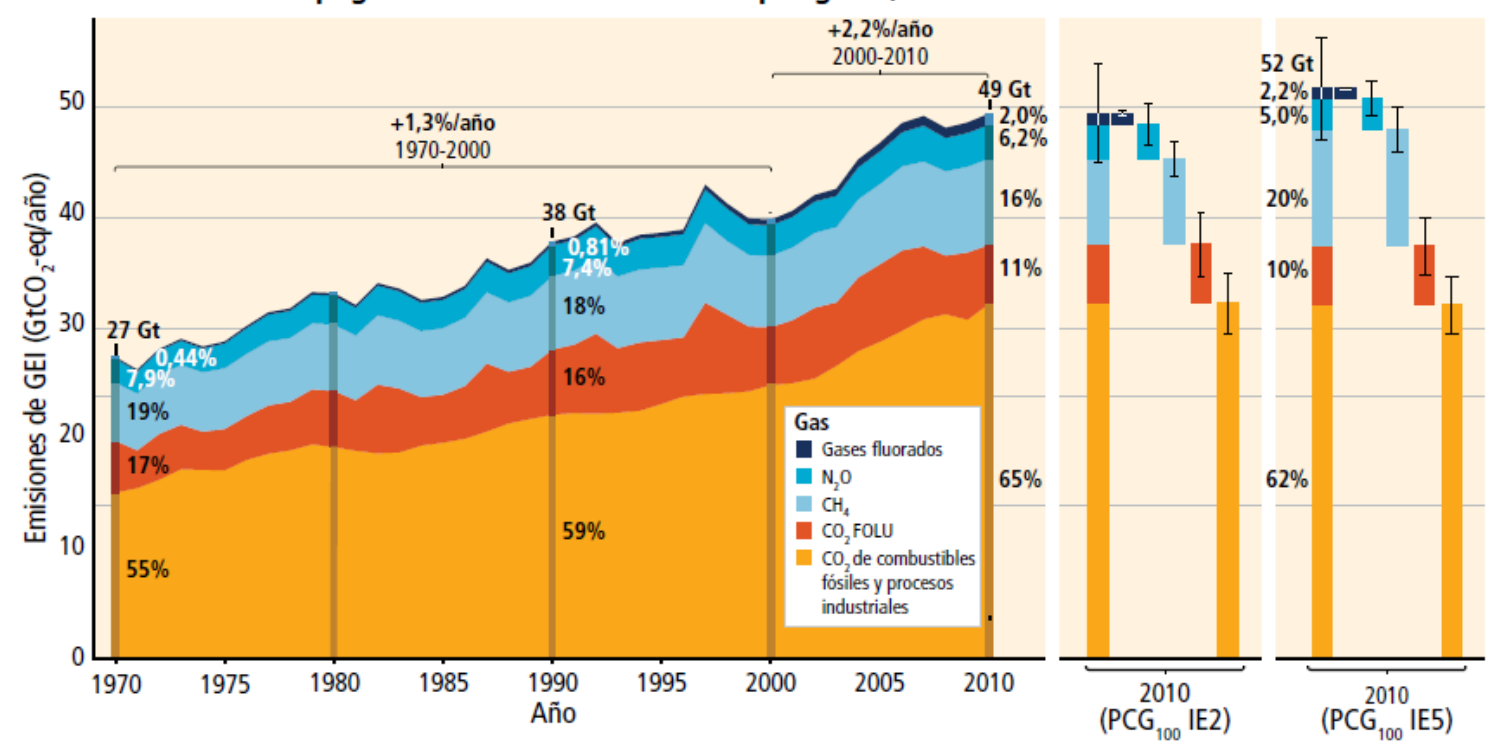

Figura 11. Emisiones antropógenas anuales totales de GEl por gases 1970-2010. a) Emisiones antropógenas anuales totales de gases de efecto invernadero (GEI) (gigatonelada de C02-equivalente al año, GtCO2-eq/año) para el período comprendido entre 1970 y 2010, por gases: C02 procedente de la quema de combustibles fósiles y procesos industriales; $\mathrm{CO} 2$ procedente de la silvicultura y otros usos del suelo (FOLU); metano (CH4); óxido nitroso (N20); gases fluorados abarcados en el Protocolo de Kyoto. A la derecha se muestran las emisiones de 2010, con ponderaciones de emisiones de C02-equivalente basadas en valores de los Informes de Evaluación segundo y quinto del IPCC. A menos que se indique de otro modo, las emisiones de CO2-equivalente en el presente informe incluyen los gases citados en el Protocolo de Kioto (CO2, CH4, N2O y los gases fluorados) calculados sobre la base de valores del potencial de calentamiento global con un horizonte temporal de 100 años (PCG100) procedentes del Segundo Informe de Evaluación (IE2). La utilización de valores de PCG100 más recientes del Quinto Informe de Evaluación (IE5) (barras a la derecha) daría un mayor nivel de emisiones anuales totales de gases de efecto invernadero (52 GtC02-eq/año) a raíz de una mayor contribución del metano, pero ello no cambiaría la tendencia a largo plazo de manera significativa. Fuente: IPCC, 2014. Informe síntesis.

Tanto el último informe del IPCC como en el anterior (2007), la resiliencia de numerosos ecosistemas se verá probablemente superada -en este siglo-, por una combinación de cambio climático, perturbaciones de tipo inundaciones, sequias, incendios incontrolados, insectos, etc., y otros factores relativos al cambio de uso de la tierra, fragmentación de sistemas naturales, sobreexplotación de recursos, entre otros. En este sentido, la incorporación de carbono neta de los ecosistemas podría alcanzar un máximo y en el mismo proceso iniciar un debilitamiento hasta la inversión de esta tendencia, agudizando el cambio climático.

Las proyecciones del IPCC (2014) para los aumentos de temperaturas promedio mundiales entre 1.5 y $2.5^{\circ} \mathrm{C}$-y las correspondientes concentraciones de C02-, indican cambios en la estructura y funciones de los ecosistemas por lo que esto implica cambios en el tipo y nivel de interacciones ecológicas. En el último informe del IPCC las principales consecuencias del cambio climático son: incremento en la temperatura global, disminución de la 
cobertura de hielo y derretimiento de los glaciares, calentamiento de los polos y pérdida de los hielos marinos, acidificación y calentamiento de océanos, cambios en los patrones de precipitación, aumentos en los niveles del mar, cambio en los ecosistemas y más eventos climáticos extremos.

En este mismo informe (2014), el IPCC establece una serie de riesgos de tipo regionales e indicadores críticos para cada región del planeta. En este esquema también se estipula el potencial de reducción del riesgo mediante adaptación y mitigación, así como los límites de la adaptación. La identificación de riesgos claves está basada en el juicio experto que el IPCC define a partir de los siguientes criterios: gran magnitud, alta probabilidad 0 irreversibilidad de los impactos, momento de los impactos, vulnerabilidad 0 exposición persistentes que contribuyen a los riesgos y el potencial limitado para reducir los riesgos mediante adaptación o mitigación.

Los niveles de riesgo son: muy bajo, bajo, medio, alto o muy alto para tres marcos temporales: el presente, el corto plazo (en este caso, para 2030-2040) y el largo plazo (en este caso, para 2080-2100). A corto plazo, los niveles proyectados de aumento de la temperatura media global no difieren sustancialmente para los distintos escenarios de emisiones. A largo plazo, los niveles de riesgo se presentan respecto de dos escenarios posibles (aumento de la temperatura media global de $2{ }^{\circ} \mathrm{C}$ y $4{ }^{\circ} \mathrm{C}$ por encima de los niveles preindustriales). Respecto a cada marco temporal, se indican niveles de riesgo para una continuación de los niveles actuales de adaptación y asumiendo niveles elevados actuales o futuros de adaptación. Ello no implica necesariamente que los niveles de riesgo sean comparables, especialmente entre regiones (IPCC,2014). Para América Latina específicamente se prevé:

- Menor disponibilidad de agua y mayor número de inundaciones y deslizamiento de tierra,

- Menor producción y calidad de los alimentos,

- $\quad$ Propagación de enfermedades transmitidas por vectores.

Resulta de vital importancia identificar en los factores de mayor impacto sobre los ecosistemas, los mecanismos y herramientas a través de las cuáles las ciudades consumen los ecosistemas no sólo en términos de eficiencia sino también de consecuencias de esta utilización. Dado que la primera instancia radica en el conocimiento de los procesos biofísicos, cada territorio adoptará variables de mayor relevancia en el estudio y el impacto de estos procesos asociados a las transformaciones territoriales.

En este sentido una de las preguntas que surgen en este punto del desarrollo teórico de este trabajo es, ¿Cómo articular desde la complejidad la lectura del crecimiento urbano y los procesos ecológicos implicados?

Fernández (2000) plantea que en principio es fundamental considerar la entidad de cuenca en la configuración territorial de las ciudades y su huella ecológica no sólo en términos de un marco de gestión sino de las interrelaciones existentes desde el punto de vista ecológico. Bajo esta propuesta y observando el fenómeno desde 
la teoría de la complejidad, las interrelaciones entre sistemas, en este caso el natural y el antrópico es posible construir un marco teórico de la planificación de áreas críticas o de mayor intensidad de interacciones. Estas áreas de contacto entre sistemas y alteraciones de procesos en relación a procesos de urbanización son entendidas como interfase. La interfase en términos físico-espaciales primero como espacio estratégico de acción y sobre todo como concepto de articulación teórico-metodológico.

\section{Planificar la interfase: una mirada compleja para la definición de variables}

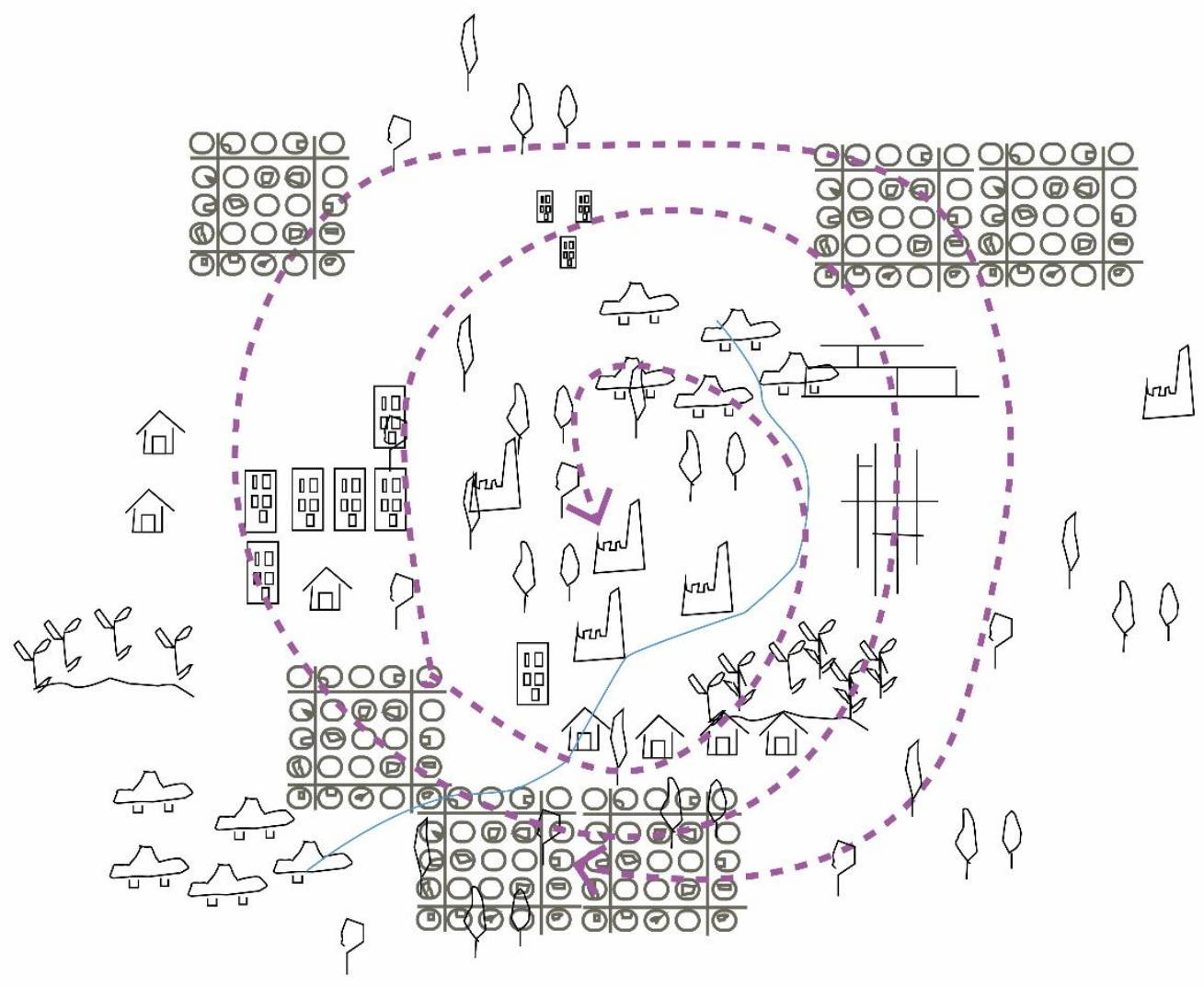

Figura 12. Esquema de interacción en la dinámica de interface urbano-rural. Céliz, 2018

Como se ha dicho anteriormente, existen instrumentos propios de la planificación y el ordenamiento del territorio que son aplicados según diferentes contextos e intereses en la configuración de procesos netamente urbanos. Por otro lado, existen normativas, planes de manejos basados en lógicas ecosistémicas que operan en entornos 
naturales o rurales y sus respectivas gradientes. Esta "delimitación de competencias", a la luz de los procesos analizados resulta por lo menos, arbitraria cuando no obsoleta. Bajo la mirada sistémica del territorio que se ha desarrollado a lo largo de este apartado teórico, la demanda de instrumentos de la planificación estará asociada a una visión holística que incluya tanto las dinámicas propias del sistema urbano, así como aquellas que tienen que ver con los sistemas naturales, los bosques, las áreas de producción de alimentos, los agro-ecosistemas, etc.

El planteo general de esta investigación implica la articulación de marcos teóricos y disciplinares para un primer abordaje. Sin embargo, el espacio o la dinámica que determina esta interfase merece necesariamente la atención y demanda nuevas estrategias por parte de la planificación territorial.

Lo primero que se establece respecto a la idea de interfase es que no se trata de un espacio determinado y estático en el tiempo. Esto implica que debe ser abordado partir de la transformación del territorio. Estas transformaciones pueden ser medidas a partir de los flujos entre fases o entre sistemas. La construcción compleja del concepto de interfase servirá para identificar aquellos elementos tanto urbanos como naturales o rurales y, las relaciones que permitan explicar cuáles son las variables de mayor impacto en este territorio.

Dado que numerosos autores se han ocupado de definir la interfase desde sus respectivos campos disciplinares, y lo que se propone es la lectura compleja de los procesos que tienen lugar en los distintos tipos de interfase, se realizó la revisión crítica de aquellos enfoques que permitan reconstruir una definición disolviendo las incumbencias disciplinares. Para esta aproximación se identificaron los sistemas principales o fases que interactúan, su caracterización espacial y a partir de allí la superación de la división tradicional campo-ciudad tradicional del ordenamiento territorial.

Esta primera identificación funcional establece que el sistema urbano es dependiente tanto del sistema rural como del natural por lo que sus acciones estarán principalmente orientadas a la obtención de bienes, productos 0 servicios derivados de otros sistemas. A su vez, las relaciones de intensidad estarán dadas por aquello que los otros sistemas brindan al sistema urbano y, en qué medida las formas en que ingresen al sistema urbano lo condicionarán. Teniendo en cuenta que los sistemas no son independientes y que la forma en que se establecen los flujos definen no solo las relaciones sino también el mismo sistema se buscó identificar estos flujos desde los enfoques identificados como relevantes: el urbano, el rural y el natural.

Desde el urbanismo y en un enfoque superador de la incumbencia disciplinar Garay (2013), plantea dos conceptos centrales: las líneas de borde y las franjas de transición. Partiendo de la idea tradicional de que existe una línea imaginaria que divide el fin de la ciudad del comienzo del campo, el autor resignifica esto planteando las dos líneas que configuran una franja que denomina borde periurbano. 
En este enfoque la configuración territorial implica una estructura urbana de gran inercia: normalmente la ciudad produce cada año el equivalente al 1 y el $2 \%$ de la superficie urbanizada y entre el 1 y el $2 \%$ de su masa construida (Garay,2013). En este contexto la transición es un espacio de configuración dinámica que atraviesa diferentes instancias que pueden ser establecidas como la progresión de la urbanización en el uso del suelo: la transformación del medio natural en rural, la transformación del medio rural en urbano y la transformación del medio urbano en otro medio urbano ${ }^{18}$.

Este proceso de tecnificación del uso del suelo está asociado a la propiedad del suelo en tanto la transformación del borde periurbano se produce parcela a parcela. Existe un actor propietario del suelo que define de manera autónoma cuál es el destino de esa parcela. Estas decisiones con mayor o menor capacidad de tensión no son aleatorias, sino que se explican en un contexto que define patrones. Es entonces que la economía urbana resulta fundamental para estudiar estas dinámicas. Garay (2013) especifica aún más esta definición enunciando que la diferencia entre la renta urbana y la renta rural (valor del suelo) es el espacio donde se desarrolla el periurbano ya que aún no están definidas las intervenciones para uno u otro uso del suelo. En tanto esta franja siga siendo un territorio de expectativa y no de intervención, la disputa determinará el valor.

La mayoría de los autores que abordan el concepto de interfase desde la mirada urbanizadora coinciden en que se trata de áreas con diversidad de usos del suelo, las cuales a menudo son variaciones de las interrelaciones funcionales entre un sector urbano y uno rural (Browder, Bohland, and Scarpaci 1995). Asimismo, son identificables rasgos de interfase ecológica y de frontera socio-productiva, donde se atenúan los servicios del sistema urbano y Ios servicios ecológicos (Castronovo 1998). En la delimitación de estos espacios, son de fundamental importancia los principios de contigüidad y proximidad espacial (Muñoz 1999). Esto implica que si bien la mirada se establece desde el proceso urbanizador 0 desde el espacio antrópico se entiende que la configuración de la interfase está asociada a una interdependencia de los sistemas entre sí.

El término más utilizado por los autores que definen este espacio es el de "área periurbana", "interfase periurbana" y "franja rural-urbana". La terminología resulta de vital importancia en esta construcción dado que la idea de periurbano -forma más difundida de este concepto- implica una visión urbana por lo que, comúnmente asociada a la idea de que aquello que esta por fuera de lo urbano y es caracterizado en función del primero. Esta lectura cuando se realiza a la luz de la teoría de que la urbanización es progreso implica que aquella fase que conforma la interfase periurbana, está en detrimento de otra y no, que se trata de dos sistemas que interactúan para configurarse mutuamente.

\footnotetext{
${ }^{18}$ De la Conferencia Magistral del arquitecto Alfredo Garay, 13 de septiembre de 2017. Congreso de "Periurbanos hacia el consenso". Ciudad de Córdoba, 12, 13 y 14 de septiembre de 2017.
} 
El urbanismo tiene herramientas capaces de abordar la dinámica de esta interfase, en tanto y en cuanto sea capaz de leer que el fenómeno de re-producción de la ciudad no es la expansión horizontal de la superficie impermeabilizada. Estas herramientas de la planificación tradicional deben ser necesariamente enriquecida con enfoques de otras disciplinas que permitan complejizar los procesos que definen esta interfase.

\section{La interfase y los agro-sistemas}

Los procesos identificados y seleccionados para definir la interfase desde un enfoque rural o agronómico presenta varios elementos particulares e interesantes a tener en cuenta en la construcción compleja de la interfase.

Uno de los trabajos de mayor referencia en el estudio de procesos territoriales y sobre todo desde lo económicoespacial, es el del alemán H. Von Thünen de 1826. La teoría de la localización que desarrolla Von Thünen se basa en la observación de actividades agrícolas y la transformación espacial provocada por la sustitución de un sistema agrícola cerrado por otro de tipo abierto o de mercado (Waibel 1979).

Se atribuye a Von Thünen el primer modelo de orden espacial racional para la producción agrícola desde un enfoque económico clásico. La transición a la agricultura de mercado condicionada por la existencia de un mercado urbano define con más claridad una diferenciación territorial del espacio agrícola y su área de influencia. Al estar en función de la distancia, la distribución espacial de la actividad agrícola se producirá en relación a los costos de transporte, resultado que Von Thünen esquematiza en una serie de círculos concéntricos que generan rentas más bajas a medida que se alejan del centro y en los que, cuando la rentabilidad por unidad de superficie desciende a un mínimo, se promueve un cambio de cultivo o de técnica agrícola que tiende a disminuir el costo de producción por unidad de superficie (Von Thunen and Hall 1966; Waibel 1979). Los círculos próximos a la ciudad corresponden a actividades intensivas o que implican elevados costos de transporte y a medida que se alejan hacia los círculos externos se configuran las actividades agrícolas de tipo extensivas (Figura 13). 

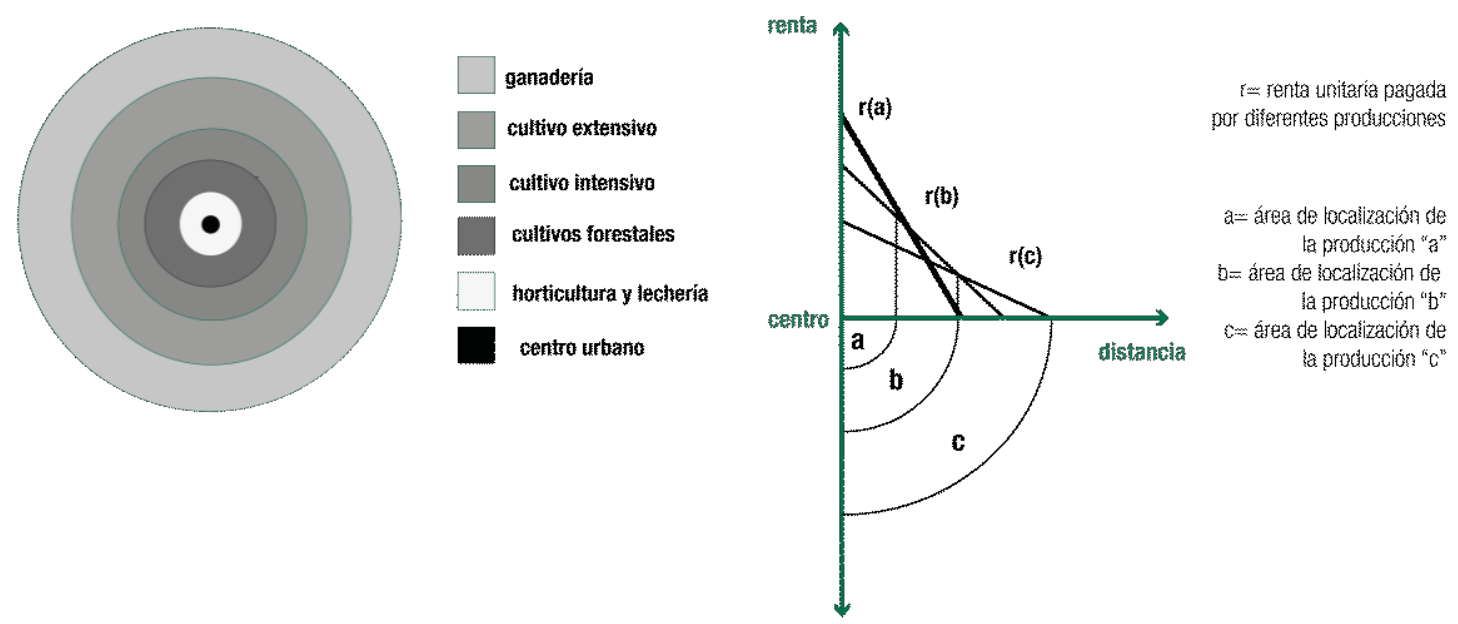

Figura 13. Teoría de la localización Von Thünen (1986). Redibujo Céliz, 2017

Este modelo territorial del año 1826, parte desde un enfoque agrícola y a partir del estudio de estas dinámicas define las áreas de influencia urbana y como esto determina las formas de la producción espacialmente. Si bien es importante definir que este modelo parte de la realidad agrícola alemana, ha sido el punto de partida de teorías y modelos territoriales a escala global, incluso la base teórica del estudio de cambios y coberturas de uso de suelo con sistemas de información geográfica y diversos modelos informáticos.

En 1961, el trabajo de Juillard sobre la urbanización del campo en Europa occidental define que la ciudad sólo puede esperar mantenerse a través de un gravamen continuo sobre el campo (Juillard 1961). Una ciudad que no sólo distribuye, encarga y drena en una región rural dominando, sino que también vive en gran medida de la renta de la tierra que recauda allí. Juillard observa la dinámica de abandono del pequeño agricultor de los viñedos por no poder adaptarse a la tecnificación de algunos cuantos propietarios y la presencia de propiedad urbana, identificando a su vez como principales impulsores al monocultivo de vid y la propiedad especulativa.

Fuera de los modelos surgidos en Europa, desde la geografía estadounidense Pryor (1937), define a la "franja ruralurbana" como la zona de transición del uso del suelo de características demográficas y sociales, situándose entre las áreas suburbanas del lugar central y su área de influencia rural, con una orientación social mixta, rural y urbana. Se trata de áreas con escasez de servicios urbanos y de planificación urbana dado que los límites van más a allá de las políticas del lugar central, con una densidad de población por encima de los demás pueblos rurales y por debajo del lugar central. Utilizando criterios de usos del suelo y demográficos subdivide la franja rural-urbana en una franja urbana con una mayor densidad residencial, un mayor crecimiento demográfico y un mayor ritmo en la reconversión de usos del suelo que la otra franja rural. (Binimelis, 1996) 
Otros autores desde la geografía social y a partir de la observación en Canadá, reinterpretan y amplían el modelo de Pryor (Bryant, Russwurm, and McLellan 1982). El análisis de los procesos de periurbanización y de contraurbanización expresan la expansión de los límites de la ciudad sobre el entorno rural, configurando una "ciudad regional" compuesta por la ciudad concentrada que incluye entre el 75 y 90\% de la población en apenas un $5 \%$ del territorio. La ciudad dispersa o "campo urbano" que en el $95 \%$ del espacio alberga entre el 10 y el $25 \%$ de la población (Figura 14).

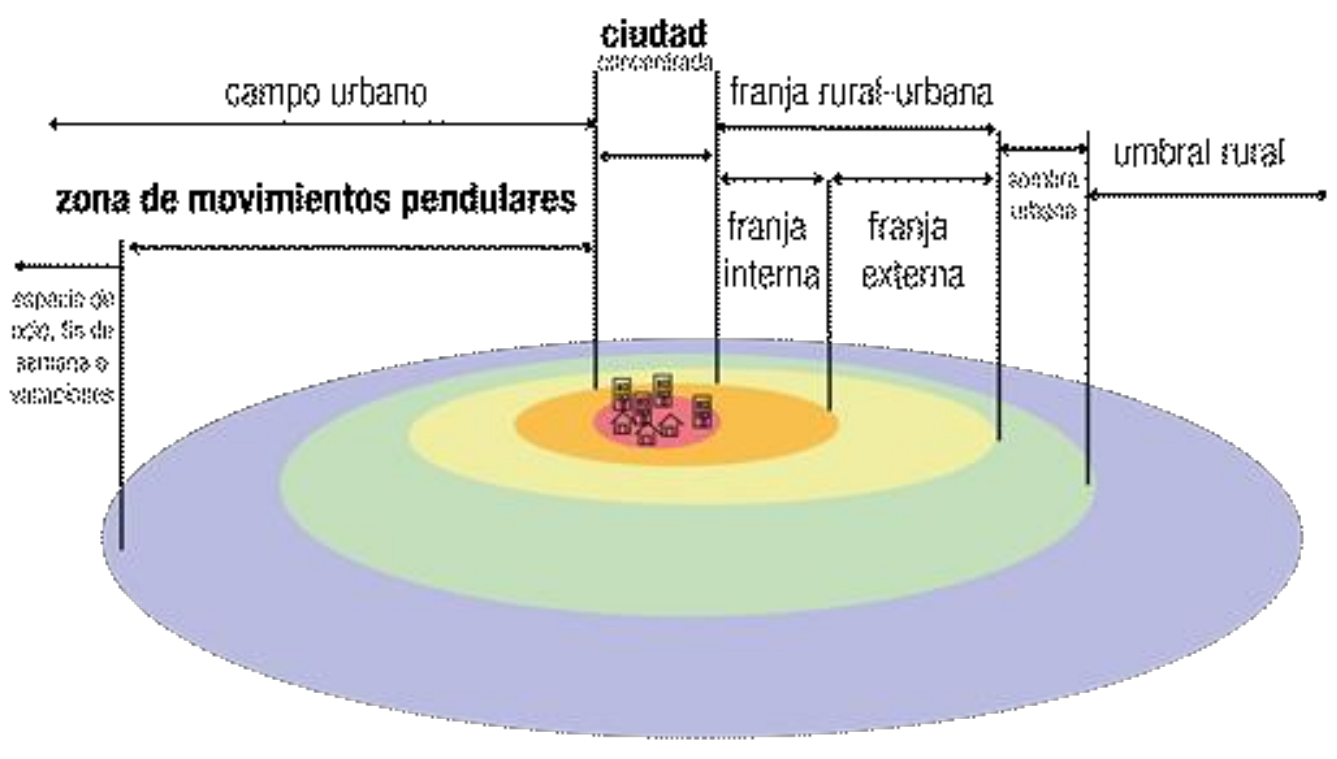

Figura 14. Organización de las distintas coronas periurbanas según Bryant y Russwurm. Redibujo Céliz, 2017. La subdivisión de círculos corresponde a 1) la franja rural-urbana, con dos zonas: interna con cambios avanzados de usos rurales a urbanos, acosada por el avance de la frontera urbana. Externa: con un claro dominio del uso rural en el paisaje, pero con elementos urbanos nítidos en el (residencias, polígonos, etc.). 2) sombra urbana, con una mínima presencia en el paisaje de elementos, pero con residencias no agrícolas y movimientos pendulares hacia la ciudad. 3) Hinterland rural, que presenta población mediatizada en proceso de aculturación. La influencia urbana, lógicamente, varía de forma inversa con la distancia al núcleo central y directamente con su tamaño.

En esta misma línea Jaillet \& Jalabert, (1982), interpretan el crecimiento de la periferia urbana en el Paris de las banlieue en los años 80 '. Este crecimiento es la expresión geográfica de las actuaciones sociales derivadas de una serie de elementos interdependientes a tener en cuenta en el análisis: i) la localización de actividades económicas, ii) la estructura productiva, iii) situación, rasgos y evolución de la agricultura, iv) mercado de suelo, v) planificación territorial y vi) actitudes y papel de los antiguos y nuevos residentes periurbanos (Delios,1991). 
Según Delios (1991), la delimitación del espacio rural periurbano ya sea cuantitativa o cualitativamente, dada la transformación constante de los mismos, la alteración en el corto plazo tanto física, económica como social determina concibiendo delimitaciones inoperantes. Los intentos de aislar el espacio periurbano del urbano y el rural es a menudo la primera limitación para comprender el fenómeno de la "periurbanización", esto implica necesariamente concebir a la ciudad, el periurbano y el espacio rural como elementos de un único sistema.

Mucho más próximo en tiempo y espacio, Barsky (2005) retoma las definiciones teóricas de mucho de los autores citados previamente y refuerza una definición de interfase urbano-rural en clave latinoamericana y más precisamente argentina. De los elementos más importantes que incorpora Barsky a la lectura de la transformación rural-urbano del uso del suelo, es el de las interrelaciones ecológicas que se establecen entre estos sistemas. De esta manera, zonas rurales donde la influencia urbana es más fuerte por la cercanía física a la ciudad se ven afectados por una serie de procesos de naturaleza diversa: económica, demográfica, social, territorial, entre otros; que permiten identificar a esta interfase a partir de la mezcla de usos del suelo y complejidad de flujos heterogéneos (bienes, servicios, personas, información). A su vez, estos territorios se configuran como áreas inmediatas de influencia urbana no sólo por la posibilidad de conversión del suelo rural a urbano por incremento de la urbe, sino porque este entorno alberga actividades y funciones relativas a la ciudad, desde la provisión de infraestructura de conexión hasta la obtención de alimentos frescos. Allí es donde comenzamos a hablar de hinterland ${ }^{19}$ de la ciudad.

El análisis de estos procesos se inicia a partir la presunción de que la transformación de rural a urbano es irreversible. Esto asociado al aumento poblacional que demanda la accesibilidad a la tecnología, eficiencia en la movilidad, acceso a las redes de infraestructuras, mayor demanda energética y cambios en los tipos constructivos y urbanos acordes a esas tecnologías. Según Rodríguez (2016), estas ideas están asociadas al progreso y al desarrollo socioeconómico. La afirmación del autor se basa en las definiciones de progreso urbano como el acercamiento a las tecnologías y avances cientíicos, dados por el acceso a las comodidades que brindan los servicios próximos a las viviendas.

La urbanización es tradicionalmente entendida como un proceso de superposición por zonas, donde los nuevos espacios urbanos van alcanzando un cierto nivel de confort, mientras los espacios rurales se relacionan generalmente con el atraso, la decadencia y el alejamiento de servicios o infraestructura (Pérez y Herrera, 2006; Carpio Martín, 2002 en Rodríguez 2016). Este proceso de ir transformando en urbano, lo rural y lo natural, es percibido como el único proceso posible y se ha naturalizado, conformando lo que sería una evolución gradual sobre el territorio. En este sentido, Rodríguez plantea que existe una escala donde los espacios naturales quedan

\footnotetext{
${ }^{19}$ hinterland proviene del idioma alemán, y significa literalmente "tierra posterior" (a una ciudad, un puerto, etc.). En un sentido más amplio al anterior el término se refiere a la esfera de influencia de un asentamiento.
} 
a un nivel inferior y sin posibilidades de obtener algún grado de habitabilidad aceptable, alejados de la modernidad la cual queda ligada a zonas urbanas donde se alcanzaría el progreso y el desarrollo.

\section{La interfase natural-urbana}

La observación de esta interfase puede realizarse desde un punto de antropización igualmente naturalizado: el área rural. Si se realiza una nueva lectura crítica, la imagen campo-ciudad imprime la idea de que por fuera de la ciudad existe un área igualmente controlada por los asentamientos humanos y los espacios naturales como bosques y reservas se encuentran a mayores distancias o no asociados a la ciudad. Es por esto necesario mencionar al área natural como infraestructura crítica que también es afectada, condiciona y establece relaciones directas con la escala urbana: la interfase urbano-natural.

En un sistema natural, a muy diferentes escalas se desarrollan procesos de cambios, identificados por discontinuidades en el suelo y la vegetación. Estos cambios -más o menos graduales-, definen una zona de transición entre sistemas ecológicos adyacentes diferentes. Esta zona de frontera, limitante con dos ecosistemas diferentes y que tiene características ecológicas particulares, se denomina ecotono y es entendido como la zona de unión entre dos comunidades, en la cual los procesos de intercambio y competencia pueden ser fácilmente observables (Clements 1905). Posteriormente, Odum (1971) lo definió como la transición entre dos o más comunidades diversas, por ejemplo, un bosque y un prado. Esta tendencia al incremento de la variedad y la densidad de las comunidades del ecotono se define como efecto borde (Odum, 1971 citado en Escribano, Encinas, \& Martin, 1997). Otros autores incorporan los parámetros de tiempo y espacio como las variables que definirán las características de este espacio, así como las fuerzas de unión entre los sistemas ecológicos se limita (Holland and Risser 1991). Es decir que puede variar a lo largo del tiempo como consecuencia de procesos naturales como la sucesión vegetal o una respuesta a un cambio en las condiciones ambientales que implique la desaparición de las comunidades vegetales 0 animales que caracterizaban al territorio.

La definición de ecotono en el ámbito de las ciencias naturales es la primera aproximación a comprender la interfase de sistemas naturales y, sistemas naturales y antrópicos. Esto en el marco de la comprensión de la dinámica de flujos que existe entre la ciudad y áreas menos antrópicas que las rurales. Esta interfase en particular es la que resulta de mayor interés para el desarrollo de esta investigación.

Si bien Morello (2000) no utiliza el concepto natural en su definición de interfase, pone el énfasis en las interacciones urbanas y rurales para definir un sistema que no es ni rural ni urbano (Figura 15). La caracterización de las variables que definen una fase urbana se componen de servicios como infraestructura de agua potable, electricidad, pavimentación, recolección de residuos, etc. En la fase rural la provisión de servicios se define a partir 
de la captación de dióxido de carbono, energía solar transformada en energía química y su posterior conversión a alimentos, incorporación de materia orgánica y ciclado de nutrientes, regulación de caudales de agua por absorción y formación de suelos, entre otros.

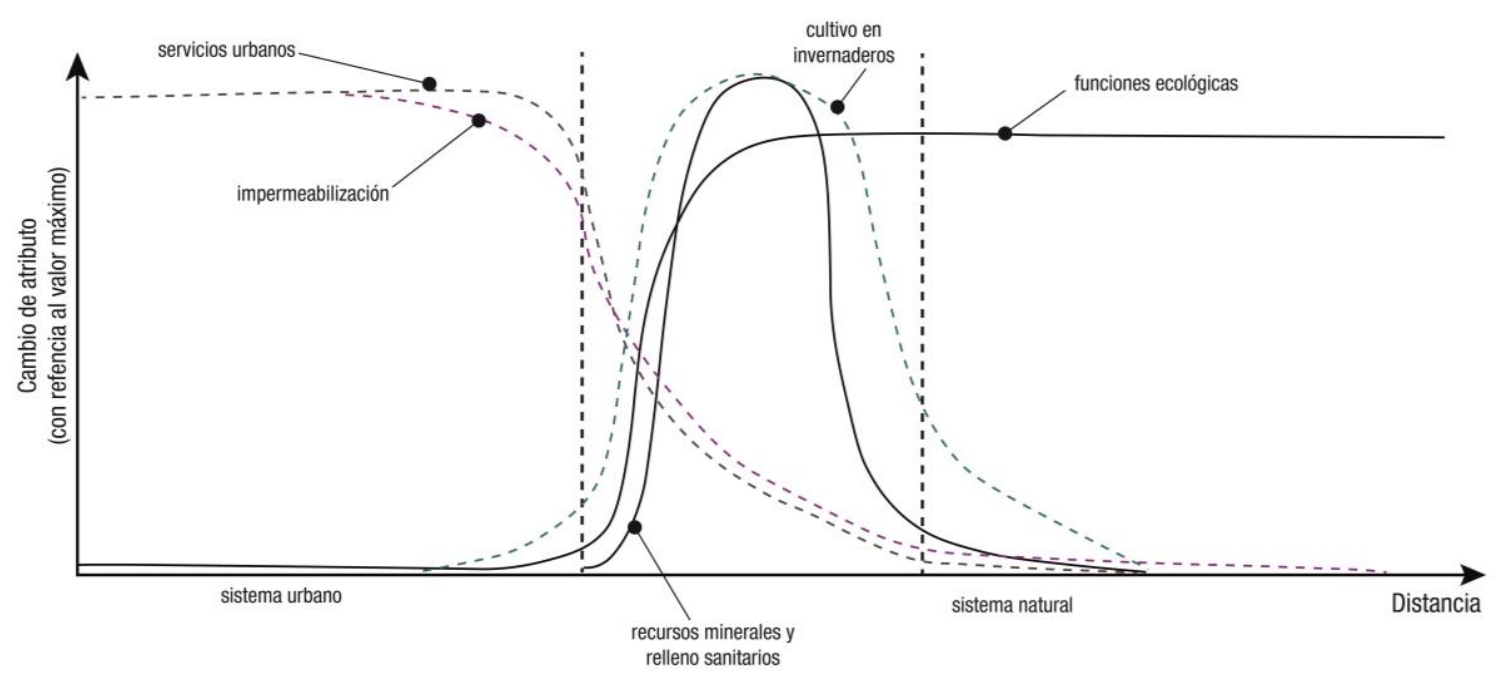

Figura 15. Proceso de intercambio de servicios en la interfase. Céliz, 2018 en base a Morello et al., 2000.

A diferencia del modelo espacial de anillos, este modelo establece un gradiente espacial a partir de la interpretación de la intersección de dos curvas cuyo punto máximo de elevación se corresponde con la mayor provisión de servicios para cada fase (urbana o rural) y a medida que descienden se interceptan configurando el área de interacción de inter-fases. En el momento en que la provisión de servicios de la fase es cero se configura el borde 0 final de la interfase.

El modelo identificará por un lado los servicios más antrópicos relativos a la demanda urbana y por otro aquellos provistos por el ambiente de importancia no sólo en términos de definición de ambientes, sino que, además permite el conocimiento del estado de ese ambiente y su biodiversidad. La operativización de este modelo definirá las condiciones particulares y específicas de la interfase de estudio.

La definición de interfase natural-urbana es definida mayormente por autores estadounidenses o europeos y están asociados, en la mayoría de los casos a dos dinámicas producto de esta interacción de fases. Por un lado las áreas forestales y de reservas con la urbanización de baja densidad y la ocurrencia de incendios por la interacción de actividades antrópicas con áreas naturales. Es así que, el concepto de interfase natural-urbana proviene de la definición inglesa de espacios mixtos o windland-urban interfase (Radeloff and Mckeefry 2005) asociado a entornos 
con viviendas en un espacio con grandes cantidades de biomasa en diferentes estadíos-bosques o matorrales(Rodríguez and Ghermandi 2016).

El estudio de la interfase natural-urbana estadounidense de Radeloff y Mckeefry (2005), identifica casi 45 millones de viviendas. Si bien el estudio no puntualiza respecto a la baja densidad, indica la relevancia de la demanda de estos entornos por lo que la planificación de estos territorios es fundamental. En el caso argentino Rodríguez y Guermandi (2016), registraron procesos que pueden asociarse a la tendencia de urbanización de áreas de grandes concentraciones de biomasa, particularmente en zonas de montaña en la Patagonia argentina.

Para Prados (2009) esta dinámica es más clara en zonas de montaña y áreas de interfase urbana, donde la actividad turística está presente. Esta demanda de condiciones urbanas no solo está asociada a la urbanización de áreas naturales sino también a la intensificación agrícola. Este proceso es definido como naturbanización para hacer referencia a la llegada de población y actividades urbanas a áreas de alto valor natural, tales como parques nacionales, generando cambios en la base socio-económica y ecológica de las áreas de influencia y en la misma área protegida. Esto significa que la presencia de espacios naturales estimula la urbanización de al menos sus áreas de influencia (Prados, 2011). La antropización de estas áreas naturales está asociada a la demanda directa 0 indirecta de servicios que el ambiente brinda a los asentamientos humanos.

Como se ha mencionado anteriormente el estudio de la dinámica natural-urbana está asociado sobre todo a cuestiones de riesgo y vulnerabilidad de la fase natural ante la presencia de la condición urbanizadora. Sin embargo, de la observación de los antecedentes bibliográficos se encuentra una dificultad en la delimitación de estos comportamientos.

En el caso argentino, Cardoso \& Fritschy (2012) proponen algunos criterios de distinción entre una fase y otra. El espacial y morfológico, bajo la premisa de borde 0 ecotono en relación a los procesos que le dan origen y los criterios cultural y social, relativo a la idea de frontera y lugar. Para las autoras esto no implica que criterios como el económico a través del precio de predios más bajos y la especulación inmobiliaria constituyan impulsores decisivos. Existe por tanto una apreciación de la naturaleza protegida en el medio ambiente residencial, asociada al aumento de calidad de vida de los habitantes de estas áreas. Sin embargo, una vez que el propietario pasa a formar parte el entorno esta apreciación se vuelve negativa de dicha naturaleza (Rodríguez and Ghermandi 2016). En comparación a los procesos de transformación del suelo rural a urbano teniendo en cuenta a la proximidad al núcleo urbano como uno de los principales impulsores de cambio, en el caso del suelo natural que pasa a superficie urbana el proceso se encuentra fuertemente condicionado por la oferta poco antropizada del territorio. Esto no implica necesariamente que cuanto más alejado de la ciudad se encuentre el ecosistema y mayor sea su condición de "prístino" mayor es su posibilidad de urbanidad. Sin embargo, hay una distancia a la ciudad que es valorada 
por la demanda. Este proceso de adaptación de la condición natural a la condición urbana persé lleva implícito la transformación del medio natural ya sea por el aumento de vías de circulación, autopistas de conexión, tendidos eléctricos, etc. Es decir, la incorporación de servicios urbanos a los servicios ecosistémicos apropiados o en proceso de apropiación.

Si la planificación territorial y sus instrumentos no consideran estos procesos ecosistémicos y sus beneficios a los asentamientos humanos, en mayor medida está asociado a la complejidad de delimitar o definir muchos de estos procesos e incluso de identificar cuáles son. La lectura compleja del fenómeno de transformación territorial que estructura esta tesis se propuso definir más no simplificar, criterios que permitan incorporar el enfoque ecosistémico a los procesos de planificación territorial. Para avanzar sobre estas definiciones, resulta imprescindible indagar como las disciplinas de las ciencias naturales y de la tierra han abordado el estudio de dichos procesos.

\section{Los socio-ecosistemas en el estudio de la interfase}

\section{natural-urbana}

Los socio-ecosistemas (SEE) o los sistemas socio-ecológicos, implican la caracterización de la relación de procesos en torno a la idea de "ser humano-en-la-naturaleza" (Berkes and Folke 1998a). Es decir que, el enfoque de la gestión de los ecosistemas no estará dado por los componentes del sistema, sino que el foco estará puesto en sus relaciones, la forma en que interactúan y lo que esto produce. El estudio de estas relaciones se define a partir de la concepción de los coupled human and natural systems -CHANS por sus siglas en inglés-. Esta idea de "los sistemas humanos y naturales acoplados", constituye un enfoque que entiende a las interacciones de componentes humanos y naturales como sistemas acoplados funcionando (Liu et al. 2007)

Con excepción de las grandes migraciones humanas, el comercio o la guerra, la mayoría de las interacciones entre el ser humano y el medio natural han sido de escala local. Esta medida de interacción ha cambiado radicalmente a regional, continental y mundial por lo que la medida de las conexiones ha aumentado y se ha dinamizado de la misma manera. Esto ha generado la intervención a escala global en la naturaleza. El concepto de CHANS plantea que, si bien en el estudio disciplinar es importante la intensidad, complejidad y escala de estas relaciones demanda necesariamente el estudio de los sistemas naturales y humanos de manera conjunta. Se trata de relaciones socioecológicas, es decir relaciones ser humano-ambiente. 
Al igual que los principales autores del enfoque de la complejidad Dietz et al., señalan la importancia de desarrollar un nuevo marco integrado para estudiar CHANS. Este planteo no resulta aislado ya que existen investigaciones y programas transdisciplinarios que lo abordan. Se trata de entender que los dominios humanos y naturales ya no son vistos por separado, sino conectados y en interacción.

Dentro de esta perspectiva se han desarrollado estudios y relevamientos del estado medioambiental terrestre motorizados por la preocupación de la acelerada transformación de los ecosistemas por sobre otros períodos de la historia de los asentamientos humanos. Estos cambios estuvieron orientados a percibir beneficios para el bienestar humano y el desarrollo de las economías, sin embargo, estas mismas acciones han contribuido, a la degradación de muchos de los "servicios" que los ecosistemas bridan para el propio sostenimiento de los asentamientos humanos. De la misma manera que implicaron el incremento de riesgos en los ecosistemas y la acentuación de la pobreza para algunos grupos de población (Millennium Ecosystem Assessment 2005). Ambos sistemas mencionados: el bio-ecológico y el sistema socioeconómico-cultural (Gowdy, 1994; Norgaard, 1994 y Norgaard, 2010 citado en Jiménez Guerrero 2016) han sufrido transformaciones debido a las relaciones que estas dinámicas implican en su desarrollo.

A partir de la recopilación de varios enunciados, se establece que la idea fundamental que aportan como marco teórico los SEE radica en la suposición de que los sistemas sociales y ecológicos no sólo están conectados, sino que su interacción los configura y reconfigura mutuamente. Por tanto, definir una frontera entre un ecosistema 0 un sistema social, es por lo menos arbitrario. Esta perspectiva es abonada por conceptos como el de "enlaces socio-ecológicos" -socio-ecological lincages en inglés- (Berkes and Folke 1998a), que pone el énfasis en las relaciones que definen y articulan ambos sistemas, con el objetivo de dar igual relevancia a la dimensión social y a la natural.

Los SEE están compuestos por diversas partes de una entidad de mayor complejidad, fruto de las interacciones socioambientales como así también de las retroalimentaciones, sean estas de tipo positivas o negativas dentro del sistema. Las personas y la naturaleza interactúan recíprocamente a través de diversos niveles de organización. Estos forman complejos canales de interacción que se encuentran incrustados unos dentro de otros. Los seres humanos dependen de la naturaleza por una amplia gama recursos y condiciones imprescindibles, incluyendo agua potable, aire limpio, nutrientes, alimentos, materiales crudos y medicinas (Liu et al. 2007)

Las características de estos sistemas en términos generales están asociadas a: i) dinámicas no lineales con umbrales de cambio y transición entre estados, ii) bucles complejos de retroalimentación, iii) lapsos de tiempo en la observación de las consecuencias, iv) resiliencia, v) heterogeneidad y vi) sorpresas (Liu et al. 2007). 
Estas características producto de diferentes niveles de interacciones implican riesgos para los asentamientos humanos: primero para aquellos que están en una relación de intercambio más directa con el socio-ecosistema y como se ha mencionado, debido a los intercambios a escala global el riesgo aumenta en esta condición general. El aumento de la condición de riesgo también está asociada a la pérdida -directamente-, de numerosos servicios de los ecosistemas esenciales para la supervivencia y el desarrollo humano.

"Los procesos naturales pueden devastar los sistemas humanos a través de la degradación del medio ambiente y los desastres, como terremotos, inundaciones, volcanes, olas de calor, sequías, huracanes, tornados, deslizamientos de tierra y enfermedades (Dilley et al. 2005). Los efectos de los desastres van desde la interrupción del trabajo y las rutinas de vida de las personas, pasando por conflictos sociales, pérdidas económicas, destrucción de infraestructuras como carreteras y edificios, hasta la propagación de enfermedades y la muerte." (Liu et al. 2007, p. 640 [traducción propia]).

Poder cuantificar las interacciones entre estos sistemas no sólo permite caracterizar al socio-ecosistema, sino que fundamentalmente permite establecer umbrales críticos de afectación del sistema. En términos de complejidad los niveles de entropía producto de las interacciones y su intensidad, como el proceso de urbanización se desarrolla en el territorio a partir del cambio de usos de suelo. Estos cambios se suceden con diferentes niveles de antropización de los ecosistemas, sean estos naturales 0 antrópicos presentan límites en los que se produce la transformación del sistema o negentropía. Indefectiblemente esta dinámica impacta sobre los asentamientos humanos configurando niveles de exposición y riesgo a estas transformaciones.

¿Es posible cuantificar los procesos ecosistémicos afectados a partir del proceso de antropización en estas áreas naturales?

Diferentes marcos teóricos han llevado adelante mecanismos y procesos de observación de aquellos procesos ecológicos en relación a los asentamientos humanos. El desafío planteado en esta instancia radica en la posibilidad de entender que estos debates y estudios territoriales sean llevados a la planificación local-regional. 


\section{Servicios ecosistémicos ¿Por qué operativizarlos para la planificación territorial?}

Las teorías y modelos que se han expuesto hasta el momento, demuestran la necesidad de un enfoque sistémico para el abordaje de las transformaciones territoriales que no se limita al conocimiento de la estructura urbana o la forma en que se establecen patrones urbanos de densidad, usos del suelo, acceso a infraestructura, etc. Si bien estos elementos son importantes al interior un sistema antrópico determinado por una jurisdicción, entenderlos como parte de un sistema mayor sometido a dinámicas de mayor escala es un paso fundamental hacia una planificación sostenible. El proceso de incluir factores ambientales en la planificación ha demostrado que no es suficiente determinar presencia y estado de la biodiversidad ${ }^{20}$ por un lado y procesos socio-económicos y patrones de uso del suelo por otro, sino que indagar en las variables que unen componentes sociales y ecológicos son acciones necesarias y estratégicas.

A lo largo de la historia han existido numerosos movimientos y acontecimientos que han puesto el eje de la discusión en el estado de salud de la Tierra y la capacidad del territorio de albergar a los asentamientos humanos frente a la intensificación de consumo que llevamos adelante. La dinámica que ha guiado al proceso de establecer el paradigma ecosistémico tiene un largo desarrollo y ha buscado estrategias y herramientas que permitan dar cuenta de la relevancia de este tipo de conocimiento y sus aspectos cuantificables.

Desde el primer congreso para la protección de la naturaleza (1923) hasta que E. Odum en 1974 se preguntó "cuánto valía la naturaleza" pasaron 50 años de debate internacional respecto del lugar que ocupaba para los gobiernos el ambiente. En 1988 en las actas del foro de la Diversidad Biológica, el término "biodiversidad" reemplaza al de "naturaleza" por lo que la noción para la comunidad de aquello tan vago comienza a complejizarse. Luego de la cumbre ambiental de Río (1992) y el auge del "desarrollo sostenible" se formaliza el cruce entre economía y ambiente, donde empiezan a encontrarse puntos comunes que se orientan a ponerle una "cuantía" a los recursos naturales y establecer intereses de los países centrales respecto a los servicios que el ambiente otorga a las sociedades. Esta etapa podría ser entendida como el principio de la instrumentalización de la naturaleza

\footnotetext{
${ }^{20}$ La biodiversidad es un resultado del proceso evolutivo que se manifiesta en la existencia de diferentes modos de ser para la vida. Mutación y selección determinan las características y la cantidad de diversidad que existen en un lugar y momento dados. Diferencias a nivel genético, diferencias en las respuestas morfológicas, fisiológicas y etológicas de los fenotipos, diferencias en las formas de desarrollo, en la demografía y en las historias de vida. La diversidad biológica abarca toda la escala de organización de los seres vivos (Halffter 1994).
} 
(Maris 2011). Este punto es considerado incluso una paradoja ya que fue motorizado en parte por diversos movimientos ambientalistas que buscaban demostrar los beneficios -incluso económicos-, de la preservación de la naturaleza y sus recursos.

La relación entre los términos económicos que fueron aproximándose a la conservación de la naturaleza y el enfoque que de esto deviene, definió posturas opuestas. Algunos autores estiman que esta aproximación entre la economía y la ecología es un paso importante para poner el foco en cuestiones que antes no estaban en la mira (Laterra, Jobbágy, and Paruelo 2010). Sin embargo, la crítica parte de la noción "servicio" y la asignación de la visión antropocéntrica de la naturaleza, en donde los ecosistemas adquieren valor en tanto y en cuanto constituyan alguna utilidad para el hombre (McCauley 2006; Sagoff 2008; Redford \& Adams 2009 citado en Schröter et al. 2014). Esta postura establece que el valor intrínseco de la naturaleza debe estar asociado a un enfoque biocentrico (Krebs 1999; Callicott 2006; Jax et al. 2013) y no un valor de uso, este enfoque se acerca al que tenían las primeras comunidades sobre la naturaleza.

Algunas líneas que especifican estas relaciones como la economía ecológica, plantean que un activo ambiental perdido es un costo concreto afectando a la sociedad. Sin embargo, la pregunta que surge de esta afirmación cuestiona la pertenencia de esos activos ambientales: ¿quiénes son los dueños de la naturaleza?, en caso de que sean las comunidades, ¿son todos los seres humanos por igual medida dueños de esta naturaleza? (Maris 2011). Una línea que podría complementar estas preguntas, es la de los "Bienes Comunes" (0strom,1990) que plantea la necesidad de establecer aquellos bienes que pertenecen a todos los seres humanos: la casa común, pero que sin embargo también tiene su propia crítica planteando que la noción de propiedad colectiva desestima la responsabilidad concreta por su destino.

La economía ortodoxa plantea que el debate sobre la naturaleza aún constituye una falla de mercado en tanto no es posible asignarle un valor de cambio. En este punto se agota aparentemente la posibilidad de un juicio dado que se opone el marco teórico de la cuantificación material de activos propio de esta rama de la economía con una valoración de un sistema cultural e incluso religioso en algunos casos. Un punto intermedio establece el rescata de la mirada antropocéntrica dado que la gestión de los ecosistemas del mundo está en manos de las personas por lo que abordar la crisis ecológica en curso será desde este enfoque innegablemente (Reid et al. 2006; Skroch \& López-Hoffman 2010 citado en Schröter et al. 2014). Esta postura abre el debate sobre los SS EE que a su vez no implica una sola posición al interior de este marco teórico.

Muchos de los instrumentos que desarrollo el enfoque neoclásico de valoración de los SSEE se enmarcan estrictamente en lo utilitario como central del servicio que se observa. Estos mecanismos de valoración de biodiversidad, en el lenguaje económico, implican una comprensión completa de la problemática y plantean la 
posibilidad de que los mismos actores de la economía puedan intervenir para revertir esta tendencia. Está claro que la noción aplicada a la naturaleza es de mercancía, lo cual implica la posibilidad de ser un bien de cambio. De esta manera, para que un bien o un servicio sea una mercancía debe por lo menos: i) ser reducible (reducción de Ios procesos a funciones), ii) el objeto de cambio debe ser apropiable (determinar quiénes son sus dueños) y, iii) el objeto en cuestión debe ser sustituible (Maris 2011). Visto de esta forma el panorama para la naturaleza y su simplificación en SS EE no parece nada alentador. En este contexto Maris pregunta:

¿Qué sucede si un bioma determinado -como un bosque o humedal-, adquiere un valor distinto según la comunidad humana o incluso distintos valores según distintos actores territoriales?

A estos debates responden líneas alternativas como el esquema de valoración energética propuesto por Odum y Odum (2000), o aquellos basados en aspectos biológicos y/o sociales (Kremen 2005). La mayoría de los autores que abordan estas temáticas señalan que al no existir en la comunidad científica un conceso sobre "marcos objetivos para valorar la naturaleza", existen tantas líneas de trabajo e investigación como puedan derivarse enfoques de ellas. De esta manera, habrá igual cantidad de enfoques gubernamentales: locales, provinciales, nacionales e internacionales. Sin embargo, es imposible negar que los seres humanos al tomar decisiones respecto al hábitat estamos valorando diversos ecosistemas y sus procesos intrínsecos indirectamente. Esto permite referir que cuánto más específicos sean los datos biofísicos que podamos construir, más allá de un enfoque más o menos oportunista, la toma de decisiones estará inmersa en un contexto de estimaciones precisas en torno al valor funcional de los ecosistemas. Es importante distinguir la posibilidad de construir el dato y el uso que se hace de este, esto no implica la quita responsabilidades, sino que fija una posición respecto a la necesidad de una investigación que servirá como insumo a los planes de ordenamiento territorial y los distintos estamentos de decisores políticos. Si la información no existe seguimos estando en desconocimiento de los procesos afectados, si la información existe y es producida bajo metodologías explícitas, la discusión se habilita sobre bases concretas. La valoración monetaria, entonces, proporciona argumentos adicionales para los procesos de toma de decisiones y no reemplaza los argumentos éticos, ecológicos u otros argumentos no monetarios (De Groot et al. 2012).

A pesar de sus deficiencias metodológicas, la valoración monetaria permite el cálculo de la suma total de múltiples SSEE, es decir que adoptando la misma unidad de medida es posible establecer, criticidades o incluso prioridades. Por ejemplo: el valor de múltiples SSEE presentes en un ecosistema natural -como el bosque- y el de un ecosistema intervenido -como un cultivo determinado-. Si bien estas comparaciones implican cierto debate, una estimación genérica pondría por sobre el segundo ecosistema, la criticidad de la pérdida del primero, incluso las consecuencias a corto y largo plazo de tal pérdida. 
Se ha revisado a grandes rasgos cómo en la historia de la valoración de la naturaleza, es cada vez más evidente la intervención del capital como forma de viabilizar su preservación. Si bien los intereses económicos implican indefectiblemente la simplificación de la complejidad sistémica, constituyen un paso adelante para la incorporación de la biodiversidad a ciertos debates. En este sentido, las políticas que se han implementado para el pago de SS $\mathrm{EE}$, en la mayoría de los casos favorecen a países que atentan directamente contra estos servicios y utilizan como proveedores a los países biodiversos ${ }^{21}$.

\section{La evaluación de los Ecosistemas del Milenio}

Actualmente existen una variedad de marcos teóricos y propuestas para el abordaje del concepto de Servicios Ecosistémicos (MEA, 2005; de Groot et al., 2010; Roy Haines-Young et al.,2011, entre otros) de los cuáles se han seleccionado dos puntos de partida con relativa distancia cronológica a los efectos de complementar los enfoques en aquellos puntos en que existan diferencias o que no fueran abordados por el otro. Por un lado, la base propuesta por la Evaluación de los Ecosistemas del Milenio como punto de partida de mayor consenso en la clasificación de funciones y servicios ecosistémicos. A su vez, este enfoque fue complementado por el marco teórico de HainesYoung and Potschin (2010) a partir de su propuesta de modelo de cascada. Esta selección no implica que el marco específico adoptado sea excluyente de otros debates, sino que está orientado a la construcción de una propuesta metodológica que busca habilitar un debate desde la planificación territorial y las ciencias de la tierra.

El concepto de servicios ecosistémicos es abordado en este trabajo como una aproximación integral de la dinámica de flujos entre el sistema social y el ecológico, capaz de ser incorporado en la dimensión ambiental tradicional de la toma de decisiones en el diseño y planificación de usos del suelo dentro de las estructuras de ordenamiento y planificación del territorio que se detallarán más adelante.

La Evaluación de los Ecosistemas del Milenio -Millenium Ecosystem Assessment- (MEA) es un programa de trabajo internacional pensado para la provisión de información científica acerca de las consecuencias de los cambios en Ios ecosistemas terrestres, que pueda ser abordado por tomadores de decisiones y público en general. El objetivo es conocer las dinámicas más importantes de los ecosistemas en interacción con los asentamientos humanos y las opciones posibles para responder a estos cambios. Durante la década de los ' 90 , científicos que venían desarrollando actividades relacionadas a convenciones internacionales como el Convenio sobre la Diversidad Biológica (CDB) y la Convención de Lucha contra la Desertificación (CLD) plantearon la necesidad de evaluaciones

\footnotetext{
${ }^{21}$ América es el continente con mayor biodiversidad del mundo, seguido por algunos países de Asia, de África y por Australia y la isla de Papúa Nueva Guinea en Oceanía. En estos lugares se encuentra más del setenta por ciento de la biodiversidad del todo el planeta, aunque su territorio representa apenas el diez por ciento de la superficie terrestre.
} 
más efectivas sobre el estado general de los ecosistemas. El primer estudio fue publicado en noviembre de 1988 por el PNUMA, la NASA y el Banco Mundial y demandó un proceso de evaluación integrado de temas que pretendían resaltar los vínculos entre las cuestiones relativas al clima, la biodiversidad, la desertificación y los bosques.

Finalmente, la Evaluación de los Ecosistemas del Milenio es presentada en el año 2005 como una síntesis internacional a cerca del estado de los ecosistemas de la Tierra. Este informe fue elaborado por más de 1000 científicos del mundo y se compone de resúmenes y directrices para la toma de decisiones en torno a las conclusiones relativas a los Servicios Ecosistémicos. Como primera instancia este informe (en su versión síntesis) presenta la plataforma de relaciones entre el "bienestar humano" y los "servicios ecosistémicos" (Gráfico 16) que considero, es el principal motor de la elección de este marco teórico.

Los servicios ecosistémicos (SSEE) fueron definidos como los componentes y procesos de los ecosistemas que son consumidos, disfrutados o que conducen de alguna manera directa 0 indirecta, al aumento del bienestar humano, esto teniendo en cuenta la demanda de los beneficiarios como también la dinámica de los ecosistemas (Boyd and Banzhaf 2007; Daily 1997; Quiéter et al. 2007; Quijas, Schmid, and Balvanera 2010). Este enfoque surge como la necesidad de establecer parámetros concretos a la conservación de los ecosistemas planteando explícitamente la relación entre la satisfacción de necesidades básicas de los asentamientos humanos y la presencia de estos procesos, críticos en determinados ecosistemas. Algunos de los beneficios de los SSEE son evidentes y directos como la provisión de alimentos, y por ello tienen un valor de mercado. Otros son difusos y suelen pasar inadvertidos hasta que su deterioro es evidente, como la regulación del clima o el control de inundaciones. Otros, finalmente, son intangibles y tiene que ver con los valores culturales sociales (Maceira 2015).

El informe síntesis del MEA (2005) establece que las relaciones entre el bienestar humano y los SSEE según la intensidad en que se presentan (Figura 16), determinan tres problemas principales que se reconocen en la utilización de los recursos y servicios de los ambientes:

- De los servicios ecosistémicos examinados, el 60\% (15 de 24) se están degradando o se usan de manera no sostenible, con inclusión del agua dulce, la pesca de captura, la purificación del aire y del agua, la regulación del clima regional y local, los riesgos naturales y las pestes. Muchos servicios de los ecosistemas se han degradado como consecuencia de actuaciones llevadas a cabo para aumentar el suministro de otros servicios, como los alimentos. Estas elecciones suelen desplazar costos de la degradación de un grupo de personas a otro, o trasladan los costos a las generaciones futuras.

- Los cambios que se han hecho en los ecosistemas están aumentando la probabilidad de cambios no lineales en los mismos incluidos cambios acelerados, abruptos y potencialmente irreversibles. Estos procesos de negntroía conllevan consecuencias importantes para el bienestar humano. Algunos ejemplos de estos cambios son la aparición de enfermedades, las alteraciones bruscas de la calidad del agua, la creación de "zonas muertas" en las aguas costeras, el colapso de las pesquerías y los cambios en los climas regionales. 
- La degradación de los servicios de los ecosistemas está contribuyendo al aumento de las desigualdades y disparidades entre los grupos de personas lo que, en ocasiones, es el principal factor causante de la pobreza y del conflicto social. Esto no significa que los cambios en los ecosistemas, como el aumento de la producción de alimentos, no hayan contribuido también a que muchas personas salgan de la pobreza o del hambre, pero esos cambios han perjudicado a muchos otros individuos y comunidades.

La clasificación que que realiza MEA, que identifica 24 de servicios (MEA, 2003; MEA, 2005; Maass et al 2005): i) los bienes 0 recursos naturales como el agua o los alimentos, ii) los procesos ecosistémicos que regulan las condiciones en los que los humanos habitan, como la regulación del clima o de la erosión, iii) la contribución de los ecosistemas a experiencias que benefician directa 0 indirectamente a las sociedades, como el sentido de pertenencia o la recreación, y iv) los procesos ecológicos básicos que permiten que se provean los anteriores.

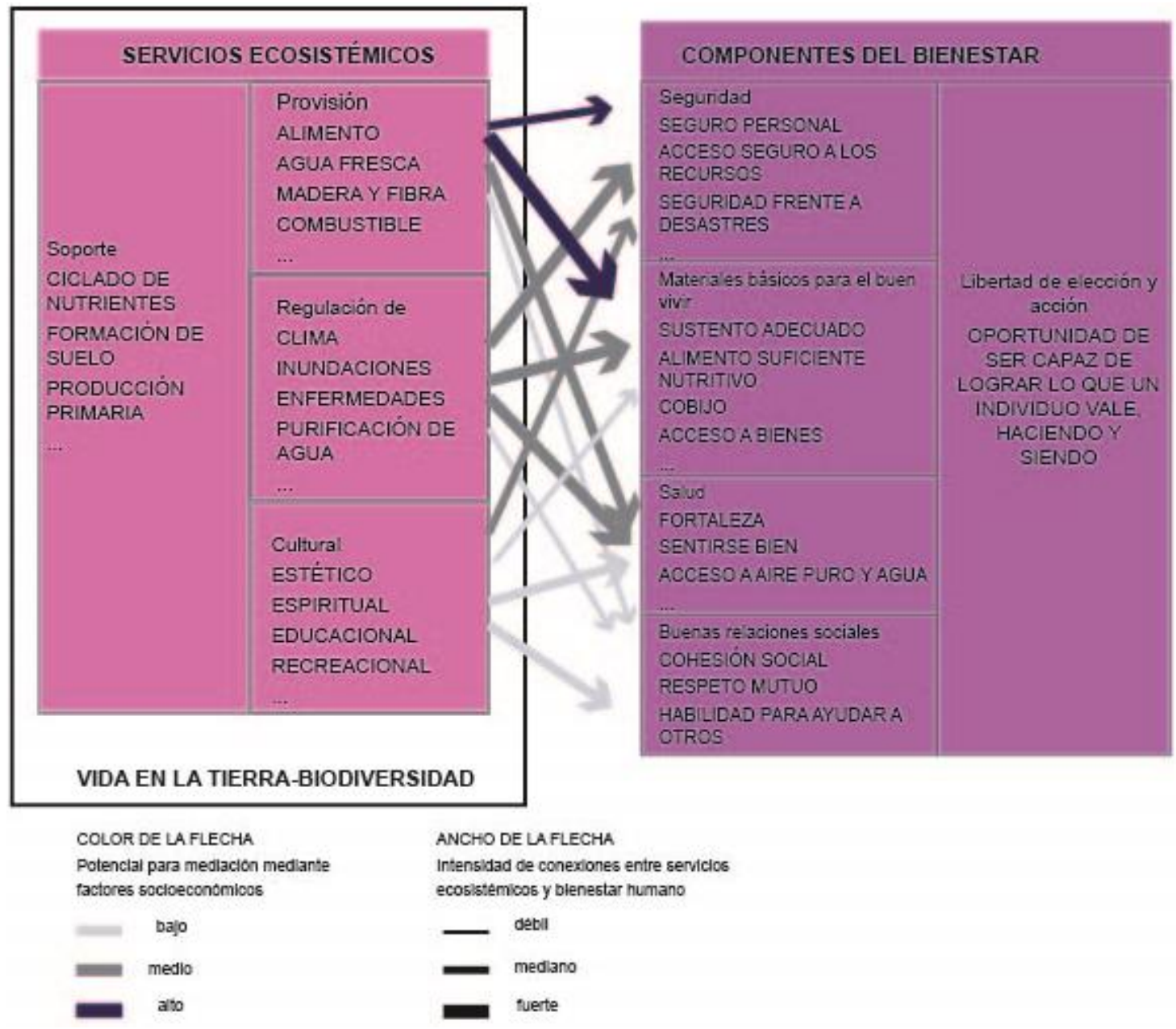

Figura 16. Contribución de los servicios ecosistémicos al bienestar humano. Fuente MEA, 2005. Traducción Céliz,2018. 
La forma en que se aunaron y profundizaron los conocimientos sobre SSEE se estableció a partir de una clasificación de estos procesos y sus vínculos con el sistema social. Aquí es donde difieren muchos enfoques que plantean la dificultad de operar sobre categorías particulares, que atienden a distintos marcos teóricos, donde cada uno establece una caracterización y clasificación particular que torna difícil los estudios comparativos 0 incluso temporales (Haines-Young and Potschin 2013).

La clasificación que realiza MEA tiene una serie de revisiones que son tomadas en el proceso de construcción crítia de este marco operativo. Haines-Young \& Potschin (2010) consideran que, en primer lugar, la "biodiversidad" per se no es un servicio, más bien aclaran que su mención referencia servicios que dependen directamente de la presencia de vida en la tierra. Como resultado, algunos comentaristas (Swallow et al. 2007, Smith 2006) piensan que puede ser útil diferenciar entre los servicios de los ecosistemas que son una consecuencia de la biodiversidad y una clase más general de "servicios ambientales", como el potencial eólico o hidráulico, que tienen una conexión más indirecta. Los flujos eólicos o hidráulicos pueden verse afectados por la presencia de organismos vivos, pero los procesos ecológicos no son los principales responsables de ellos. Otro punto señalado por los autores es que los servicios de soporte se relacionan de manera distinta con el bienestar humano ya que no benefician directamente a las personas, sino que forman parte de mecanismos y procesos complejos que generan otros servicios ${ }^{22}$.

Wallace (2007, citado en Haines-Young \& Potschin 2010), sugiere que, si la idea de servicios de los ecosistemas es utilizada en la toma de decisiones, es fundamental clasificarlos de tal forma que permita comparaciones y la evaluación de consecuencias de diferentes estrategias de gestión o políticas. La crítica a la clasificación de MEA es que se confunden los fines con los medios; es decir, el beneficio que la gente disfruta realmente y los mecanismos que dan lugar a ese servicio. Si un servicio es algo que la gente consume o experimenta, el resto forma parte de las estructuras y procesos ecológicos que dan lugar a ese beneficio. Estos mismos autores proponen una tipología de servicios (Tabla 08) asociado al nivel trófico, la unidad funcional y la escala espacial como forma de diferenciar procesos ecológicos del servicio percibido directamente.

\footnotetext{
${ }^{22}$ Banzhaf y Boyd (2005), Boyd y Banzhaf (2005-2006) y Wallace (-2007), señalan que la clasificación de MEA y la literatura de investigación más amplia, resultan extremadamente ambiguas sobre cómo distinguir entre los mecanismos por los cuales se generan los servicios (llamados por algunas "funciones del ecosistema") y los servicios mismos. Esta situación prevalece a pesar de los numerosos intentos de proporcionar tipologías sistemáticas de las funciones, bienes y servicios de los ecosistemas (Binning et al. 2001, Daily 1997, de Groot 1992, de Groot et al. 2002, MEA 2005).
} 
Tabla 8. Una tipología de servicios ecosistémicos y sus características (posterior a Kremen 2005)

\begin{tabular}{|c|c|c|c|c|}
\hline servicios & $\begin{array}{l}\text { Servicio ecosistémico } \\
\text { provisto/ Nivel trófico }\end{array}$ & Unidad funcional & $\begin{array}{l}\text { Escala } \\
\text { espacial }\end{array}$ & $\begin{array}{l}\text { Potencial para aplicar } \\
\text { este marco conceptual } \\
\text { a estudios ecológicos }\end{array}$ \\
\hline Cultural-estético & Toda la biodiversidad & $\begin{array}{l}\text { Poblaciones, } \\
\text { especies, } \\
\text { comunidades y } \\
\text { ecosistemas }\end{array}$ & Local-global & bajo \\
\hline $\begin{array}{l}\text { Bienes } \\
\text { ecosistemicos }\end{array}$ & Diversas especies & $\begin{array}{l}\text { Poblaciones, } \\
\text { especies, } \\
\text { comunidades y } \\
\text { ecosistemas }\end{array}$ & Local-global & medio \\
\hline Protección UV & $\begin{array}{l}\text { Ciclos biofeoquímicos, } \\
\text { micro-orgaismos y } \\
\text { plantas }\end{array}$ & $\begin{array}{l}\text { Ciclos } \\
\text { biogeoquímicos, } \\
\text { grupos } \\
\text { funcionales }\end{array}$ & global & bajo \\
\hline Purificación del aire & $\begin{array}{l}\text { Migro-organismos y } \\
\text { plantas }\end{array}$ & $\begin{array}{l}\text { Ciclos } \\
\text { biogeoquímicos, } \\
\text { poblaciones, } \\
\text { especies, grupos } \\
\text { funcionales }\end{array}$ & Regional-global & Medio (plantas) \\
\hline $\begin{array}{l}\text { Mitigación } \\
\text { inundaciones }\end{array}$ & Vegetación & $\begin{array}{l}\text { Comunidades, } \\
\text { hábitats }\end{array}$ & Local-regional & medio \\
\hline Mitigación de sequía & Vegetación & $\begin{array}{l}\text { Comunidades, } \\
\text { hábitats }\end{array}$ & Local-regional & medio \\
\hline Estabilidad climática & Vegetación & $\begin{array}{l}\text { Comunidades, } \\
\text { hábitats }\end{array}$ & Local-global & medio \\
\hline Polinización & $\begin{array}{l}\text { Insectos, pájaros, } \\
\text { mamíferos }\end{array}$ & $\begin{array}{l}\text { Poblaciones, } \\
\text { especies y grupos } \\
\text { funcionales }\end{array}$ & local & alto \\
\hline Control de pestes & $\begin{array}{l}\text { Invertebrados, } \\
\text { parasitoides, predadores } \\
\text { y predadores } \\
\text { vertebrados }\end{array}$ & $\begin{array}{l}\text { Poblaciones, } \\
\text { especies y grupos } \\
\text { funcionales }\end{array}$ & local & alto \\
\hline Purificación del agua & $\begin{array}{l}\text { Vegetación, micro- } \\
\text { organismos del suelo, } \\
\text { micro-organismos } \\
\text { acuáticos, invertebrados } \\
\text { acuáticos }\end{array}$ & $\begin{array}{l}\text { Poblaciones, } \\
\text { espcies, grupos } \\
\text { funcionales, } \\
\text { comunidades y } \\
\text { hábitats } \\
\end{array}$ & Local-regional & Medio a alto \\
\hline $\begin{array}{l}\text { Desintoxicación y } \\
\text { descomposición de } \\
\text { desechos }\end{array}$ & $\begin{array}{l}\text { Hojarasca, invertebrados } \\
\text { del suelo, micro- } \\
\text { organismos del suelo, } \\
\text { micro-organismos } \\
\text { acuáticos }\end{array}$ & $\begin{array}{l}\text { Poblaciones, } \\
\text { especies, grupos } \\
\text { funcionales, } \\
\text { comunidades y } \\
\text { hábitats } \\
\end{array}$ & Local-regional & medio \\
\hline $\begin{array}{l}\text { Formación y } \\
\text { fertilidad de suelos }\end{array}$ & $\begin{array}{l}\text { Hojarasca, invertebrados } \\
\text { del suelo, micro- } \\
\text { organismos del suelo, } \\
\text { plantas fijadoras de } \\
\text { nitrógeno, producción }\end{array}$ & $\begin{array}{l}\text { Poblaciones, } \\
\text { especies, grupos } \\
\text { funcionales }\end{array}$ & local & medio \\
\hline
\end{tabular}




\begin{tabular}{|l|l|l|l|l|}
\hline & $\begin{array}{l}\text { vegetal y animal de } \\
\text { productos de desecho }\end{array}$ & & \\
\hline $\begin{array}{l}\text { Dispersión de } \\
\text { semillas }\end{array}$ & $\begin{array}{l}\text { Hormigas, pájaros y yamíferos } \\
\text { mablaciones, } \\
\text { especies, grupos } \\
\text { funcionales }\end{array}$ & local & alto \\
\hline
\end{tabular}

Fuente: Haines-Young and Potschin 2010. Traducción Céliz, 2018.

El diagrama de cascada (Figura 17) plantea una distinción entre las estructuras y procesos ecológicos creados 0 generados por organismos vivos y los beneficios que las personas eventualmente derivan. Si bien la configuración real de los enlaces no es tan simple ni lineal, el modelo plantea una cascada o cadena de producción que establece un esquema de procesos. Por ejemplo:

La presencia de estructuras ecológicas como bosques y humedales en una cuenca de captación puede tener la capacidad (función) de ralentizar el paso de las aguas superficiales. Esta función puede tener el potencial de modificar la intensidad del flujo. Es algo que los humanos encuentran útil - y no una propiedad fundamental del ecosistema en sí mismo - por lo que es útil separar esta capacidad y llamarla una función. Sin embargo, el hecho de que esta función se considere como un servicio o no depende de si el "control de los flujos" se considera un beneficio. Por lo tanto, al definir cuáles son las funciones "significativas" de un ecosistema y los "productos intermedios", los "productos finales y lo que constituye un "servicio ecosistémico", la comprensión del contexto espacial (ubicación geográfica), las opciones y valores de la sociedad (sean monetarios como culturales) es igual de importante como el conocimiento de la estructura y la dinámica de los propios sistemas ecológicos".

\section{ROY HAINES-YOUNG AND MARION POTSCHIN}

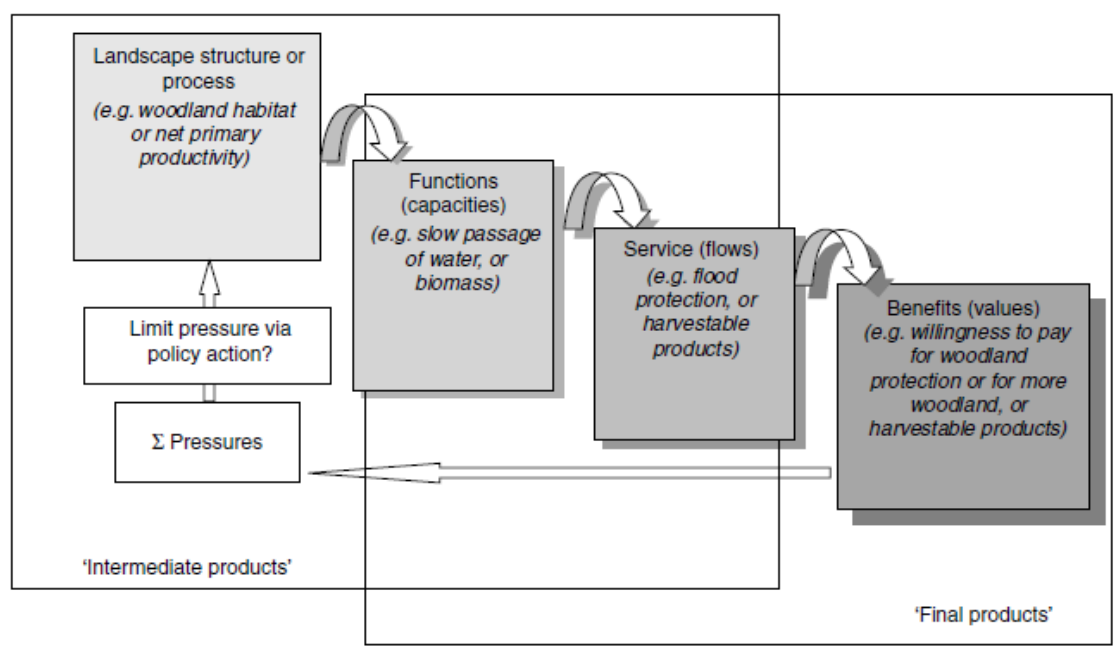

Figura 17. Modelo de cascada. Relación entre biodiversidad, funciones ecosistémicas y bienestar humano. Fuente: Haines-Young and Potschin 2010. 
En este modelo es importante entender que la palabra función indica la capacidad o capacidad del ecosistema para hacer algo potencialmente útil para las personas. Sin embargo, como señala Jax ("2005"), el término "función" puede significar una serie de otras cosas en ecología. Puede significar algo así como "capacidad", pero a menudo se utiliza más genéricamente para referirse a procesos que operan dentro de un ecosistema (como el ciclo de nutrientes 0 la depredación). Aquí la idea de las funciones como capacidades ayuda como introducción al campo de debate actual. Por otro lado, el concepto de cascada indica que los servicios no existen aislados y que es necesario identificar un beneficiario específico para definir qué es y que no es un servicio ${ }^{23}$.

A partir de la clasificación propuesta por la Evaluación de los ecosistemas del Milenio y el modelo de cascada se establecieron los principales elementos críticos para la adopción de este marco teórico orientado a la generación de la metodología que este trabajo desarrolla a través del caso de estudio. De esta manera, el concepto de SSEE además de considerar los beneficios que la sociedad recibe de los ecosistemas, propone el análisis de las complejas interacciones tanto positivas como negativas entre servicios y la sociedad (MEA 2003; Maass et al., 2005; Rodríguez et al., 2006; Quétier et al., 2007; citado en Laterra et al., 2010) y el orden procesual que relaciona estos beneficios percibidos con los procesos ecológicos esenciales. De la misma manera en que se plantea la relevancia de estas interacciones es preciso enfatizar la necesidad de mantener los ecosistemas y su biodiversidad no en términos exclusivos de utilidad directa para las sociedades, sino que los ecosistemas en su conjunto y su estado definen condiciones en el planeta que exceden a las sociedades como beneficiarias exclusivas.

A partir de esta lectura crítica, se propone la operativización de los SSEE de un área específica a través de una matriz que toma la clasificación MEA (2005), y para la cual se seleccionan las funciones esenciales basadas en el modelo de cascada (Haines-Young and Potschin 2010) que permite identificar las relaciones principales y la afectación de los asentamientos humanos.

\footnotetext{
${ }^{23}$ Banzhaf y Boyd (2005) sugieren que las tipologías de servicios son difíciles de construir ya que la identificación de lo que es un servicio de los ecosistemas depende del contexto porque son "continuos" en "actividades o deseos humanos particulares" (Haines-Young and Potschin 2010)
} 


\section{Reflexiones I}

La revisión histórica del proceso de urbanización de las ciudades occidentales implica establecer en primer lugar, la relación entre la explotación de los recursos naturales para la producción de alimentos 0 el uso rural del territorio y la consolidación de la idea de ciudad. Esta relación abre la discusión en el primer apartado, poniendo atención a los dos usos históricos del territorio habitado: el campo y la ciudad, y como ambos se justifican mutuamente. Para Soja en su afirmación "las ciudades primero", fue el asentamiento de la población en proto-ciudades lo que genero el espacio de producción de alimentos. Esta relación embrionaria de flujos, entre dos tipos de usos aparentemente opuestos del territorio, pone de relieve la complejidad de un sistema que es la expresión territorial de los asentamientos humanos.

Durante el período denominado como "de las revoluciones urbanas", el sistema urbano -y las demandas económicas, políticas y sociales- pone el énfasis en la reproducción del suelo urbano como expresión de la adaptación de los asentamientos humanos a los procesos de crecimiento poblacional y la sectorización social con la consiguiente fragmentación durante las etapas fordista y posfordista. La afirmación de los autores de que transitamos la cuarta revolución urbana se basa en que estas dinámicas se intensificaron en tiempo y espacio, no sólo a partir de expansión horizontal sino también, por especialización y globalización de las relaciones entre centros urbanos mundiales.

Algunos de los autores que han observado los procesos de expansión urbana, plantearon que uno de los impulsores de cambio de las ciudades, estaba definido por la segregación espacial de las funciones de la vida cotidiana, que en las ciudades latinoamericanas implicó una segregación social explícita. Esto llevó a una homogeneización dispersa, que tiene en la vereda opuesta a la diversidad concentrada en una superficie compacta que logre disminuir trayectos de circulación y por ende consumo energético.

La mayoría de estas reflexiones entre modelos urbanos fueron hechas observando la ciudad europea. En este punto del relato se explicitan las diferencias tanto en los procesos de configuración como de expansión con la ciudad latinoamericana. En la mayoría de los casos esta ciudad ha tenido una fuerte imposición en su configuración durante el período de "fundación", lo que ha determinado gran parte de la relación de las sociedades latinoamericanas con su territorio, condicionadas por un modelo urbano que espacializa las actividades planteadas al momento de su configuración morfológica colonial. Es decir que, los patrones básicos de la ciudad latinoamericana se definieron a partir de una estructura urbana colonial que planteaba el gradiente centro-periferia que comienza a complejizarse a partir de un centro histórico. Eso se expresa en la superposición de una trama de división sectorial funcional, a partir de puntos de tensión reconocibles como los barrios de sectores altos, sectores industriales emergentes y sectores de trabajadores o bajos ingresos, unidos por autopistas al centro urbano. Esto 
se intensifica en la expansión celular característica de los barrios periurbanos a partir de planes de viviendas, asentamientos precarios y barrios cerrados.

Si bien esta dinámica es reconocible en las principales ciudades latinoamericanas, ha sido el resultado de la globalización del suburbio estadounidense a partir de urbanizaciones privadas en segundas y terceras periferias. La diferencia más notoria, como se ha mencionado, es que dadas las diferencias socio-económicas previas de la ciudad latinoamericana, la expansión del modelo Los Ángeles ha contribuido a profundizarlas. En este contexto y como se ha visto en el apartado de los enfoques de ordenamiento territorial, existen dos dinámicas complementarias que posibilitan la segregación territorial. Por un lado, el actor privado en la decisión de la transformación de los usos del suelo y por otro, la planificación por detrás de los hechos consumados.

Dado que los instrumentos que ordenan el territorio son producto no de la previsión sino de las acciones ya realizadas en materia de usos del suelo y estructura urbana sobretodo, cabe preguntarse cuál es el lugar de la naturaleza y los procesos ambientales bajo este accionar tardío. En países europeos, al menos hasta la década del 90' los enfoques de 0T-sistemas naturales han sido nulos, sin embargo, la figura del paisaje y de la gestión del paisaje como instrumento ha sido la brecha mediante la cual se consiguieron figuras proteccionistas de estos sistemas más naturales, como es el caso de Alemania e Italia. Otro punto importante es que la mirada de lo rural ha sido asociada al territorio de características antrópicas o de provisión de materias primas y alimentos, lo que lo ha dejado fuera áreas de protección la mayoría de las veces. En los casos que existe un ordenamiento territorial rural, generalmente no presentan una articulación con los planes y programas urbanos.

Otra de las diferencias que es necesario remarcar es de tipo conceptual y se ha mencionado en los enfoques de la planificación. Por un lado, la idea de OT tiene un origen europeo y refiere a los procesos territoriales normativos, organizativos y de regulación de usos del suelo. Esta idea de $0 \mathrm{~T}$ tiene que ver con ordenar lo que ya existe e incluye una limitación a ocupar áreas nuevas o creación de suelo urbano. Por otro lado, la planificación está más asociada al enfoque estadounidense y latinoamericano e implica establecer pautas para una futura ocupación del espacio, por lo que la creación de suelo urbano es una posibilidad.

La pregunta es, si los actores económicos toman decisiones de gran impacto para las ciudades y sus áreas de influencia, y la planificación urbana solo define pautas que parecieran recomendaciones, donde no existen instrumentos que limiten 0 establezcan umbrales en la expansión urbana, ¿cuáles son los lineamientos concretos que permitirían establecer estos límites a partir de considerar procesos ecológicos del territorio? 
A su vez, ¿qué factores de la urbanización pueden tomarse como indicadores del impacto de avance urbano sobre los ecosistemas? ¿Son indicadores posibles de estimar la pérdida de la capacidad de producir alimentos, materias primas, la regulación del clima o las inundaciones?

Como se ha desarrollado previamente, los marcos teóricos iniciales en la aproximación a instrumentos de OT biofísico son: los límites del crecimiento, el concepto de huella ecológica y el último informe del IPCC sobre el cambio climático y las capacidades de resiliencia de los territorios, particularmente en las ciudades latinoamericanas. Si se observan cronológicamente estos antecedentes, los datos cuantificables de la afectación de ecosistemas son cada vez más precisos. Esto no es menor, dado que indica que no sólo los especialistas han avanzado en esta cuantificación según cada disciplina, sino también que, la disponibilidad de modelos y mecanismos para alcanzar diferentes niveles de cuantificación también aumenta.

Dado que la mayoría de los instrumentos tanto para ordenar como para planificar el territorio responder al espacio urbano 0 al espacio rural y en el mejor de los casos, se cuenta con planes de manejo de áreas protegidas o el espacio natural, es preciso identificar y conocer la dinámica de los espacios de mayor intensidad de interacción entre áreas urbanas y rural o naturales: la interfase. Dado que esta interfase depende de las fases en interacción, sean estas urbano-rural o urbano-natural como mínimo, y en qué contexto se ha llevado a cabo la producción del suelo urbano, entro otros factores; conocer las características básicas de cada proceso de interfase, es fundamental.

Si consideramos que existió tempranamente una relación entre los procesos de intercambio de flujos entre sistemas urbanos y los sistemas naturales primero y rurales como un estadio de antropización posterior, resulta ineludible el estudio de los intercambios que se producen. No puede la planificación en este contexto, generar fricciones entre los instrumentos que ordenan un territorio rural, las normativas para el área natural y, por otro lado, más lejano aún, la ordenación del territorio urbano como una línea que se corre constantemente y avanza sobre otros usos.

De los autores revisados para identificar configuraciones de interfase, se señalan elementos síntesis que serán abordados para el caso de estudio: el esquema de área buffer en torno a la ciudad como principal elemento espacial, espacio que presenta dinámicas en tensión en relación a la disminución del valor del suelo urbano y la presencia de suelo rural que disminuye su rentabilidad en tanto más cerca de la ciudad se encuentra. Este espacio presenta indudables alteraciones físicas, económicas y sociales al corto plazo, lo que inhabilita la mayoría de las delimitaciones previas. Si bien la mayoría de los procesos de interfase identificados son aquellos donde el uso del suelo urbano avanza sobre el rural, existen otros relativos a áreas naturales. Estos procesos de antropización de áreas naturales presentan antecedentes sobre todo en zonas turísticas y de segunda residencia. Estas dinámicas, 
además están asociadas al aumento de vulnerabilidad para los asentamientos humanos y riesgo de incendios, inundaciones, etc.

Teniendo en cuenta el proceso histórico de incorporación de los conceptos de naturaleza y posteriormente de biodiversidad en la valorización económica de la dinámica territorial y dada la necesidad de incorporar esta variable en la ordenación del territorio es de gran importancia la existencia de instrumentos de valorización ecosistémica. Entonces,

\section{¿Es posible cuantificar los procesos ecosistémicos afectados a partir del proceso de antropización en estas áreas naturales?}

En principio, es imposible negar que los seres humanos al tomar decisiones respecto al hábitat estamos valorando diversos ecosistemas y sus procesos, directa o indirectamente. Esto refuerza la idea de que cuánto más específicos sean los datos biofísicos que podamos construir, más allá de un enfoque más o menos oportunista, la toma de decisiones estará inmersa en un contexto de estimaciones precisas en torno al valor funcional de los ecosistemas. En esta línea el concepto de servicios ecosistémicos es elegido en esta tesis como una aproximación por su potencial metodológico, aportando una idea de flujos entre sistemas ecológicos y sociales. El fin radica en aprovechar la simplificación de este enfoque para ser incorporada en la dimensión ambiental tradicional, en el diseño de instrumentos para la toma de decisiones en torno al uso del suelo. Es importante señalar que la cuantificación no es un fin en sí mismo, sino que propone un debate sobre la información que existe sobre los procesos biofísicos a la hora de planificar el territorio.

El desafío está planteado desde la inquietud teórica que acompaña este proceso de investigación y que, reside en el enfoque complejo de estos procesos. Por un lado, pensar qué insumos teóricos alimentan la búsqueda de parámetros ecosistémicos a ser observados en el proceso de avance urbano y por el otro, el desafío de la construcción metodológica que defina herramientas superadoras a las del OT tradicional que puedan incorporar valores ecosistémicos medibles en el proceso de cuantificar afectaciones o pérdidas en el intercambio de procesos y funciones ecosistémicas. 


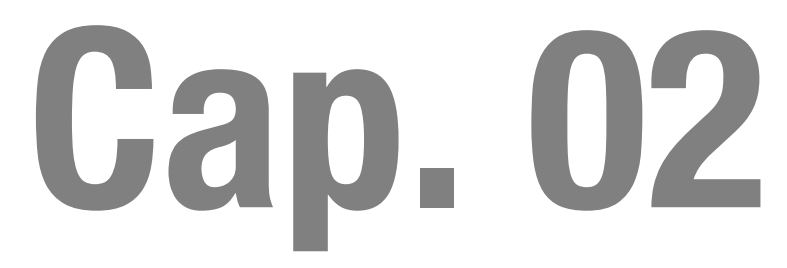

Aproximaciones metodológicas 


\section{Definición de la interfase metodológica}

Como se ha desarrollado en el marco teórico, esta investigación parte de una búsqueda interdisciplinaria por lo que la construcción metodológica es fundamental. Esto implica como primera aproximación una propuesta de articulación metodológica entre marcos metodológicos 0 antecedentes. Se plantean herramientas propuestas por otros autores como punto de partida y forma de aproximación al objeto de estudio desde la base de la lectura compleja. Esto no significa que el abordaje que se realiza constituya una mirada integral o completa, sino que el recorte que se realiza está basado en varias líneas de investigación metodológicas precedentes.

\section{La lectura de la complejidad y un abordaje posible}

Giobellina (2011) propone una herramienta conceptual que integra la complejidad desde el enfoque tradicional del desarrollo sustentable (Figura 18). De esta manera no se limita a entender la relación entre las dimensiones que configuran el concepto de sustentable, sino que relaciona estos aspectos desde la lectura compleja. El análisis interpela a la lógica cartesiana y coloca en el centro del pensamiento sostenible a la persona y la necesidad de un contexto frente al cuál debe observarse el fenómeno a estudiar.

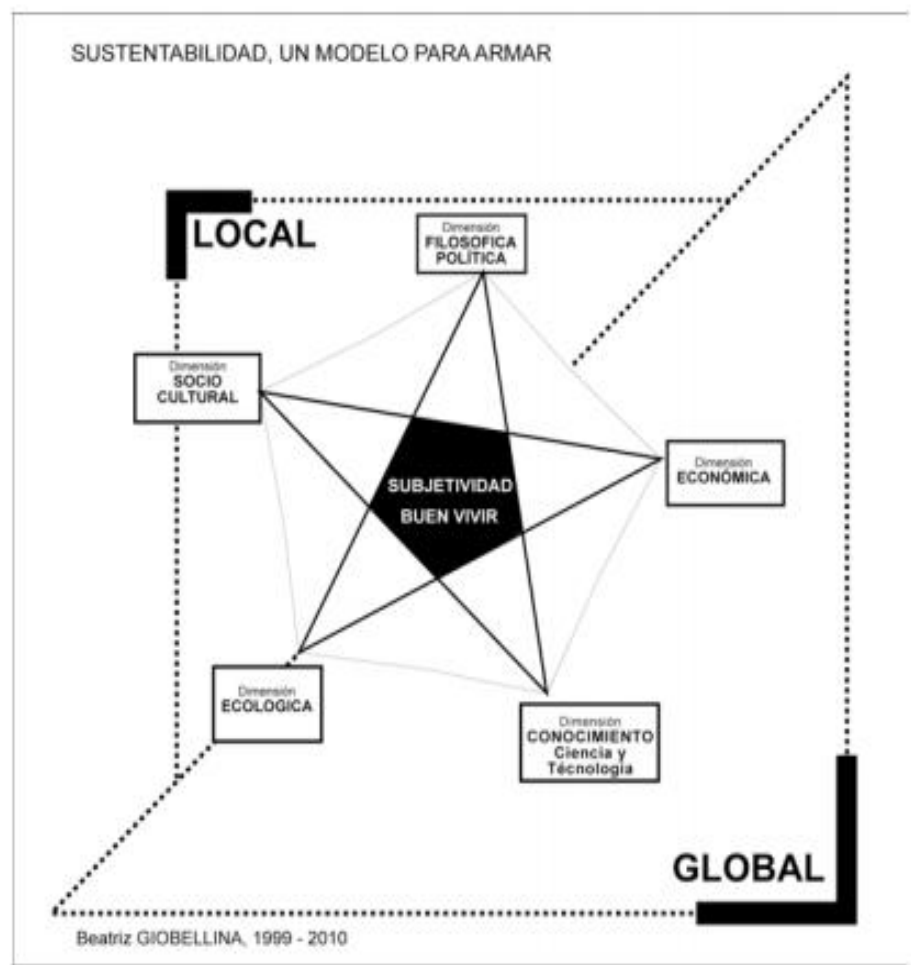

Figura 18. Sustentabilidad un modelo para armar. Fuente: Giobellina, 2011 
Este enfoque para leer la complejidad implica la necesidad de la lectura inter-escalar y extra-escalar. Es decir, el cambio de escala no sólo contextualiza al sistema, sino que le permite identificar como dice la teoría de los sistemas las relaciones relevantes que lo definirán como tal y a partir de las cuáles es preciso indagar en su estudio fenomenológico. En este modelo para armar de la sustentabilidad, Giobellina (2011) plantea que las escalas posibles van desde la microbiológica hasta la astro-biofísica, entendido que los intercambios entre el sistema y su entorno incluyen factores que es necesario tener en cuenta pero que no todos son abordables en el momento de enfrentar al caso de estudio.

De esta manera la aproximación al objeto de estudio se definió por el recorte de la meso-cuenca como escala de trabajo y sistema analizado. Dentro de la macro-cuenca del río Primero, y en el nor-noroeste del área metropolitana de Córdoba se definió la cuenca del río Saldán-Ceballos como caso de estudio y escala de abordaje principal. Las relaciones de tipo antrópicas se definen a partir del análisis del proceso de urbanización-expansión urbana del área y las dinámicas socio-económicas que las definen. Los elementos naturales serán definidos principalmente por los procesos hidrológicos en la transición de cambios de usos del suelo en los últimos 30 años (4ta. Revolución urbana). La estructura analizada está definida por el modelo territorial y el análisis del modelo actual o existente y la incorporación de factores biofísicos al modelo territorial.

\section{La gestión del paisaje en la interfase disciplinar}

Si bien se han definido los principales enfoques que han contribuido al ordenamiento y planificación del territorio y a partir de estos enfoques, los instrumentos clásicos de que se ha valido la disciplina, es preciso establecer un antecedente metodológico próximo a la interfase. La gestión ambiental del paisaje no tiene el suficiente prestigio o desarrollo en américa latina 0 argentina que pueda endilgarle la capacidad de ofrecer herramientas de aplicación concretas capaces de definir ambientalmente el uso del territorio. Sin embargo, las aproximaciones que han permitido a este trabajo de investigación integrar conceptos transdiciplinarios tienen sólidas bases en este enfoque de la gestión. El convenio europeo del paisaje en su artículo 1 del capítulo 1 ,

"por gestión de los paisajes se entenderán las acciones encaminadas, desde una perspectiva de desarrollo sostenible, a garantizar el mantenimiento regular de un paisaje, con el fin de guiar y armonizar las transformaciones inducidas por Ios procesos sociales, económicos y medioambientales." (CEP,2000 [traducción Busquets and Cortina 2009])

En primera instancia se entenderá al paisaje como cualquier parte del territorio tal como la percibe la población, cuyo carácter sea el resultado de la acción y la interacción de factores naturales y/o humanos., durante mucho tiempo el concepto de gestión ha ocupado un lugar secundario a otros conceptos asociados al paisaje (análisis, diseño, protección, ordenación proyectación...). Sin embargo, la acelerada transformación del paisaje y la 
generalización de los procesos de transformación ha alcanzado casi la totalidad de las regiones y de medios geográficos.

Considerar al paisaje como una variable -cuando no escala-, útil en la ordenación del territorio y el urbanismo contemporáneo, a un nivel cada vez más cercano a otras variables que tradicionalmente han formado parte de estas disciplinas, lo involucra a varias lógicas a la vez como articulador teórico-espacial, incluso contenedor de varios de estos campos disciplinares. En definitiva, la gestión del paisaje se presenta como una modalidad de intervención en-el-paisaje y un conjunto de técnicas que, teniendo en cuenta la concurrencia de diversas aportaciones disciplinares, pone a disposición de la sociedad un método de trabajo que promueve la valorización del paisaje, el desarrollo sostenible y la calidad de vida de las personas (Busquets et al.,2009).

Cabe destacar que la importancia de este antecedente metodológico radica en la certeza de que el diagnóstico territorial tiene bases transdisciplinares y que, además de las propuestas teóricas aquí desarrolladas el enfoque de paisaje constituye una alternativa superadora de la fragmentación jurídico-administrativa de los territorios y el enfoque tradicional.
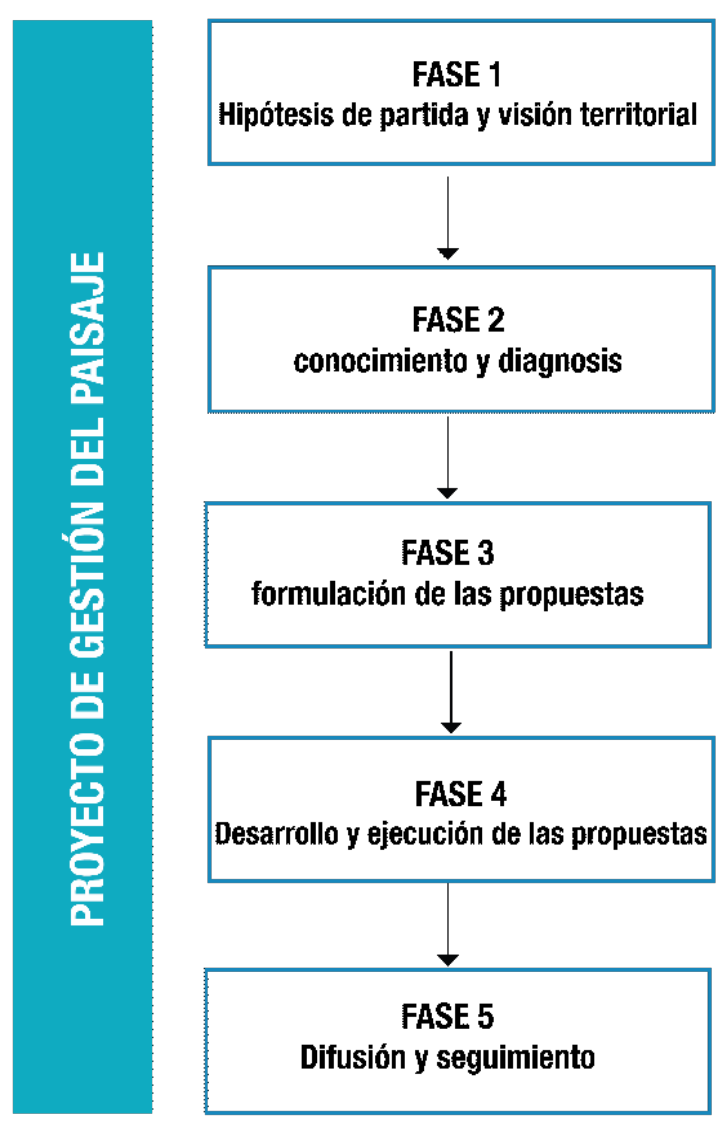

Figura 19. Etapas de proyecto de gestión del paisaje. Fuente: Busquets et al.,2009. Redibujo Céliz, 2018 


\section{Determinación crítica de funciones y servicios ecosistémicos}

Este marco metodológico es fundamental en la construcción de los datos que realiza este trabajo. Parte del marco teórico fundamental de servicios ecosistémicos para cuantificar procesos biofísicos territoriales. Es así que ha transitado diferentes procesos críticos de formulación y re-formulación por parte de varios autores.

La comprensión de este marco particular de funciones ecosistémicas tiene dos instancias. Primero la simplificación o discriminación de procesos a partir de identificar funciones y servicios a partir del modelo de cascada (Gráfico 20) de Haines-Young y Potschin (2010).

El modelo de cascada (Figura 20) plantea un proceso de desarrollo secuencial concebido como un conjunto de etapas que se ejecutan una tras otra. El flujo de ejecución a diferencia de un modelo tradicional de cascada es de abajo hacia arriba. El objetivo es identificar aquellas funciones ecosistémicas capaces de ser aisladas en términos de análisis y que su estado, aumento o detrimento influyan decididamente en el aumento de la vulnerabilidad socioecosistémica y puedan ser trasladables a un diagnóstico de ordenamiento territorial.

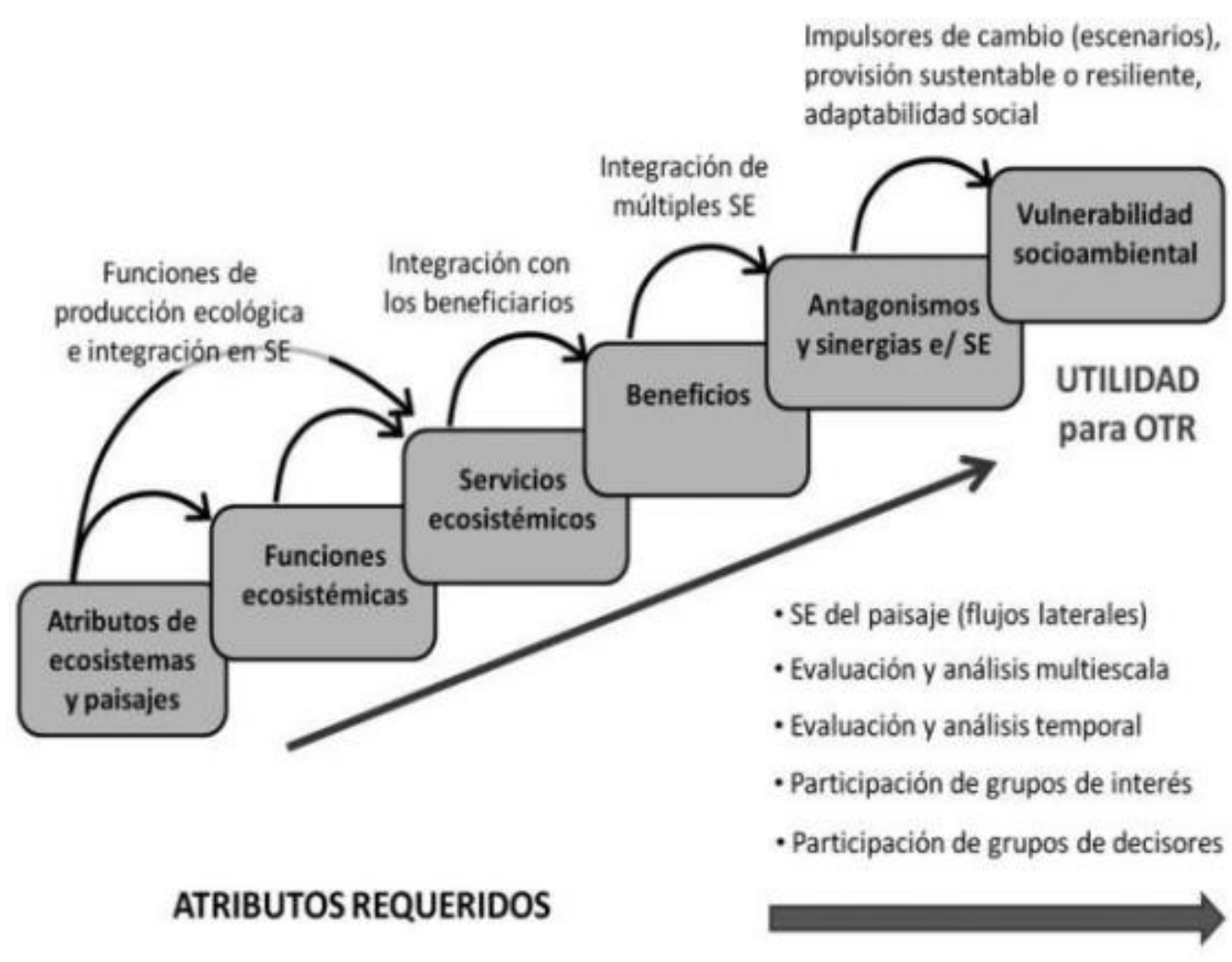

Figura 20. Escalera ascendente de integración de procedimientos de evaluación y mapeo de SE y su capacidad para orientar la toma de decisiones en el contexto del 0T. Fuente: (Laterra et al. 2015), modificado de Heines-Young y Potschin, 2010 y Laterra y Nahuelhual, 2014. 
Obtener estos indicadores de servicios ecosistémicos posibilita entender e identificar aquellas funciones que los ecosistemas realizan para mantener ciertas condiciones que hacen posible el hábitat de los asentamientos humanos y las condiciones de criticidad, escenarios, modelos y tasas de cambio de estas funciones en los sistemas naturales-antrópicos. Aquellas funciones o servicios que no puedan ser concebidos a partir del modelo de cascada no serán descartados en un proceso de análisis, hecho que resultaría en extremo arbitrario. Sin embargo, este modelo permite una interacción clara entre las funciones y la afectación de los asentamientos humanos en un contexto socio-ecológico por lo que es un antecedente fundamental a la hora de identificar patrones biofísicos de diagnóstico, evaluación y valoración ecosistémica.

La contribución que los ecosistemas realizan al bienestar humano puede ser medibles en tanto y en cuanto ciertas funciones que construyen una determinada forma de contribución puedan ser incorporadas al diagnóstico territorial. Haines-Young y Potschin (2010), plantean una serie de indicadores para simplificar esta información de tal manera que pueda ser comunicada y entendida. A partir de allí, los planificadores pueden basar sus decisiones en evidencia concreta, identificar y priorizar intervenciones, monitorear el progreso de objetivos, e informar acciones de corrección de manera oportuna (Nahuelhual et al., 2016). El otro aporte fundamental de este antecedente metodológico son estos indicadores, para la construcción de una matriz de análisis para el caso de estudio, a realizarse posterior a la identificación de las funciones más importantes. Esta matriz fue construida para esta tesis a los efectos de operativizar el concepto de servicios ecosistémicos, parrtiendo del análisis del modelo de cascada y los indicadores propuestos por estos autores.

\section{(Una) matriz de funciones ecosistémicas}

A los efectos de operativizar el concepto funciones y servicios ecosistémicas se construye una matriz de doble entrada que permita identificar los patrones más relevantes de estos indicadores críticos del ecosistema serrano. Para la construcción de esta matriz se utilizó como base la clasificación de Haynes Young and Potschin (2010) sobre tipología de servicios ecosistémicos y sus características ecológicas (posterior a Kremen 2005). A partir de las relaciones entre biodiversidad, funciones ecosistémicas y el bienestar humano se constituye la base a partir del formato cascada (Haynes Young \& Potschin,2010), que permitirá identificar las relaciones que producirán la afectación de los servicios ecosistémicos según las funciones principales y su influencia en los procesos que permiten el bienestar humano. 
En el modelo de cascada, es importante tener en cuenta la utilización de la palabra función para indicar cierta capacidad o capacidad del ecosistema para hacer algo que sea potencialmente de utilidad para los asentamientos humanos. Esta es la forma en que autores como de Groot et al. (2002) y otros (Costanza et al. 1997, Daily 1997) la utilizan en su definición y organización de sistemas. Wallace (2007) por ejemplo, utiliza este término para referir a procesos que operan dentro del ecosistema como el ciclado de nutrientes o depredación. Para Laterra et. al (2015) en el manual de Eco-ser determinan a las funciones -que serán inputs de este modelo-, como capacidades que serán identificables para alimentar el modelo en la construcción de servicios ecosistémicos que pueden ser espacializados.

Entendemos que en términos biofísicos hay funciones que no pueden ser aisladas de otras para ser concebidas como tal y que, haciendo esta salvedad, hay procesos que no serán analizados bajo la simplificación de un modelo pero que al menos a los efectos de determinar áreas críticas son de gran utilidad. Banzhaf y Boyd (2005, p. 12 en Laterra et al.,2015) sugieren que las tipologías de servicios son difíciles de construir. Identificar un servicio ecosistémico dependerá del contexto, dado que son contingentes, sobre actividades o deseos humanos particulares.

Por otro lado, los criterios para el filtro de servicios ecosistémicos como tal fueron tomados de la clasificación de la Evaluación de los ecosistemas del milenio (MEA;2005) ya que en tanto simplificación significa una forma clara de evidenciar desde que procesos estos servicios son considerados.

Se definen así los cuatro grupos principales de clasificación: i) servicios ecosistémicos de provisión, ii) servicios ecosistémicos de regulación, iii) servicios ecosistémicos culturales y se incorpora iv) servicios ecosistémicos de soporte que si bien no fue desarrollado en esta matriz es fundamental incorporar la noción de que el suelo en tanto componente fundamental lleva adelante procesos químicos y físicos que permiten el desarrollo de los asentamientos humanos previamente a los distintos niveles de antropización que de aquí se desprendan.

La valoración de las funciones ecosistémicas en la matriz propuesta plantean dos metodologías de ponderación: por un lado, la realización de talleres con diferentes actores a los efectos de validar la herramienta y establecer el impacto de las funciones ecosistémicas a partir de diferentes actores. Dado que esta propuesta excede a los objetivos de esta tesis se realizó a partir de información secundaria dada la basta bibliografía existente sobre el caso de estudio, particularmente posterior a las últimas inundaciones de febrero de 2015. Se propone luego de finalizado este trabajo la puesta en común con actores del territorio los resultados obtenidos a modo de validación de las funciones resultantes. La valoración propuesta refiere al impacto de las funciones seleccionadas a partir de cuartiles que van desde 0 a 1, donde 1 es la valoración más alta, y 0 la más baja. 
Tabla 9. Criterios para la selección de servicios ecosistémicos

\begin{tabular}{|c|c|c|c|c|c|c|c|c|c|c|c|}
\hline \multicolumn{12}{|c|}{ Criterios para la selección de servicios ecosistémicos } \\
\hline 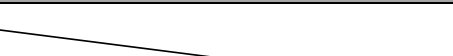 & \multicolumn{3}{|c|}{ SE de provisión } & \multicolumn{3}{|c|}{ SE de regulación } & \multicolumn{2}{|c|}{ SE soporte } & \multicolumn{3}{|c|}{ SE culturales } \\
\hline 1.Valoración ecológica del SE & $\mathbf{F 1}$ & $\mathbf{F 2}$ & F3 & F1 & $\mathbf{F 2}$ & F3 & $\mathbf{F 1}$ & F2 & F1 & F2 & F3 \\
\hline $\begin{array}{l}\text { 2.Intensidad del vínculo entre el SE } \\
\text { y el bienestar humano }\end{array}$ & & & & & & & & & & & \\
\hline $\begin{array}{l}\text { 3.Potencial para que el vínculo } \\
\text { entre el SE y distintos componentes } \\
\text { del bienestar humano sean } \\
\text { mediados por factores socio- } \\
\text { económicos }\end{array}$ & & & & & & & & & & & \\
\hline $\begin{array}{l}\text { 4.Importancia para comunidades } \\
\text { locales humanas }\end{array}$ & & & & & & & & & & & \\
\hline 5.Disponibilidad de datos aproiados & & & & & & & & & & & \\
\hline 6.Exposición al cambio climático & & & & & & & & & & & \\
\hline 7.Sensibilidad al cambio climático & & & & & & & & & & & \\
\hline $\begin{array}{l}\text { 8.Exposición al cambio de usos de } \\
\text { suelo }\end{array}$ & & & & & & & & & & & \\
\hline $\begin{array}{l}\text { 9.Congruencia con el modelo de } \\
\text { cascada }\end{array}$ & & & & & & & & & & & \\
\hline
\end{tabular}

Fuente: Céliz,2018 en base a MEA, 2005 y Haynes Young \& Potschin,2010.

\section{Diseño metodológico de esta tesis}

Esta tesis se define como una investigación explicativa, de enfoque cuantitativo. El desarrollo está determinado principalmente por la utilización de sistemas de información geográfica y teledetección. Se compone de tres grandes etapas que combinan técnicas y materiales para cumplimentar con los objetivos propuestos.

\section{Definición de una matriz de funciones ecosistémicas}

Operativización del concepto de servicios ecosistémicos a partir de la construcción de una matriz de doble entrada en base a MEA (2005) y Haines Young et Postchin (2010).

Base Eco-ser. (INTA-CONICET). 
A partir del estado del arte se produce una sistematización de la información sobre normativa y planificación territorial a partir de los siguientes criterios:

-Documentos producidos y publicados por organismos de aplicación de normativa territorial que involucran al área de estudio

-Normativa: leyes y ordenanzas espacializadas

-Estudios, informes y artículos publicados sobre dinámicas de transformación territorial del área de trabajo.

\section{Definición de áreas de ocupación urbana efectiva o superficie impermeabilizada}

Definición de manzanas para muestreo a partir de porcentaje de área construida por manzana. Tipificación de manzanas asociadas a tipo de barrio y ubicación

Poligonización del área a partir de fotointerpretación de imágenes de alta resolución de Google Earth Pro para el año 1987 y 2017.

Análisis de aumento de área efectivamente ocupara o impermeabilizada para la cuenca.

Definición del mapa de área urbanizada para aplicar a modelo/s de funciones ecosistémicas para la cuenca.

\section{Evaluación de funciones ecosistémicas críticas}

Aplicación del protocolo Eco-ser para valoración y evaluación de funciones ecosistémicas a partir de un modelo biofísico.

Incorporación de la variable urbana en la determinación de áreas de valor ecosistémicos de interfase urbanonatural.

Definición del modelo territorial integrado.

\section{Modelo territorial integrado y prospectiva}

Se incorporó al modelo territorial tradicional la variable de áreas de retención de excesos de precipitación por cobertura vegetal.

Identificación de áreas de interfase urbano-natural de avance urbano.

Generación de escenarios de pérdida de áreas de retención de excesos de precipitación por cobertura vegetal. 


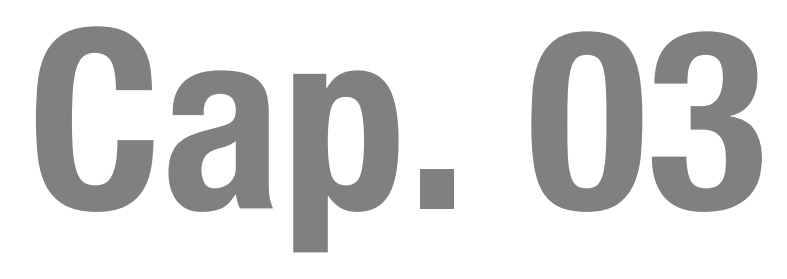

Córdoba al pie del monte (el) caso de estudio 


\section{Córdoba: Crecimiento urbano e impulsores de cambio}

La ciudad de Córdoba se ubica en el centro geográfico de Argentina, situación que le confiere una ubicación estratégica dentro del país. Es la segunda ciudad de importancia, después de Buenos Aires, en términos de población, desarrollo económico, industria y educación. A su vez, la ubicación de Córdoba, respecto a otras ciudades portuarias como Buenos Aires (Argentina) y Valparaíso (Chile) la ubican en una zona de paso y de gran valor de flujos. Esta misma ubicación estratégica la vincula con las regiones metropolitanas de Buenos Aires (hacia el este) y Santiago de Chile (al oeste) (Figura 21). La ruta panamericana vincula la configuración estelar de las ciudades de América del Sur -de origen colonial-, dándole una localización geoestratégica en el corredor bioceánico Mercosur. Estas relaciones dan cuenta del rol singular de esta ciudad mediterránea.

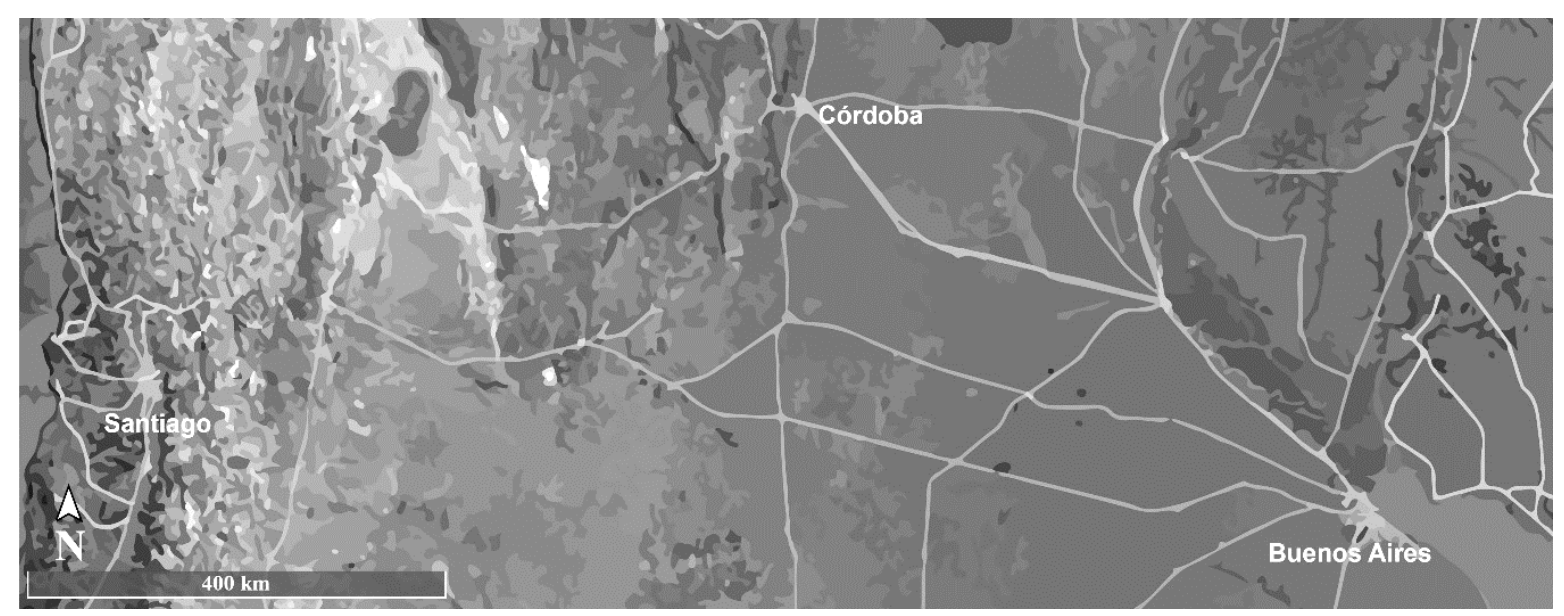

Figura 21. Ubicación de Córdoba respecto a regiones metropolitanas en el corredor bioceánico Mercosur. Fuente: vectorización sobre mapa base Google Earth Y. Céliz, 2017.

La superficie de esta ciudad capital es de 576 km2 (Giunta 2014). El ejido municipal lo constituye un cuadrado de 24 kilómetros de lado. Del total de la superficie que abarca el municipio, el 27,50\% -según la Dirección Municipal de Catastro- constituye área rural dominante, por lo que hablamos de un municipio en su mayoría urbano 0 con características rurales. En términos naturales, el paisaje se distribuye entre la llanura pampeana y sistemas de pequeñas serranías que sobre su área metropolitana se extienden sobre todo en el sector norte y noroeste donde se ubica el Sistema Serrano Noroeste o Sierras Chicas con mayor proximidad a la ciudad capital.

La ciudad es atravesada por el río Suquía de oeste a este, el arroyo la Cañada y el Infiernillo. Hasta el último censo (2010) la población era de 1.329.604 habitantes. La región metropolitana de Córdoba, se encuentra dentro de una zona semiárida y se abastece de tres cuencas pluviales, la del dique San Roque, la de Los Molinos y la de La 
Quebrada. Tanto la disponibilidad de agua para consumo humano y riego como el control de las crecientes que inundaban la ciudad constituyeron preocupaciones de los gobernantes de principios del siglo XX, tales preocupaciones derivaron en la construcción del dique San Roque.

\section{Los principales ejes de la configuración territorial}

Como he desarrollado en el marco teórico (MT) de este trabajo, los últimos treinta años han sido de gran relevancia en el estudio de las dinámicas de crecimiento de áreas urbanizadas en ciudades latinoamericanas. Las interacciones que se producen en la interfases urbano-rurales, urbano-naturales y urbano-industriales, de Córdoba, ponen de manifiesto la complejidad territorial de la expansión urbana. Para este proceso Irós et al. $(2012,2014)$, utilizan el concepto de ciudad región (Geddes, 2014 en Irós et al., 2014), para referir al área metropolitana de Córdoba -AMC en adelante-.

El AMC está configurada por dos procesos antrópicos que conviven y caracterizan las dinámicas del sector. Por un lado, el de metropolización propiamente dicho ya que una ciudad "madre" ejerce una significativa gravitación sobre otras menores. El otro proceso es el de conurbación que se expresa en el área noroeste de la ciudad, en las localidades serranas denominadas Sierras Chicas -SSCC-. En este proceso, Córdoba como ciudad gravitante establece una interacción con un conjunto de pueblos y ciudades de diferente tamaño (Irós et al., 2014). Estas ciudades se relacionan en contacto directo con la capital. Otras conurbaciones como las del valle de Punilla no se relacionan de manera directa, aunque también existe una fuerte dependencia.

Desde el IPLAM (2012), se establece una diferencia entre los términos "área" y "región" metropolitana de Córdoba. El concepto de área metropolitana implica a las ciudades que conforman un continuo urbano con la ciudad principal y, región metropolitana, remitirá al espacio geográfico mayor que contiene a otras ciudades, algunas dispersas en esta geografía, pero que en conjunto constituyen un sistema de ciudades (Irós et al. 2014).

Los trabajos más importantes que se han elaborado respecto la configuración y crecimiento de la "Córdoba metropolitana han sido desarrollados por la ADEC -Agencia para el desarrollo económico de Córdoba-, donde se destacan el informe descriptivo del Sistema del área metropolitana de Córdoba (2014), las 2 leyes del IPLAM Instituto de planificación del área metropolitana de Córdoba-: Ley N. ${ }^{\circ} 9841$ de regulación de usos del suelo del área metropolitana de Córdoba y, ley N. ${ }^{0} 10004$ de uso del suelo en la región metropolitana de Córdoba (Figura 22). Sector segunda etapa. Ambos documentos, sus borradores y anexos, puntualizan en la necesidad del abordaje preferencial en el comportamiento y variación de la interfase de la ciudad de Córdoba. Esto fundamentado en los cambios abruptos que han sufrido, 
"Ios límites entre la urbanización y ruralidad o la relación de ambas situaciones con los accidentes topográficos o hidrográficos del territorio (...) donde resultan frecuentes las situaciones de fricción y conflicto que se producen en estos encuentros como consecuencia generalmente, de haber transcurrido estos procesos de expansión sin modelos e instrumentos de planificación regional” (Irós, et al., 2014, p.518).

Es asimismo el abordaje de la interfase un desafío de complejidad ya que implica avanzar sobre modelos territoriales regionales que involucran varios municipios. Esto pone en debate cuestiones asociadas a la autonomía y necesita de acuerdos supramunicipales. Las dinámicas de conurbación, por su parte, implican a la escala provincial con los correspondientes actores territoriales en la definición de lógicas, ya sean estatales endógenas, las del mercado o terceros.

Uso del suelo en el área metropolitana de Córdoba

Urbanizable

No urbanizable

Área indutrial

Espacio de rutas y colectoras

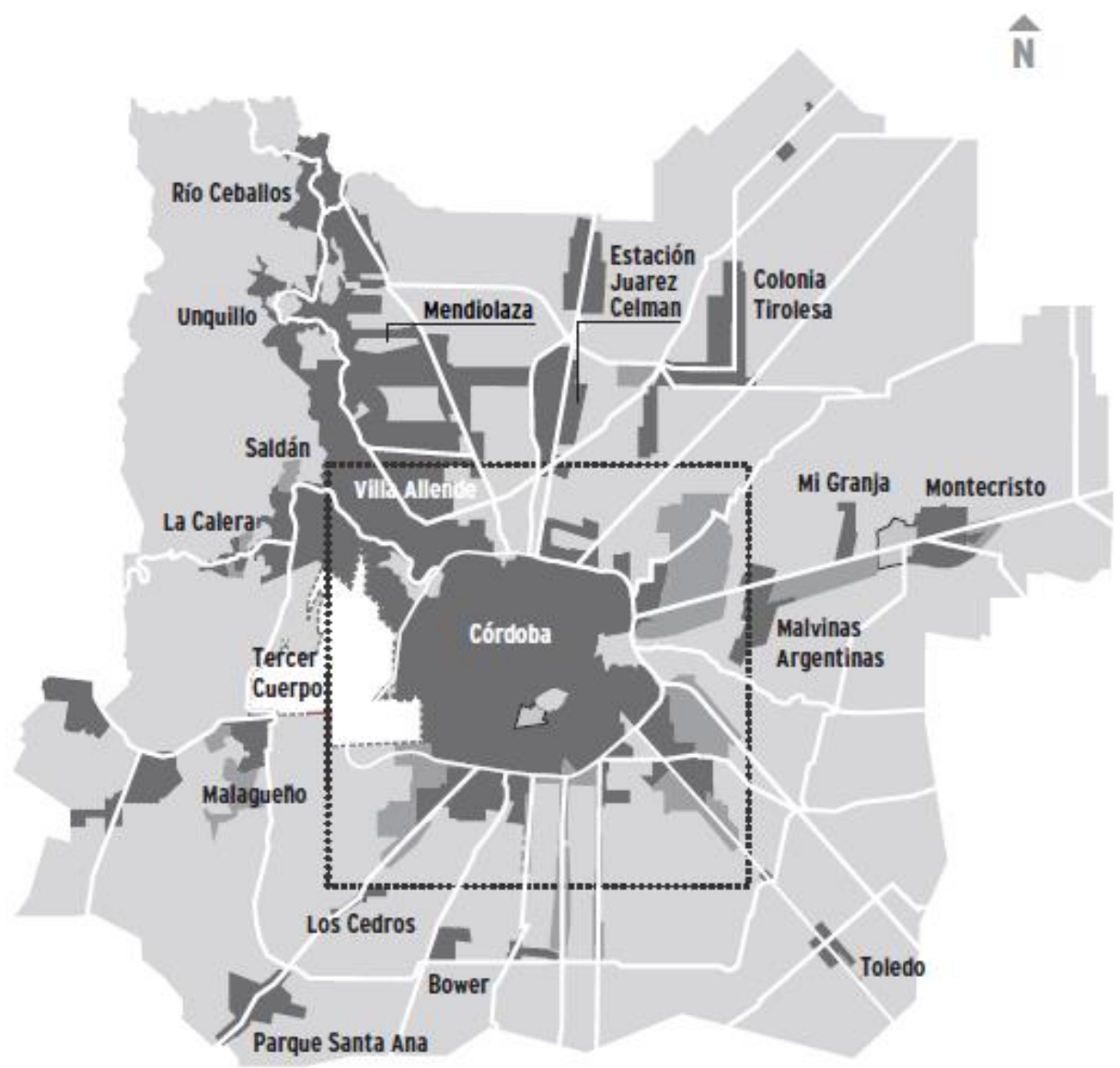

Figura 22. Mapa de usos del suelo del área metropolitana de Córdoba. Fuente: IPLAM,2012. 
La región metropolitana comprende un conjunto de 56 localidades con una población aproximada de 1.8 millones de habitantes en el año 2010, de los cuales tres cuartos viven en la ciudad de Córdoba. La ADEC -Agencia para el desarrollo económico de Córdoba-, define al área metropolitana como el conjunto de ciudades que se encuentran interrelacionadas en términos de movilidad y prestación de servicios con la ciudad principal.

De este modo, como área metropolitana de la ciudad de Córdoba se contempla aquellos que limita la Ley Provincial 10004/2011 más los aglomerados de Jesús María y las localidades ubicadas entre Carlos Paz y Cuesta Blanca. Su superficie estimada es de $4.291 \mathrm{~km} 2$, de los cuales el 13\% pertenece al distrito capital y conforma el 2,6 \% del territorio provincial."

Dado el pasado español de la ciudad de Córdoba, la actividad económica de la colonia condiciono su configuración estructural. La ciudad de Córdoba constituía un camino obligado que comunicaba el Virreinato del Río de la Plata con el Virreinato del Perú a través del Ilamado "Camino Real” (Figura 23). Esta ruta determino además de otros factores los asentamientos humanos en relación del núcleo urbano inicial, pero a lo largo de su recorrido configurando lo que podríamos denominar "proto-expansión urbana". Esto, acompañado de la presencia de las Estancias Jesuíticas como centros de producción (obtención de cueros y tejidos principalmente) ya establecían la extensión radial de la antropización del territorio.

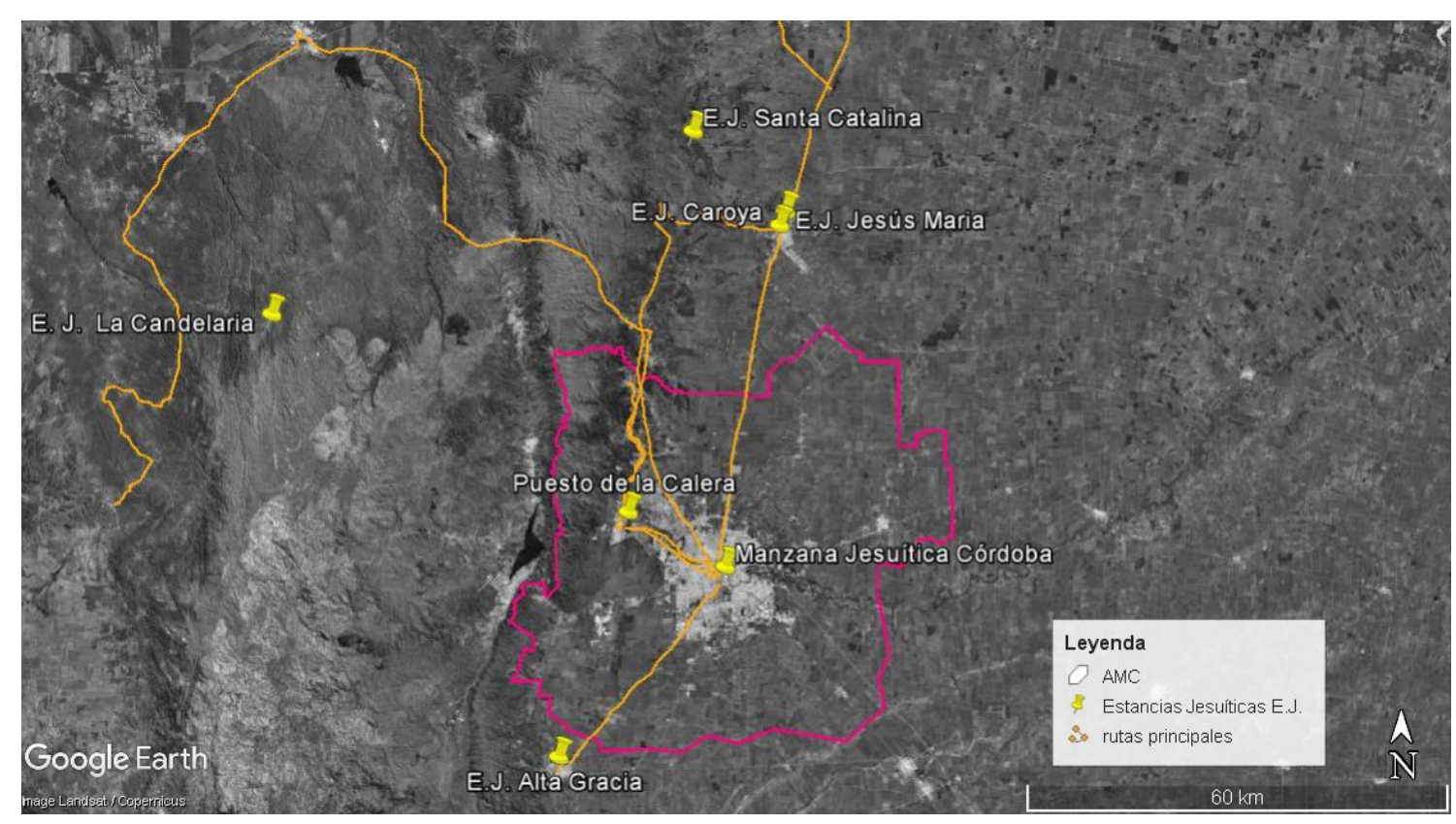

Figura 23. Camino real y estancias jesuíticas en Córdoba. Fuente: Céliz, 2017. 
La construcción del sistema ferroviario y el proceso de inmigración, que tuvieron lugar durante la segunda mitad del siglo XIX, transformaron el perfil productivo del AMC hacia la actividad rural agrícola (ADEC 2014). Durante este período se incorporaron máquinas más sofisticadas al sistema de producción. Otro punto relevante que tuvo su correlación en el territorio fue el hecho de que la ciudad fue la primera del país en contar con una Universidad, eso, vinculado a los hechos producto de la Reforma Universitaria de 1918, permitió el acceso de todos los argentinos al estudio universitario, que trajo como consecuencia la radicación de manera definitiva de estudiantes de otras localidades, impulsando el sector terciario-comercios y servicios.

Desde la crisis financiera internacional de 1929 se fomentó la industria a partir del impulso a la economía de Córdoba a través de la creación de dos grandes establecimientos: La Industria Aeronáutica y Mecánica del Estado (IAME) y el complejo industrial FIAT. Estos hechos constituyeron importantes centros de capacitación empresarial y laboral para el desarrollo de ramas subsidiarias de aquellas. Si bien la industria aeronáutica tuvo su ocaso a principios de los ochenta, la automotriz se siguió consolidando (Parisi and Vargas 2014). La apertura de la economía en los años noventa, definió aspectos importantes de la estructura productiva de Córdoba, desarrollando el comercio de una variedad de bienes; y nuevamente produjo una importante atracción de nuevos residentes (estudiantes y personas del interior en búsqueda de mejoras laborales), impulsó la construcción, cambiando significativamente la morfología urbana con la incorporación de grandes edificios y superficies comerciales. Córdoba estaba teniendo su propia revolución urbana de la mano de la industria.

En el siglo XXI, el auge el sector terciario es impulsado por la consolidación de las Sierras en el AMC -incluidas Sierras Chicas-, como destino turístico nacional, la actividad inmobiliaria orientada hacia el desarrollo de grandes complejos habitacionales, la aparición de contact center ${ }^{24}$ y el desarrollo del sector de software. En el año 2014 (en el que ADEC concretó el Informe descriptivo del sistema AMC), en la estructura productiva de Córdoba prevalecen las actividades de servicios y comercio, las cuales tienen una alta participación del PBR en el orden del $76 \%$, y la producción de bienes es solo un cuarto del total con un $24 \%$. Dicha composición se ha mantenido constante a lo largo de los últimos 10 años con picos de participación máxima del 30\% para la producción de bienes en los años 2010 y 2011. En los últimos años aumentó el fenómeno de personas que habitan en localidades del conurbano de Córdoba, tributando en estos lugares, pero trabajando en la ciudad de Córdoba (la expansión especializada), utilizando sus servicios públicos. Este fenómeno se verifica en la intensificación de grandes vías de

\footnotetext{
${ }^{24}$ Un Contact Center, es un centro de llamadas telefónicas, un sistema administrativo y de gestión cuya principal actividad es la recepción y emisión de información. Puede relacionarse al call center, sin embargo, este concepto implica más canales para la recepción/emisión de la información, a través de: llamadas telefónicas, correos electrónicos, fax, y comunicaciones online, incluyendo la mensajería instantánea a través de las redes sociales. A todo este centro de recepción 0 emisión de información, también se le denomina Comunicaciones Unificadas.
} 
circulación y transportes interurbanos que componen la simbiosis: aumento de población del área conurbadarefuerzo del sistema vial y creación de estructuras de soporte del sistema vial principal.

"La ciudad de Córdoba, como la mayoría de las grandes ciudades latinoamericanas, presenta serios problemas en la movilidad de pasajeros y transporte de cargas. Los ejes fundamentales que contribuyen a agudizar el problema son la conurbanización, producto de la diferencia en el precio de la tierra, en la rigidez normativa y en la presión tributaria de la ciudad de Córdoba respecto a las localidades del conurbano; el incremento del parque automotor derivado de la inexistencia de políticas que fomenten el uso del transporte masivo de pasajeros y la falta de coordinación interjurisdiccional en la materia". (ADEC 2014, p.14)

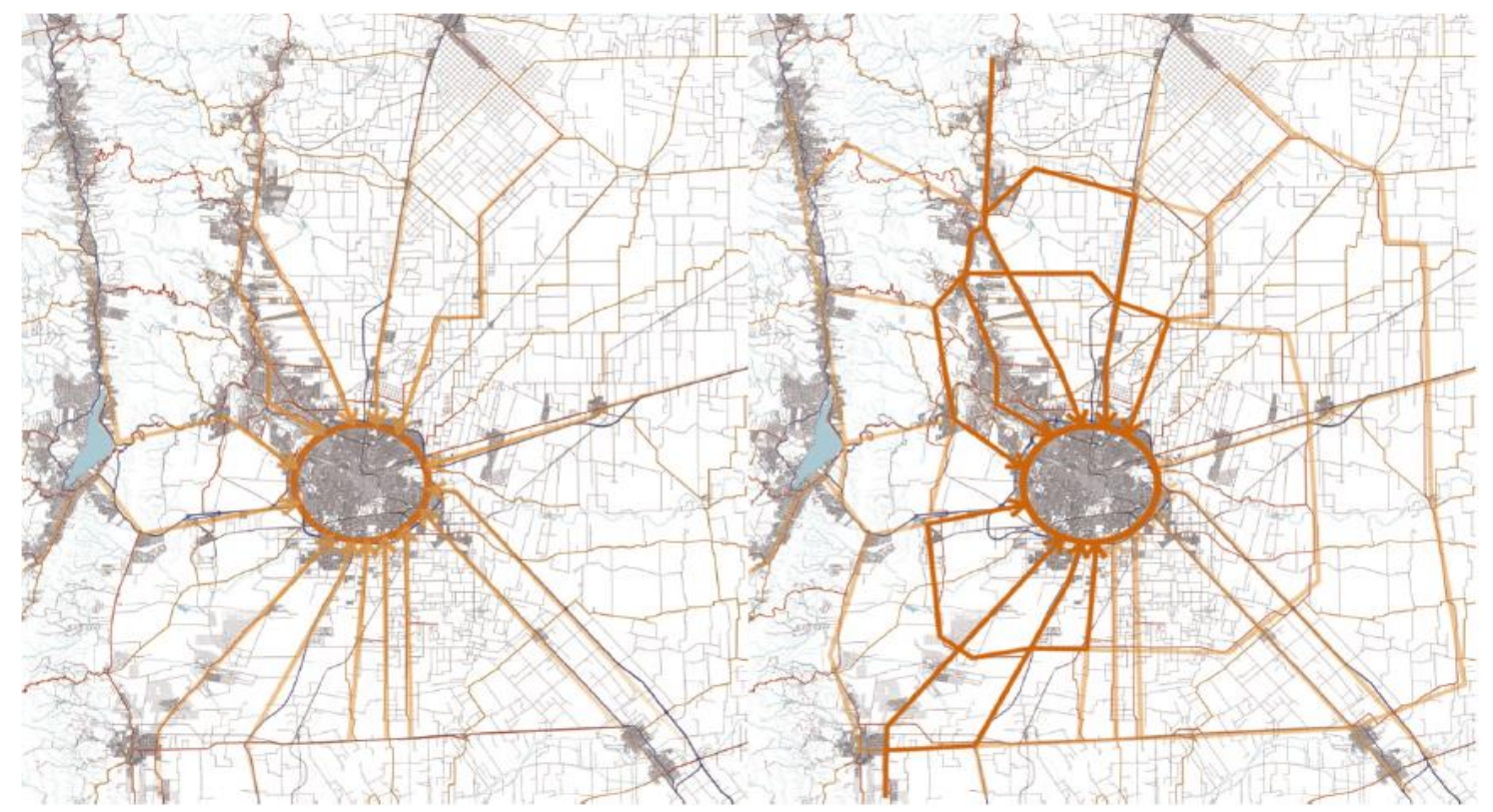

Figura 24. (Izquierda) Sistema vial del AMC al año 2012. (Derecha) Sistema vial a escala regional propuesto por IPLAM (2012) Fuente: Irós, 2014.

La población del conurbano de Córdoba, es de 159.000 habitantes y tuvo un crecimiento intercensal de 49\%(ADEC,2014). La mayoría de los ocupados en el área metropolitana de Córdoba pertenece al sector de los servicios (58\%), le sigue el sector comercial, con un 19\%; en tercer lugar, se posiciona el empleo en la industria, con un $13 \%$ de ocupados, en el cuarto puesto está la construcción, con un $10 \%$ de empleo. Dentro de los rubros de servicios, se posicionan en los primeros lugares de participación la enseñanza (8,7\% del total de ocupados), la administración pública (7\% del total de ocupados) y la salud (6,9\% del total de ocupados).

Otro sector que se localiza en el área es el de producción de software, constituido por un número reducido de grandes empresas, la mayoría de capitales extranjeros, que se dedican a la comercialización de productos 
exportables y a la prestación de servicios informáticos. De acuerdo con el Registro Industrial de la Provincia, el sector de industrias informáticas, electrónicas y de comunicaciones está conformado por casi 200 empresas, que se encuentran radicadas sobre todo en la ciudad capital. Además, el AMC, reúne seis universidades, la Universidad Nacional de Córdoba, la Universidad Tecnológica Nacional, el Instituto Universitario Aeronáutico, la Universidad Provincial, la Universidad EmpresaOrial Siglo XXI y la Universidad Blas Pascal.

El crecimiento económico de la última década, más el aumento de la población con deseos de aprovechar el diferencial en el gradiente del precio de la tierra y una menor presión impositiva, escaparse de la polución ambiental, disfrutar de los espacios verdes, alejarse de los focos de inseguridad urbana y esquivar las exigencias normativas para la construcción de la ciudad de Córdoba, llevó a una inusitada demanda de terrenos en las afueras de la ciudad $(A D E C, 2004)$ (Figura 25-26). Por lo tanto, terrenos que antes fueron parte del cinturón verde 0 tierras agrícolas se transformaron en countries o barrios cerrados que rápidamente fueron vendidos y construidos (Figura 27). Paralelamente creció en forma explosiva la necesidad de transporte hacia la ciudad y desde esta. Tal fenómeno ha generado el colapso de los accesos a la ciudad de Córdoba, así como de sus principales arterias.

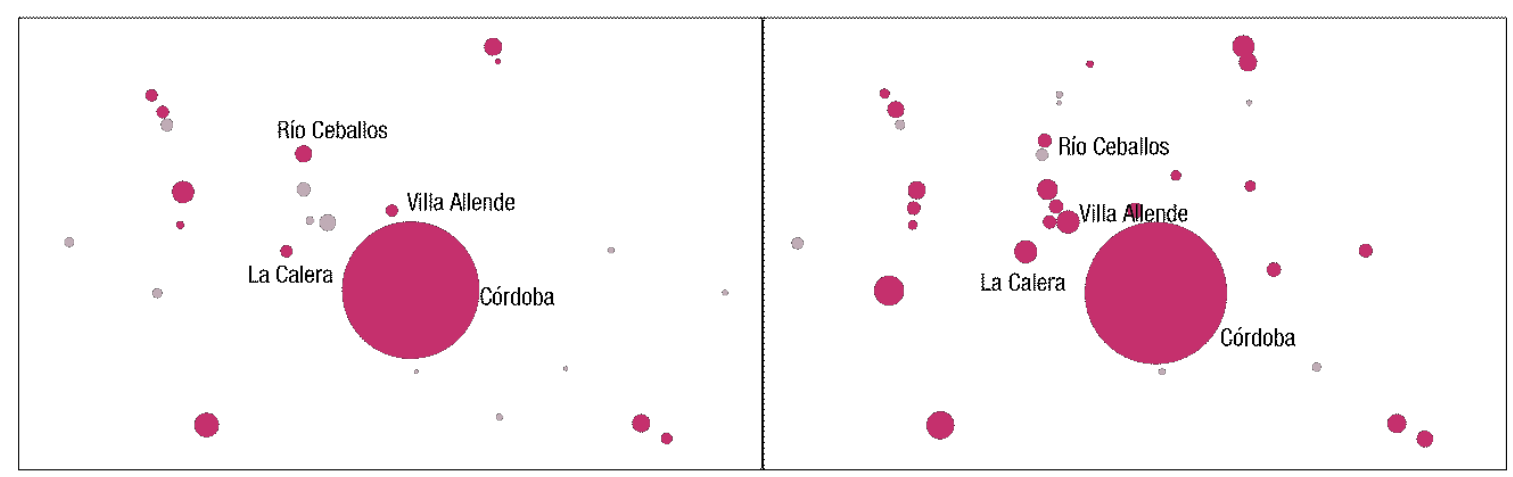

Figura 25. Comparación intercensal crecimiento demográfico de las principales ciudades de Sierras Chicas. Relación demográfica censo nacional 1947. Reelaboración: Céliz 2017en base a ADEC 2014

Figura 26. Comparación intercensal crecimiento demográfico de las principales ciudades de Sierras Chicas. Relación demográfica censo nacional 2010. Reelaboración: Céliz 2017en base a ADEC 2014 


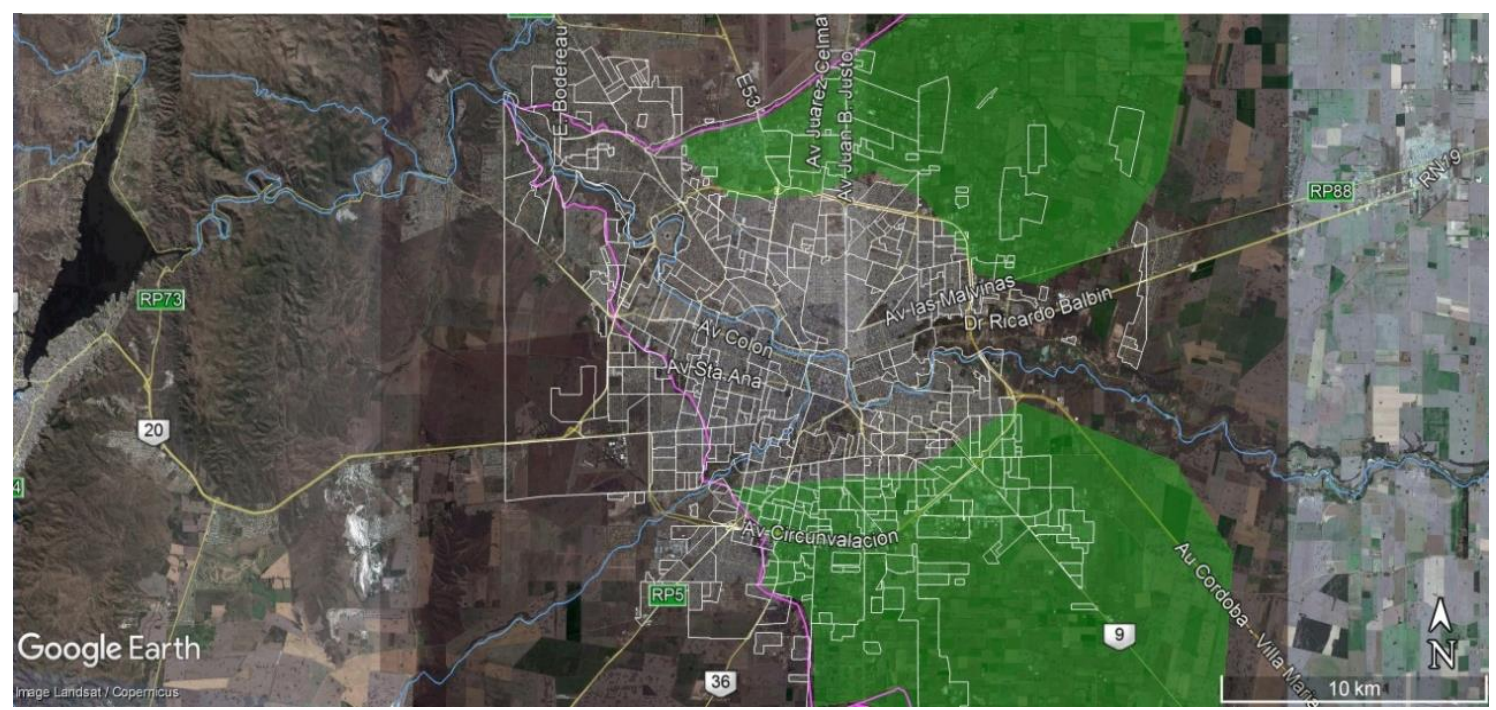

Figura 27. Antigua área de producción hortícola bajo riego (verde) sobre área urbanizada al año 2016 (polígonos blancos). Fuente: OAUPA-INTA,2017.

En cuanto a las principales actividades que definen los usos del suelo del AMC, se destaca la agrícola. La conjunción de las características climáticas con el acceso a infraestructura, la cercanía a la ciudad, cuestiones culturales y sociales favorecieron diferentes emprendimientos, producciones agropecuarias y los encadenamientos agroalimentarios-industriales con valor agregado y empleo de origen (ADEC, 2004). Es importante hacer la distinción entre producción intensiva y extensiva según el uso del suelo, en esta región ya que en el uso del suelo del AMC, la producción intensiva tiene mayor impacto que en los índices relativos al uso del suelo rural provincial. La producción intensiva se concentra en el sector frutihortícola, destacándose la importancia socioeconómica y su dependencia a la disponibilidad de riego (Figura 28). El informe de ADEC de 2014, identificó 57.600 ha que producen bajo riego gravitacional, y, de estas, 52.000 ha corresponden a cuatro grandes zonas que tienen como centro de consumo principal a Córdoba:

1. cinturón verde de Córdoba -CVC-, con el $24 \%$ de área regada con agua que proviene de los diques San Roque y Los Molinos, con 12.500 ha.

2. Región Colonia Caroya-Jesús María, con un $15 \%$ que toma agua del subsuelo, los río Carnero y río Jesús María, ocupa unas 7.800 ha.

3. Zonas de riego de la localidad de Río Primero y área de influencia, riego por bombeo de agua subterránea, al igual que la de Río Segundo y Pilar (tomas de agua del río Segundo). 


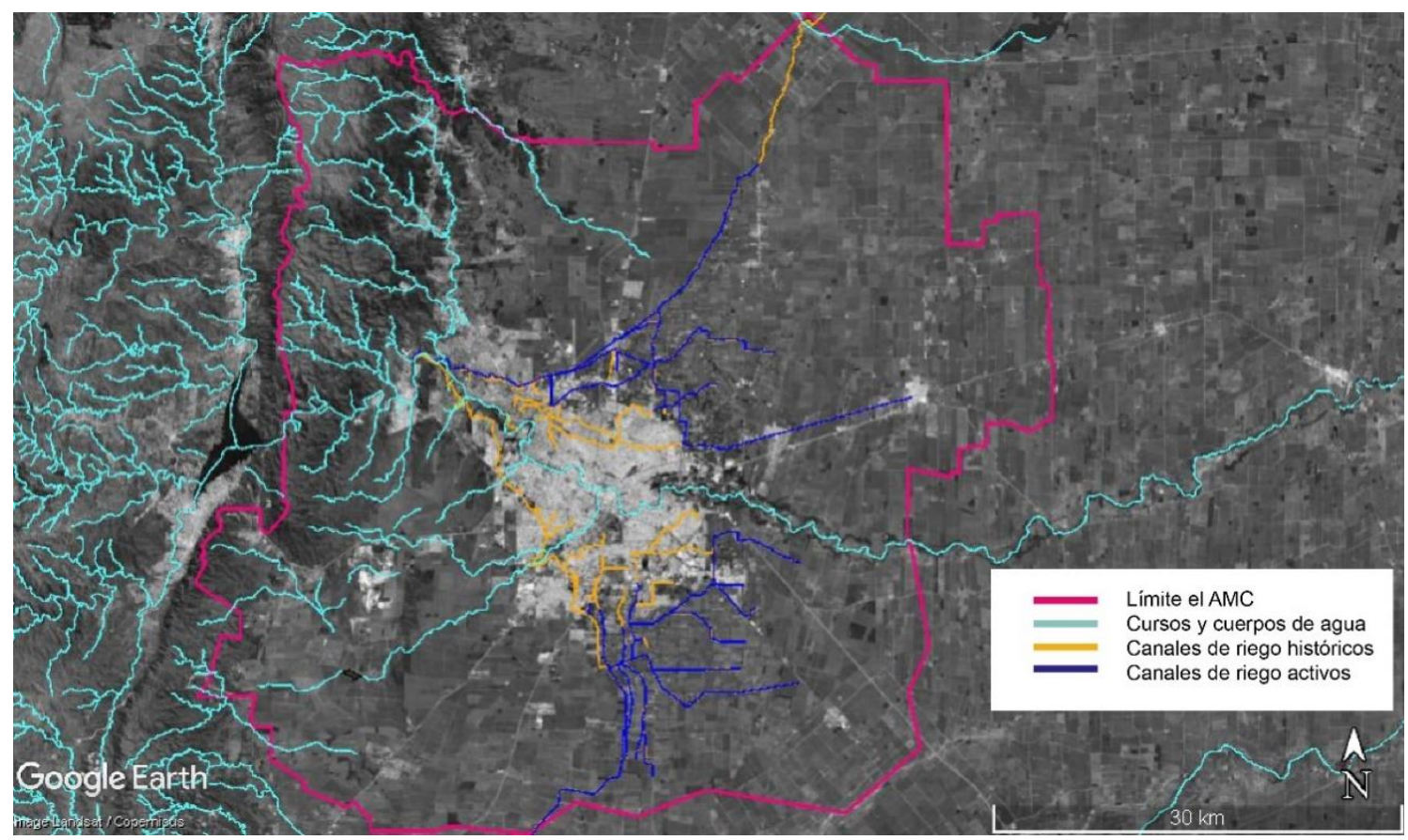

Figura 28. Cursos, cuerpos de agua y canales de riego AMC. Fuente: Céliz, 2018 en base a datos IGN

En cuanto a producción de frutas, se producen frutales de carozo (durazno, ciruela y damasco). Estas producciones están casi extinguidas en el CVC (Figura 29), pero aún quedan plantaciones de valor económico y comercial en Jesús María y Colonia Caroya, donde también se destaca el cultivo de la vid en variedades para vinificación. Otras producciones de importancia para el mercado interno en el CVC son: zanahoria, batata, lechuga, acelga, espinaca, espárrago, calabaza, anquito y maíz dulce para choclo. Posterior a este informe se registraron la inversión en sistemas de riego a partir de perforaciones en el CVC a través de la secretaria de recursos hídricos de la provincia. En relación a la producción de granos, los datos más relevantes tienen que ver con el impacto de la soja en la provincia ${ }^{25}$, según ADEC (2014) se encuentra en máximos históricos, llegando en 2010 a los 12,3 millones de toneladas con un rendimiento de $2.431 \mathrm{~kg}$ por hectárea. En el caso de la producción maicera, se destaca la alta participación de los departamentos Colón (40\%) y Santa María (40\%). En Córdoba capital existe una gran dependencia económica del maíz y un bajo nivel de producción. Las producciones de animales de tipo intensivas como feed lots, porcinas y aviares (huevo y carne), se encuentran muy próximas a la producción de granos,

\footnotetext{
${ }^{25}$ En términos generales el impacto de la producción de granos, a escala provincial, hasta la campaña 1991-1992 la tasa de crecimiento promedio anual de la superficie fue de 0,4\%; en cambio, a partir de la campaña 1992-1993, el área implantada se incrementó a una tasa promedio anual del 4\%. En la campaña 2010-2011 Córdoba destinó 7.313 .850 a todos sus cultivos, un 6,6\% por encima de lo que había utilizado en 2009-2010
} 
favorecida también por la cercanía tanto del alimento como de los mercados consumidores, ubicándose geográficamente en las Sierras Chicas ${ }^{26}$. El otro uso del AMC junto con el residencial y el agrícola de relevante importancia es el industrial: el sector automotor constituyendo uno de los más importantes, seguido por la industria de alimentos y bebidas.

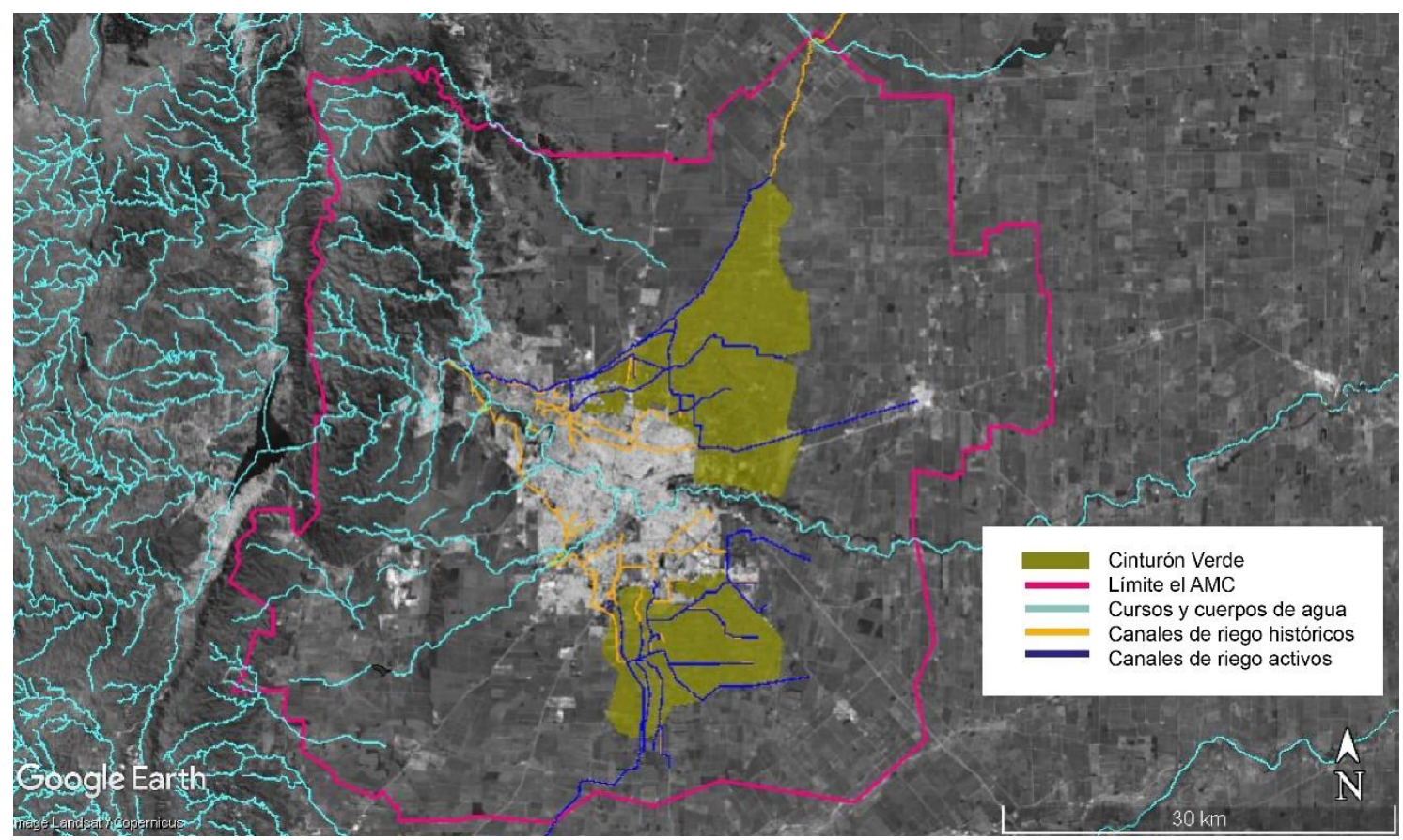

Figura 29. Superficies de producción hortícola en el AMC. Cinturón Verde. Fuente: Céliz, 2017 en base a Collado et al., 2009 y capas de base de la cátedra de Ordenamiento territorial FCEFyN-UNC.

En referencia a la expansión de la frontera agrícola, vemos que este proceso también se observó en los departamentos provinciales cercanos a Córdoba capital, desplazando a la ganadería, e incluso, en algunos casos, a cultivos frutihortícolas de larga tradición en el lugar (Tabla 10).

\footnotetext{
${ }^{26}$ En el informe de ADEC (2014) se estima que la producción de alimentos de proximidad en el AMC no es suficiente para
} abastecer la demanda en Córdoba por lo que es necesario importar desde otras provincias (ver Giobellina, 2016). 
Tabla 10. Variación de la superficie agrícola (2002-2004 contra 2008-2010)

\begin{tabular}{|l|l|l|}
\hline & En valores absolutos (has) & En forma relativa \\
\hline Capital & 117 & $1.9 \%$ \\
\hline Río Segundo & 338 & $0.1 \%$ \\
\hline Río Primero & 54.996 & $13.5 \%$ \\
\hline Colón & 3.512 & $2.8 \%$ \\
\hline S. María & 5.704 & $3.9 \%$ \\
\hline
\end{tabular}

Nota: Modificado del informe económico 2011. Capítulo 17 del instituto de investigaciones económica la Bolsa de comercio de Córdoba. ADEC, 2014.

Para ADEC (2014), los principales desafíos que presenta esta dinámica metropolitana se relacionan con la producción. Existen deficiencias en el sistema de riego debido a su antigüedad y a la falta de mantenimiento; al desvío del agua de riego para consumo humano -en especial luego de la intensificación de barrios cerrados-, y a los problemas de financiamiento para mejoras e infraestructura, de asociativismo y de capacitación de productores frente a las nuevas tendencias de los consumidores. También existen inconvenientes relacionados con la logística y una carencia muy marcada de centrales de procesamiento hortofrutícola (agroindustria). Esto se articula con una desvalorización del CVC dada la ausencia de políticas municipales y provinciales de preservación y tecnificación. En este sentido ADEC caracteriza positivamente la revitalización que tuvo el sector de la mano del asentamiento de trabajadores bolivianos que, durante los últimos 15 años se consolidan como productores de vanguardia.

\section{La cuenca del río Saldán}

Como se ha establecido en el MT, los procesos que ocurren en el territorio no se limitan a las jurisdicciones 0 áreas de gestión municipales e incluso metropolitanas. Dado que la mayoría de los procesos biofísicos que se estudiaran en relación al proceso de antropización ocurren en el área nor-noroeste de la ciudad de Córdoba, se eligió la escala de cuenca (meso-cuenca) para abordar la lectura de la dinámica territorial.

La cuenca hidrográfica está constituida por el territorio que delimita el curso de un rio y el espacio donde se colecta el agua que converge hacia un mismo cauce. La cuenca hidrográfica, sus recursos naturales y habitantes poseen condiciones físicas, biológicas, económicas, sociales y culturales que les confieren características particulares a cada una. Considerar esta unidad para la planificación es entonces de gran relevancia. Existen numerosos casos de países donde muchos planes y políticas territoriales, se establecen actualmente a escala de cuenca. 
En grandes cuencas con descargas de agua importantes y con amplios valles relativamente planos, el eje de los ríos se constituye también en una zona de articulación entre sus habitantes, -especialmente por el uso del cauce del rio para navegación, transporte y comunicación-. El territorio de las cuencas facilita la relación entre sus habitantes, independientemente de que, si estos se agrupan dentro de dicho territorio en comunas delimitadas por razones político-administrativas, debido a su dependencia común a un sistema hídrico compartido, a los caminos y vías de acceso y al hecho de que existe una común exposición frente al riesgo.

"el medio acuático es una entidad que alberga y sostiene todo un mundo animal y vegetal, sus aguas y sus riberas conforman un edificio biológico particular. La intervención no pensada del hombre sobre uno solo de estos elementos rompe este equilibrio precario y determina un empobrecimiento general del medio natural". (Tapia 1997 citado en

(Martínez and Suárez 2015))

Una gestión adecuada de los recursos hídricos requiere como primera instancia reconocer la unidad cuenca hidrológica o hidrogeológica-, como entidad socio-ecológica. Esta acción constituye un marco en la definición de objetivos específicos para cada territorio y la ejecución de acciones necesarias para llevar a cabo estos objetivos. Planteado este enfoque general, realizaré la aproximación al caso de estudio propuesto.

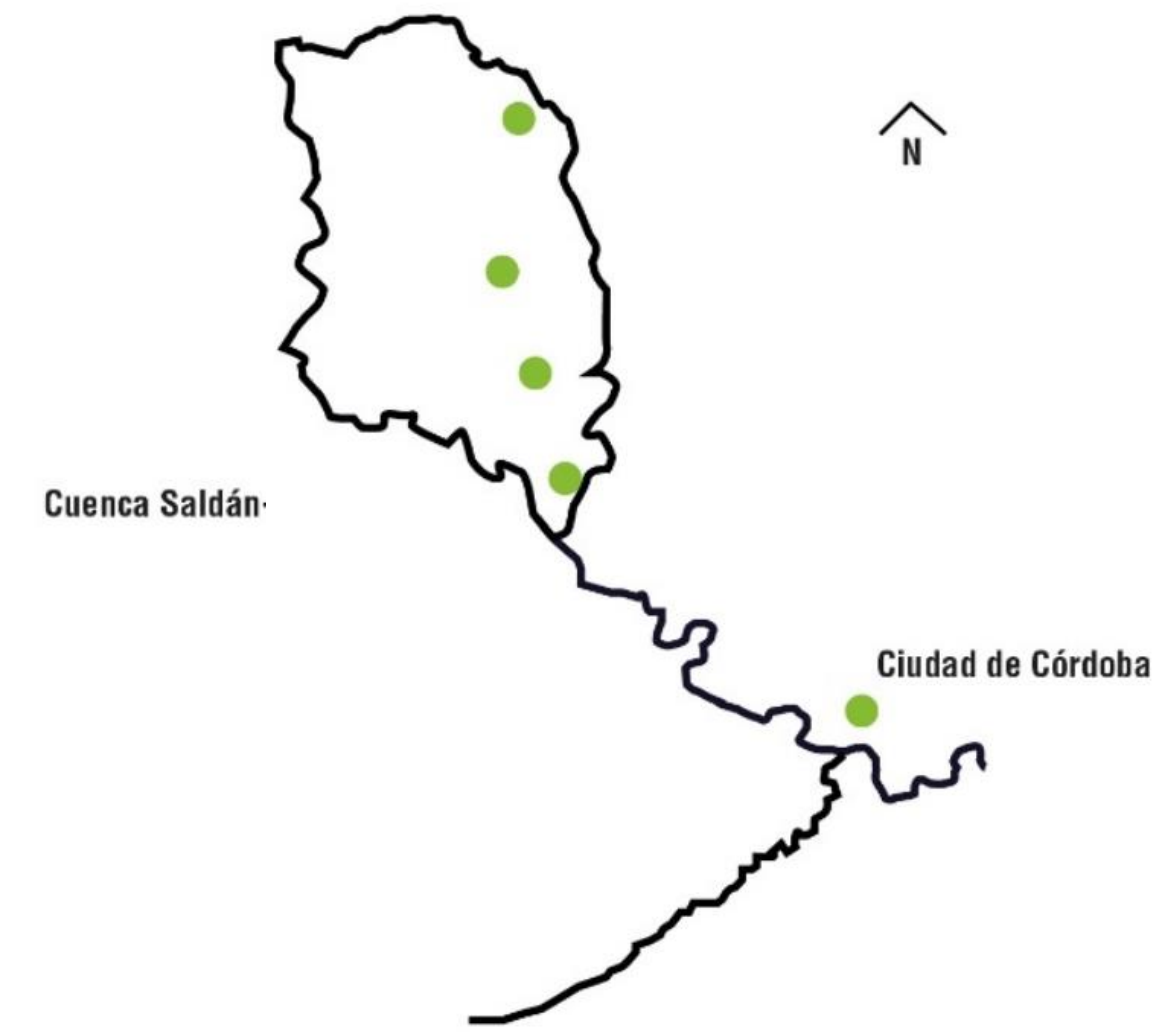

Figura 30. Esquema de ubicación de la cuenca de estudio respecto la ciudad de Córdoba y las principales relaciones hidrológicas. Fuente: Céliz, 2017. 
Los tres cordones montañosos principales de la provincia de Córdoba, nacen por fallamiento y levantamiento de bloques de la corteza terrestre como consecuencia de empujes provenientes del oeste que han generado flancos asimétricos. En efecto, en todos los casos el talud occidental aparece como una fractura o labio con mayor exposición de la masa rocosa caída abrupta hacia los valles o las pampas -superficies relativamente planas y elevadas-. Por el contrario, la cara oriental se manifiesta con un descenso suave que, complementado con extensos procesos de acumulación sedimentaria con menos debilidad frente a las acciones erosivas, han generado una cubierta boscosa más rica y variada particularmente en la zona de transición del pedemonte. Esta condición geomorfológica del faldeo oriental de las Sierras Chicas constituye un escenario natural que ha favorecido desde siempre a los asentamientos humanos.

La cuenca del arroyo Saldán está conformada por los ríos Ceballos y Unquillo, cuya área de recepción se desarrolla en la vertiente oriental tendida de las Sierras Chicas. Dentro del área de influencia de la cuenca, se emplazan las localidades de: Río Ceballos, Unquillo, Mendiolaza, Saldán y Villa Allende (Figura 31), estas localidades que han protagonizado el aumento de área urbana se han expandido en el ámbito fluvial de la cuenca, lo que ha aumentado los niveles de exposición de la población al riesgo de inundaciones.

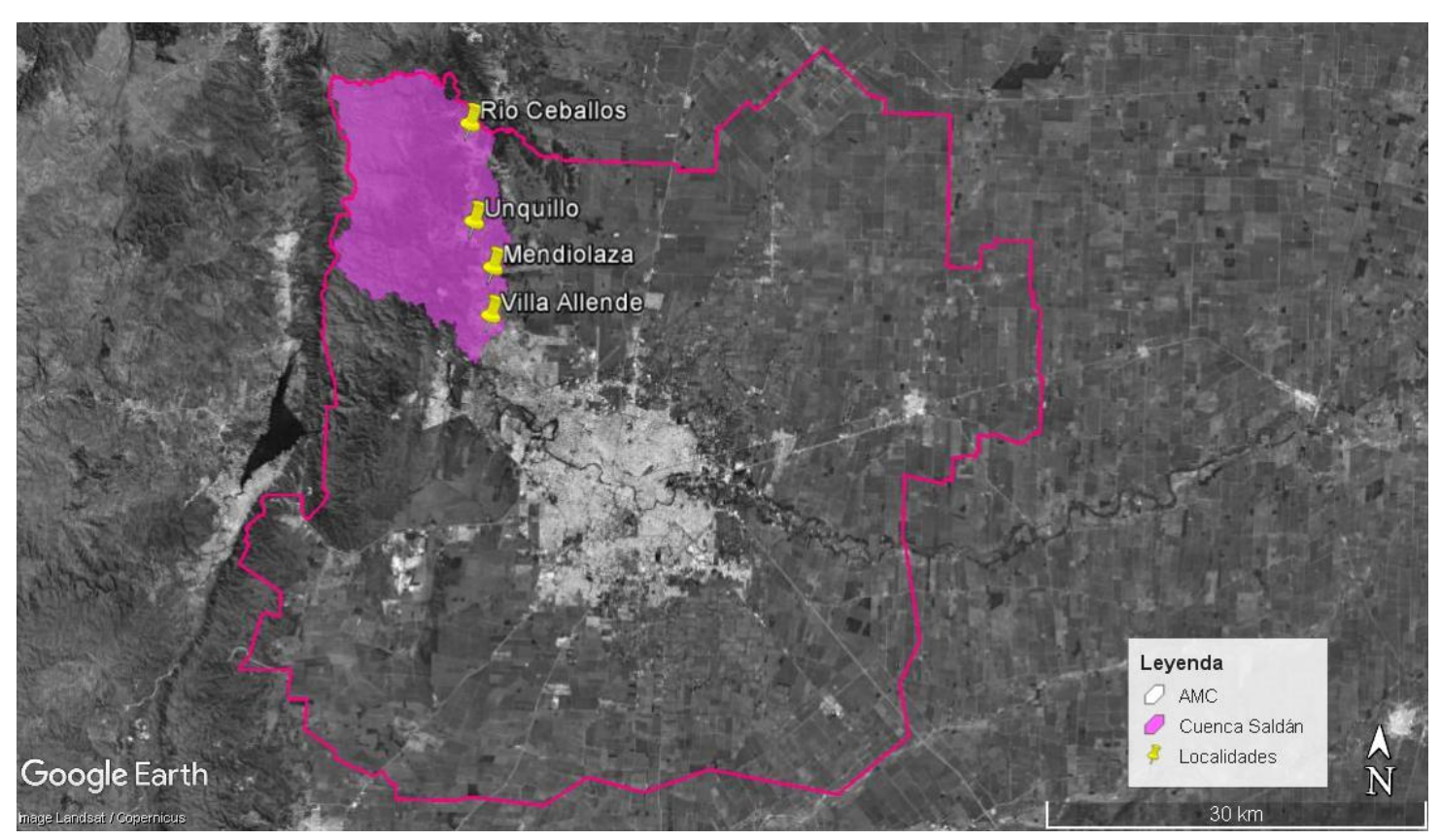

Figura 31. Ubicación de la cuenca Saldán dentro del AMC. Fuente: Céliz 2017 sobre imagen Google Earth.

"La realidad actual de la urbanización no es ajena al conjunto de destacados atributos naturales, que exhibe este faldeo serrano en su transición hacia la llanura pampeana extendida hacia el este de la geografía provincial." (IPLAM, 2016, p.15). 
El sistema del arroyo Saldán constituye el colector de la vertiente oriental en el sector más poblado de las Sierras Chicas (Figura 32). Recorre el faldeo serrano con dirección predominante norte-sur, recibiendo el aporte de La Reducción y el Unquillo entre otros arroyos más pequeños que descienden desde las cabeceras de cuenca situadas al oeste. Aguas arriba, desde el noroeste recibe al río Ceballos cuyos afluentes convergen en el dique La Quebrada con $3,3 \mathrm{hm} 3$ y $30 \mathrm{hs}$. de espejo de agua.

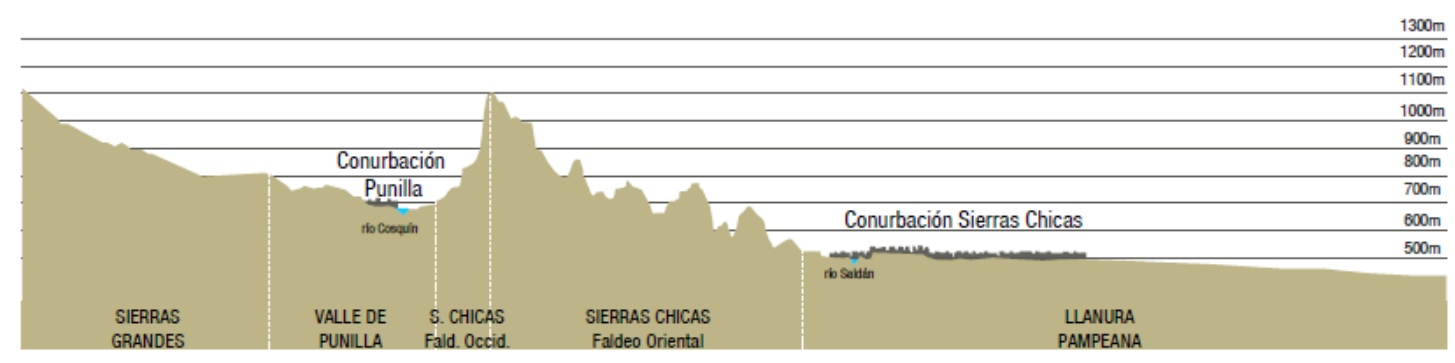

Figura 32. Perfil cordón serrano de córdoba. Fuente: Céliz, 2017 en base a datos de altimetría Google Earth.

En la transición del pedemonte a la llanura los cursos de agua pierden la contención de estructuras bien definidas. Los sistemas menores en general se infiltran en los sedimentos porosos y solo se proyectan a las zonas distales en los casos de precipitaciones extraordinarias (Barbeito, 2006). Más al norte los ríos Salsipuedes, Carnero y Jesús María (Guanusacate) con nacientes enteramente en el faldeo oriental de la Sierra Chica se infiltran en las tierras llanas hacia el este con avances variables que devienen en el progresivo aumento de las precipitaciones y la expansión agrícola que involucró una sustantiva pérdida de la cubierta vegetación natural, con disminución de la infiltración y aumento de la escorrentía. El primero con dirección a la ciudad de Juárez Celman con daños eventuales en zona rural que deben considerarse ante nuevas urbanizaciones (IPLAM, 2016). El río Carnero cuyas cabeceras de cuenca aportan a los arroyos San Cristóbal o Agua de Oro y La Granja, con caudales normales se insume en la llanura proximal, pero en los últimos años ha provocado serios daños por un progresivo aumento de las escorrentías extendiendo el cauce hacia el noreste en dirección Tinoco y Rangel.

El bosque de llanura pedemontana se ubica por debajo de los $750 \mathrm{msnm}$ (Figura 33), dominado por quebracho blanco (Aspidosperma quebracho blanco). En su mayor parte ha sido degradado a bosques secundarios 0 espinillares por acción antrópica, con un marcado incremento de espinillo (Acacia caven), aromo (A. atramentaria), garabato (A. praecox) y algarrobo (Prosopis spp.) (Cabido \& Zak 1999). En la transición de la zona llana hacia el piedemonte se encuentra el Distrito Chaqueño Serrano, con predominancia de molles, cocos, espinillos, moradillos y manzano del campo en los pisos bajos y pastizales en pisos superiores (Terzaga 1963) 


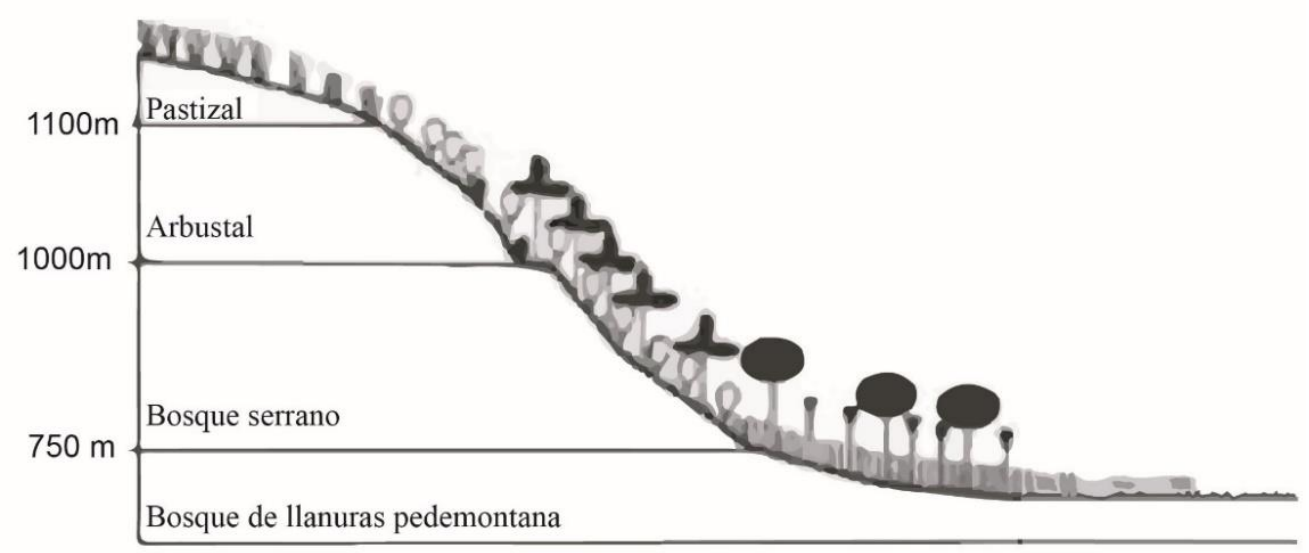

Figura 33. Perfil de la distribución altitudinal de la vegetación nativa en las Sierras Chicas. Fuente: Vectorización Céliz, 2020, en base a Kurtz 1904 Luti et al. 1976, Estrabou 1983 y Cabido \& Zak, 1999.

El sistema hidrológico que define a la unidad de estudio es más complejo que lo que aquí se describe ${ }^{27}$, simplemente se intenta esbozar que no existe un sistema trunco o que en un lugar un curso de agua comienza y termina definiendo una línea de ribera inamovible. El sistema como tal es dinámico, tiene etapas diversas y responde a la complejidad de los factores que lo alteran -sean estos antrópicos o naturales-, con igual complejidad. Esto es en un orden de prioridades el punto principal para el estudio de un diagnóstico orientado a la planificación de la cuenca.

La ampliación de la frontera agrícola con el consecuente desmonte, los incendios y la urbanización modifican el comportamiento de la cuenca que registra caudales inusuales con consecuencias destructivas por inundación, erosión hídrica acelerada en todas sus formas (laminar, regueros y cárcavas) y colmatación (Barbeito, 2006).

\section{Proceso de consolidación de las localidades serranas}

Peralta (1997) organiza el proceso de consolidación de las localidades de las SS CC en tres etapas caracterizadas por la dinámica -de apropiación- territorial y los actores que la definen. Estas etapas en el marco de las configuraciones territoriales provinciales y nacionales, adquieren particularidades, otorgadas en la mayoría de las

\footnotetext{
${ }^{27}$ Los ríos Cosquín y Las Morrajas desde el norte y el San Antonio y los Chorrillos, con naciente en el cordón central de las sierras desde el sur llegan al actual Dique San Roque. Desde la junta de estos ríos tributarios se constituye el Suquía que atraviesa la sierra en una profunda garganta. Aguas abajo, el dique Mal Paso, eleva el nivel del agua para dar inicio al sistema de riego, cuyo canal maestro norte cruza el acueducto sobre la quebrada del arroyo Saldán, que a poca distancia desemboca en el Suquía. Entre el dique y La Calera, ingresan arroyos pequeños, aunque con superficies de cuenca lo suficientemente extensas como para provocar, en caso de precipitaciones extraordinarias, situaciones de inundaciones hasta la ciudad de Córdoba, la última registrada en marzo del 2000, donde la crecida del arroyo la Cañada de Malina ingresa con gran caudal al Suquía (IPLAM, 2016, borrador plan Sierras Chicas).
} 
veces por los condicionantes del sistema natural en el que se desarrollan los asentamientos humanos. En la Tabla 11 se resumen las etapas que consolidan este sistema urbano:

Tabla 11. Síntesis de las etapas de consolidación del sistema urbano en Sierras Chicas

\begin{tabular}{|c|c|c|c|c|}
\hline ETAPA & período & Dinámica de ocupación & Organización territorial & Actor territorial \\
\hline ABORIGEN & $\begin{array}{c}\text { Antes de } \\
1573-\end{array}$ & $\begin{array}{l}\text { Comunidades agrícolas que se } \\
\text { ubican en relación a los cursos } \\
\text { de agua en la zona de valles. Se } \\
\text { destaca la ocupación del valle } \\
\text { del San Roque (actual dique) }\end{array}$ & $\begin{array}{l}\text { Dos provincias indígenas } \\
\text { de gran magnitud: } \\
\text { Sanavirones y } \\
\text { Comechingones. Divididas } \\
\text { en "ayllos". Se estimó el } \\
\text { total de } 30.000 \text { a } 40.000 \\
\text { habitantes divididos en } 600 \\
\text { pueblos. }\end{array}$ & $\begin{array}{l}\text { Comechingón, } \\
\text { Sacate y } \\
\text { Sanavirón en } \\
\text { menor medida }\end{array}$ \\
\hline COLONIAL & & $\begin{array}{l}\text { La campaña cordobesa: El } \\
\text { gobernador otorgaba tierras a los } \\
\text { conquistadores como obsequio } \\
\text { por su labor. Los territorios más } \\
\text { poblados, eran codiciados por la } \\
\text { mano de obra que incluían. } \\
\text { Primeras plantaciones y } \\
\text { desmontes masivos del medio } \\
\text { natural. Se abren caminos para } \\
\text { carreteras. }\end{array}$ & $\begin{array}{l}\text { Asiento y fundaciones } \\
\text { españolas sobre los } \\
\text { poblados pre-existentes. } \\
\text { Grandes estancias y } \\
\text { predios agrícolas. La } \\
\text { tipología era el rancho. }\end{array}$ & $\begin{array}{l}\text { Españoles y } \\
\text { aborígenes en } \\
\text { situación de } \\
\text { esclavitud. }\end{array}$ \\
\hline $\begin{array}{c}\text { LAS } \\
\text { ESTANCIAS }\end{array}$ & $\begin{array}{c}\text { S. XVII y } \\
\text { XVIII }\end{array}$ & $\begin{array}{l}\text { Fomento del poblamiento a partir } \\
\text { del otorgamiento de tierras. } \\
\text { Escaso cultivo de la tierra }\end{array}$ & $\begin{array}{l}\text { Grandes latifundios: La } \\
\text { estancia San Roque, el } \\
\text { puesto de La Calera, la } \\
\text { estancia de Saldán, la } \\
\text { estancia San Isidro en el río } \\
\text { de los Ceballos. }\end{array}$ & $\begin{array}{l}\text { ciudadanos de } \\
\text { alta posición } \\
\text { social y } \\
\text { económica } \\
\text { A partir del S. } \\
\text { XVIII: jesuitas. }\end{array}$ \\
\hline S. XIX & $\begin{array}{l}\text { Fines del } \\
\text { S. XIX }\end{array}$ & $\begin{array}{l}\text { Unidades familiares productoras } \\
\text { se asientan alrededor de los } \\
\text { centros urbanos. Desarrollo de la } \\
\text { red vial. Se traza la actual ruta E- } \\
57 \text { que une Río Ceballos con } \\
\text { Córdoba. En } 1910 \text { el FFCC llega a } \\
\text { Unquillo y se abren las rutas } \\
\text { hasta el valle de Punilla en } 1913 .\end{array}$ & $\begin{array}{l}\text { Nuevos barrios: Ñu Pora y } \\
\text { La Quebrada en Río } \\
\text { Ceballos. Chacras y } \\
\text { huertas de poca pendiente } \\
\text { alrededor de Salsipuedes. }\end{array}$ & $\begin{array}{c}\text { Familias } \\
\text { productoras se } \\
\text { suman a los } \\
\text { actores del } \\
\text { período } \\
\text { anterior. }\end{array}$ \\
\hline
\end{tabular}

Fuente: Reelaborado por Céliz 2018; en base a Peralta 1992 y Page 1985 citado en Peralta, 1997.

Durante este período de configuración del valle serrano como sistema urbano, las distintas etapas han consolidado la localización de las comunidades aborígenes que se situaron en las tierras fértiles del valle serrano, en relación 
directa a la oferta del sistema de arroyos. La modificación del territorio natural fue propiciada por la necesidad de abastecimiento de recursos y aumento de la población del valle (Figura 34). Asimismo, la comunicación entre distintos valles -SS CC-Punilla, por ejemplo-, para el traslado de materias primas y las comunicaciones con la ciudad de Córdoba hoy, significan la conexión entre las zonas turísticas de mayor relevancia del sector. Otro aspecto a destacar, es el registro de los primeros desmontes masivos. Estos fueron promovidos por la necesidad de contar con superficies de menor pendiente para cultivo, motorizado por el creciente aumento poblacional del valle. La creación de la autopista E-57, que actualmente es la vía estructural que conecta a las SS CC con la ciudad de Córdoba.
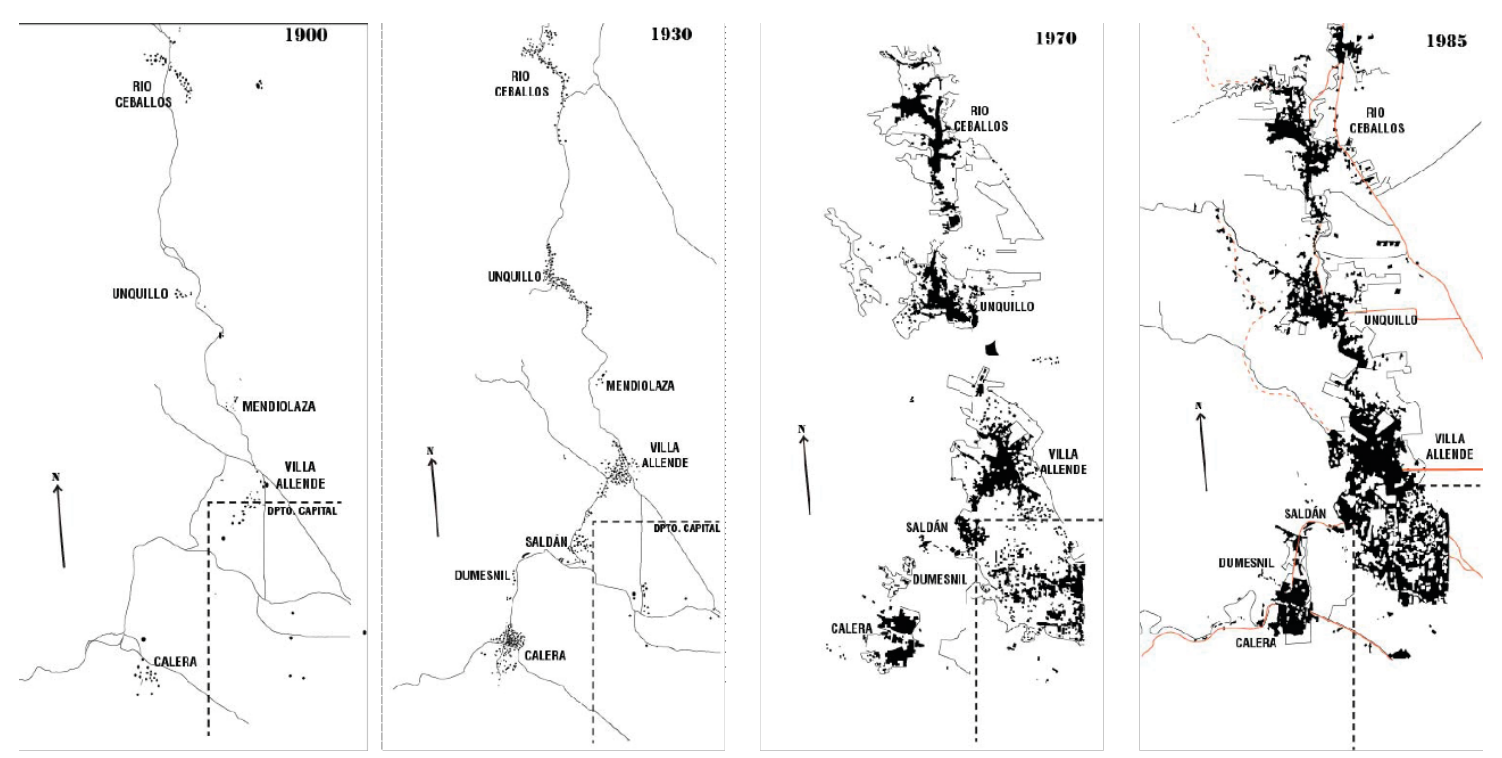

Figura 34. Síntesis gráfica de etapas de ocupación y consolidación del sistema urbano SS.CC. 1900-1985. Fuente: Redibujo de Céliz 2016 en base a Peralta, 1997.

Para el año 1900 se estimaban que ya estaba urbanizadas $120 \mathrm{Ha}$. de la cuenca, ocupadas por un total de 5.400 habitantes. En el mapa del año 1985 resulta explícita la continuidad entre la ciudad de Córdoba y la localidad de Villa Allende, también es posible identificar importantes rutas de acceso a las principales localidades de la cuenca. La población estimada para el año 1986 es de 48.477 habitantes y 18.142 viviendas (Peralta, 1992). De estos datos se establecen dos grandes dinámicas de ocupación: i) por un lado el crecimiento de la ciudad de Córdoba hacia el sector de Sierras Chicas y la conectividad que proponía este hecho y, por el otro ii) la oferta paisajística asociada a casas de segunda residencia y veraneo. Estos factores pueden ser asociados a indicios de una nueva etapa: la urbanización-que constituye la etapa posterior al proceso que describe Peralta (1997)-. 
Durante una etapa posterior, la metropolización, produce el acelerado crecimiento tanto de la población como del área urbanizada de SSCC, fuertemente impulsado por las vías de conexión con la ciudad de Córdoba. Dentro de este proceso también se identificaron tres sub-dinámicas: i) el impulso del desarrollo de vías de acceso y comunicación al área noroeste, ii) la tendencia a la migración por amenidades ${ }^{28}$ en busca de la oferta paisajística a poca distancia de Córdoba que significan las Sierras Chicas y iii) la relación del valor del suelo relativamente más bajo del área metropolitana en relación de la ciudad de Córdoba (ADEC 2014).

\section{Crecimiento urbano. El boom de Sierras Chicas}

Una de las explicaciones del boom demográfico del AMC es el costo de vivienda en la ciudad capital y la búsqueda de lugares tranquilos para residir. En el año 1945, Córdoba representaba el 93,7\% de la actual región metropolitana, las localidades eran muy pequeñas y solo Alta Gracia era considerada ciudad, por ser la única que superaba los 10.000 habitantes. En el año 2010, la importancia de Córdoba se veía reducida al $73 \%$ de la población total, y las localidades del conurbano presentaban un crecimiento exponencial, en especial, entre 2001 y 2010.

El departamento Colón -donde se encuentra el sistema conurbado de SS CC-, es el que presenta mayor crecimiento urbano-poblacional, en las últimas décadas. Las principales ciudades de Sierras Chicas crecen en población en especial entre los años 1991-2010 (Tabla 12). Según ADEC, la mayoría de las personas que han contribuido al crecimiento poblacional de estas localidades trabajan en la ciudad de Córdoba, pero tributan en las localidades del área metropolitana noroeste (ADEC, 2014). Este proceso de expansión se ha definido en el MT como "ciudades dormitorio". La población de este conjunto de localidades es de 159.000 habitantes y tuvo un crecimiento intercensal de 49\%. A continuación, se muestra la evolución de las principales localidades que conforman este grupo: Río Ceballos, Saldán, Unquillo y Villa Allende.

\footnotetext{
${ }^{28}$ La migración por amenidades 0 migración por opción se registra como uno de los impulsores de cambio territorial de tipo global. Está definida como la migración desde las grandes metrópolis a ciudades pequeñas o pueblos del interior, sobre todo destinos de montaña donde la calidad ambiental y cultural adquiere una percepción superior a la de los antiguos lugares de residencia (González,2011).
} 
Tabla 12. Crecimiento demográfico en las principals ciudades de las Sierras Chicas

\begin{tabular}{|c|c|c|c|c|}
\hline Año & Río Ceballos & Saldán & Unquillo & Villa Allende \\
\hline 1947 & 4.584 & S/D & 3.748 & 3.428 \\
\hline 1960 & 5.760 & 1.298 & 4.405 & 5.548 \\
\hline 1970 & 7.747 & 2.417 & 6.121 & 11.360 \\
\hline 1980 & 9.603 & 1.646 & 7.506 & 11.753 \\
\hline 1991 & 12.802 & 1.868 & 11.693 & 16.025 \\
\hline 2001 & 16.632 & 2.099 & 15.369 & 21.683 \\
\hline 2010 & 20.242 & 10.606 & 18.483 & 28.374 \\
\hline
\end{tabular}

Fuente: censo nacional

Localidades como Villa Allende, presentan un crecimiento constante entre 1947 y 2010, al igual que Río Ceballos. Sin embargo, Saldán que presentaban cierta estabilidad en su población, la incrementa considerablemente en el último año analizado y aumenta en un 405\%, siendo el mayor crecimiento del grupo analizado. La localidad de Mendiolaza si bien no es incorporada en la tabla de crecimiento, constituye un punto de interés dado que solo en el 2015 fueron aprobados 276 nuevos planos de vivienda (ADEC, 2014). Como veremos más adelante la configuración urbana de Mendiolaza en la cuenca adquiere un particular interés que inicia a partir de la observación de la forma arbitraria en que se antropiza el territorio.

Como se ha mencionado anteriormente factores como la conectividad al centro de Córdoba, el valor del suelo urbano -o urbanizable-, en relación al valor del suelo en Córdoba han contribuido notablemente al incremento de viviendas en las SS CC. Ahora, la pregunta obligada es, ¿qué tipo de viviendas son las que se incrementan? ¿por qué este factor resulta relevante?

Las tendencias estudiadas desde el urbanismo y los fenómenos de interfase planteados en esta tesis, permiten identificar además de estos factores, la tendencia a este tipo de migración como una búsqueda de calidad ambiental y paisajística, es decir como una "demanda indirecta de servicios ecosistémicos". Sin embargo, el fenómeno de las urbanizaciones cerradas en este contexto de migración, da cuenta de la apropiación del paisaje serrano a partir de la baja densidad habitacional lo que ocasiona además de la impermeabilización del suelo una urbanización nada sostenible del territorio. 


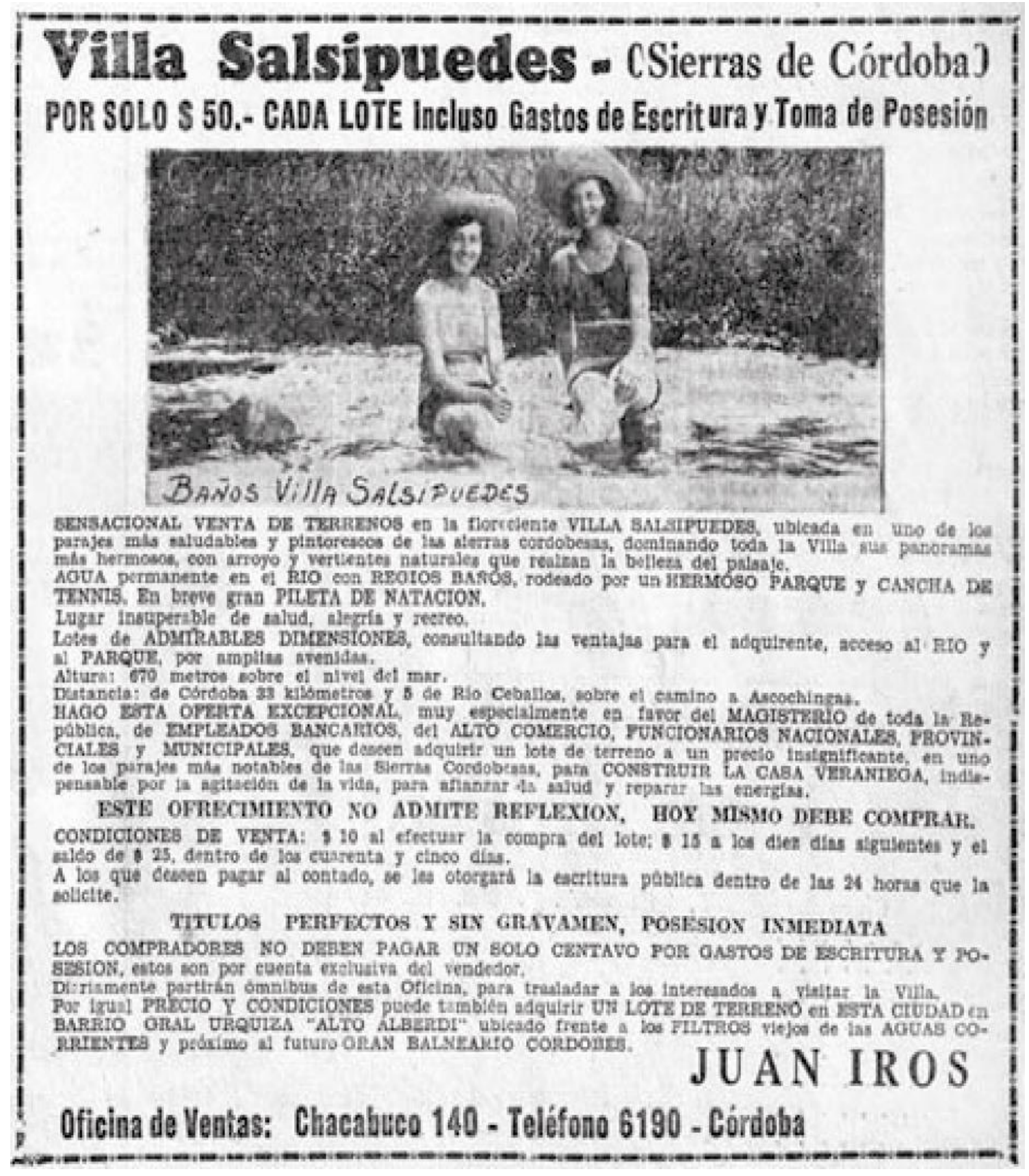

Figura 35. Anuncio venta de terrenos Villa Salsipuedes. Diario Los Principios año 1932, recuperado de Deón, 2014. 


\section{El uso del suelo en la cuenca: las definiciones arbitrarias}

Como se ha desarrollado anteriormente, los patrones de ocupación del valle serrano por las primeras comunidades, fueron consolidados como núcleos urbanos posteriormente. Sin embargo, la delimitación de localidades no ha seguido criterios muy claros, dejando incluso "áreas grises" o de competencia provincial próximas a las áreas de expansión urbana y de bosque (Figura 36). Esto implicó diversas consecuencias a la hora de estimar áreas deforestadas certeramente, aprobación de loteos en áreas provinciales, dado que aún al día de hoy en el sector existen "ejidos pretendidos" y "ejidos reales" que no coinciden y presentan áreas de superposición con otras localidades del área conurbada.

La problemática de las definiciones administrativas en estas localidades conurbadas al área capital de la ciudad de Córdoba, es ampliamente conocida por lo que la propuesta de unificar decisiones a escala regional configuró la propuesta de la "comunidad de Sierras Chicas" (ver cap. 04 de esta tesis), que sin embargo no logró definir un ente de gobierno supramunicipal que defina los usos del suelo y las limitantes de los distintos casos.

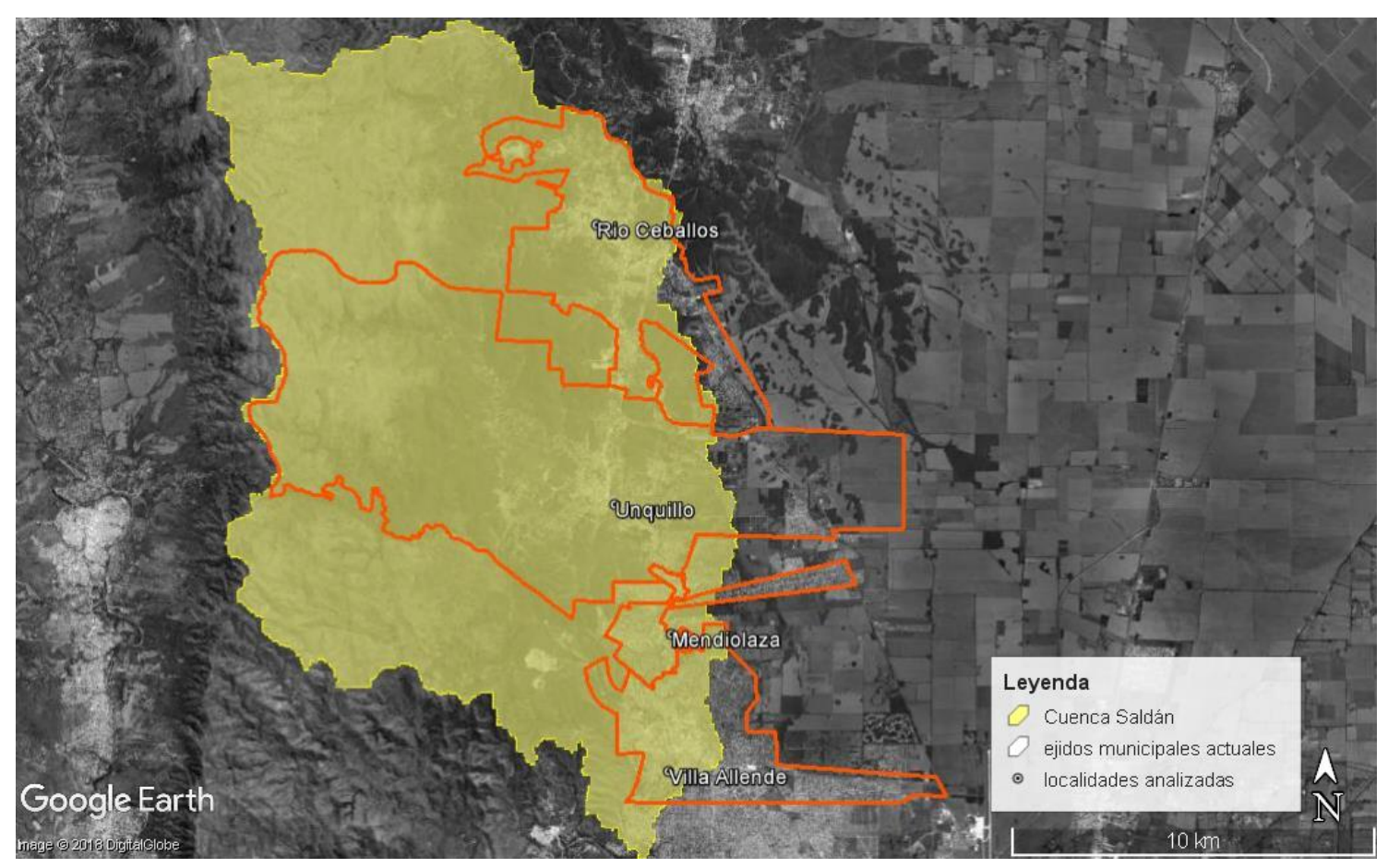

Figura 36. Principales localidades de la cuenca y sus ejidos municipales. Fuente: Céliz, 2018. 
Dado que estos procesos de urbanización incorporan dinámicas urbanas en áreas naturales la impermeabilización de la cuenca constituye un aumento considerable de los procesos de vulnerabilidad y riesgo para los asentamientos humanos. Los dos sistemas en interacción son el ecosistema natural y el ecosistema urbano. A partir de entender las dinámicas más importantes se identificaron otras unidades ambientales (UA) (Figura 38) con el objetivo de entender las relaciones entre los diferentes sistemas y sub-sistemas de la cuenca. Las UA se diferencian a partir de fotointerpretación de componentes biofísicos relevantes (ruptura de pendientes, cobertura de suelo, cursos de agua, etc.).

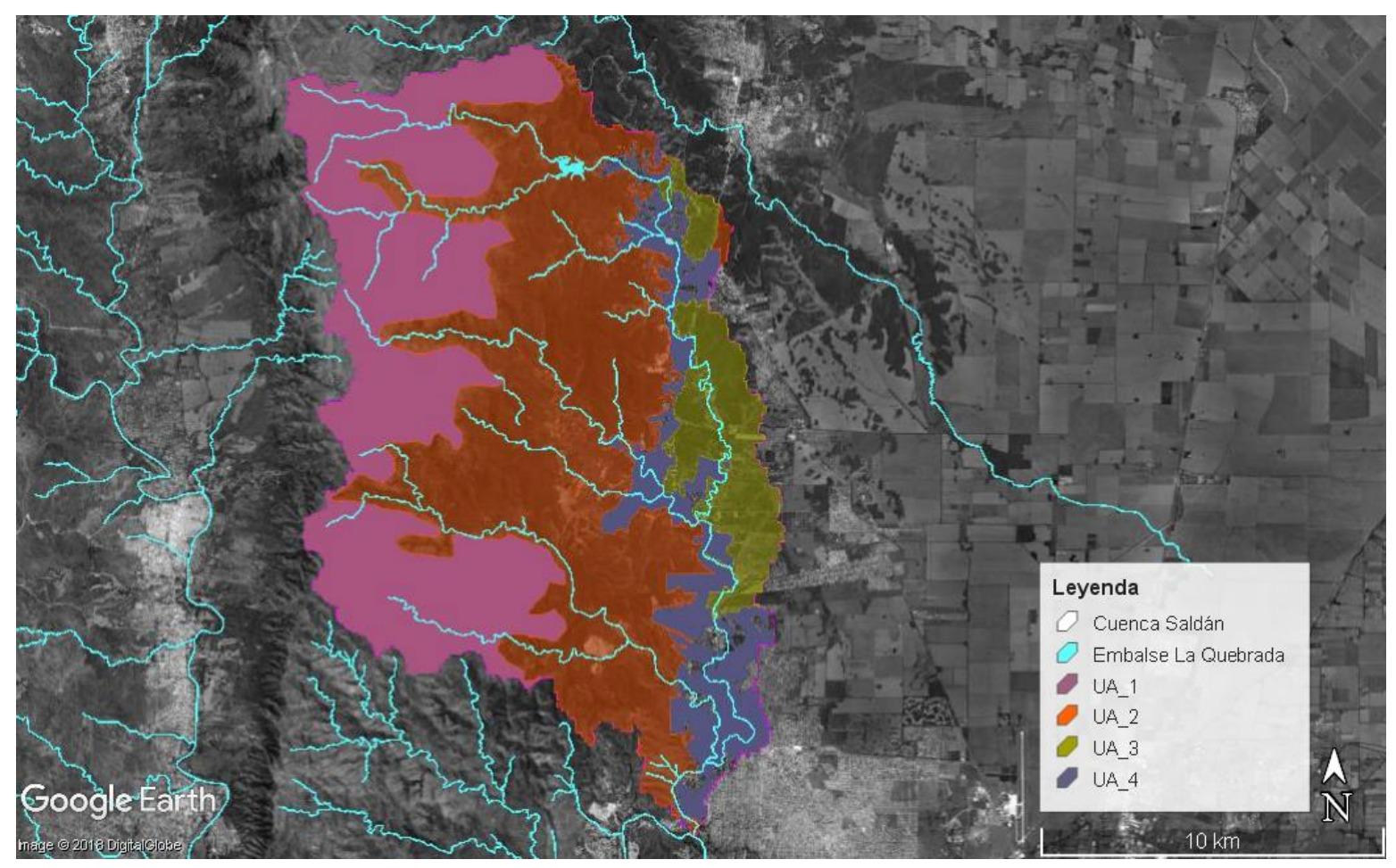

Figura 37. Unidades ambientales en la cuenca Saldán. UA1: roquedal-pastizal, es la parte más alta de la cuenca que presenta la mayor parte de su cobertura rocosa expuesta con áreas de pastizal. UA2: bosque. El área de bosque con mayor desarrollo y el área media de la pendiente con valles de gran desarrollo de bosque nativo. También es el área de avance de vegetación exótica principalmente compuesta por siempre-verde. UA3: agro-sistema. Área de producción agrícola de la cuenca, coincide con áreas de menor pendiente y es atravesada casi en su totalidad por cursos de agua. UA4: área urbanizada al año 2017, superficie de mayor nivel de antropización que coincide con el área de valle de la cuenca. 


\section{Indicadores críticos del ecosistema serrano}

Una vez identificadas las UA principales se caracterizaron las interacciones más significativas entre ellas, partiendo de la dinámica de cambio de usos de suelo y como a partir de la alteración de los ecosistemas y las diferentes intensidades de estas variables, aumenta la exposición de los asentamientos humanos a procesos de entropíanegentropía en el sistema. A partir de allí se identificaron dos indicadores críticos en la interacción: i) deforestación e ii) inundaciones.

El ecosistema natural es definido por características biológicas, regionales y de uso del suelo a grandes rasgos. En este sentido el bosque constituye un sistema natural de alta complejidad cuya dinámica aumenta en tanto y en cuanto las transformaciones adquieren velocidades asociadas a la proximidad con el sistema urbano ${ }^{29}$. Las funciones que desempeña el bosque están asociadas a la biomasa acumulada y a partir de esta la protección del suelo, regulación del clima, amortiguación de inundaciones, regulación de gases atmosféricos a partir de la captura de carbono y provisión de hábitat para diferentes especies (MA 2007, Nepstad et al. 2008 citado en Laterra, Jobbágy, \& Paruelo, 2011). Otro estrato de bosque lo constituyen los pastizales, que de igual manera capturan y retienen carbono (José M Paruelo et al. 2004) como así también proveen hábitat para la flora y la fauna. Las zonas más cercanas a los cursos de agua son áreas "buffer" de inundaciones, sobre todo, regulan flujos, purifican y proveen agua, reciclan nutrientes, y también constituyen hábitat de biodiversidad (Pattanayak 2004, MA 2005; Verhoeven et al. 2006 citado en Laterra et al., 2011). Estos conceptos básicos de provisión de procesos y funciones constituyen los elementos estructurantes del diagnóstico biofísico.

En cuanto al ecosistema urbano y los impactos de las dinámicas de antropización, el más relevante en relación a cambios de usos del suelo en la cuenca, tiene que ver con la sustitución de cubiertas de bosque o pastizal por superficie urbanizada. La intensificación de este proceso de sustitución está relacionada, entre otras cosas, con la alteración en los ciclos hidrológicos y el aumento del riesgo por inundaciones. En general las llanuras aluviales -0 valles-, tienden a ser tierras fértiles lo que históricamente ha significado el asiento de población y con el proceso de consolidación de ciudades se definieron como áreas de alta densidad urbana (van Dijk et al. 2009).

\footnotetext{
${ }^{29}$ Según FAO (2016), la causa de pérdida de bosque más significativa es la conversión de tierras para uso agrícola. Esto está generalmente asociado al aumento de la demanda de materias primas -y crecimiento poblacional-, traducido en nuevas superficies de cultivo. Existen otros dos factores no tan directos asociados a la seguridad de la tenencia de la tierra y las dificultades asociadas a la gobernanza de los territorios que muchas veces desencadenan pérdida de superficie de bosque al no estar tan claros el destino o políicas de protección de estos territorios. Esto mismo ocurre cuando no existe una definición clara sobre jurisdicción y planes de manejo en áreas de bosque, facilitando las acciones de deforestación.
} 
La asociación general entre el bosque e inundaciones indica que, a menor cobertura de bosque, más probabilidades tiene el ecosistema de sufrir los efectos adversos de grandes lluvias e inundaciones críticas para los asentamientos humanos. Sin embargo, es fundamental entender los procesos que definen esta relación.

Las inundaciones, ocurrirán cuando más agua de la que puede ser almacenada o pasar aguas abajo, haya entrado al cauce de un río (Rodríguez Iturbe \& Rinaldo, 1997 citado en van Dijk et al., 2009) . Se trata entonces, de una relación entre la tasa de entrada y la tasa de flujo de salida de agua a un contenedor determinado, influenciado decididamente por el uso del suelo y la actividad humana. Entonces, no solo se trata de que es lo que se encuentra sobre el suelo, sino también en las condiciones en que este es afectado por las inundaciones dada la relación que el agua establece en el momento de contacto y dicho uso del suelo. Esta relación es aún más compleja en términos de área periurbana ya que no existe una definición tan taxativa del estado ni el uso del suelo específico.

Los efectos de variabilidad y las tendencias climáticas son difíciles de separar de los efectos del suelo y los cambios en el uso. FAO (2005) advierte sobre inundaciones y la relación que existe entre estas y los bosques río abajo en eventos de gran escala. Esta afirmación que asocia directamente la presencia del bosque a la reducción de afectaciones por inundaciones, se debe a que a escala local bosques y suelos forestales son capaces de reducir escorrentía lo que se debe en la mayoría de los casos, a la mayor capacidad de infiltración y almacenamiento ${ }^{30}$. En el caso de eventos extremos de lluvias -y en particular cuando estos ocurren luego de períodos prolongados de precipitaciones previas-, el suelo del bosque ya se encuentra saturado por lo que el agua no infiltra, sino que se desplaza sobre la superficie.

En esta línea diversos estudios estimaron que la rápida urbanización sin el adecuado diseño de sistemas de flujo pluvial aumentaba la probabilidad de inundaciones locales repentinas (Barnolas et Llast, 2007 citado en Van Dijk et al., 2009). En este sentido, los principales impactos de la urbanización sobre el ciclo del agua están asociados a: (a) la impermeabilización del suelo, (b) la aceleración de los escurrimientos, (c) la construcción de obstáculos al escurrimiento, (d) la "artificialización" de las acequias, arroyos y ríos en áreas urbanas y, (e) la contaminación de Ios medios receptores (Chocat 1997). A priori podemos afirmar que el acento debe estar puesto en las transformaciones a escala de paisaje en términos de procesos biofísicos y no en patrones aislados como la presencia 0 ausencia -solamente- de cobertura arbórea.

En terrenos con pendiente, el suelo se desplaza cuesta abajo principalmente por efecto de la fuerza de gravedad. La presencia de bosque en sí misma no garantiza la reducción directa o evita la ocurrencia de inundaciones, sin

\footnotetext{
${ }^{30}$ La tala de árboles, generalmente está asociada a la reducción de la tasa de infiltración en el suelo, en mayor medida cuando la remoción es seguida por el cambio de uso del suelo: agricultura, construcción de vías de circulación, urbanización o simplemente degradación de la tierra. Esta acción mejora el drenaje del suelo, favorecido por la creación de carreteras, desagües y ríos de los diques.
} 
embargo, se establecen relaciones entre la presencia del bosque y procesos biofísicos relativos al retardo 0 reducción de impactos del evento extraordinario: a) reducción de escorrentías a escala local por infiltración y almacenamiento de agua, b) control de la erosión, con especial énfasis en terrenos con pendiente, c) evaporación de precipitaciones interceptadas por el dosel y d) protección mecánica del suelo.

El grupo Eurydice 92 (Chocat 1997) introduce el concepto de "hidrología de medios bajo fuerte impacto antrópico", planteando que no es posible diferenciar la hidrología urbana e hidrología rural dado que, en los modos de usos y coberturas de suelo no existe tal división, en particular en las áreas de interfase. El estudio del ciclo del agua perturbado por actividades humanas de forma integrada implica diversos procesos hidrológicos asociados a diversos procesos de uso del suelo sobre todo en América Latina y Arrgentina (Ambrosino et al. 2004).

\section{“(...) cuando un loteo es proyectado los municipios solamente exigen que el proyecto de drenaje pluvial asegure el} drenaje eficiente del sector, sin considerar el impacto del aumento del caudal máximo aguas abajo. Una característica causante del descontrol observado en la mayoría de las ciudades es que quien impermeabiliza no sufre las consecuencias; los efectos hidrológicos solo se verifican hacia aguas abajo." (Ambrosino et al.,2004, p. 14)

Por la misma razón que los procesos hidrológicos comienzan a ser estudiados desde un enfoque sistémico entendido que la delimitación de usos de suelo no constituye un límite en el ciclo del agua, la planificación del agua en entornos urbanos tiene impacto en territorios de influencia y no se limita al área urbanizada. Un ejemplo puede ser el que establece Tucci (2007), que expone que para sectores con urbanización media la variación del coeficiente de escurrimiento entre áreas urbanas y rurales podía variar en el orden del $200 \%$. Para la ciudad de Rafaela. A su vez, Bertoni (2001) determinó, en base a datos hidrológicos y de urbanización, que un crecimiento del 15 \% en el porcentaje de urbanización representó $140 \%$ de reducción del tiempo de concentración y 100 \% de aumento del caudal de punta específico. Cuando los municipios no controlan la urbanización o no amplían la capacidad del sistema de desagües el porcentaje de crecidas urbanas aumenta. El flujo pluvial escurre por acción de la gravedad por tanto este es un aspecto fundamental del diagnóstico de condiciones urbanas frente a las posibilidades de inundación.

Como se ha dicho, la urbanización en una cuenca tiende a llenar las áreas bajas cuya función está directamente asociada al almacenamiento y la pavimentación de área permeables que proveían infiltración al ecosistema (Ambrosino et al. 2004). Asimismo, esta impermeabilización a través de la construcción calzadas provoca mayor escurrimiento, aumentando volumen y caudales pico, produciendo daños al cauce receptor ${ }^{31}$.

\footnotetext{
${ }^{31}$ En EEUU se ha recomendado capturar y tratar el escurrimiento a partir de 5,8 $\mathrm{mm}$ por hectárea impermeable hasta el tiempo de retorno de 2 años y duración 24 Hs. (Ambrosino et al., 2004). Esto implicaría un control parcial y una reducción de la exposición de la población a inundaciones repentinas bajo la ocurrencia de lluvias de mediana intensidad.
} 
Según Gavier \& Bucher (2004) la situación del bosque serrano en Córdoba ha sido calificada como vulnerable, en una reciente evaluación del estado actual de conservación de ecoregiones terrestres de Latinoamérica y el Caribe (Dinnerstein et al., 1995). Dentro del área cubierta por el bosque serrano de las Sierras Chicas existen muy pocas áreas protegidas. La más importante es la Reserva Hídrica Natural La Quebrada, creada en 1987 con el fin prioritario de proteger la cuenca hídrica del dique de La Quebrada y su vegetación (Ley 6964/83, Áreas Naturales Provinciales y sus Ambientes Silvestres. Córdoba, Argentina. Decreto 5620).

A fines del 2013 un estudio científico de la Universidad Nacional de Córdoba alertó sobre los riesgos de deslizamientos (tierra, roca y agua) e inundaciones en la zona de las Sierras Chicas, particularmente en la cuenca de los ríos, frente al avance descontrolado de las urbanizaciones y el desmonte. Según estimaciones del Equipo de Ordenamiento Territorial del Instituto Superior de Estudios Ambientales, en siete años en esa región se perdieron 2.000 hectáreas de bosques. Las zonas que más sufrieron las inundaciones en 2015 (Villa Allende, Mendiolaza, Unquillo, Río Ceballos) coinciden con los mapas de riesgo elaborados por los investigadores.

A partir de estas dinámicas abordadas y los efectos que han tenido sobre los asentamientos humanos, la cuenca del río Saldán, es un sistema ampliamente estudiado. Se identificaron en los estudios más importantes del sector tres impulsores generales en las transformaciones del territorio:

i) el valor del suelo en relación a la ciudad de Córdoba,

ii) el acelerado crecimiento urbano como producto de la expansión del área metropolitana de la ciudad de Córdoba, iii) la oferta turística -y paisajística- como corredor serrano.

Este trabajo toma el caso de estudio por la particularidad de las dinámicas de interfase urbano-natural que presenta y, dado que existen números estudios en la zona, brindan la posibilidad de contrastar la información producida a partir de la valoración de SSEE y las metodologías que puedan ser incorporadas en la elaboración de insumos técnico-científicos para la toma de decisiones. Es decir que para este trabajo cobra gran importancia por un lado la recolección y sistematización de la información ya producida, como así también aquellos mapas productos de la valoración a partir del enfoque de los socio-ecosistemas para determinar las zonas de protección que permitan reducir en términos climáticos, la exposición de los asentamientos humanos del sector.

Los datos biofísicos aquí producidos como la metodología utilizada, serán puestos a disposición de los actores del territorio como insumo, tanto para Gestión del Riesgo como para la definición de límites de crecimiento urbano, 0 planes regionales que incorporen umbrales ecosistémicos críticos. 


\section{Deforestación}

Como he desarrollado en el MT, existen dos grandes indicadores críticos del ecosistema de bosque por un lado y de los asentamientos humanos. No implica esta distinción que alguno de estos indicadores este construido en función del otro arbitrariamente, sino que los datos que proporcionan estos estudios servirán como suministro del desarrollo de los modelos de diagnóstico. Por un lado, los estudios de Zak y Cabido (2009), y Argañaraz et al. (2015), exponen condiciones características del estado actual del bosque serrano, así como Gavier \& Butcher (2014), datos respecto a la deforestación y la transición en el ecosistema de estudio. Por otro lado, Barbeito et al. $(2001,2015$,$) , Barchuck et al. (2015) y otros han realizado estudios que estiman la relación entre la ocurrencia de$ inundaciones históricas en la región, la situación biofísica que define el territorio y como estos factores constituyen indicadores de riesgo para los asentamientos humanos.

Durante el período 1970-1997 desaparecieron alrededor de 5759 ha de bosque en el área de SSCC (alrededor de un $40 \%$ ), a una tasa anual de $1,8 \%$. La pérdida de masa boscosa fue un $22 \%$ mayor en la llanura pedemontana que en en el área de sierra. Las áreas deforestadas de mayor extensión se encontraban entre Salsipuedes y EI Pueblito y en el este de Río Ceballos. Las áreas deforestadas mostraron una clara asociación con las áreas urbanas y las rutas principales, concentrándose principalmente sobre una franja en la porción central del área de estudio en el contacto entre la sierra y la llanura pedemontana, (Gavier \& Butcher, 2004).

Otras áreas con pérdida boscosa significativa incluyeron el límite altitudinal superior del bosque, para Gavier \& Butcher (2004), esto puede estar asociado a incendios recurrentes iniciados en los pastizales, y la conversión a agricultura de algunos de los últimos fragmentos remanentes de bosque ubicados al este de la llanura pedemontana.

La Tabla 13 muestra una sostenida disminución del área de bosque, particularmente en el área de llanura (52\%) durante el período analizado, asimismo la tasa de deforestación del período 1987-1997 aumenta un 50\% con respecto al período 1970-1987, es decir que en 10 años se aceleró la pérdida de superficie natural, la cual no registró proceso de regeneración durante los años del estudio. 
Tabla 13. Superficie deforestada por período analizado en área de Sierras Chicas y subregiones

\begin{tabular}{|c|c|c|c|c|}
\hline Subregión/período & $\begin{array}{c}\text { Superficie } \\
\text { deforesta (ha) }\end{array}$ & $\begin{array}{c}\text { Pérdida } \\
\text { acumulada desde } \\
1970(\%)\end{array}$ & $\begin{array}{c}\text { Pérdida con } \\
\text { respecto al período } \\
\text { anterior (\%) }\end{array}$ & $\begin{array}{c}\text { Tasa de } \\
\text { deforestación anual } \\
(\%)\end{array}$ \\
\hline $\begin{array}{c}\text { Área total } \\
1970-1987\end{array}$ & 2753 & 19 & 25 & 1.2 \\
$1987-1997$ & 3007 & 39 & 20 & 2.8 \\
\hline Sierra & 901 & 11 & & 2.1 \\
$1970-1987$ & 1446 & 29 & 33 & 1.9 \\
$1987-1997$ & 1848 & 28 & & 3.8 \\
\hline Llanura pedemontana & 1560 & 51 & & 2.6 \\
\hline $1970-1987$ & & & & \\
$1987-1997$ & & & & \\
\hline
\end{tabular}

Fuente: Gavier \& Butcher, 2004.

El reemplazo del bosque por áreas urbanizadas fue importante, principalmente a causa de la expansión de las localidades de Río Ceballos y Salsipuedes. Entre 1970 y 1987 el crecimiento urbano fue uno de los principales factores de deforestación en la subregión de la sierra (Figura 39). Más del 50\% del crecimiento proviene del bosque (1175 ha), lo que equivale al 20\% del total deforestado en el período. La urbanización ocupó en primer lugar las áreas con escasa pendiente, expandiéndose luego sobre las laderas de las sierras (Gavier \& Butcher, 2004).
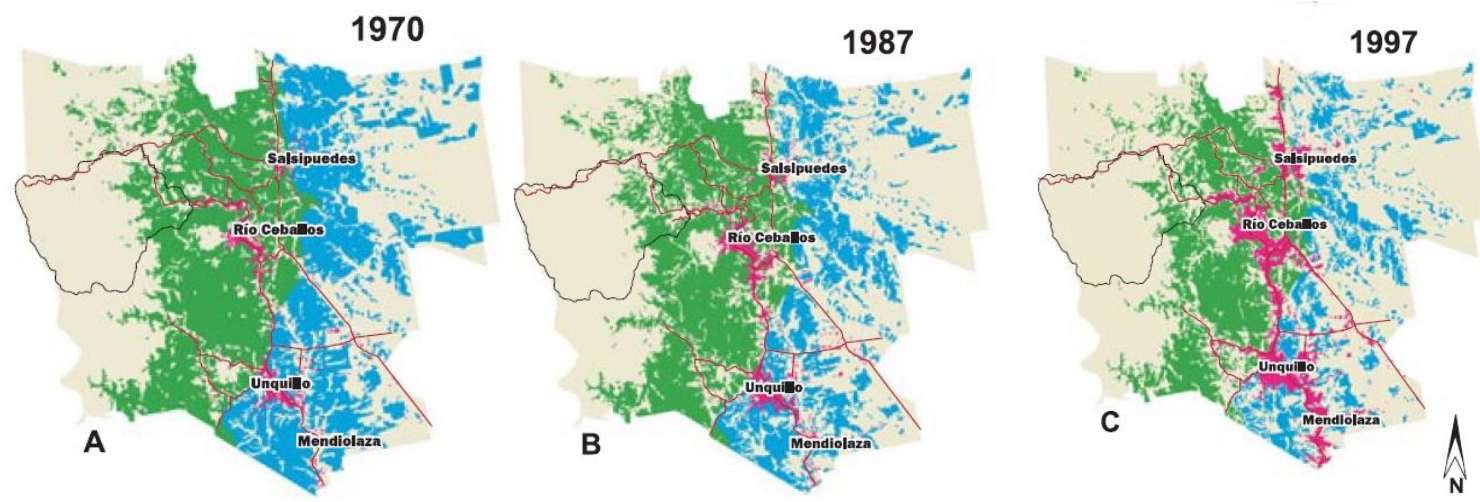

Figura 38. Deforestación 1970-1987-1997. Sierras Chicas. Las localidades mapeadas son desde Salsipuedes hasta Villa Allende. Fuente: Gavier \& Butcher, 2004. 
Según estudios de Gavier \& Butcher (2004), las áreas deforestadas durante el período 1970-1997 se localizaron principalmente en zonas de menor pendiente: entre 0 y $5^{\circ}$. Entre los 5 y $40^{\circ}$ la deforestación fue menor. Asimismo, se verifica que el trazado de caminos afectó significativamente la tasa de deforestación: el área de bosque a menos de 200 metros del camino trazado desapareció en mayor porcentaje que el área boscosa más alejada. Esto determina en gran medida las posibilidades de urbanización del valle (Tabla 14). La influencia de los caminos en la deforestación se observa como progresiva dado que no sólo contribuye a la fragmentación de paisaje, sino que, además la deforestación para vías de circulación habilita nuevos procesos de antropización. En lo relativo a la pendiente: el bosque de sierra expresó una pérdida de 1.2\% y el de llanura pedemontana un $2.6 \%$. En el último período del estudio (2004) los valores de deforestación se duplican. Este estudio también determino que el avance de la urbanización sobre áreas de bosque a veces alcanza pendientes de hasta un 30\% impulsados por el valor paisajístico que adquiere el bosque. Además de los factores mencionados la deforestación tiene un fuerte componente cultural cuando el uso de suelo de destino es residencial.

Tabla 14. Área ocupada en el año 1997 por coberturas que reemplazaron a superficies originalmente cubiertas por el bosque nativo en el año 1970

\begin{tabular}{|c|c|c|c|c|c|c|}
\hline Coberturas de reemplazo & Área total $(\mathrm{h})$ & $\%$ & Sierra $(\mathrm{h})$ & $\%$ & $\begin{array}{c}\text { Llanura pedemontana } \\
(\mathrm{ha})\end{array}$ & $\%$ \\
\hline Arbustales & 2453 & 43 & 1039 & 44 & 1405 & 41 \\
\hline Pastizales & 1602 & 28 & 546 & 23 & 1040 & 31 \\
\hline Urbanización & 1175 & 20 & 671 & 29 & 517 & 15 \\
\hline Cultivo & 364 & 6 & 2 & 0.1 & 353 & 10 \\
\hline Otros & 165 & 2.5 & 90 & 4 & 79 & 2.5 \\
\hline
\end{tabular}

Fuente: Gavier \& Butcher, 2004.

\section{Régimen de lluvias del sector}

Inundaciones extraordinarias que afectaron la cuenca

- febrero de 1939. En la cuenca del río Saldán. Cinco muertos, viviendas enteras desaparecidas. Desmonte para leña, mineras y ferrocarril. Habitantes 10.500

- $\quad$ enero de 1951. En ríos Salsipuedes, Chavascate y Saldán. Anegamiento de calles, rotura de puentes. Desmonte por el auge minero y exportación de carbón a Europa. Habitantes 14.500 (año 1950)

- $\quad$ 1966-1967. Crecidas en todas las Sierras Chicas. Anegamiento de calles, rotura de puentes. Habitantes: 22.500 (año 1960). 
- 1980-1981. Cuenca del Saldán y Salsipuedes. Dos muertos en Saldán, destrucción de industrias, viviendas, anegamientos de barrios. Habitantes 55.645 (año 1980).

- 1995. En todas las Sierras Chicas. Anegamiento de barrios. Incendios durante toda la década: se queman más de 100 mil hectáreas. Habitantes 68.326 (año 1991).

- 2000. En todas las Sierras Chicas. Evacuación de más de 600 personas, tres muertos, destrucción de viviendas, anegamiento de calles. Hubo otras inundaciones en lo sucesivo de la década: años 2004, 2008, 2010, 2012 y 2013. Habitantes 96.474 en 2001, y 140.102 en 2010.

*Hasta aquí fuente: J. Deón en La Voz del Interior del 22 de febrero de 2015. “Una cuenca en problemas”.

- $\quad 15$ de febrero de 2015. Cuenca Saldán Ceballos. 9 víctimas fatales, más de 2.000 viviendas afectadas (muchas con destrucción total o parcial que tuvieron que ser relocalizadas), comercios, industrias, establecimientos productivos y barrios enteros fueros impactados. Destrucción de puentes, vados y calles. (Diario la voz del interior)

\section{Reflexiones II}

La ubicación estratégica de la ciudad mediterránea de Córdoba le confiere particularidades en torno a otras regiones urbanas argentinas y del Mercosur, hecho que indica a priori que existen factores de tipo económicoproductivos que condicionan la configuración urbana y en particular los procesos de expansión. Sumado a esto desde sus orígenes presenta líneas territoriales (sobre todo rutas y caminos que exceden su ejido municipal) que planteaban la expansión del núcleo urbano, como el caso del Camino Real. Estos indicadores en el contexto del análisis de la ciudad colonial y su proceso de consolidación la posicionan como un caso de gran interés a la hora de analizar las dinámicas de transformación socio-ecológica.

Asimismo, como se desarrolló en el marco teórico (MT) de este trabajo, los últimos treinta años han sido de gran relevancia en el estudio de las dinámicas de crecimiento de estas áreas urbanas y las interacciones sistémicas que se producen al respecto. Los autores que refieren los antecedentes más importantes señalaron que los límites entre la urbanización y la ruralidad de un territorio condicionado por la topografía y la hidrografía presentan desde temprana data situaciones de fricción y conflicto en el encuentro de estos usos tradicionales del suelo. Esto, acompañado a la ausencia de modelos e instrumentos de planificación ha determinado la complejidad de su abordaje.

Dado que la ciudad de Córdoba, así como sus áreas de influencia atravesaron, según los diferentes contextos de impulso económico en el país, procesos y etapas de expansión, es posible afirmar que la ciudad estaba organizada 
radialmente a partir del núcleo urbano-colonial y su área de crecimiento, un primer anillo industrial y hacia el área rural, el anillo productor de alimentos o producción intensiva y un tercer anillo de producción de granos o extensiva, estos últimos de gran valor tanto provincial como nacional. A lo largo de los últimos años los procesos sin planificación de expansión urbana y en algunas etapas de baja producción interna, generaron la pérdida de áreas productivas valiosas del entorno urbano inmediato, sobretodo en el primer y segundo anillo.

Como caracterizaba Garay (2013) en el MT, la puja económica y de indefinición del uso del suelo periurbano definió lote a lote la transformación de áreas bajo regadío y de producción de alimentos en nuevas áreas urbanas o zonas de urbanizaciones cerradas al sur de la ciudad y nuevos procesos de antropización conurbada hacia el pedemonte del nor-noroeste de la región metropolitana.

Históricamente las condiciones del valle de Sierras Chicas han configurado un atractor de población urbana y rural, sin embargo, la dinámica de globalización urbana ha terminado por incluir este sistema serrano dentro de la ciudad de Córdoba por expansión y conurbación. Estos elementos han constituido una fuerte dinámica de interfase urbanorural y urbano-natural. Esta dinámica configuró estructuras antrópicas que definieron ejidos 0 jurisdicciones municipales arbitrarias. Esta idea de una planificación basada en sistemas viales a escala regional y, una realidad biofísica definió áreas de riesgo y eventos que aumentaron la vulnerabilidad de los asentamientos humanos.

Otra consecuencia de esta falta de interacción entre sistemas antrópicos y naturales es la existencia de áreas grises de gestión dado que la definición de ejidos (reales o pretendidos) en algunos casos de contraponen entre municipios o dejan áreas de jurisdicción provincial que en muchos casos constituyen áreas de bosque nativo o de riesgo ecológico.

La propuesta de análisis de las consecuencias de estos impactos sobre los procesos biofísicos parte de la concepción del territorio desde la unidad de cuenca. Esta unidad no se encuentra delimitada por límites administrativos y propone entender el territorio no desde el proceso de urbanización, sino desde las lógicas que rigen el territorio y como podrían interactuar respecto a los impactos en cada sector de, por un lado, un OT sostenible y por otro la planificación de umbrales 0 áreas críticas que no deberían alcanzar altos niveles de antropización.

Como se ha mencionado a lo largo de la presentación del caso de estudio y los principales elementos que lo configuran, el sector de Sierras Chicas, y en particular la cuenca Saldán han sido el principal eje de expansión urbana de la ciudad de Córdoba, incluso por sobre sectores como el sur de la ciudad con características de llanura (Figura 39). Esta dinámica de cambio de usos del suelo ha generado pérdidas significativas coberturas de bosque 
y la consecuente alteración de los ciclos hidrológicos a través de la impermeabilización de áreas de la cuenca que desempeñaban funciones críticas para el sistema socio-ecológico.
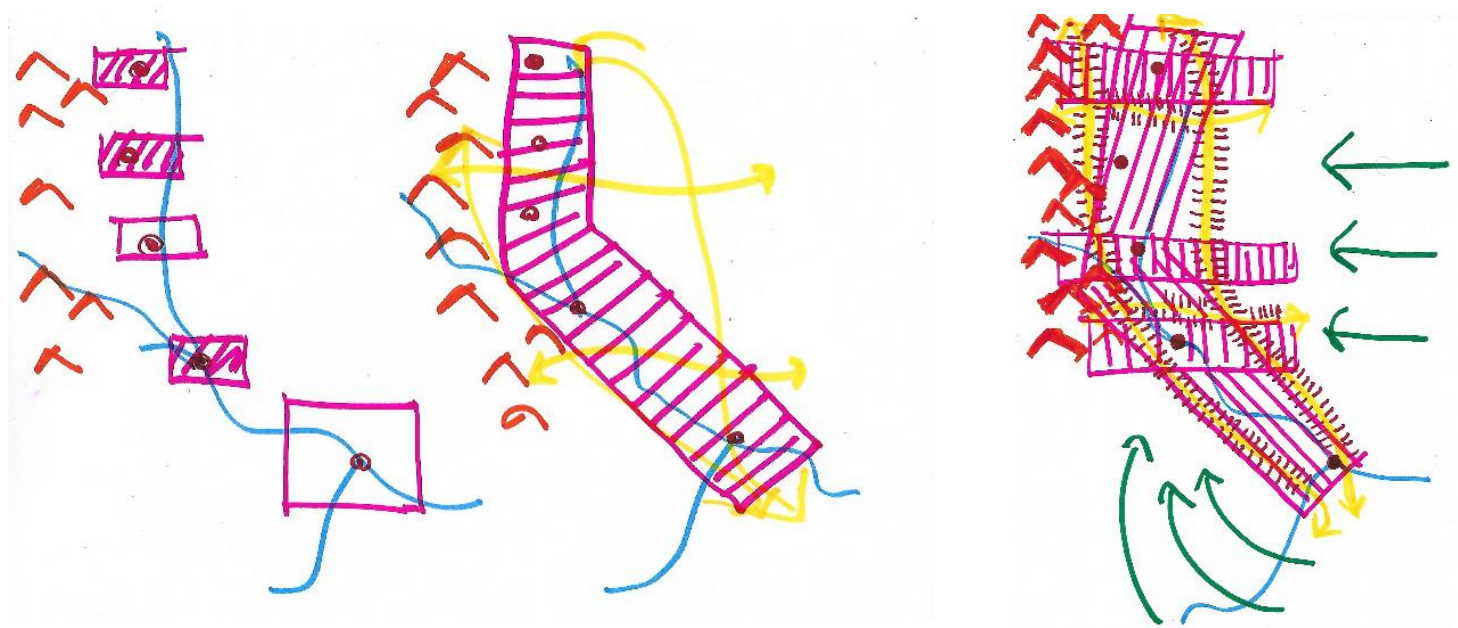

Figura 39. Diagrama síntesis del sistema natural-urbano de Sierras Chicas. (Izquierda): Límites naturales y ejes principales de urbanización del valle. (Derecha): Modelo de crecimiento urbano y movimientos de expulsión de la ciudad capital. Fuente: Céliz, 2017.

Este crecimiento exponencial presentó impulsores muy claros desde un enfoque urbano, en primer lugar, la cercanía al área central, la rápida accesibilidad daba por importantes vías de comunicación y la gran cantidad de flujo vehicular que son capaces de soportar a pesar de su ya saturada circulación. Por otro lado, si bien aquí no se ha explorado tal variable, existen dados que permiten inferir que el valor del suelo al alejarse del área central de Córdoba disminuye, hecho que permitió una etapa de urbanización reciente en donde las viviendas del sector pasaron a ser de segunda residencia, a primera.

De esta etapa se desprenden varias incógnitas:

¿Cuál es la relación cuantitativa que puede diagnosticarse entre el proceso de avance urbano sobre la cuenca del arroyo Saldán y las consecuencias en términos de entropía-negentropía del sistema?

¿Es la urbanización un impulsor por sí mismo de afectaciones ecosistémicas en el valle serrano?

¿Qué tipo de urbanización afecta la cuenca? ¿El aumento de esta urbanización se dio en términos de alta o baja densidad de ocupación del suelo? ¿Qué elementos permiten estimarlo en el tiempo analizado? 


\section{Cap. 04}

Sierras Chicas: de los planes a los socio-ecosistemas 


\title{
Hacia el modelo territorial actual
}

\author{
Ordenamiento territorial en Sierras Chicas: una cronología
}

Directa o indirectamente, numerosos planes y normativas han influenciado la forma en que se configura el uso del suelo en las Sierras Chicas. En algunos casos han estado incluidas dentro de propuestas de OT generales, como es el caso de la Ley de bosques para la provincia de Córdoba o las leyes del IPLAM (2012). Otras veces se ha hecho énfasis en la necesidad de "ordenar" este sector debido al crecimiento urbano exponencial de los últimos años, es el caso del "Plan de Ordenamiento para Sierras Chicas" (IPLAM 2016).

La primera etapa de diagnóstico focaliza en la revisión de los principales impulsores de cambio en el uso del territorio serrano. Para esto se realizó una síntesis de los planes y leyes que afectaron la cuenca como forma de entrada a este territorio, teniendo en cuenta el marco general en el que se impulsaron. De la misma manera se aborda el modelo territorial actual de la cuenca, señalado aquellos elementos y conceptos que han contribuido a la sostenibilidad del sistema, en algunos casos de manera indirecta. Otros abordajes no son proyectos, sino estudios del sector que no implican simplemente un estado del arte, sino que aportan zonificaciones o directrices relevantes para el $0 \mathrm{~T}$.

Como se analizó en el MT, la mayoría de los procesos de planificación en las ciudades latinoamericanas han venido "por detrás" de la ocupación del territorio y esto mismo se verifica en los lineamientos que mencionan a las SSCC como objeto de estudio y OT posteriores al año 2000.

\section{Comunidad regional metropolitana de Sierras Chicas: Propuesta IPLAM}

El antecedente inmediato de esta propuesta de Irós (2007), es la ley provincial del año 2004 "Ley 9206 de creación de comunidades regionales." Si bien a la fecha la aplicación de las comunidades regionales no ha implicado avances o transformaciones en la gestión del territorio, constituye un instrumento novedoso sobre la lectura del territorial. Si bien en su discusión el foco estaba puesto en la descentralización hacia los departamentos del interior, su aplicabilidad a la región metropolitana de Córdoba configura una lectura de particular interés. Este proyecto propone la creación de tantas comunidades regionales como departamentos, y la vinculación de distintos municipios pertenecientes a distintas comunidades podrían asociarse a través de la creación de comunidades regionales a tal fin. La participación de cada municipio sería voluntaria y adoptada por los órganos institucionales de cada gobierno. Podrían formar parte por resolución de los cuerpos orgánicos, los representantes de los Consejos de la Sociedad Civil de la región. Un punto de interés en este trabajo es el que define que la Comunidad Regional, 
tiene jurisdicción y competencia en todo el territorio de la región, con exclusión de las zonas que correspondan a radios urbanos donde los municipios y las comunas presten efectivamente los servicios permanentes a la población, salvo que, sobre este punto exista un convenio o acuerdo particular. Esta salvedad constituye un aporte de interés al OT, sobretodo en el caso de las denominadas "zonas grises" que superponen o niegan jurisdicción sobre determinadas áreas del territorio provincial en Córdoba. En ese sentido, el ejercicio del Poder de Policía, la provincia lo delega en las comunidades regionales, las cuales pueden aceptar o rechazar este punto que se establecería de común acuerdo con la provincia (art. 8).

En definitiva, el objetivo de la regionalización es el de descentralizar acciones y recursos a partir de una figura de OT territorial novedosa -no porque no se haya implementado en otras regiones, ya hemos visto ejemplos en el OT europeo-. También implican salvar vacíos legales y políticos que se agudizan en territorios conurbados y metropolitanos como el caso de la cuenca Saldán.

Según Irós (2007), este instrumento no era más que el aumento de instancias burocráticas en términos de planificación, orientada a superponer un estamento de gobierno supramunicipal. Sin embargo, plantea que en el caso de Sierras Chicas podría ser tenido en cuenta, dato que no es menor dadas las ya mencionadas problemáticas administrativas-territoriales. Una de las principales críticas es que, si la CR responde al departamento, resulta nuevamente en la complejidad de territorios que a veces pertenecen a distintos departamentos, pero comparten tanto problemáticas como condiciones naturales y antrópicas. Del mismo modo que sucede con aquellas localidades que por cuestiones normativas y de organización jurisdiccional forman parte de un departamento pero que no comparten la idea regional en términos reales.

La comunidad regional metropolitana de Sierras Chicas integra entonces, un territorio con características comunes que otorgan territorialidad al sector como tal. La propuesta de Irós (2007) se verá reflejada e incorporada -aunque tímidamente- en las "bases `para el plan director de la ciudad de Córdoba" (2008) de la secretaría de desarrollo urbano de la ciudad de Córdoba y la facultad de arquitectura de la UNC.

El concepto más relevante que aporta la propuesta se define a partir de la frase "de lo urbano a lo rural", para plantear una progresión secuencia de densidades de tejido y dieñar las transiciones del uso del suelo. Asimismo, este concepto se establece con más fuerza a partir de la propuesta de fortalecimiento de nodos que configuren las redes territoriales. Estos nodos se materializan principalmente a partir de la red vial (Figura 40) y corredores forestales desfasados entre sí. De esta manera, pocos elementos de la propuesta difieren de los planes tradicionales. Los elementos centrales radiales y anulares de reminiscencia haussmanniana, referencian el esquema básico sobre el cuál se extiende el territorio, dadas las características propias de la figura radial que ya 
es característica de la morfología urbana cordobesa y que se ve reforzada hasta aquí. Este esquema refuerza también las conexiones y por lo tanto la expansión hacia SSCC.

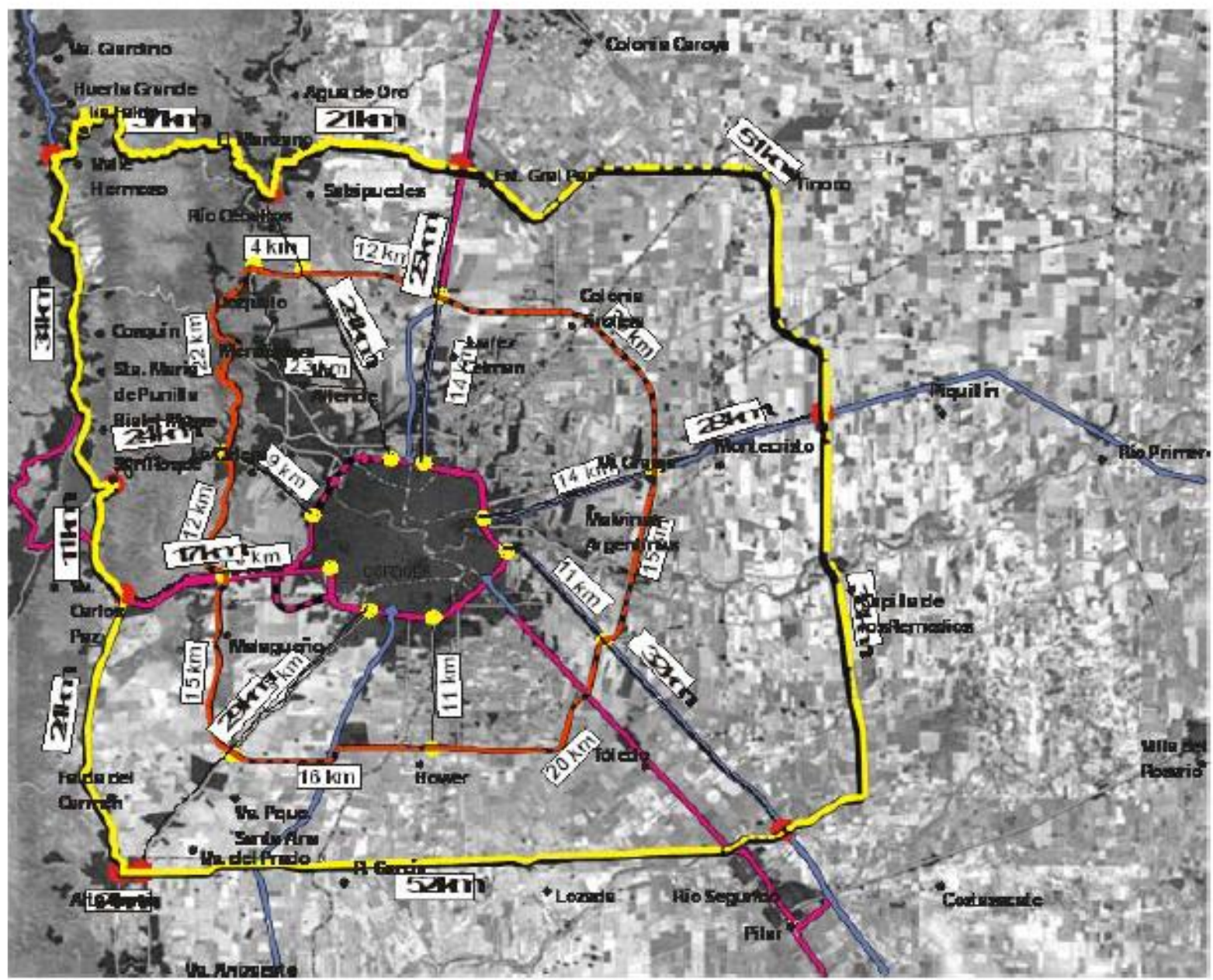

Figura 40. Diagrama de conectividad: nodos y redes ampliados. (fucsia) Avenida de circunvalación, (azul pastel) autovías y autopistas, (naranja) Circunvalación metropolitana. Longitud aproximada 142 Km, (amarillos) Circunvalación regional. Longitud aproximada 270 Km. Fuente: Plan director Córdoba 2020.

Un aporte interesante es la revalorización de ramales ferroviarios como sistema de transporte masivo metropolitano. Si bien en términos teóricos la propuesta señala las problemáticas producto de la ampliación de la superficie urbana y la necesidad de compatibilizar usos con el área rural, así como la idea de progresión en el cambio del uso del suelo, el reforzamiento de la morfología radial del sistema vial, no hace más que favorecer la expansión urbana del área metropolitana. 


\section{Ley N09814. ordenamiento territorial de bosques nativos de la provincia de Córdoba}

En Argentina, la política a nivel nacional sobre la gestión de los recursos forestales depende de dos organismos distintos. Los bosques nativos están bajo la órbita de la Secretaría de Ambiente y Desarrollo Sustentable de la Nación, a través de su Dirección de Bosques; mientras que las plantaciones forestales están bajo la órbita de la Secretaría de Agricultura, Ganadería, Pesca y Alimentos a través de su Dirección de Producción Forestal.

En el año 2007, el gobierno nacional implementó la Ley N. ${ }^{\circ} 26.331$ de presupuestos mínimos de protección ambiental de los bosques nativos. Esta herramienta fija los presupuestos mínimos para el manejo sustentable y la conservación de los bosques nativos a los que deben ajustarse las autoridades de las jurisdicciones provinciales que, de acuerdo a la Constitución Nacional, tienen el dominio originario de los recursos naturales existentes en sus territorios. Esta ley contempla acciones como la mitigación en el proceso de pérdida de cobertura forestal por desmontes y establece una regulación de la deforestación mediante un ordenamiento territorial de los bosques, fomenta la conservación y el manejo sustentable a través de un subsidio directo, de carácter económico a los propietarios, reconoce el pago de SS EE y crea un programa nacional de protección de los bosques nativos en el marco del manejo forestal sustentable. Como en muchas provincias argentinas, la adecuación de esta ley tuvo controversias e intereses diversos.

La instrumentación de esta ley se expresa, luego de instancias de relevamiento y trabajo con especialistas, en un mapa de zonificación de usos permitidos del suelo según grados de protección del bosque (Figura 41). Córdoba particularmente, no obtuvo el visto bueno de nación tras presentar su primera propuesta, por lo que finalmente (en 2010) y por decreto, se realiza el mapa de OTBN aún vigente. Este mapa define 3 áreas principales de posibles usos y modificaciones del suelo del bosque nativo:

Categoría I (rojo): sectores de bosque nativo de muy alto valor de conservación que no deben transformarse. Se incluyen áreas que, su valor de conectividad, la presencia de valores biológicos sobresalientes y/o la protección de cuencas que ejercen, ameritan su persistencia como bosque a perpetuidad, aunque estos sectores puedan ser hábitat de comunidades indígenas y campesinas y pueden ser objeto de investigación científica y aprovechamiento sustentable.

Categoría II (amarillo): sectores de bosque nativo de mediano valor de conservación que pueden estar degradados 0 en recuperación, pero que con actividades de restauración pueden tener un alto valor de conservación. Se permiten en esta categoría los siguientes usos: aprovechamiento sustentable, turismo, investigación y recolección científica. Esta categoría es la más confusa ya que se entiende como una categoría permisiva en detrimento de otras zonas y no una categoría en progresión a convertirse en zonas de alto valor de conservación. 
Categoría III (verde): sectores de bosque nativo de bajo valor de conservación que pueden transformarse parcialmente 0 en su totalidad dentro de los criterios establecidos por la ley.
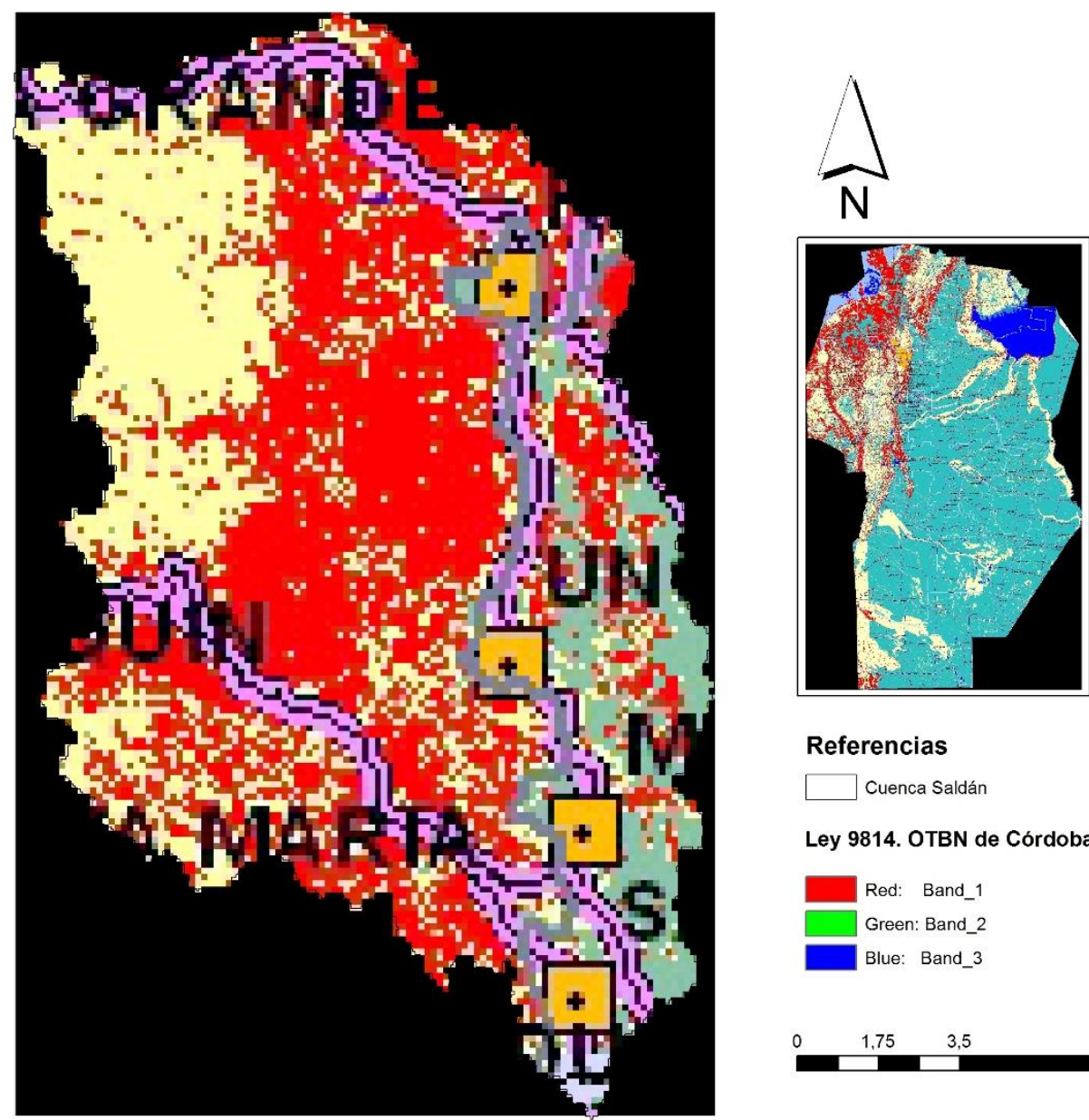

Referencias
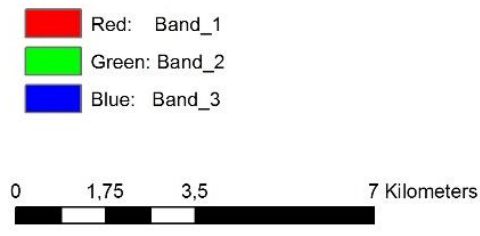

Figura 41. Ley 9814 de ordenamiento territorial de bosques nativos de Córdoba. Recorte del área cuenca Saldán de imagen jpg original. Fuente: Céliz, 2018 sobre base en Qgis de la cátedra de ordenamiento territorial FCEFyN.

La crítica más importante que recibió desde diversos sectores estuvo asociada a las definiciones de áreas de mayor protección de bosque. En diciembre del año 2016, nación solicitó la actualización del mapa de 0TBN de la provincia, sin embargo, aún no fue avalada dicha actualización. El rechazo más importante provino de sectores de la sociedad civil y el activismo ambiental de Córdoba. 
2009. Propuesta de la Comisión de Ordenamiento Territorial de Bosques Nativos para adecuación de la ley N. ${ }^{\circ} 9814$ de OTBN

Este proyecto es resultado de un proceso participativo, que inicia con la conformación de la comisión de ordenamiento territorial del bosque nativo (COTBN) propuesta por la secretaría de Ambiente de la provincia de Córdoba el 24 de noviembre de 2008. La misma está integrada por miembros de instituciones y organizaciones vinculadas a la problemática ambiental: Unidad Ejecutora para Ordenamiento Territorial de los Bosques Nativos de la Secretaría de Ambiente de la provincia de Córdoba, Ministerio de Agricultura Ganadería y Alimentos de la provincia de Córdoba, Secretaría de Turismo de la provincia de Córdoba, Instituto Nacional de Tecnología Agropecuaria (INTA), Programa Social Agropecuario (PSA - SAGPyA), Universidad Nacional de Córdoba (UNC - SEU, ISEA, IMBIV, CERNAR, GI-OTP, MAM, SPCB, CER, AAAM, CPA, Escuela de Biología), Universidad Nacional de Río IV (UNRC), Universidad Nacional de Villa María (UNVM), Universidad Católica de Córdoba (UCC), Administración de Parques Nacionales (APN), Federación Agraria Argentina (FAA), Movimiento Campesino de Córdoba (MCC), y las ONGs FUNAM, CEDHA, Ecosistemas Argentinos, Grupo Escalera, Wichan, PCRSC, Foro de los Ríos, Fun. Conydes, Colegio de Ingenieros de agronomía de la provincia de Córdoba.

La propuesta tuvo como premisa la construcción colectiva, interdisciplinaria e interinstitucional de la zonificación para el OTBN (Figura 42). Se realizaron siete talleres regionales en el interior de la provincia, en las localidades de: Sebastián el Cano, Río Cuarto, Cruz del Eje, Ballesteros, Villa General Belgrano, Villa Dolores y Río Ceballos, donde se focalizó en el debate intersectorial sobre el proceso de ordenamiento territorial en cada una de estas regiones, generando propuestas para la resolución de conflictos ambientales que surjan en cada uno de los módulos de gestión ambiental, fomentando actividades y alternativas sustentables en el tiempo. Este proyecto de ley surge como respuesta al estado crítico del bosque nativo de Córdoba, proponiendo un marco protector de las áreas remanentes y señalando la necesidad de recuperar el bosque degradado.

“(...) Como resultado de ello y del alto grado de fragmentación de parches de bosque remanentes, se ponen en riesgo también la provisión de servicios ambientales esenciales para nuestra sociedad, como la provisión de agua a toda la provincia, los ingresos cercanos a los $\$ 3900$ millones anuales aportados por el turismo y el desarrollo de numerosas economías regionales." (Cabido 2008, citado en COTBN, 2009, p.3) 


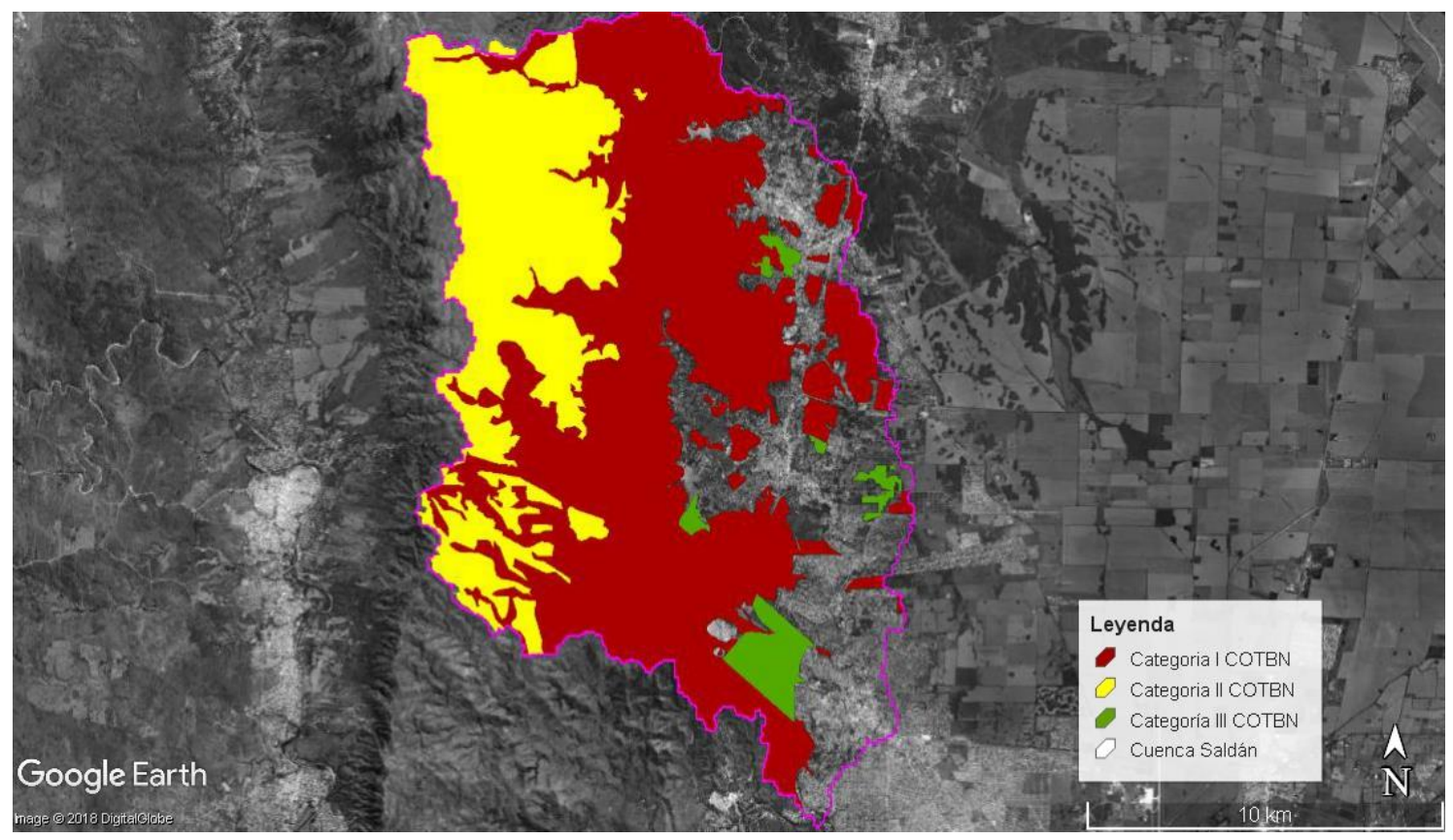

Figura 42. Mapa de la propuesta COTBN 2010. Área cuenca Saldán. Fuente: Céliz, 2017 sobre imagen Google Earth.

El bosque, como componente fundamental de la continuidad de las ciudades y ambientes productivos, funciona como el soporte que garantiza a través de la biodiversidad las condiciones de sustentabilidad de los sistemas antrópicos y productivos. Cuanto mayor sea la biodiversidad que alberga y produce, mayor serán las posibilidades de seguir siendo un sistema en sí mismo. En tanto disminuyen las condiciones que favorecen estos procesos, sea esta la pérdida de superficie por completo o la fragmentación de esta superficie mayor será la pérdida de SE necesarios para las comunidades. El enfoque de este proyecto de ley es construido a partir del conocimiento de diversas disciplinas científicas y con actores territoriales desde los saberes populares. El texto de la propuesta resalta la necesidad de declarar la emergencia forestal en la provincia y la urgencia de legislar con normas que protejan los bosques nativos y por extensión a la sociedad a fin de preservar la seguridad ambiental, calidad de vida, economía y salud (COTBN 2009).

\section{Lineamientos del plan estratégico urbano territorial del área metropolitana de Córdoba. IPLAM}

I. Ley $9687 / 09$ para el plan vial director y

II. Ley $9841 / 10$ de regulación de los usos del suelo

El 28 de noviembre de 2008 se firma entre la provincia de Córdoba y los municipios involucrados el "convenio de avance para el plan de ordenamiento territorial del área metropolitana de Córdoba”, la Ley N. 9.595 . Se organizan 
así, los rasgos generales del proyecto que definen: una primera aproximación al sistema Vial expresado en el documento "lineamientos para un plan vial director de la región metropolitana de Córdoba" que se pone a consideración de las municipalidades. Luego se sigue un mecanismo de consulta sobre usos del suelo, según una metodología de categorización en base a una "guía para el relevamiento de datos sobre usos del suelo" (IPLAM Tomo I, 2012).

Esta propuesta, retoma las ideas planteadas en su antecesora del año 2007: "comunidad regional de Sierras Chicas" y trabaja sobre los conceptos de red y trama; y nodos y centros de actividad urbana. La base es la estructura urbana con sus diferentes escalas y su integración tanto a la estructura local con la metropolitana (Figura 43). La red queda expresada en la conexión de los diferentes sistemas de circulación vial entre sí y a los nodos definidos como puntos de jerarquía y especialización dentro de la red. Hay una importante incorporación de suelo destinado a corredores verdes, forestales, reservas naturales y, definiciones de espacios de producción y tipo de producción tanto rural como industrial.

Esta caracterización que realiza el IPLAM, 6 años después de la propuesta de la comunidad regional de SSCC implica una lectura ampliada de la problemática territorial, es decir que se ha puesto al territorio "en contexto" definiendo a partir de las etapas de actuación los anillos del área metropolitana de Córdoba.

Una Primera etapa denominada "ámbito del plan", involucra a los municipios próximos a la ciudad de Córdoba, un total de 16 localidades. De esta forma el plan vial define el límite del área metropolitana que se diferencia de la región por la continuidad de los municipios con la ciudad de Córdoba (Ley № 9.687). Se excluye de este grupo a la misma ciudad capital, por su grado de complejidad y por contar ésta con un extenso cuerpo normativo sobre usos y ocupación del suelo. La segunda etapa -o región metropolitana-, abarca 30 localidades relacionadas con el anillo regional, desarrolladas siguiendo un radio promedio de $35 \mathrm{~km}$ desde el centro de la ciudad de Córdoba. Ambas etapas -excluyendo capital-, cubren todo el territorio metropolitano bajo este estudio. De esta manera se definen dos anillos metropolitanos para la ciudad de Córdoba.

Es de vital importancia aclarar que gran cantidad de la información sobre el territorio caso de estudio de esta tesis proviene del trabajo realizado por el IPLAM en esta instancia, y que no se limita a la obtención de una clasificación de usos de suelo. 

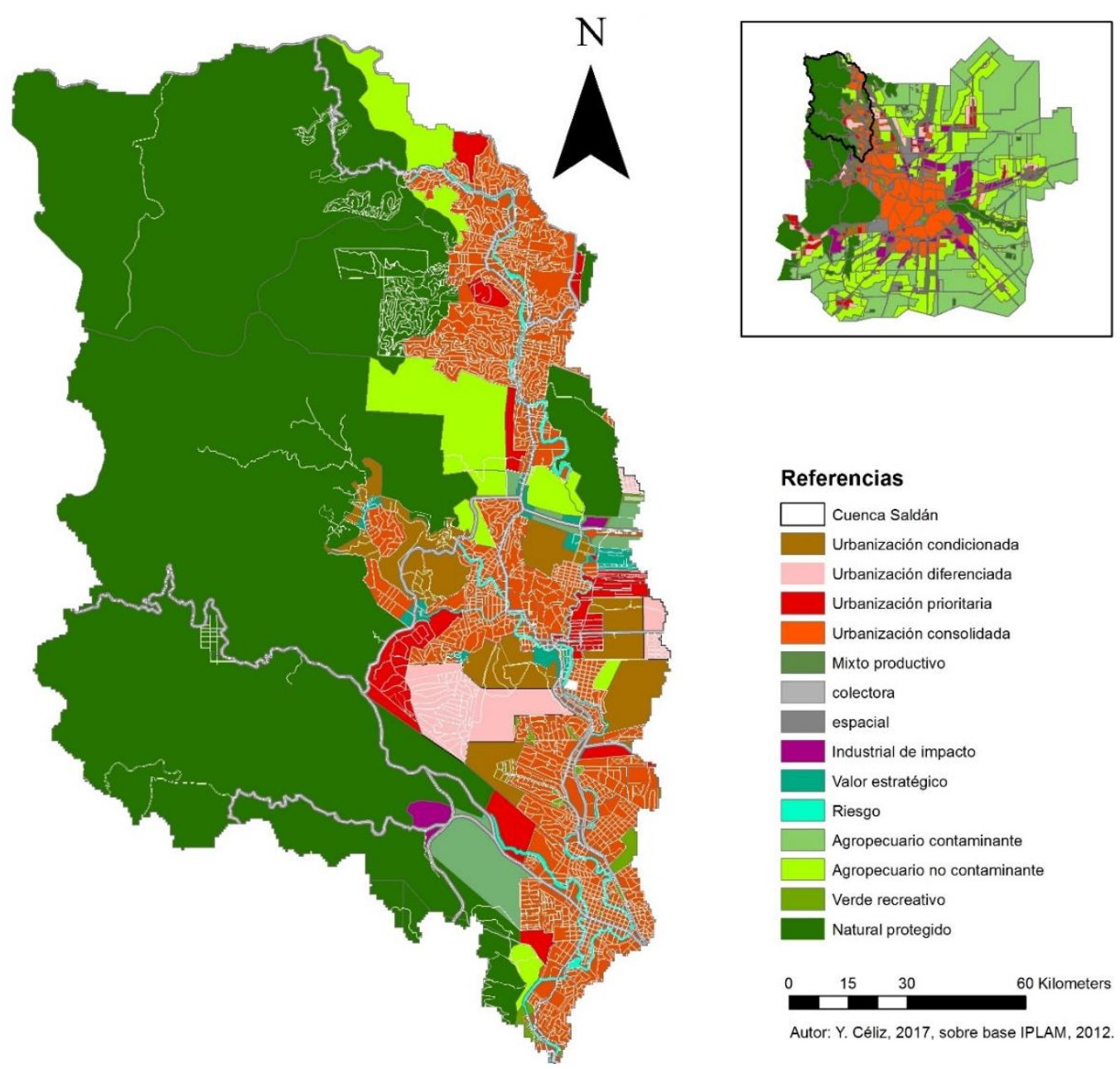

\section{Referencias}

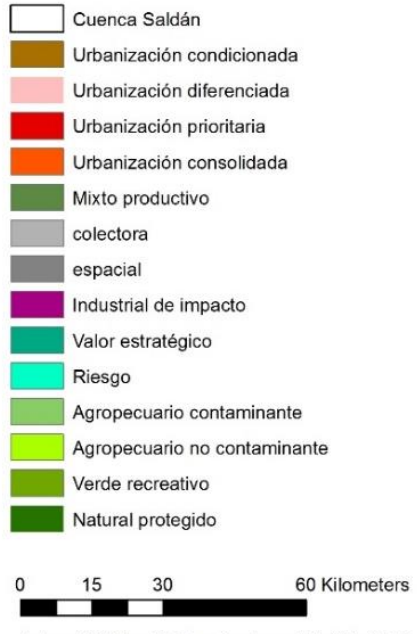

Autor: Y. Céliz, 2017, sobre base IPLAM, 2012.

Figura 43. Ley 9687 de usos del suelo cuenca Saldán. SSCC. Fuente: Céliz, 2018 sobre base de datos IPLAM, 2012 y base en Qgis cátedra de ordenamiento territorial FCEFyN-UNC.

Según IPLAM (2012) el uso de suelo de la cuenca Saldán, se distribuye de la siguiente manera:

Tabla 15. Usos de suelo en la cuenca en $\mathrm{Km}^{2}$

\begin{tabular}{|l|c|}
\hline \multicolumn{1}{|c|}{ Uso del suelo } & Área en $\mathrm{Km}^{2}$ \\
\hline Natural protegido & 130.24 \\
\hline Verde recreativo & 1 \\
\hline Agropecuario no contaminante & 10 \\
\hline Agropecuario contaminante & 0.05 \\
\hline Mixto productivo & 3.40 \\
\hline Área de riesgo & 2.80 \\
\hline Área de valor estratégico & 1.20 \\
\hline Urbano consolidado & 35 \\
\hline
\end{tabular}




\begin{tabular}{|l|c|}
\hline Urbano condicionado & 5.40 \\
\hline Urbano diferido & 4.70 \\
\hline Urbano prioritario & 6 \\
\hline Industrial de impacto & 0.60 \\
\hline Red vial: colectora & 7 \\
\hline
\end{tabular}

Fuente: Céliz, 2018.

Según la designación de superficies que hace el IPLAM en la ley de usos del suelo (Figura 44) y en orden de impacto se encuentran: el uso de suelo natural protegido (53\%), el uso de suelo urbano consolidado (\%14), agropecuario no contaminante (4\%) y la superficie destinada a calles, colectora y demás infraestructura de conexiones viales (3\%). Cabe señalar que el área que se define como estratégica no tiene incidencia alguna en este gráfico de porcentajes; lo mismo sucede con el área definida como de riesgo -ubicada principalmente en zonas de ribera de arroyos y curvas naturales de los cursos de agua superficiales. El otro porcentaje llamativo es lo que se hemos designado como "sin definir", que constituye el $16 \%$ de superficie de toda la cuenca.

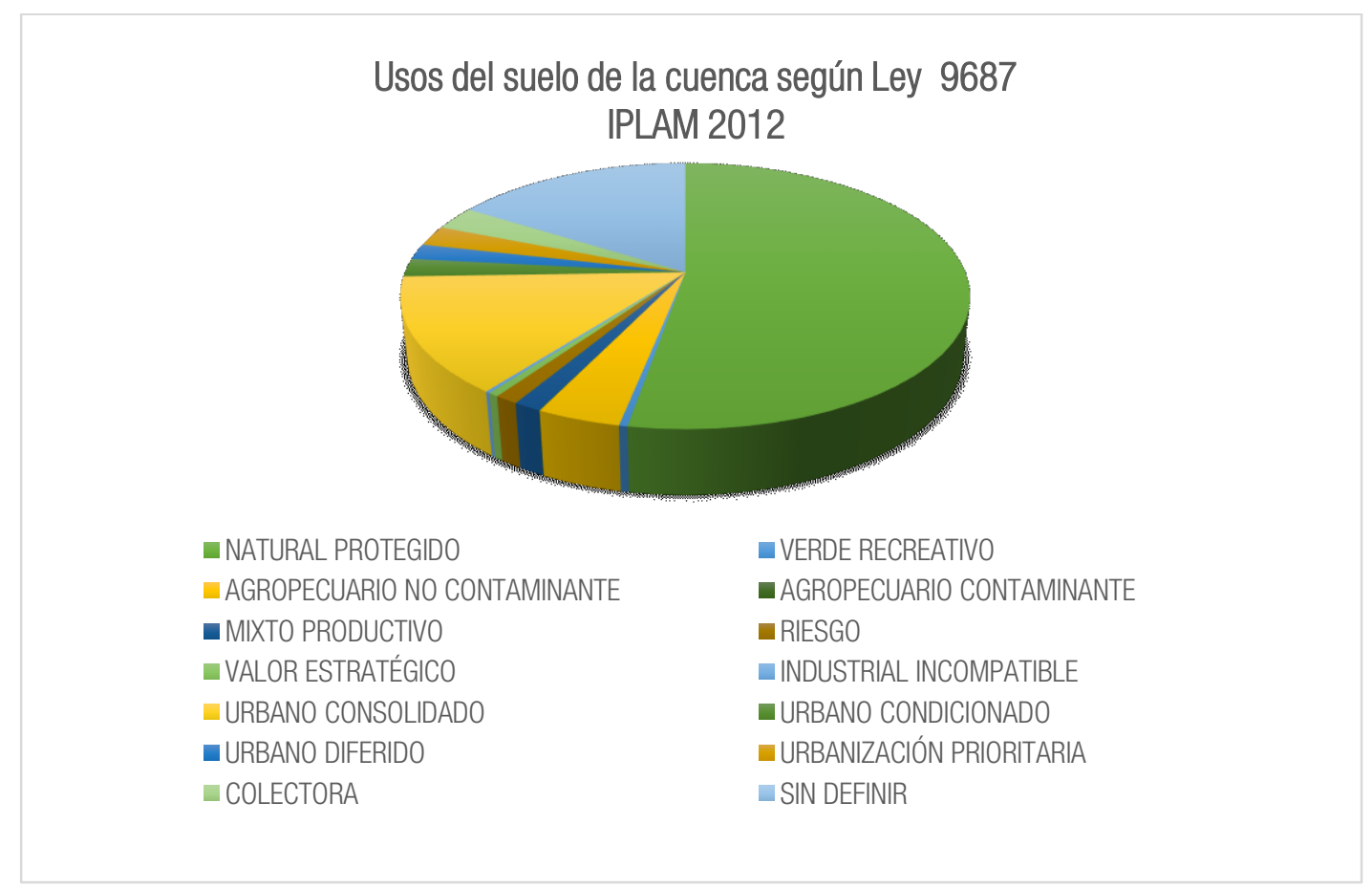

Figura 44. Porcentajes de ocupación del suelo en la cuenca según IPLAM 2012. Fuente: y. Céliz, 2018. 
2016. Mapa de Riesgo de inundaciones en la cuenca del río Ceballos y Saldán. Impacto de las inundaciones de 14 de febrero de 2015 Informe del ISEA

"A fines de 2013, la Universidad Nacional de Córdoba difundió un trabajo científico que alertaba sobre los riesgos de deslizamientos (tierra, roca y agua) e inundaciones en la zona de las Sierras Chicas de Córdoba, particularmente en la cuenca de los ríos Ceballos y Saldán.” (Redacción UNCiencia, 2016).

El estudio de riesgo en las SSCC realizado por el equipo de ordenamiento territorial del ISEA, se enmarca en un proyecto de investigación de la secretaria de ciencia y tecnología de la universidad nacional de Córdoba (SECyT UNC), sobre efectos de los cambios de cobertura y usos de la tierra en las cuencas hídricas de la provincia de Córdoba durante los años 2014 y 2015. La metodología adoptada para el caso de la cuenca de estudio responde a los siguientes aspectos: i) sistemas de información geográfica, ii) clasificación de coberturas y cambios de uso, iii) modelos multicriterio en base a la teoría de la decisión, y iv) la validación a campo de los datos obtenidos. Este estudio analizó el estado del bosque para el año 2014 en base a imágenes satelitales y su relación con la dinámica urbana del sector. A partir del modelo multicriterio se evaluaron variables de pendiente, distancia a los ríos y arroyos, niveles de altitud en relación al mar y la manera en que participan las subcuencas hasta la salida de la cuenca de Río Ceballos-Saldán. Los muestreos realizados por el equipo se realizaron 5 días después del último evento de lluvias extraordinarias a la fecha (15/02/2015). Los sitios de muestreo se localizaron en Villa Allende, Mendiolaza, Unquillo, Río Ceballos y zonas del dique La Quebrada. En cada estación de muestreo (se obtuvieron 102 puntos), se observaron daños: en puentes, vados, viviendas, rutas y caminos vecinales, casas anegadas, altura de huella de barro y restos vegetales en cercos y paredes de viviendas (Barchuk 2016).

El resultado de este trabajo es un mapa de riesgo de la cuenca (Figura 45), que definen zonas de alto y bajo riesgo de inundaciones ante lluvias extraordinarias. Esta Información, así como su divulgación constituyen material de suma importancia a nivel de planificación territorial no sólo teniendo en la exposición a lluvias extraordinarias, sino que es un instrumento fundamental para definir los límites de la expansión urbana y el estudio de dinámicas hidrológicas y de bosque como procesos que deben ser incorporados al OT. 


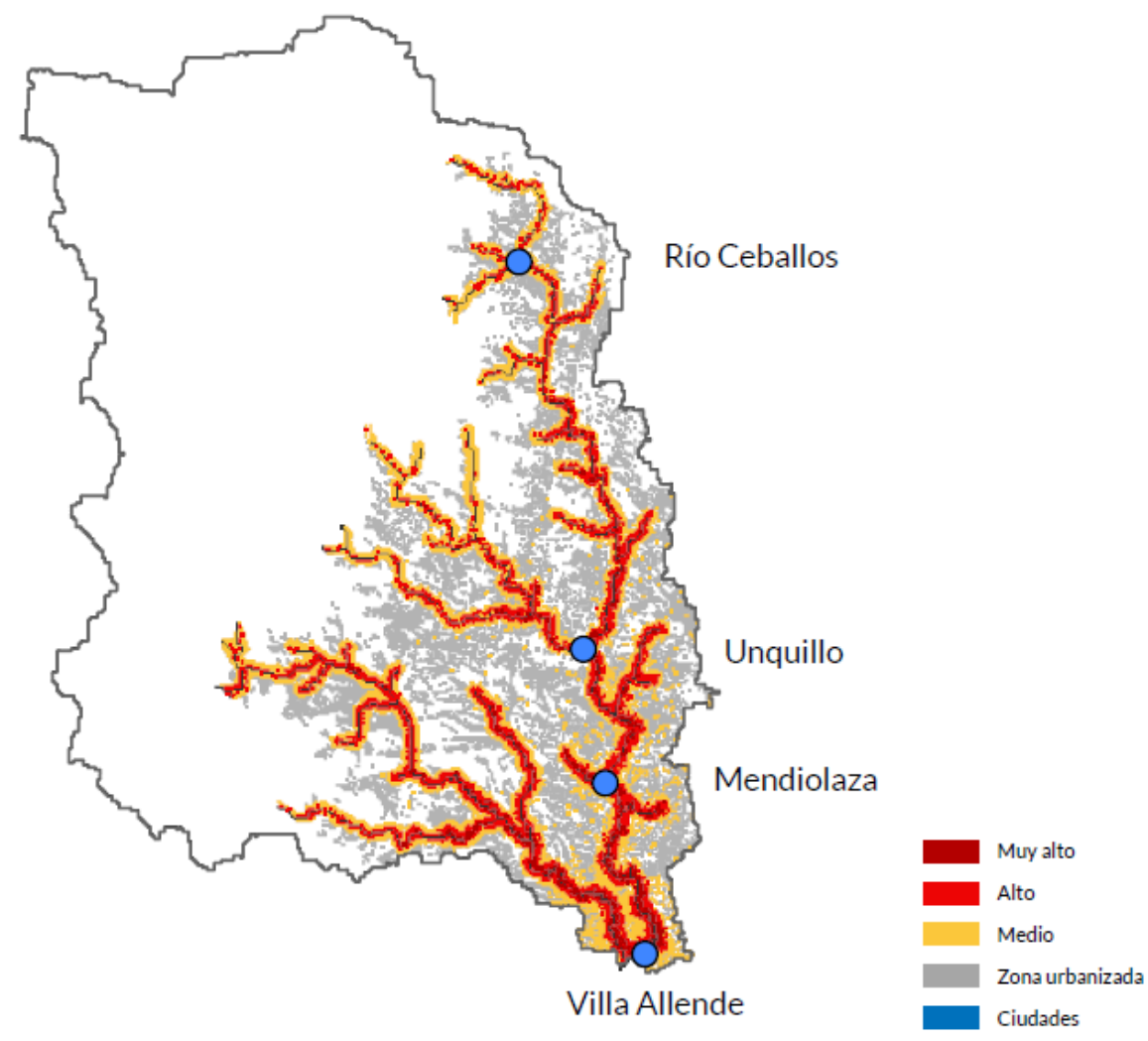

Figura 45. Mapa de riesgo de inundaciones en la cuenca Saldán. Fuente: Barchuck et al. 2015

La observación histórica del estudio y planificación de la cuenca ha demostrado que recién en los últimos 15 años se logra identificar la problemática de interfase urbano-natural. Esto se verificó en el sector de estudio debido a la complejidad de factores que intervienen en la dinámica territorial. En este caso los procesos de urbanización caracterizados, se desarrollan en un ecosistema con características propias del bosque chaqueño y de pendiente serrana. Esto implica condicionantes naturales que no pueden ser sorteados. La integración del OT con los procesos biofísicos del territorio es cuanto menos urgente.

la mayoría de las acciones tendientes a ordenar el territorio conurbado consistieron en profundizar las vías de acceso a las SSCC y la extensión de áreas urbanas sobre áreas de bosque. Como se ha mencionado con anterioridad, el reemplazo del área de bosque por área urbana no implica necesariamente un aumento en la exposición de la población a inundaciones extremas, sin embargo el reemplazo de bosques nativos en situación de pendiente sin conocimiento de base respecto los procesos bio-físicos que impactan en el territorio, implica necesariamente la alteración de procesos naturales que se ven reflejados en las condiciones en que los asentamientos humanos habitan el territorio. La atención sobre el área de interfase urbano-natural, donde la 
mayoría de las dinámicas se intensifican por avance de un uso del suelo y retroceso de la cobertura de bosque, no ha sido hasta el momento de esta tesis, objeto de estudio para el OT en el área metropolitana de Córdoba.

\section{El modelo territorial de Sierras Chicas}

Esta revisión de los principales aportes de la normativa y los planes de 0T para la cuenca se articularon en un modelo territorial que incorpora los aportes más significativos en términos de protección de procesos biofísicos del sector. De los aspectos más relevantes observados en esta lectura territorial, se observa la coincidencia de la mayoría de las propuestas en el área de protección ambiental, en algunos casos definida como reservas, áreas de máxima protección o zona de bosque, contradictoriamente la mayoría de estas propuestas no desarrolló planes de manejo o instrumentación de leyes o normativas por lo que la mayor parte de esta superficie no cuenta con ninguna figura de protección ambiental efectiva.

En la observación sistémica más amplia, también es posible observar que la superposición de las curvas de nivel y los cursos agua a este modelo, evidencian que no son tenidos en cuenta y que, la zonificación se realiza como si fuera una tabula rasa donde se dibujan líneas que dividen procesos como lo hacen con los usos del suelo.

Las zonas de urbanización de alta densidad coinciden con los cursos de agua y las áreas de mayor riesgo, sumado a esto, las zonas propuestas como de urbanización futura siguen una lógica morfológica y se definieron sin información de base territorial específica. Dado que es la interfase urbano-natural la mayor área de contacto con la urbana es probable que también en la mayoría de los casos, esas áreas de completamiento sean de bosque. Si bien es mucho menor el porcentaje de áreas de contacto urbano-rurales, también son impactadas por las superficies destinadas a urbanizar. En el caso de la ley de zonificación y usos de suelo de IPLAM (2012) existe una referencia denominada "de riesgo" pero no se accedió a datos que especifiquen a que hace referencia.

La superposición de toda la normativa influyente en este modelo refleja que sobre las áreas netas naturales hay acuerdos de protección pero que se encuentran disociadas de las propuestas urbanas, este mapa superpuesto (Figura 46) no existe en términos de planificación. Aquellos que generan la información de Bosques no consideran el avance urbano como así tampoco, la planificación urbana no establece umbrales o zonas que no deberían ser negociables a la expansión urbana. Esto entendiendo que existen zonas críticas ambientales, que en su mayoría son las de mayor proximidad a las ciudades. El sistema es uno, es socio-ecológico y los municipios no consideran una visión regional 0 incluso más pequeña que es la cuenca que los incluye en este caso. Esta delimitación arbitraria del territorio e incluso confusión de competencias, es aprovechada por los loteos para urbanizaciones. 


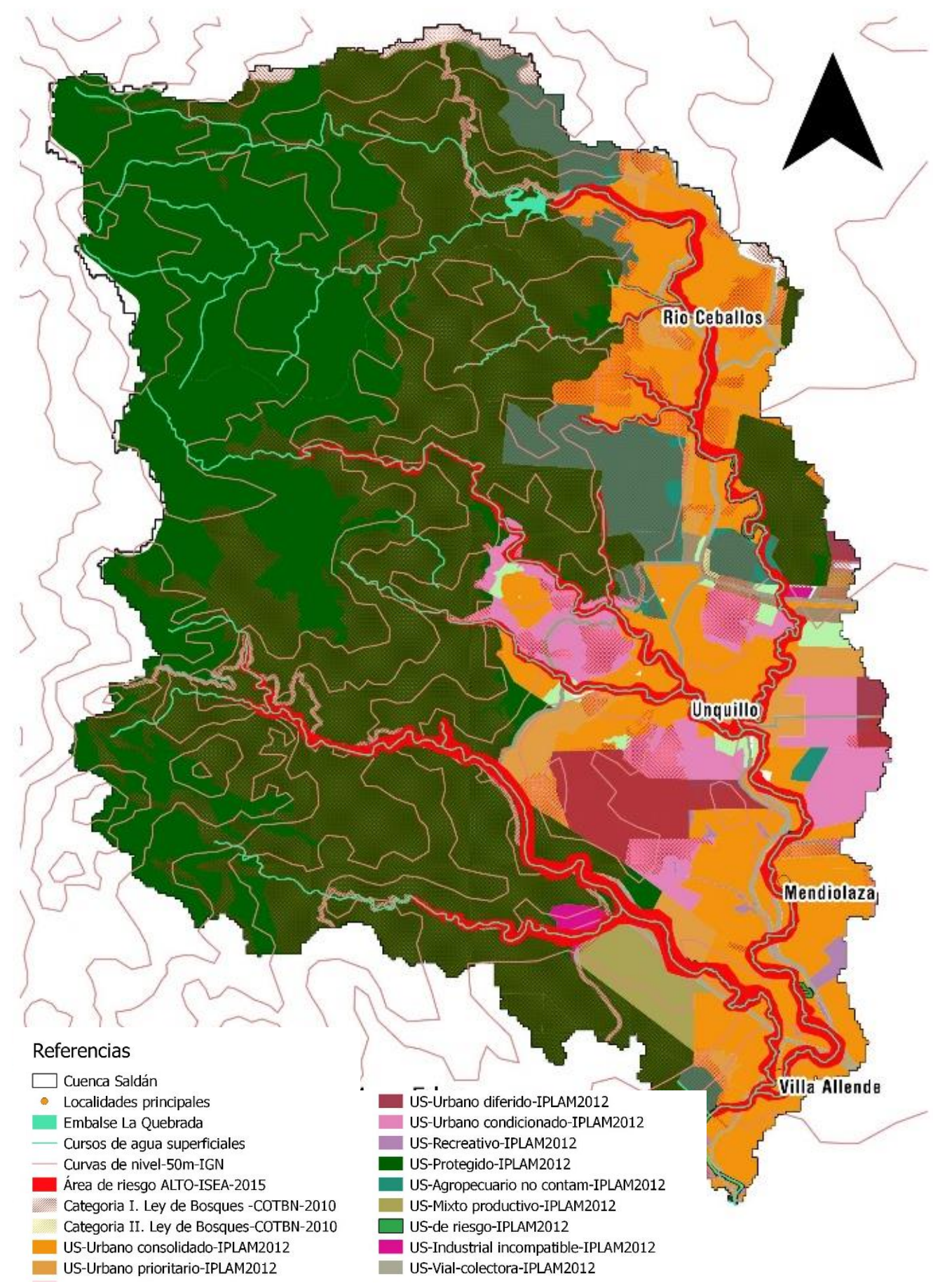

Figura 46. Modelo territorial actual de SS CC. Fuente: Céliz,2018. 
Es el caso de la zonificación asignada a usos de suelo diferido y condicionado por ejemplo que se encuentran sobre áreas de categoría I de ley de bosque, áreas de ribera de inundación o incluso avanzan sobre otros usos ya existentes. Un dato particular de este proceso de integración de información, es la identificación de la interfase rural-natural, al menos en términos de planificación, en el sector noreste de la cuenca. Según OT de IPLAM (2012) en esta área de cuenca conviven el uso del suelo agropecuario no contaminante con el uso de suelo protegido. Particularmente en esta interfase ambos usos se encuentran en categoría I de ley de bosque.

En el sector medio de la cuenca se identificó, por otro lado, la interfase natural-rural-urbana. En donde el uso de suelo de producción agropecuaria no contaminante articula el área de bosque con el área urbana consolidada. Esta articulación resulta en una interesante estrategia para ambos sub-sistemas. el uso de suelo productivo cumpliría funciones de tipo transitivas tanto en manejo antrópico como de conservación.

Otro dato relevante de la superposición de SS CC es el porcentaje de área urbana consolidada que es atravesada por la zona de riesgo "alto", definida por Barchuck et al. (2015) posterior al último evento de lluvias extraordinarias en la cuenca. como ya se ha mencionado (capítulo 1 de esta tesis), las zonas de mayor consolidación urbana en zonas pedemontanas son los valles, por lo cual este hecho no es nuevo, sin embargo, la tendencia tanto en términos geológicos como en la zonificación de IPLAM (2012), indicaría que las áreas donde continuará el proceso de expansión urbana serán las más bajas e incluso, aquellas con más proximidad a los cursos de agua. Eso puede verse en la mayor parte del área destinada como "urbanización prioritaria". Este hecho no determina simplemente un aumento en el porcentaje de la población expuesta a riesgo de inundaciones, sino la necesidad imperiosa de un cambio de zonificación para área urbanizable. Si bien en este mapa síntesis no se incluyó el límite por jurisdicciones (ver en este capítulo más arriba "las definiciones arbitrarias"), es posible identificar que la mayor parte de superficie destina a urbanización en sus diferentes categorías (IPLAM, 2012), pertenecía a la localidad de Unquillo.

Si bien escapa a los objetivos de esta tesis, la lectura de los procesos ecosistémicos de estas interfases identificadas a escala de cuenca y el uso real que se lleva a cabo en estos sectores debe ser comprobada a campo a los efectos de establecer otra escala de estudio 


\section{La interfase crítica y el aumento de superficie impermeabilizada}

¿Cuál es la dinámica de áreas críticas, de protección e incluso de riesgo? ¿cuáles son las localidades que más han avanzado sobre los entornos que proveen funciones ecosistémicas críticas? ¿Es posible definir niveles de protección 0 criticidad para áreas tanto de bosque, productivas e incluso urbanas?

El área total de la cuenca Saldán fue calculada mediante el uso de sistemas de información geográfica en un total de 24.729 ha (sobre una imagen Landsat 80LI del 11 de marzo de 2017). A partir de allí se realizó un análisis comparado de crecimiento urbano "manzana a manzana", de los últimos treinta años a partir de fotointerpretación en Google Earth línea histórica. Este análisis se realizó en dos instancias. Primero, se identificó la manzana como unidad y a partir de allí se definieron tipologías a partir de dos indicadores: i) proximidad al núcleo urbano de valle histórico y, ii) representatividad del tipo de manzana de porcentaje de superficie impermeabilizada para el tipo de urbanización del sector. Estos criterios obedecen a que el tipo de ocupación del suelo del área no es asimilable al del área urbana en forma directa ya que, en muy pocos casos el pixel se encontraba completamente impermeabilizado. De esta manera se obtuvieron 3 formas de impermeabilización por manzana (Figura 47) y 9 tipos de manzana según el sector que se observaba (Tabla 16). Por ejemplo, es notable que la proximidad al área de la ciudad de Córdoba, determina un pixel más urbano, como así también sucede en áreas históricas de ocupación del valle serrano. Sin embargo, la asociación a superficie urbanizada también está dada en este contexto por la falta de cobertura vegetal lindera. Las muestras de pixeles se tomaron en Google Earth -línea histórica (1987-2017)-. A partir de este esquema básico, la segunda instancia de análisis fue la clasificación por fotointerpretación de toda el área. El resultado es la definición de superficie urbanizada efectiva (Figura 48).
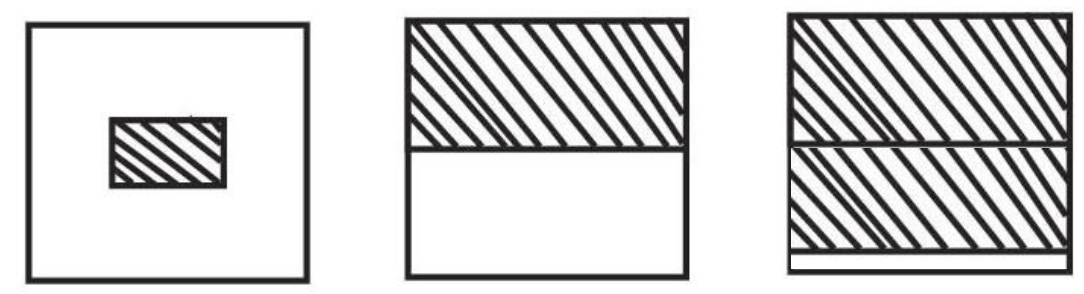

Figura 47. De izquierda a derecha tipos de ocupación por manzana identificados en la cuenca: a) 25\% urbano-75\% vegetación, b)50\% urbano-50\% vegetación y, c) <50\% urbano->50\% vegetación. Fuente: Céliz, 2020. 
Tabla 16. Muestras para definición de manzanas urbanas consolidadas

\begin{tabular}{|c|c|c|c|c|c|c|c|}
\hline ID & Ubicación & $\begin{array}{l}\text { Tipo de } \\
\text { Barrio }\end{array}$ & Tipo de muestra & $\begin{array}{c}\text { Suelo } \\
\text { impermeabilizado } \\
\%\end{array}$ & $\begin{array}{c}\text { Cubierta } \\
\text { vegetal } \\
\%\end{array}$ & $\begin{array}{c}\text { Superficie } \\
\text { total } \\
\mathrm{M}^{2}\end{array}$ & $\begin{array}{l}\text { Sup. } \\
\text { Urbana } \\
\text { consid. }\end{array}$ \\
\hline $\begin{array}{c}\text { Manzana } \\
01\end{array}$ & Villa Allende & $\begin{array}{l}\text { Abierto. } \\
\text { centro }\end{array}$ & representativa & 85 & 15 & 8.860 & si \\
\hline $\begin{array}{c}\text { Manzana } \\
02\end{array}$ & Villa Allende & $\begin{array}{l}\text { Abierto. Las } \\
\text { polinesisas }\end{array}$ & intermedia & 55 & 45 & 6.337 & si \\
\hline $\begin{array}{c}\text { Manzana } \\
03\end{array}$ & Mendiolaza & $\begin{array}{c}\text { Cerrado. } \\
\text { Country } \\
\text { Estancia Q2 }\end{array}$ & representativa & 36 & 64 & 35.061 & si \\
\hline $\begin{array}{c}\text { Manzana } \\
04\end{array}$ & Villa Ñu Pora & $\begin{array}{l}\text { Abierto.Cerro } \\
\tilde{N} u \text { Pora }\end{array}$ & particular & 30 & 70 & 17.632 & no \\
\hline $\begin{array}{c}\text { Manzana } \\
05 \\
\end{array}$ & Río Ceballos & Abierto & intermedia & 41 & 59 & 2.721 & si \\
\hline $\begin{array}{c}\text { Manzana } \\
06\end{array}$ & Río Ceballos & Abierto & representativa & 87 & 13 & 7.462 & si \\
\hline $\begin{array}{c}\text { Manzana } \\
07\end{array}$ & Mendiolaza & $\begin{array}{c}\text { Cerrado. El } \\
\text { Talar }\end{array}$ & particular & 20 & 80 & 27.304 & si \\
\hline $\begin{array}{c}\text { Manzana } \\
08\end{array}$ & Mendiolaza & $\begin{array}{c}\text { Cerrado. } \\
\text { Country } 4 \\
\text { hojas }\end{array}$ & representativa & 26 & 74 & 17.210 & si \\
\hline $\begin{array}{c}\text { Manzana } \\
09\end{array}$ & Unquillo & Abierto & intermedia & 12 & 88 & 19.229 & no \\
\hline
\end{tabular}

Fuente: Céliz, 2017

Con estos datos se definió la superficie de ocupación efectiva -consolidada urbana- de la cuenca durante los últimos 30 años. La primera escena de lectura fue diciembre del año 1987, con corroboración de datos intermedios para los años 2001 y 2009. La última escena corresponde al 31 de diciembre del año 2017.

Para el año 1987, la superficie urbanizada consolidada de la cuenca era de 994 ha, y para el año 2017 de 3503 ha. Esto implica que en treinta años la cuenca aumento más de un $300 \%$ su superficie impermeabilizada. 

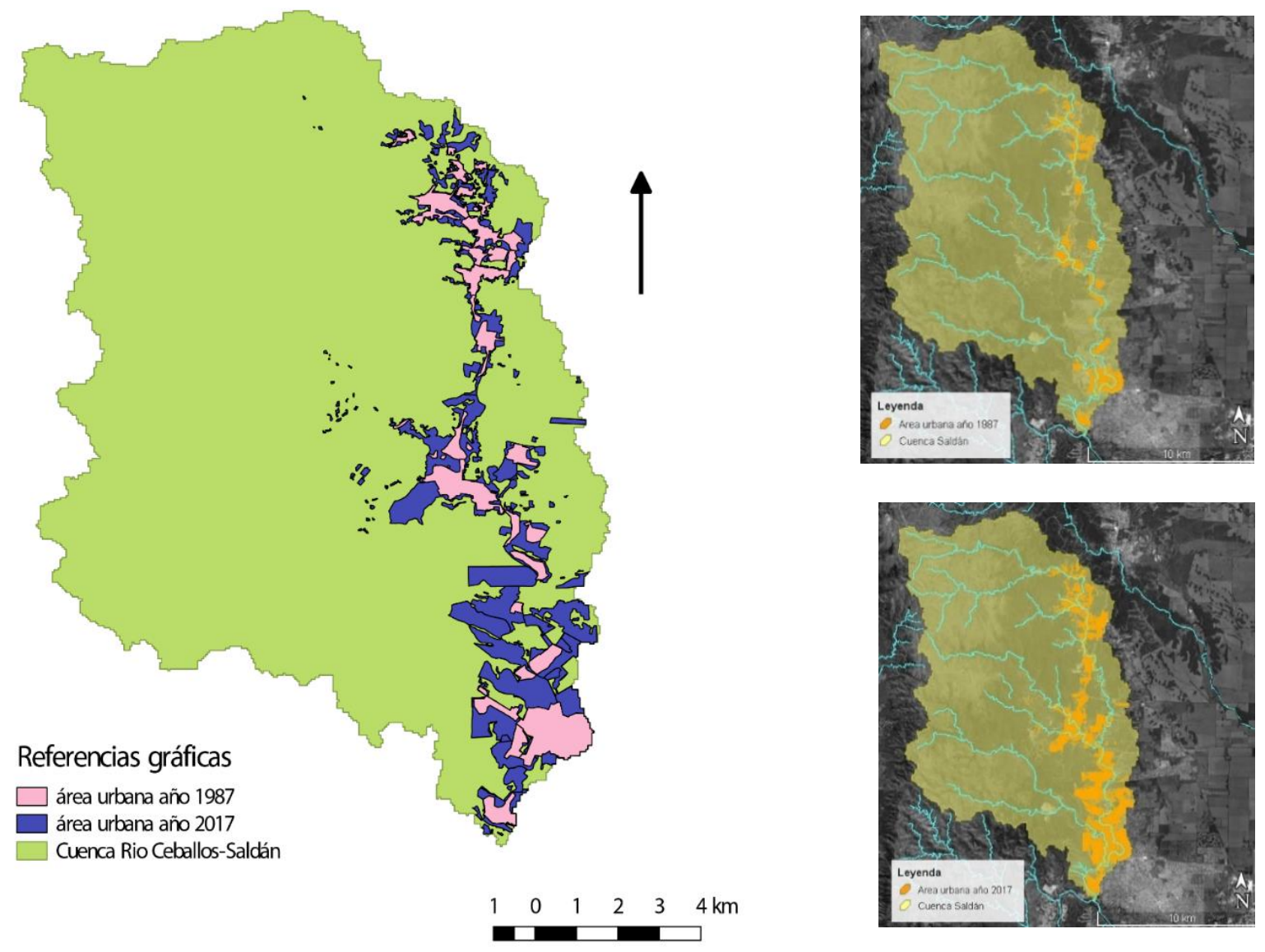

Figura 48. Avance del área urbana en la cuenca Saldán. Fuente: Céliz, 2017.

La expansión del área urbanizada en los últimos 30 años sobre la cuenca, y en particular en zonas de valle de recepción de inundaciones corresponde como se ha visto con anterioridad, a las cuatro principales localidades atractoras de población estable.

Es posible establecer una relación entre el aumento de superficie urbanizada y el impacto de lluvias extraordinarias en la región (Figura 49). No se han estimado valores de aumento de cantidad de agua 0 intensidad en las lluvias. De la misma manera, el dato de frecuencia no constituye un valor estimable en el caso histórico ya que los valores aportados en su totalidad no son posibles de ser discriminados a intervalos regulares debido a la información de base no disponible. Sin embargo, los registros de eventos climáticos de lluvias extraordinarias en intervalos de 10 años han aumentado progresivamente comparablemente con la superficie de área impermeabilizada. Esto implica una relación directa entre la ocurrencia de lluvias por fuera del régimen anual y el aumento de la exposición de los asentamientos humanos, hecho que está asociado al reemplazo de coberturas de suelo -productivo, de bosque maduro, renoval, etc.-, por suelo urbano. 


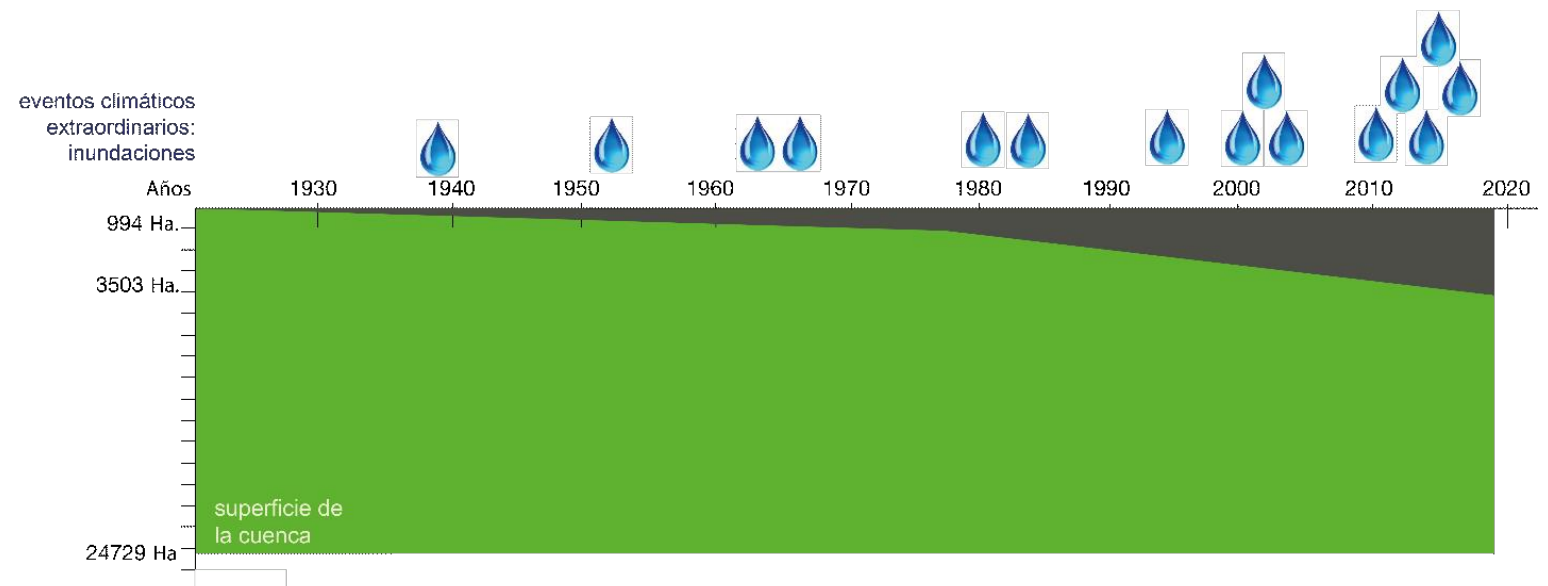

Figura 49. Relación entre el aumento de superficie urbanizada (gris) y lluvias históricas en relación a la superficie de la cuenca Saldán (verde). Fuente: Céliz 2017.

A partir de la interpretación de la figura 50, se indagó en aquellas superficies que ocupaban la cuenca, además del área urbanizada o impermeabilización efectiva. De esta manera se identificaron las principales interfases en interacción a partir de técnicas de teledetección para realizar una clasificación de usos y coberturas del suelo.

A partir de los datos de superficie urbanizada efectiva, obtenidos a través de fotointerpretación, se utilizaron los datos de superficie del año 2017 para realizar una máscara previa a la clasificación supervisada de una imagen completa de la cuenca para ese año, la misma pertenece a la colección Landsat 80L/del día 15 de marzo del 2017. Las clases propuestas, previas al proceso de clasificación fueron: 1) bosque, 2) arbustal, 3) pastizal-roquedal y 4) urbana, que es la superficie que se aplicará como máscara. Como etapa de pre-clasificación se aplicaron índices (algebra de bandas) a los efectos de potenciar la respuesta espectral de las clases del área natural.

Los índices que se generaron fueron: NDVI o índice de vegetación diferencial normalizada (Gilabert et al, 1997), NDWI 0 índice de agua diferencial normalizado (Gao, 1996), NDSI y el índice normalizado diferencial de nieve (Sibandze et al.,2014), este último utilizado de manera indirecta para obtención de valores de humedad en el suelo. Posterior a la obtención de estos índices se crearon imágenes multibanda para la clasificación. La geometría de las muestras ha sido de puntos del $100 \%$ de los datos relevados se utilizaron el $60 \%$ para la clasificación y el $40 \%$ restante para validación de las clases obtenidas. La clasificación propiamente dicha se realizó a partir de un software tradicional y el algoritmo utilizado fue el de máxima verosimilitud (Bolstad and Lillesand 1991) (Figura 50). El porcentaje de exactitud obtenido fue del $90 \%$ y el índice Kappa resultó en 0.87 . 


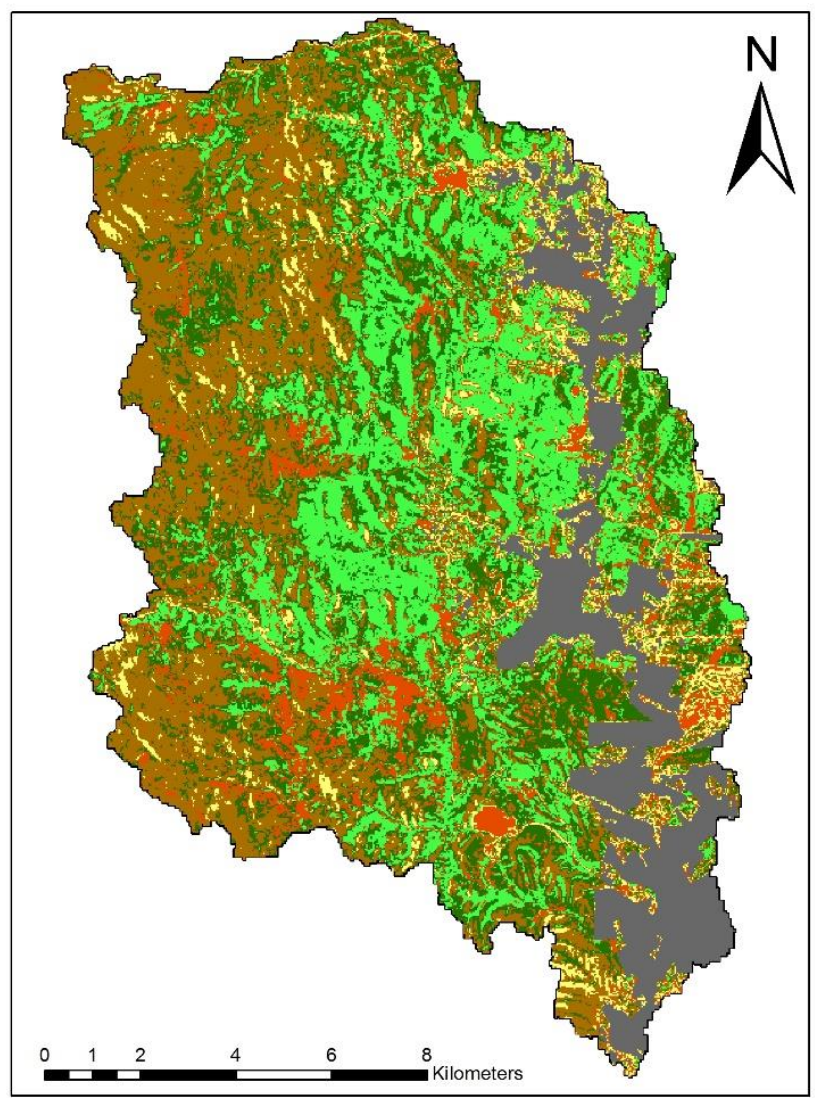

\section{Referencias}

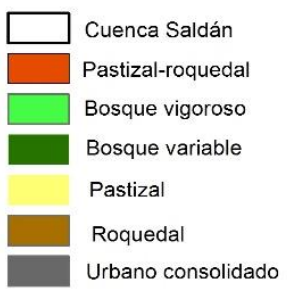

Clasificación supervisada. Método de máxima verosimilitud Clasificacion supervisada. Mèto de maxima verc Autor: Y. Céliz, 2018

Figura 50. Clasificación supervisada. Cobertura de suelo para la cuenca Saldán. Máscara del área urbana obtenida previamente (Figura 48). Para el resto de las clases se utilizó el algoritmo de máxima verosimilitud. Fuente: Céliz, 2018.

La interfase del área urbana de SS CC se constituye principalmente de bosque, es decir que se trata de una interfase urbano-natural casi en un 100\% (Figura 51). Si bien los usos de suelo (IPLAM, 2012) -pretendidos -, establecen una mayor variabilidad en la interfase, en el procesamiento de imágenes satelitales no se han podido verificar -al menos a esta escala- la presencia de otros usos no-urbanos en la cuenca.

La aproximación sistémica primero a partir de la definición de unidades ambientales generales, los usos y coberturas de suelo posteriormente y, las interfases en interacción al interior de la cuenca permitieron el abordaje de las transformaciones de interfase que implica la dinámica de expansión del uso de suelo urbano, identificado previamente como dinámica de impermeabilización del valle de la cuenca. 


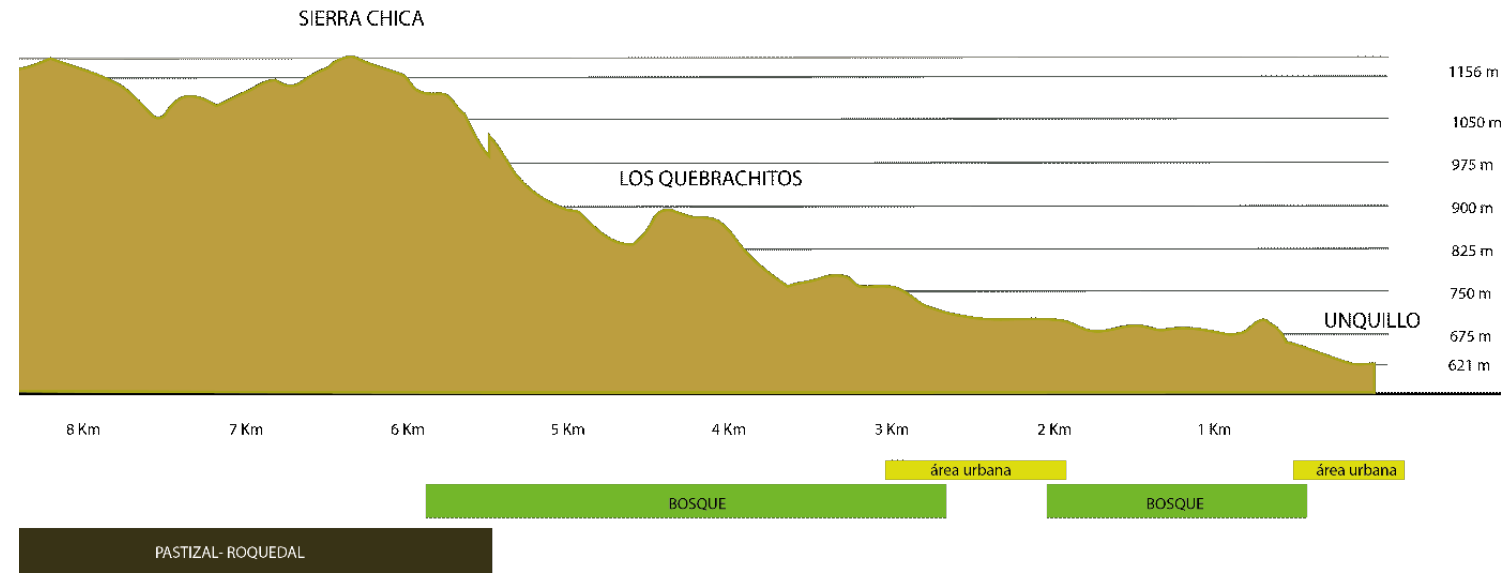

Figura 51. Perfil de altimetría de la cuenca desde los 1156 msnm hasta la calle San Martín en la localidad de Unquillo. Unidades ambientales en interfase compatibilizadas con clasificación supervisada de usos y coberturas de suelo de la cuenca: Urbano (amarillo), Bosque-arbustal (verde), pastizal-roquedal (marrón). Fuente: Céliz, 2016 sobre datos de altimetría de Google Earth.

Como estas dinámicas estarán dadas por el intercambio de flujos entre funciones ecosistémicas y funciones urbanas (Laterra et al., 2015; Morello et al., 2000), se observaron los principales componentes de la interfase y una valoración posterior para la elaboración del modelo Eco-ser. Se presenta la información en la Tabla 17, a partir de la clasificación de SE (MEA, 2005):

Tabla 17. Identificación de SSEE en la cuenca Saldán

\begin{tabular}{|c|c|c|c|}
\hline & SE de abastecimiento & SE de regulación & SE culturales \\
\hline \multirow{8}{*}{$\begin{array}{l}\text { FUNCIONES } \\
\text { O PROCESOS }\end{array}$} & Alimentos tradicionales & polinización & Conocimiento científico \\
\hline & medicinales & regulación climática & Educación ambiental \\
\hline & Acervo genético & Control biológico & Actividades recreativas \\
\hline & $\begin{array}{c}\text { Materiales de origen } \\
\text { geológico: piedra, arena }\end{array}$ & $\begin{array}{c}\text { Perturbaciones } \\
\text { naturales }\end{array}$ & Disfrute del paisaje \\
\hline & $\begin{array}{c}\text { Materiales de origen } \\
\text { biótico }\end{array}$ & Fertilidad del suelo & Identidad cultural \\
\hline & Agua & Control de la erosión & $\begin{array}{c}\text { Conocimiento ecológico } \\
\text { local }\end{array}$ \\
\hline & & Calidad del aire & Disfrute espiritual \\
\hline & & Regulación hídrica & \\
\hline
\end{tabular}

Fuente: Céliz, 2016. 


\section{Valoración (eco)sistémica}

En esta instancia se trabajó con el protocolo Eco-ser de valoración de SSEE como ensayo de diagnóstico socioecológico (Barral 2016). Las funciones ecosistémicas con mayor nivel de exposición frente a los procesos de avance urbano, se identifican a partir de tres factores: i) referencia bibliográfica de estudios y antecedentes sobre los eventos de lluvias extraordinarias ocurridas en el sector, ii) los datos disponibles para elaborar el modelo y, ii) los criterios de selección de funciones ecosistémcias (Haines-Young et Potschin, 2010).

Según el modelo de cascada de (Laterra et al. 2015) (modificado de Haines-Young y Potschin, 2010), la selección de la función ecosistémica a cuantificar está orientada a su posterior incorporación al proceso de OT para la toma de decisiones. Existen instancias de valoración previa donde tanto los actores sociales, la información disponible y el conocimiento experto deben intervenir en el proceso de valoración y evaluación. Sin embargo, en el desarrollo de este modelo, no se han incorporado lecturas de los actores sociales -aunque se hayan hecho relevamientos informales-, para la selección de entradas al modelo. Asimismo, existe una extensa literatura que da cuenta de la relevancia en el sector para los diferentes actores del territorio: la academia, la existencia y producción de organizaciones sociales y ambientales, los decisores políticos a través de los números planes y estudios del sector. Dada la recurrencia de los eventos de lluvias registradas, los estudios recopilados y las entrevistas informales se identificaron funciones hidrológicas de regulación como las de mayor impacto en la valoración ecosistémica.

Existen muchas formas en las que el agua influye desde su ciclo continuo en el socio-ecosistema. Desde el momento en que cae de la atmósfera como precipitación hasta que regresa a la misma en forma de vapor. La relación entre el aumento de la exposición de los asentamientos humanos y los eventos de lluvias extraordinarias implican relaciones relevantes necesarias de explicitar a partir de estudios de base.

Para este escenario descriptivo en el cual el agua lleva a cabo un "ciclo cerrado" en el que el agua ingresa al ecosistema y retorna a la atmósfera, es necesario que sea interpelada la función que cumple la gran cantidad de superficie impermeabilizada en las zonas bajas de la cuenca directa o indirectamente dentro de este proceso. Este junto con otros factores alteran significativamente la capacidad del territorio de responder a la recepción de precipitaciones en términos de regulación y constituyen la criticidad de la interfase del caso de estudio.

La valoración realizada a partir de la construcción de una matriz de funciones ecosistémicas fue en términos cualitativos dado que como se ha mencionado, existe gran cantidad de información disponible. Se estima que para trasladar esta matriz a otros casos deberá ser ajustada a partir de trabajo con actores territoriales en talleres 0 realizarse encuestas específicas. 
La matriz de valoración ecosistémica que se desarrolló previamente (capítulo metodológico) fue aplicada a la cuenca del río Saldán luego de identificadas las funciones principales (Tabla 18). Estas se valoraron a partir de cuartiles que van desde 0 a 1, donde 0.75 corresponde al valor de mayor impacto, 0.50 indica un impacto medio de la función y 0.25 al valor de impacto más débil de la función analizada. Estos valores en su totalidad indican un análisis del impacto de las funciones identificadas en el ambiente. En base a los resultados obtenidos por sumatoria de todas las variables aplicadas a cada función, la regulación hídrica es la que mayor impacto tiene en esta cuenca.

Tabla 18. Matriz de funciones ecosistémicas

\begin{tabular}{|c|c|c|c|c|c|c|c|c|c|c|c|c|c|c|}
\hline \multicolumn{15}{|c|}{ Criterios para la selección de servicios ecosistémicos } \\
\hline & \multicolumn{5}{|c|}{ SE de provisión } & \multicolumn{4}{|c|}{ SE de regulación } & \multirow{2}{*}{\begin{tabular}{|c|} 
SE soporte \\
$\begin{array}{c}\text { Formación } \\
\text { de suelo }\end{array}$
\end{tabular}} & \multicolumn{4}{|c|}{ SE culturales } \\
\hline & alimentos & $\begin{array}{c}\text { agua } \\
\text { potable }\end{array}$ & maderas & áridos & $\begin{array}{c}\text { hierbas } \\
\text { medicinales }\end{array}$ & $\begin{array}{l}\text { Reg. } \\
\text { Hidrica }\end{array}$ & $\begin{array}{l}\text { Reg. } \\
\text { Climática }\end{array}$ & \begin{tabular}{|c|} 
Reg. \\
Desastres
\end{tabular} & $\begin{array}{c}\text { Purif. del } \\
\text { agua }\end{array}$ & & \begin{tabular}{|c} 
Disfrute del \\
paisaje
\end{tabular} & $\begin{array}{l}\text { Educativo- } \\
\text { cientifico }\end{array}$ & Identidad & Espirituales \\
\hline 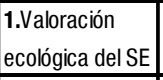 & sd & 0.75 & sd & sd & sd & 0.75 & 0.75 & 0.75 & 0.75 & 0.75 & 0.5 & 0.5 & 0.5 & 0.5 \\
\hline $\begin{array}{l}\text { 2.Intensidad del } \\
\text { vínculo entre el } \\
\text { SE y el bienestar } \\
\text { humano }\end{array}$ & 0.75 & 0.5 & 0.5 & 0.25 & 0.75 & 0.75 & 0.75 & 0.75 & 0.75 & 0.5 & 0.5 & 0.25 & sd & 0.5 \\
\hline 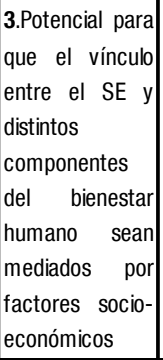 & 0.75 & 0.5 & 0.75 & 0.75 & 0.75 & 0.25 & 0.25 & 0.5 & 0.5 & 0.5 & 0.5 & 0.25 & 0.25 & 0.25 \\
\hline $\begin{array}{l}\text { 4.Importancia } \\
\text { para } \\
\text { comunidades } \\
\text { locales humanas }\end{array}$ & 0.5 & 0.75 & 0.5 & 0.5 & 0.5 & 0.75 & 0.25 & 0.75 & 0.5 & 0.25 & 0.75 & 0.25 & 0.75 & 0.25 \\
\hline 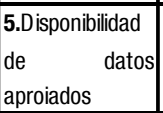 & 0.25 & 0.5 & 0.5 & 0.5 & 0.25 & 0.75 & 0.5 & 0.5 & 0.25 & 0.25 & 0.25 & 0.25 & 0.25 & 0.25 \\
\hline $\begin{array}{l}\text { 6.Exposición at } \\
\text { cambio } \\
\text { climático }\end{array}$ & 0.25 & 0.25 & 0.75 & 0.5 & 0.5 & 0.75 & 0.75 & 0.75 & 0.5 & 0.25 & 0.75 & 0.25 & 0.25 & 0.25 \\
\hline $\begin{array}{l}\text { 7.Sensibilidad at } \\
\text { cambio } \\
\text { climático }\end{array}$ & 0.75 & 0.75 & 0.75 & 0.75 & 0.75 & 0.75 & 0.75 & 0.75 & 0.5 & 0.5 & 0.75 & 0.25 & 0.25 & 0.5 \\
\hline $\begin{array}{l}\text { 8.Exposición al } \\
\text { cambio de usos } \\
\text { de suelo }\end{array}$ & 0.75 & 0.75 & 0.5 & 0.5 & 0.75 & 0.75 & 0.75 & 0.75 & 0.25 & 0.5 & 0.75 & 0.25 & 0.5 & 0.5 \\
\hline $\begin{array}{l}\text { 9.Congruencia } \\
\text { con el modelo } \\
\text { de cascada }\end{array}$ & 0.75 & 0.75 & 0.5 & 0.5 & 0.5 & 0.75 & 0.75 & 0.75 & 0.75 & 0.75 & 0.25 & 0.25 & 0.25 & 0.25 \\
\hline
\end{tabular}

Fuente: Céliz,2018 en base a Haynes Young \& Potschin,2010 y MEA, 2005 
La propuesta de Eco-ser para poder estimar la función ecosistémica detectada mediante el uso de la matriz, es trabajar con el indicador de retención de excesos de precipitación por cobertura vegetal (2). Este indicador forma parte del modelo de estimación relativa de servicios ecosistémicos propuesto por (Viglizzo et al. 2011) y (Carreño, Frank, and Viglizzo 2012), que asumen que la biomasa y la disponibilidad de cursos y cuerpos de agua son factores claves en la provisión de servicios. De la misma manera involucra factores biofísicos como la pendiente del terreno, la temperatura media, la capacidad de infiltración de los suelos.

El modelo inicial del que se desprende este indicador, está asociado a la irrupción de agua dentro del paisaje (Vliglizzo et al.,2011) y su utilización en el contexto de las funciones ecosistémicas está asociado a la capacidad del ecosistema de incorporar los excesos de precipitación al ciclo hidrológico. En este punto es relevante subrayar que el modelo no analiza el agua que necesita el ecosistema boscoso en general ni cuál es el porcentaje que incorpora del total de lluvia caída; sino que revela la capacidad del ecosistema para retener los excesos de precipitación para eventos extraordinarios del régimen y, se calcula como:

$$
\operatorname{REP}=\mathrm{B}^{\star}(1-\mathrm{CVB}){ }^{\star} \mathrm{Fcis}^{\star} \mathrm{Fprec}^{\star}(1-\text { Fpend })
$$

"Donde se asume que la capacidad del ecosistema para interceptar, retener e infiltrar la precipitación depende de la biomasa (B) y su variación (CVB) (Odum,1971; Odum \& Odum,2000), la capacidad de infiltración del suelo (Fcis), la precipitación (Fprec) y que, desciende con la pendiente (Fpend) ya que se reduce el tiempo de residencia del agua dentro del paisaje (Carreño \& Viglizzo,2007).” (Carreño et al., 2012, p.71)

\section{Determinación de capas de entrada del modelo de REP}

A continuación, se calcularon los mapas de base para alimentar el modelo de REP por cobertura vegetal. En cada caso se menciona de donde provienen los datos utilizados. En algunos casos son datos directos de organismos estatales, algunas entradas son información espectral de imágenes satelitales y en otros casos se construyeron a partir de datos primarios.

\section{Determinación de la biomasa (B) y su variabilidad (CVB) para el año 2017}

A partir de la misma base se obtuvieron dos mapas. Por un lado, el de biomasa para un momento determinado del año, para el que se utilizó una imagen Landsat 8 OLI del día 21 de enero de 2017 a los efectos de obtener los valores máximos de vigor vegetal, para esto se utilizó la respuesta espectral de la imagen seleccionada a los efectos de obtener una respuesta funcional ecosistémica asociable a datos de biomasa (Paruelo, 2008). Se calcularon, valor del índice de diferencia vegetal normalizada o NDVI (Tucker et al. 1985) para la fecha seleccionada 
y se establecieron valores entre 0 a 100 para el área de la cuenca (Figura 52). La variabilidad de los datos de biomasa para la cuenca se tomó para el año 2017 para la misma colección de imágenes Landsat 80LI, seleccionándose el valor del pixel promedio anual entre el 01 de enero al 31 de diciembre de 2017, evitando escenas con presencia de nubes. Con estos datos se volvió a calcular índice NDVI, pero respecto al promedio anual obtenido previamente. El resultado fueron valores de NDVI anual entre 0 y 1 que representan la variación estacional de biomasa para el año 2017 (Figura 53).

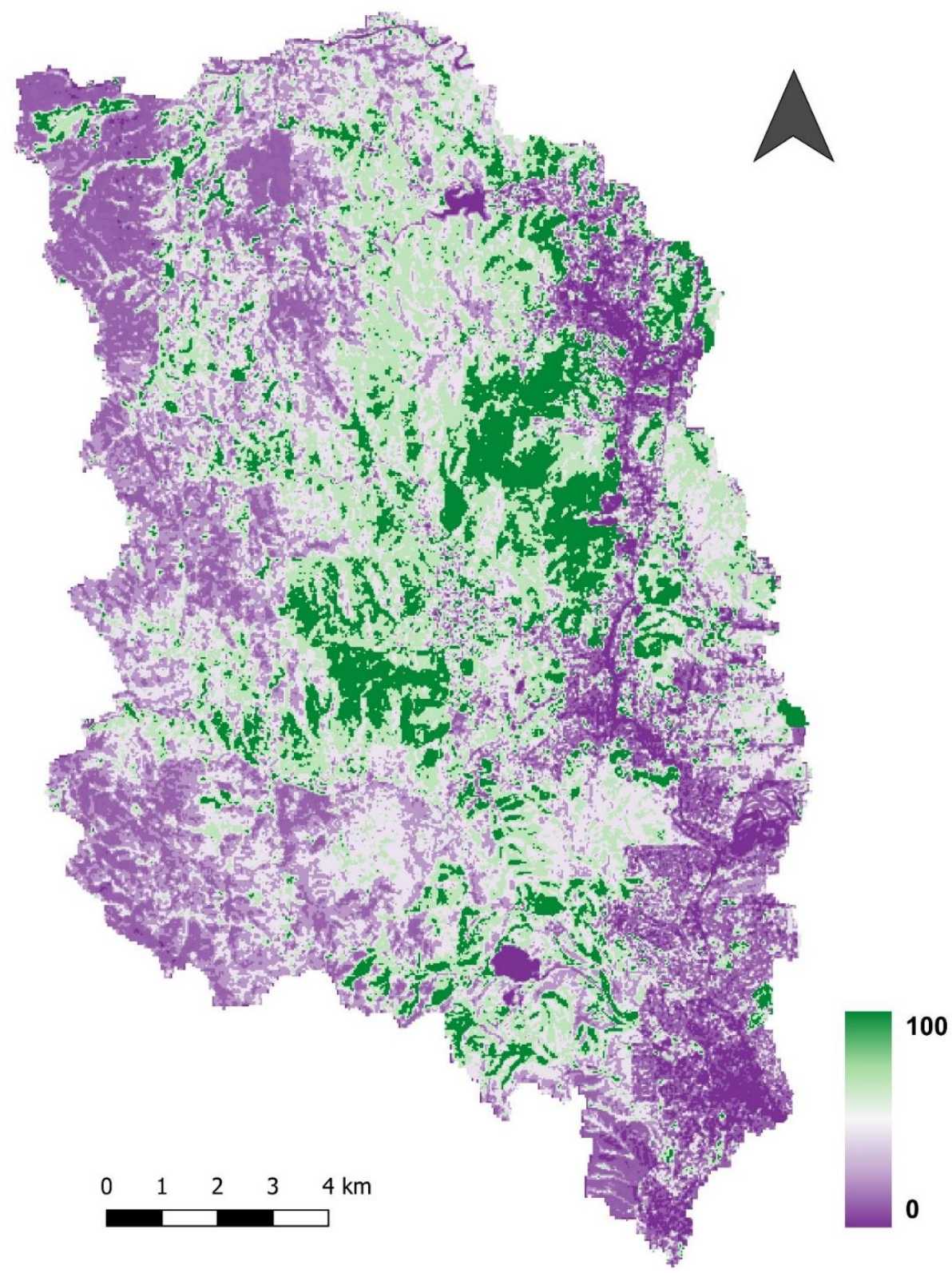

Figura 52. Mapa de biomasa (NDVI) para el año 2017, cuenca Saldán. Fuente: Céliz, 2018. 


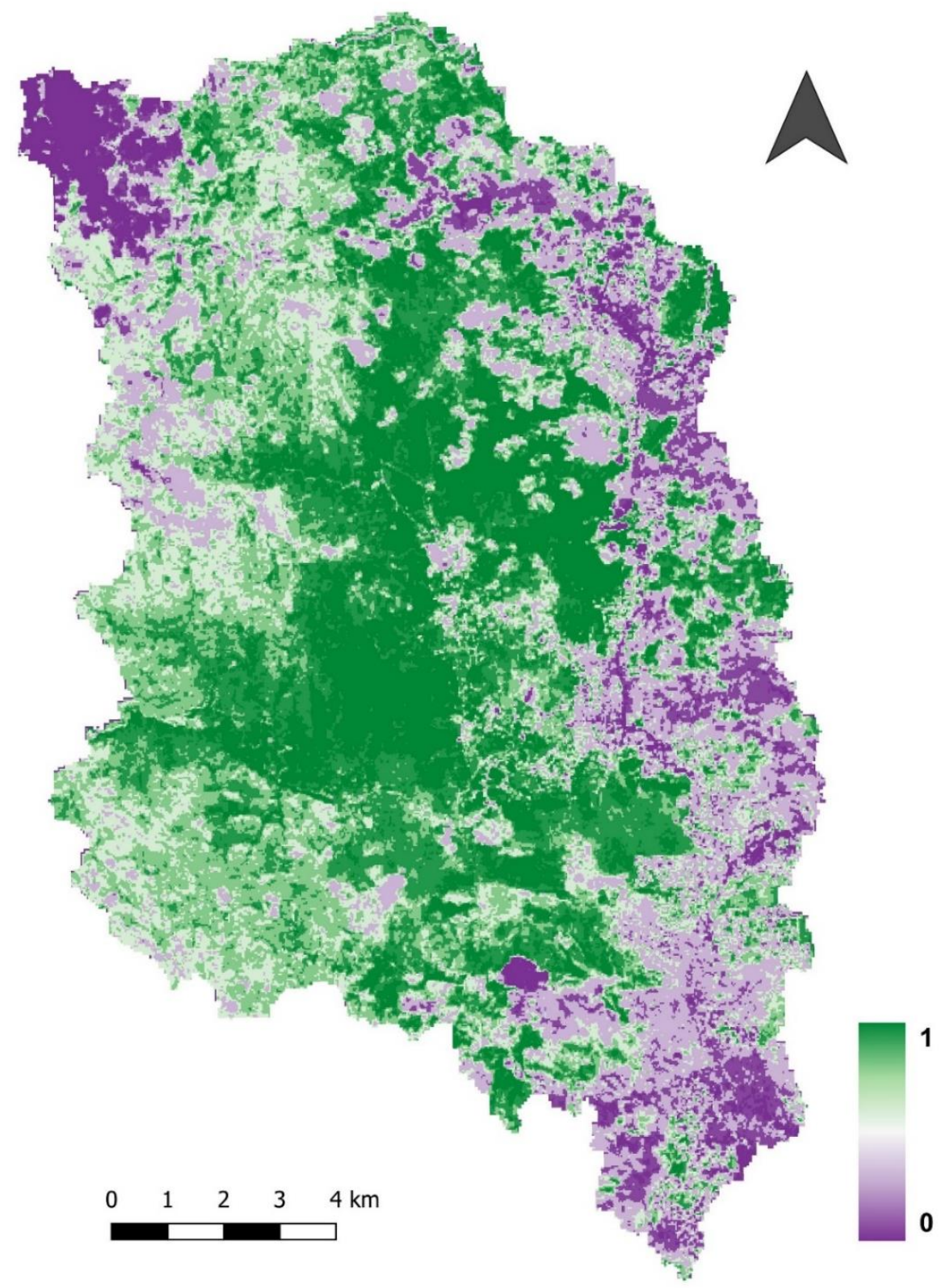

Figura 53. Mapa de variación anual de biomasa para el año 2017 en la cuenca Saldán. Fuente: Céliz, 2018

Si bien en la cuenca no existe superficie relevante de cultivos 0 áreas agrícolas y el bosque no sufre muchas variaciones si tenemos en cuenta ambos mapas, en el mapa de variación de NDVI se observó un aumento de superficie de verde, principalmente en zonas de pastizal-roquedal. De la misma manera, en zonas del mapa de NDVI los valores más bajos que se corresponden con superficie urbana en algunos lugares desaparecen lo que permite inferir que hay áreas de suelo desnudo para un momento del año que luego indican presencia de vegetación 
en el mapa de variación de NDVI. Esto último no resulta en un dato menor, dado que es fundamental identificar las diferencias en las coberturas de suelo, y diferenciarlas de la superficie impermeabilizada para la elaboración del indicador definitivo.

\section{Determinación de la capacidad de infiltración del suelo (Fcis) para la cuenca Saldán}

El insumo principal para este mapa es la carta de suelos del INTA -Instituto Nacional de Tecnología Agropecuariaen donde se identificaron las principales características del suelo de la cuenca. Los tipos presentes fueron: arenoso franco y franco arenoso.

A partir de la interpretación de las clases texturales de suelo (Figura 55), se identificaron las características principales: un suelo arenoso franco tiene entre un 70 y $80 \%$ de arena y entre un 10 y un $20 \%$ de arcilla. A su vez, un suelo franco arenoso tiene entre un 70 y un $50 \%$ de arena y entre un 15 y un $20 \%$ de arcilla.
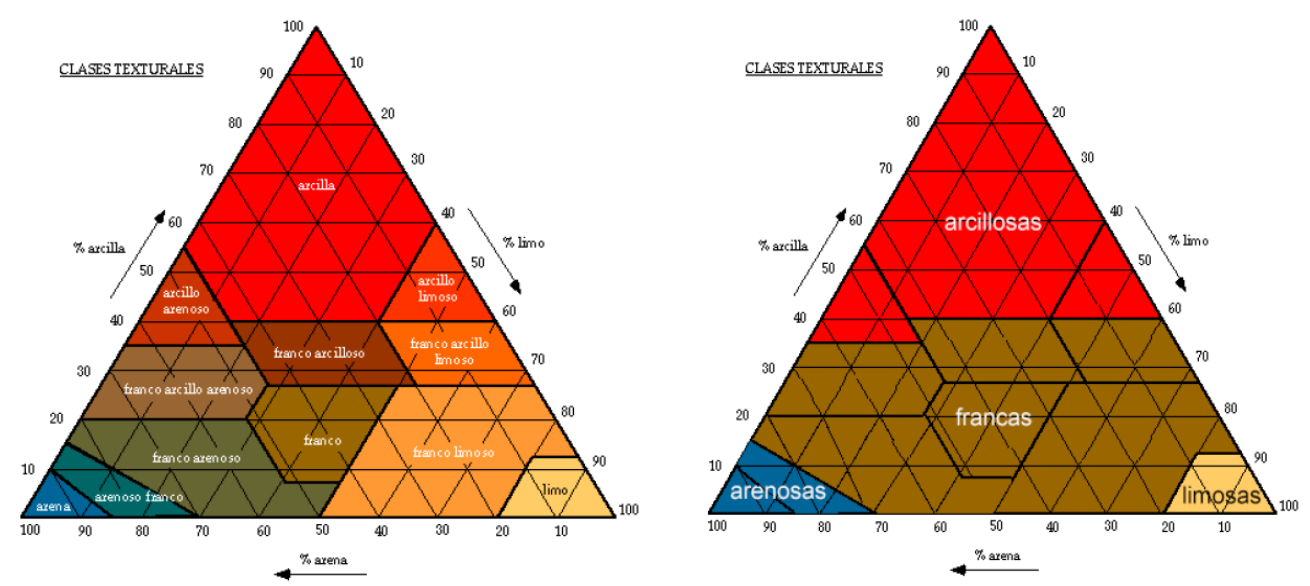

Figura 54. Clases texturales de suelo. Fuente: Recuperado de http://www.edafologia.net/introeda/tema04/text.htm

Para construir el mapa final (Figura 55), se realizó una ponderación a partir de los datos de textura de suelo como principal indicador relacionado a su vez con la capacidad de infiltración. Como segundo indicador se determinó el tipo de drenaje para estimar diferencias entre ambos tipos de suelo y por último el tipo. Se construyen 4 valores para la capa raster según los datos obtenidos (Tabla 19). 
Tabla 19. Ponderación de textura de suelo para determinar capacidad de infiltración

\begin{tabular}{|c|c|c|c|c|c|}
\hline textura & drenaje & tipo & ponderación & valor & Entrada modelo \\
\hline Areno franca & Excesivo drenaje & entisoles & 1 & 0.45 & 45 \\
\hline Areno franca & Excesivo drenaje & entisoles & 2 & 0 & 0 \\
\hline Areno franca & Excesivo drenaje & entisoles & 3 & 0 & 0 \\
\hline Franco arenosa & Mejor drenado & molisoles & 4 & 1 & 100 \\
\hline
\end{tabular}

Fuente: Céliz 2018, con la colaboración del departamento de Suelo de INTA AER Córdoba

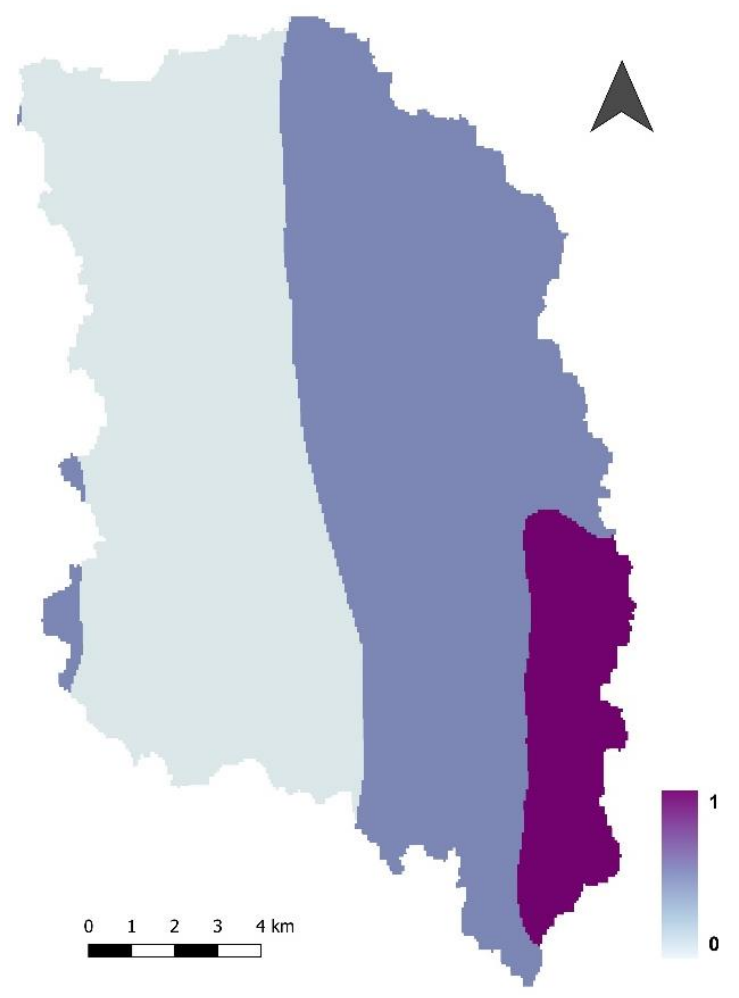

Figura 55. Mapa de capacidad de infiltración de suelo suelo según textura, drenaje e infiltración. Fuente: Céliz, 2018.

\section{Determinación de mapa de precipitaciones (Fprec)}

De los mapas de base necesarios para alimentar el modelo este es el que requirió mayor tiempo de producción y traducción de datos disponibles. Dado que todos los mapas de entrada al modelo final deben tener el mismo "Ienguaje" es decir, todos deben ser imágenes en formato raster con una variación de valor entre 0 y 100 y 100 para el caso de variación de biomasa. En este caso no sólo fue necesario re-escalar el valor del pixel sino también, 
construir la información base dado que para la escala de cuenca no existen datos espacializados que permitan identificar una variación de precipitación tan pequeña entre localidades conurbadas.

Los datos de precipitaciones fueron obtenidos de la página del Ministerio de Agroindustria de la Nación que proporciona valores mensuales para cada coordenada seleccionada en un mapa. Esto implicó la construcción del dato medio anual a partir de los datos de precipitaciones mensuales para cada localidad (Tabla 20). Estos datos fueron interpolados en Qgis para construir una imagen raster de toda el área de la cuenca (Figura 56).

Tabla 20. Precipitaciones máximas media para el año 2017 en la cuenca Saldán

\begin{tabular}{|r|l|r|}
\hline \multicolumn{1}{|l|}{ ID } & \multicolumn{1}{|c|}{ Localidad } & $\begin{array}{c}\text { Precipitaciones en } \\
\text { MM }\end{array}$ \\
\hline 1 & Córdoba & 87 \\
\hline 2 & Villa Allende & 79 \\
\hline 3 & Saldan & 79 \\
\hline 4 & Mendiolaza & 79 \\
\hline 5 & Unquillo & 92 \\
\hline 6 & Pajas Blancas & 92 \\
\hline 7 & Los Quebrachitos & 92 \\
\hline 8 & Villa Nu Pora & 92 \\
\hline 9 & Los Altos & 92 \\
\hline 10 & Rio Ceballos & 92 \\
\hline 11 & Villa Colachanga & 92 \\
\hline 12 & Salsipuedes & 92 \\
\hline 13 & Dumesnil & 79 \\
\hline 14 & Casa Bamba & 79 \\
\hline 15 & La Granja & 92 \\
\hline 16 & La Cumbre & 80 \\
\hline 17 & Molinari & 92 \\
\hline 18 & Villa Independencia & 80 \\
\hline
\end{tabular}

Fuente: Céliz, 2018 en base a datos TRMM. Ministerio de agroindustria de la Nación 


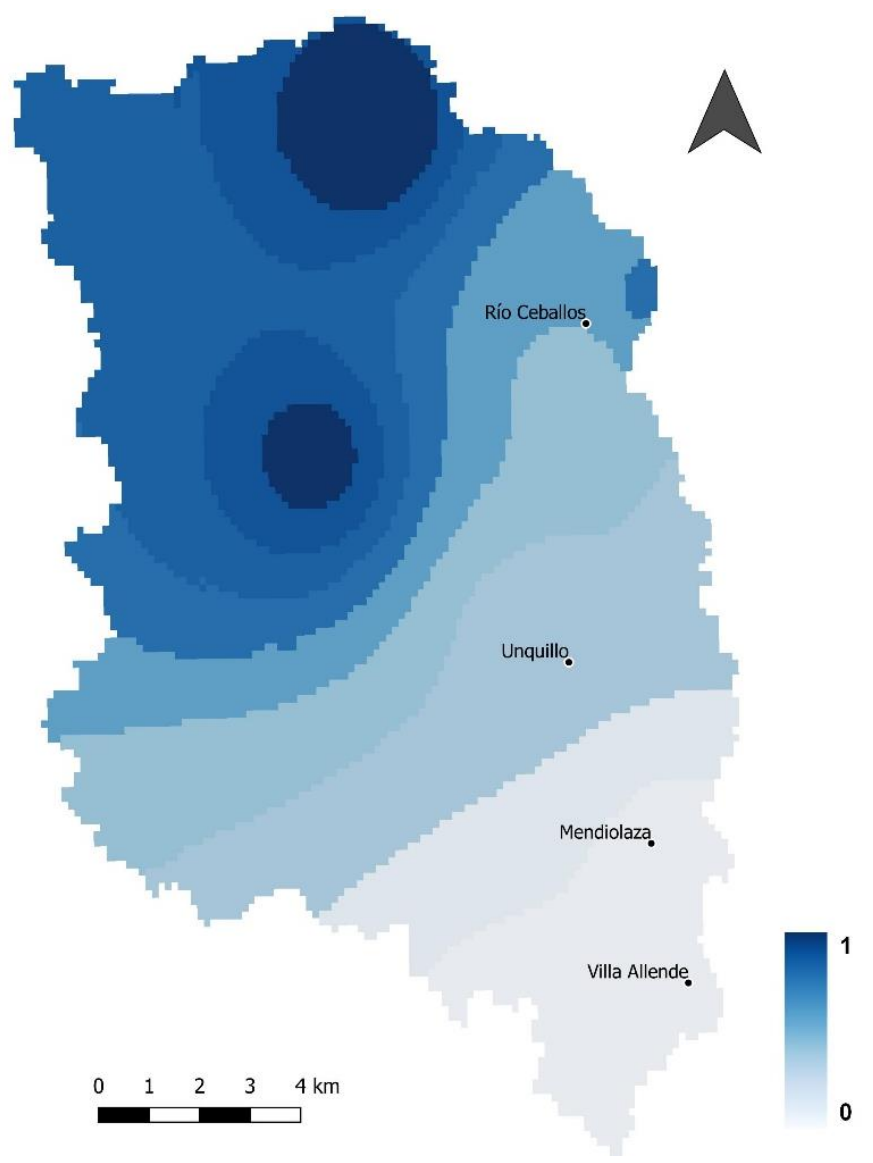

Figura 56. Mapa de precipitaciones máximas media en mm para la cuenca Saldán en año 2017. Fuente: Céliz, 2018.

\section{Determinación del mapa de pendientes (Fpend)}

Para la elaboración del raster de Mapa de pendientes (Fpend) se utilizó un modelo de elevación del terreno o DEM por sus siglas en inglés. Un DEM es una base de datos espacializados que representa el relieve de una superficie entre puntos de elevación conocidos. Mediante la interpolación de datos de elevación conocidos de fuentes tales como estudios de terreno y captura de datos fotogramétricos, se puede obtener una cuadrícula rectangular de modelo digital de elevación. La información del DEM del sector de la cuenca fue utilizado como base para generar un modelo secundario en este caso con valores de pendiente a partir del cual se estableció la ponderación teniendo en cuenta que las áreas de mayor altitud o pendiente son menos aptas para retener excesos de precipitación y las de menor pendiente (o zonas de valle) presentan mayores aptitudes para retenerlos (Figura 57). 


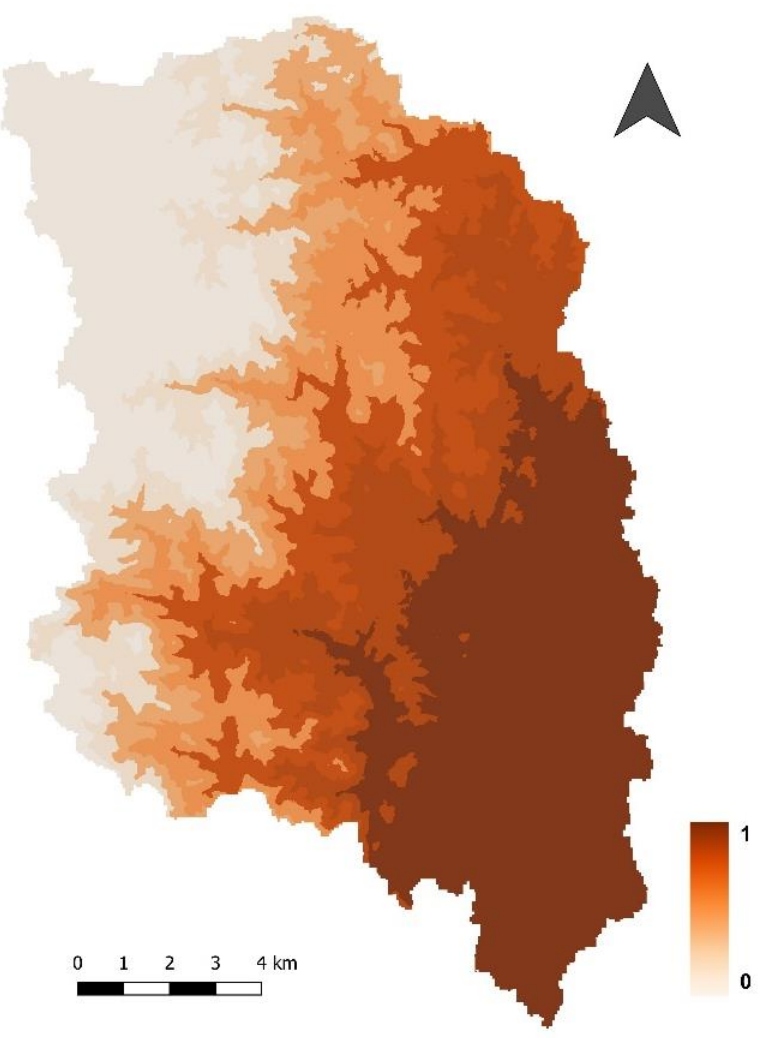

Figura 57. Mapa de pendientes en valores relativos 0-1. Donde cero representa los valores más altos y por lo tanto menos aptos para retener excesos de precipitación y los valores cercanos a 1 son las superficies con mayor aptitud de retenerlos y están asociados al área del valle. Fuente: Céliz, 2018.

\section{Modelo de retención de excesos de precipitación por cobertura vegetal: Cuenca Saldán, año 2017}

El modelo se realizó en dos etapas dada la importancia de la incorporación del uso del suelo urbano y la posterior incorporación al modelo territorial integrado. En primera instancia se obtuvo el modelo de Retención de excesos de precipitación por cobertura vegetal-RexCV-, original propuesto por Eco-ser. De este modelo se obtuvieron valores relativos entre 0 y 1 de las áreas específicas de la cuenca donde el territorio es capaz de retener, de manera más eficiente los excesos producto de las precipitaciones (Figura 58), dados los condicionantes de biomasa, variación de biomasa, condiciones geomorfológicas del terreno y la textura del suelo para el año 2017. Posteriormente se agregaron las superficies de área impermeabilizada efectiva relevadas para este año en la cuenca (Figura 48). Esto determinó en primera instancia aquellas áreas que frente al escenario actual no se encuentran disponibles en el ecosistema para llevar a cabo esta función. Se propone para una instancia posterior, avanzar en la mejora del modelo propuesto por Carreño et al.(2012) para incorporar al algoritmo utilizado, el impacto del suelo urbano a los efectos de comparar los resultados aquí expuestos. 


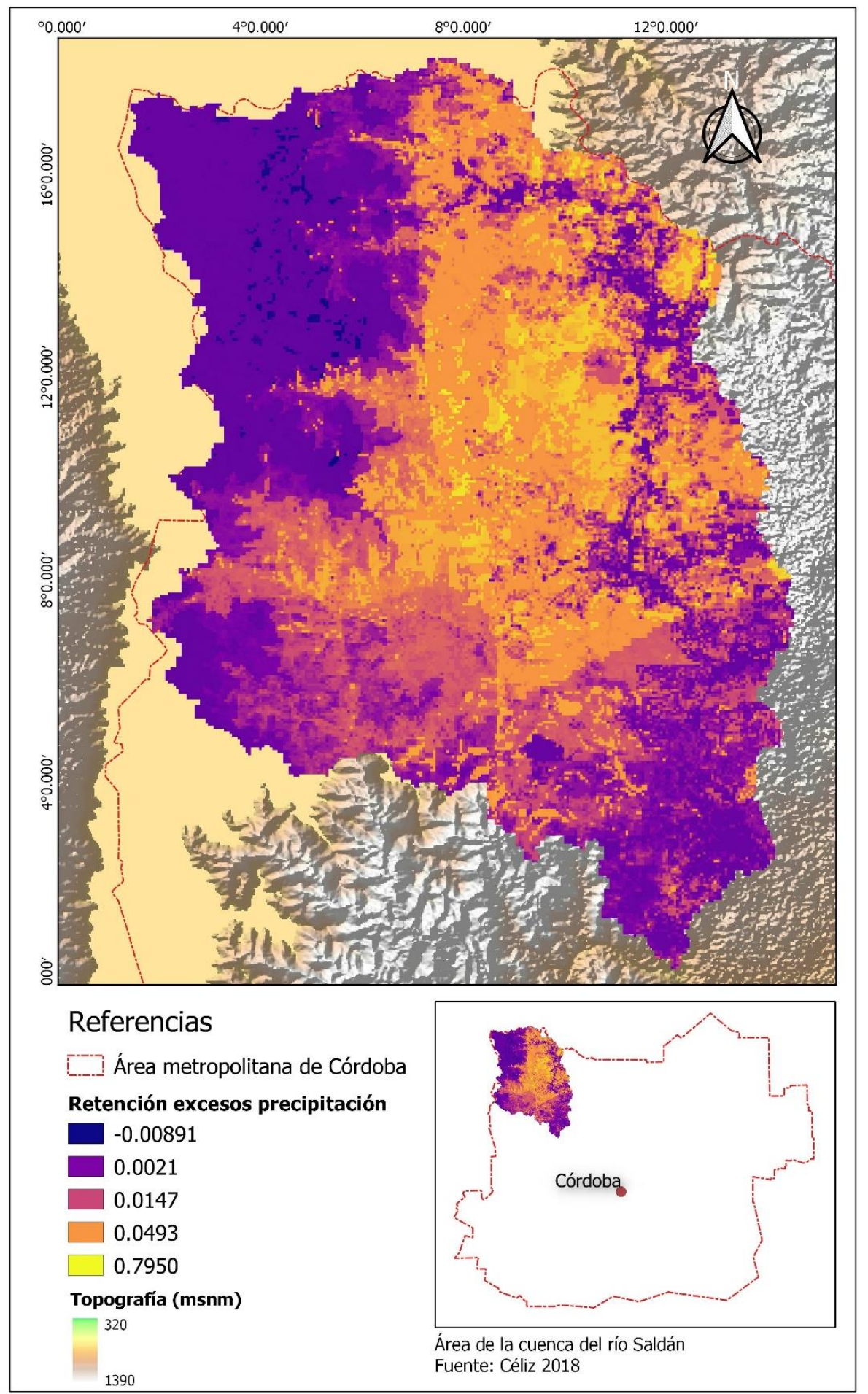

166

Figura 58. Modelo de retención de excesos de precipitación por cobertura vegetal para el año 2017 en la cuenca SaldánCórdoba. Los valores representados en amarillo constituyen las zonas con mayor aptitud de retención de excesos de precipitación por cobertura vegetal del sistema. Dado que este modelo no incluye el impacto del área urbana como insumo, este modelo pretende que en el total de la cuenca no existe superficie urbanizada. Fuente: Céliz, 2018. 
Es importante señalar que este mapa es el resultado de un modelo matemático, por lo que el resultado no es irrefutable y como todo modelo resulta en una simplificación de la realidad por lo que es imposible incluir todos los factores territoriales que puedan determinar con exactitud estos resultados. Se trata de procesos que incluyen los sistemas y a los que afectan y son afectados los seres humanos. Estos datos son suministros para repensar la forma en que se planifica el territorio y como "olvidar" aquello que es fundamental, como el agua, el bosque o el suelo, puede ser crítico no sólo en términos de la vida de las personas que se pierden en un contexto de cambio global, sino que nos privaremos de disfrutar de algo inestimable tanto en modelos como irremplazable en términos económicos como es el ambiente natural.

\section{Áreas críticas de interfase o el avance de la impermeabilización del suelo}

Dado que le modelo empleado en la cuantificación de la función ecosistémica de REPXCV, no incorpora superficies de uso de suelo urbano debido al origen agronómico con que se plantea este modelo, es necesario contraponer la variable urbana a los resultados obtenidos en el modelo original (Figura 58). Los valores de superficie urbana efectiva, definidos previamente por porcentaje de área impermeabilizada (Tabla 16), fueron incorporados al modelo inicial y se re-calcularon los resultados de superficie de retención de excesos de precipitación por cobertura vegetal (Figura 59).

Asimismo, como ya se expuso, la metodología mediante la cual se definió el área urbana efectivamente ocupada, no incorporó superficies de uso de suelo urbano de baja densidad ya que para el área impermeabilizada se incluyeron porcentajes elevados de antropización del suelo. En muchos casos, las áreas de baja densidad ofrecen grandes superficies de absorción de excesos de precipitación. Esto no determina que un área no urbanizada dentro de la ley 9841/10 (IPLAM, 2012) fuera a permanecer en esta condición. Bajo esta lógica se analizó la zonificación propuesta por dicha ley para los usos de suelo de la cuenca y cuáles son los impactos en términos de superficie de esta zonificación en términos de antropización de zonas con capacidad de retener excesos de precipitaciones en condiciones de lluvias extraordinarias.

Los aumentos de superficie impermeabilizada por urbanización según los datos que proporcionan las leyes de IPLAM (2012) indican que, si la superficie efectivamente urbanizada aumenta según los diferentes niveles de urbanización propuestos, la reducción de las funciones que el ecosistema lleva adelante para retener los excesos de precipitación aumenta considerablemente (Tabla 21). Esto nos permitió observar e identificar las áreas de interfase crítica (Figura 60). 


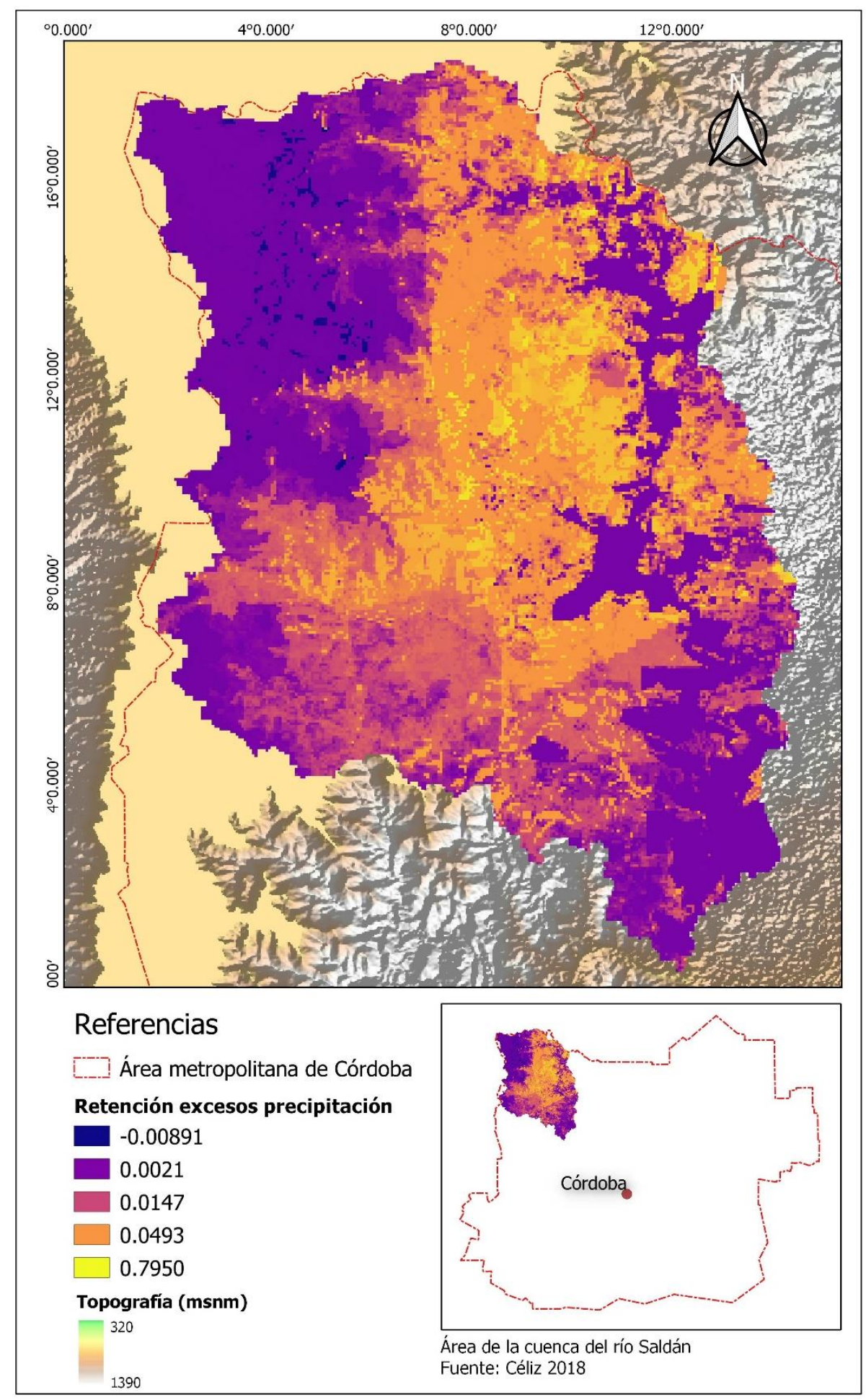

Figura 59. Modelo de retención de excesos de precipitación por cobertura vegetal para el año 2017 en la cuenca SaldánCórdoba. Los valores representados en amarillo constituyen las zonas con mayor aptitud de retención de excesos de precipitación por cobertura vegetal del sistema. La incorporación de la variable urbana le otorga los valores más cercanos a 0 a la superficie impermeabilizada y aumenta la superficie del valle no apta para retención. Fuente: Céliz, 2020. 
Tabla 21. Comparación del impacto de superficie impermeabilizada (Céliz, 2017) y área de uso de suelo urbano consolidado (IPLAM, 2012)

\begin{tabular}{|l|c|}
\hline \multicolumn{1}{|c|}{ Superficies por categorías } & ha \\
\hline Superficie de REP xCV inicial & 1260 ha. \\
\hline (1) Superficie de REP xCV con impacto urbano efectivo & 1129 ha. \\
\hline (2) Superficie de REP xCV con impacto urbano IPLAM & 893 ha. \\
\hline $\begin{array}{l}\text { (3) Superficie de REP xCV con impacto urbano total } \\
\text { IPLAM }\end{array}$ & 720 ha. \\
\hline
\end{tabular}

Nota: Elaborado en base a algebra de mapas producidos para esta tesis. Por un lado, Figura 43 de datos re-construidos de Leyes (IPLAM,2012) y Figura 58 de funciones de regulación hidrológica: retención de excesos precipitación por cobertura vegetal. Fuente: Céliz, 2018.

Si se tiene en cuenta la superficie con impacto urbano efectivo (1), es decir aquella que se ha definido en este trabajo como: superficie efectivamente impermeabilizada, la reducción de la capacidad del ecosistema de retener excesos de precipitación se reduce en un 10\%. Esto constituye la pérdida real al momento, producto de un ajuste del modelo inicial al incorporar el factor urbano, no considerado por el modelo biofísico original. Para el caso de la superficie denominada por IPLAM como urbano consolidado (2), la pérdida de la capacidad del ecosistema de responder a excesos de precipitación se reduce en un 30\%. Esta zonificación plantea a diferencia de la ocupación efectiva que el porcentaje de urbanización en zonas de protección aumenta un $20 \%$ a la actual (calculada para el año 2017). Si consideramos el resto de la superficie destinada a urbanización de la cuenca, incluyendo urbanización excepcional y condicionada (3), la pérdida de la función ecosistémica analizada asciende a un 42\%.

En la figura 60, se espacializaron los valores arriba descriptos con el objetivo de establecer la real criticidad de la interfase analizada en este proceso de investigación. Los valores expresados en la clase blanco tiza, representan la superficie efectivamente impermeabilizada. Esto indica la superficie urbanizada consolidad para el año 2017. Como se ha mencionado anteriormente, esto no significa que no existan superficies urbanizadas en el resto de la cuenca, sin embargo; la morfología de baja densidad significa que no se trata de superficie impermeabilizada de gran impacto frente al ciclo analizado de intercepción de agua de lluvia por superficie.

La superficie en naranja y fucsia, representan el resto de los usos de suelo urbano (consolidad, prioritario, condicionado, especial y diferido) propuesto por la zonificación que rige actualmente el uso del suelo.

El análisis cuantitativo que se presenta en este sentido, corresponde al año 2017 y no significa que su consideración en el tiempo le asegure el mismo valor, ya que los procesos de ocupación real del suelo de la cuenca y en la interfase como se ha mencionado, los procesos de transformación ocurren con una dinámica intensa. Sin embargo, es posible utilizar este modelo para clarificar los procesos críticos de interfase que se han descripto como hipótesis de este trabajo de investigación. 


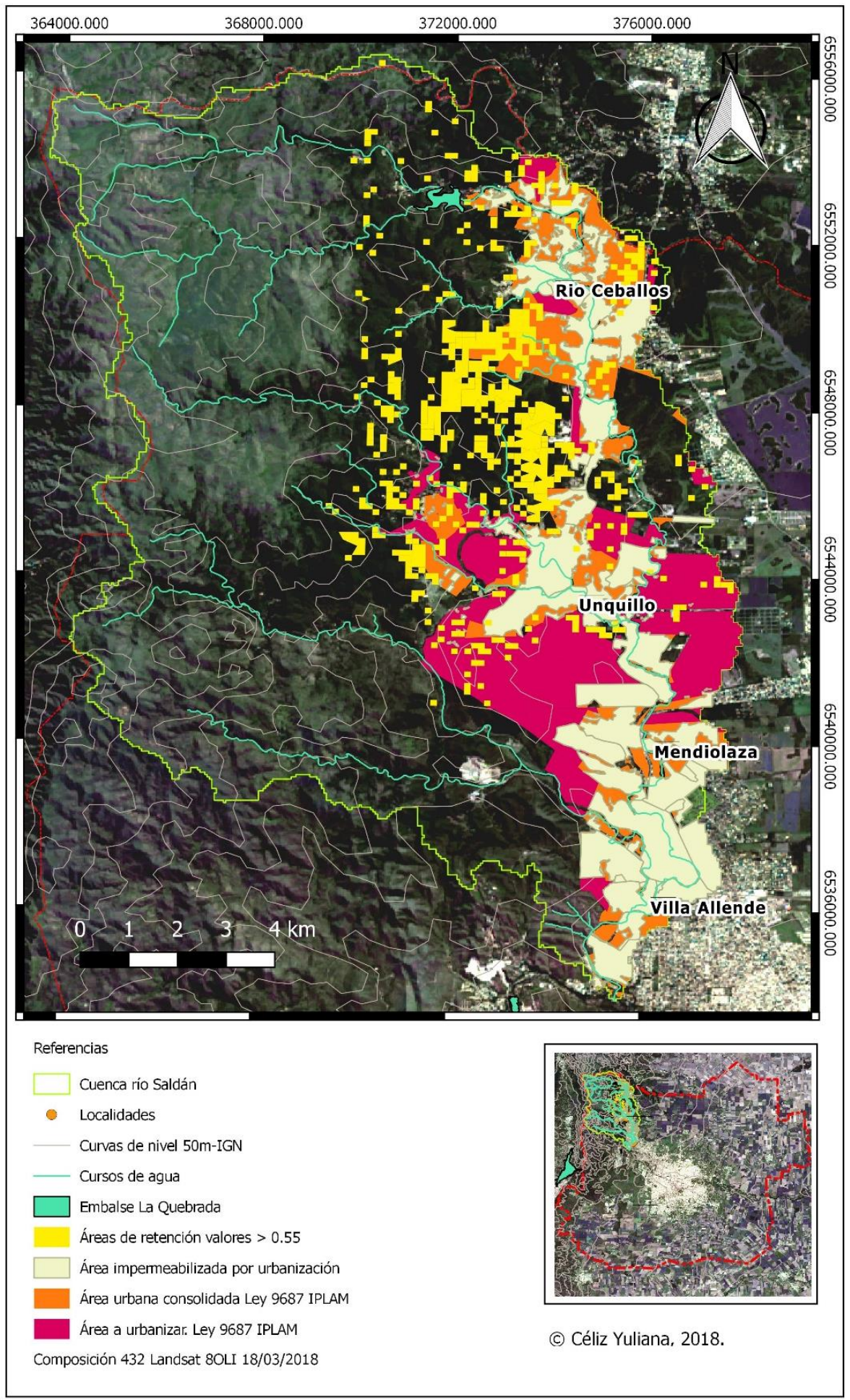

Figura 60. Interfase crítica y afectación por impermeabilización urbana y prospectiva de áreas a urbanizar según Ley 9687/10 del IPLAM. A los efectos de trabajar con el área de interfase urbana, se tomaron los valores mayores a 0.055 del indicador de retención de excesos de precipitación por cobertura vegetal final -REPxCV-. Fuente: Céliz, 2018. 


\section{Definición del modelo territorial integrado}

La incorporación de una zonificación a partir del modelo de REPxCV es en términos parciales, la determinación de áreas de protección ecosistémicas en el proceso de diagnóstico para una planificación territorial a escala de cuenca. Si esta zonificación es incorporada a la gestión del paisaje en términos de conservación de áreas naturales, por ejemplo, asociados a la zonificación del OTBN del área de estudio, se refuerza la propuesta de incorporar planes de manejo para áreas de máxima protección de bosque en la interfase urbano-natural (Figura 61).

A su vez, las áreas que han sido definidas como riesgo para la cuenca, asociadas a la ocurrencia de inundaciones y el aumento de caudales en ríos y arroyos, en el caso de las localidades de Unquillo y Río Ceballos tienen como área de soporte a zonas de REPXCV, por lo que resulta de gran interés en términos de planificación local.

Por otro lado, y dados los resultados obtenidos por el modelo es de gran importancia que la mayor cantidad de superficie asociada a la REPxCV se encuentra en el área de interfase urbano-natural, cuando no es en el área urbana. Esto constituye razón suficiente para considerar esta variable en la planificación local-regional del sector. Un modelo territorial integrado incluirá no sólo decisiones respecto a zonificación y usos de suelo sino también aspectos naturales como cursos de agua y principales arroyos, cotas de nivel, tipos biofísicos y la mayor cantidad de funciones ecosistémicas que estén asociadas a la espacialización de superficies necesarias para garantizar el intercambio de flujos sostenibles en el socio-ecosistema. 


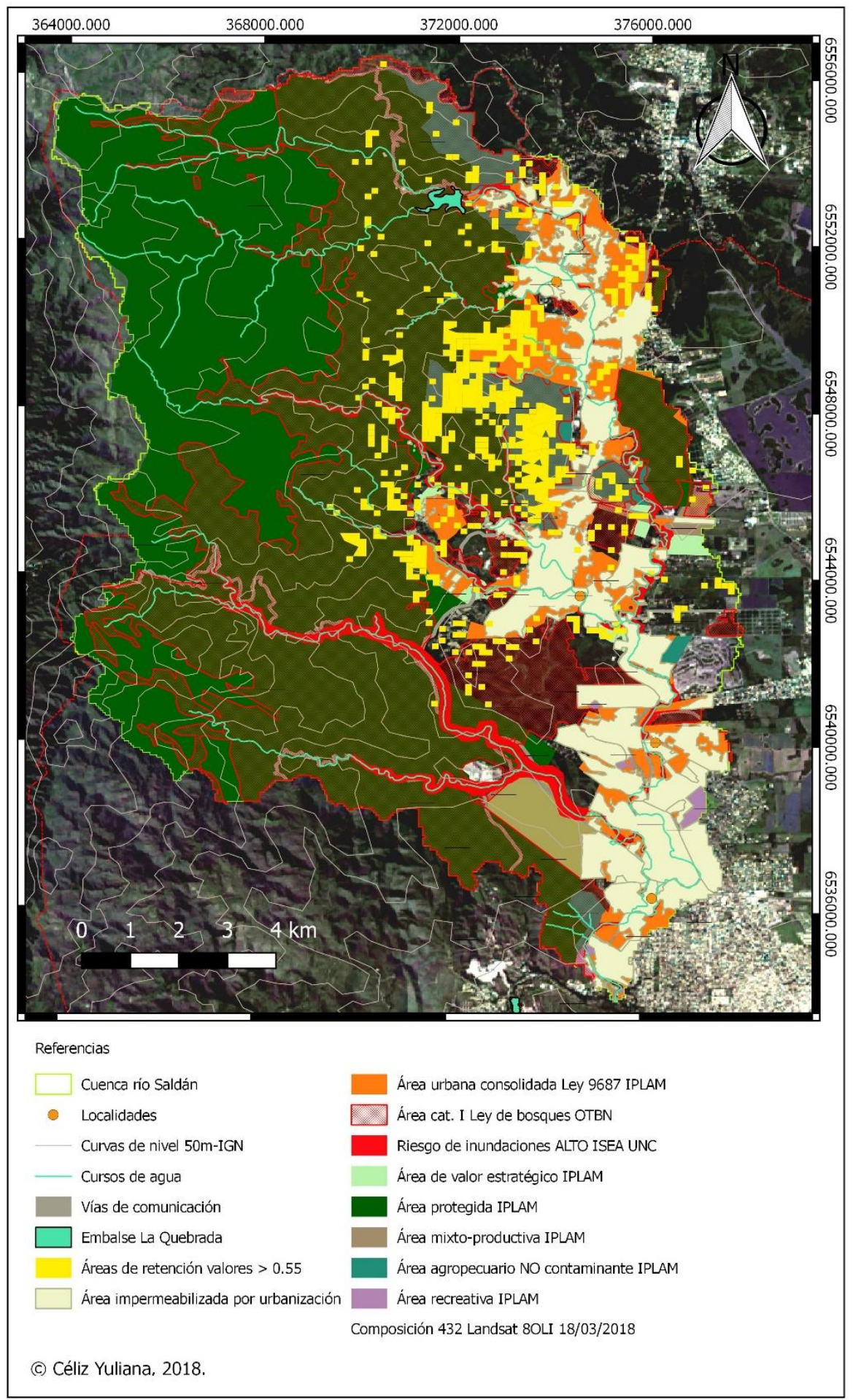

Figura 61. Modelo territorial integrado. En este mapa se integraron las zonificaciones más importantes de áreas de protección ambiental, la zonificación de riesgo sobretodo urbana y las áreas de retención de excesos de precipitación por cobertura vegetal (REPXCV), incluyendo la superficie urbana e impermeabilizada efectiva para el año 2017. Fuente: Céliz, 2018. 


\section{Cap. 05}

Conclusiones y debate 


\section{Conclusiones}

El objetivo general planteado por esta tesis estuvo orientado a generar aportes a la planificación del territorio a partir de la incorporación de contenidos de otras disciplinas en la lectura y diagnóstico de casos. En particular se seleccionó el caso del sistema urbano serrano de la cuenca del río Saldán en la provincia de Córdoba dada la relevancia del proceso de urbanización en el sector de los últimos treinta años y la posibilidad de constatar los datos producidos, con informes científicos y estudios realizados en el territorio estudiado.

Esta tesis permitió llevar adelante dos procesos que fueron construyéndose y alimentándose mutuamente. Por un lado, el aprendizaje de la metodología cuantitativa de modelos a partir de imágenes satelitales y su traducción a la arquitectura y el urbanismo y, por el otro lado, el estudio de casos de Sierras Chicas no sólo desde el enfoque de la planificación tradicional sino desde la articulación con otras disciplinas que enriquecieron la mirada.

El enfoque metodológico general de esta tesis fue desde la investigación cuantitativa por lo que la mayoría de los datos aquí plasmados fueron construidos a partir de técnicas y métodos cuantitativos. Sin embargo y aunque no ha sido plasmado específicamente, los actores del territorio han aportado la mirada más específica de este trabajo definiendo la criticidad del socio-ecosistema desde el enfoque de los asentamientos humanos, un enfoque que aquí no es desarrollado pero que sin dudas es la otra mitad de una lectura territorial integral.

El trabajo realizado, en términos generales permitió establecer la existencia de relaciones entre la incorporación de enfoques metodológicos propios de las ciencias biológicas y agronómicas al ordenamiento territorial y la detección de superficies 0 áreas críticas para la preservación de servicios ecosistémicos en el territorio serrano noroeste de la ciudad de Córdoba. De esta manera, los últimos treinta años planteados como recorte temporal de estudio y, la constatación con las diferentes propuestas de ordenamiento territorial tradicional, demuestran que no tener en cuenta los procesos ecosistémicos en la generación de planes territoriales, anula la posibilidad de reducir riesgos y aumenta la reducción de áreas estratégicas en la provisión de servicios ecosistémicos.

Meadows en 1972 planteaba que nada puede crecer indefinidamente en un medio finito y al menos desde entonces, existe la noción de que no es posible antropizar el territorio sin asumir los costos que ello implica. Como se expuso a lo largo del MT, los procesos de urbanización han respondido a diferentes demandas de las sociedades con sus diferencias pero que permitieron establecer etapas de la demanda ecosistémica. Como conclusión de los procesos que expresaban tanto Ascher como Soja, las revoluciones urbanas establecieron demandas claras al territorio: en principio la demanda de lo rural como forma de alimentar a las ciudades, la expansión de la conquita del territorio y la globalización de las ciudades en la acumulación. Esta última etapa ha permitido verificar que 
existe una demanda de lo natural al territorio, una valoración más consciente de los procesos ecológicos que generan bienestar humano. En el caso estudiado, un proceso de expansión sobre áreas serranas de bosque en contraposición a los centros urbanos. Entonces, dada la tradición estadounidense de nuestras ciudades, la tendencia está vinculada a la generación de pautas para la futura ocupación y no tanto a ordenar lo que existe. Esta inercia en la ocupación del territorio se ha verificado, genera pérdidas de áreas críticas sobre todo en la interfase. La constatación de los resultados aquí expuestos con las propuestas de ocupación territorial de los planes vigentes para la región así lo han demostrado.

\section{Conclusiones I}

\section{De la metodología propuesta}

Uno de los desafíos más importantes de la investigación estuvo dado por la traducción de la herramienta "Eco-ser, protocolo para el mapeo de servicios ecosistémicos", un software de modelado de servicios ecosistémicos desarrollado desde la visión de las ciencias agrarias y en vistas del ordenamiento territorial rural.

Los modelos probados y el posterior modelo utilizado específicamente: el de la función de retención de excesos de precipitación por cobertura vegetal fue planteado para un escenario netamente rural o natural, pues la variable urbana no era determinante para la obtención de superficies de provisión de esta función. De esta manera la obtención de resultados implicaría un margen de error muy amplio, teniendo en cuenta que, al proporcionar información al modelo sobre características de suelo, el suelo urbano no existía como variable por lo que fue necesario incorporarla a partir de la construcción de cartografía específica. De esta manera se estimó como primera necesidad para acercar el modelo a los planificadores urbanos, incorporar inputs básicos para modelar servicios en entornos periurbanos y urbanos: el primero, el uso del suelo urbano como condicionante. En el caso de esta tesis se consideró el suelo urbano como suelo impermeable.

Otra dificultad encontrada en la metodología estuvo asociada al territorio serrano como condicionante del modelo antes mencionado, se entiende que el territorio en cuestión presentaba características propias de un área de interfase pedemontana, si bien la urbanización se desarrolla en gran porcentaje en área de valle, la incidencia para la retención de excesos de precipitación es de suma importancia. Para este caso, la incorporación del dato de pendiente era posible, sin embargo, en el desarrollo de pruebas del modelo se observaron que esta variable esta incorporada de manera tal que condiciona completamente a los resultados ya que a partir del razonamiento "a mayor pendiente, menor capacidad del territorio de retener excesos de precipitación", el resto de los factores que si tenían gran relevancia en este proceso se veían afectados, pero no he podida determinar en qué medida. Más claramente: la superficie de bosque en este modelo no parece tener gran incidencia en la retención de excesos de 
precipitación por cobertura vegetal, sin embargo, desde el apartado teórico e incluso el saber colectivo-la superficie de bosque incide enormemente en este proceso hidrológico. Estos hallazgos nos llevan a las siguientes preguntas: ¿Es necesario indagar en los algoritmos y los procesos internos de toma de decisiones del modelo para conocer cuál es el grado de incidencia real de cada variable en la construcción del modelo?

¿Es posible incorporar al proceso del servicio ecosistémico estudiado una función específica relativa a la capacidad del ecosistema bosque de retener excesos de precipitación o retardar el escurrimiento de agua durante un evento de lluvias extraordinarias?

Estos cuestionamientos, a su vez, plantean el interrogante de que si es posible simplificar los procesos que son necesarios llevar adelante para la construcción de estos modelos o si la construcción de modelos territoriales es una especificidad de la que los planificadores pueden permanecer ajenos.

El planteo no es retroceder hacia la especificidad de la disciplina sino al contrario, la necesidad de incorporar nuevos marcos teóricos para poder abordar el desafío de los servicios ecosistémicos me permitió entender los procesos metodológicos para su medición -o evaluación- por lo que fue posible realizar una lectura crítica de la metodología, incluso incorporando un enfoque urbano. De esta manera, y entendiendo que las metodologías son procesos en construcción continua; resulta en un gran aporte el debate en sí mismo.

Para esta tesis el planteo metodológico ha resultado de gran importancia dado el marco teórico planteado desde los sistemas complejos y los servicios ecosistémicos el desafío más importante consistía en verificar la necesidad de incorporar enfoques de procesos biofísicos en la planificación territorial, de la misma manera en que resulta enriquecedor la comprensión de estos procesos, la traducción en herramientas para la planificación es de igual manera una tarea compleja. Hasta el punto en que esta tesis constituye el cierre de un primer proceso de aproximación al tema puedo concluir que, en el contexto global actual, es urgente la incorporación de estos enfoques a la hora de pensar y re-pensar el territorio, de otra manera siempre es en términos ambientales, humanos y hasta económicos mucho más costoso afrontar consecuencias propias de los desequilibrios de los socio-ecosistemas y el aumento del riesgo de los asentamientos humanos.

\section{Conclusiones II}

\section{Del caso de investigación}

Como se ha mencionado a lo largo de esta tesis, las Sierras Chicas son un territorio ampliamente abordado, razón por la cual se ha seleccionado la cuenca Ceballos-Saldán a los efectos de comprobar los datos producidos con los informes realizados en este territorio y constatar la definición de áreas críticas, vulnerables o de protección. 
De la síntesis de los planes: las propuestas de planificación territorial para la cuenca a lo largo de los años e incluso posterior a la ocurrencia de lluvias extraordinarias no han logrado responder a las dinámicas territoriales que afectan el territorio. Estos planes han sido elaborados por oficinas de planeamiento en su mayoría conformadas por arquitectos - urbanistas y en el mejor de los casos se han realizado mesas de participación o consultas con algunos actores territoriales, sin embargo la ausencia de miradas de disciplinas relativas a las ciencias de la tierra, la biología y la agronomía son factores que han generado planes bi-dimensionales basados en una zonificación de usos del suelo y el desarrollo de infraestructuras viales como las únicas variables necesarias de ser definidas.

Del análisis del crecimiento urbano de la cuenca Ceballos-Saldán: se ha podido comprobar que en los últimos treinta años la superficie impermeabilizada ha crecido casi tres veces su tamaño, razón por la cual me acerco cuantitativamente a la idea de que, frente a la ocurrencia de lluvias extraordinarias, el aumento de la superficie impermeabilizada constituye un límite crítico en el intercambio de flujos del sistema serrano.

La realización de los mapas de funciones ecosistémicas permitió constatar la pérdida de la capacidad de la cuenca de retener excesos de precipitación en caso de lluvias extremas. Los factores que han determinado esta pérdida están directamente relacionados con la impermeabilización del suelo. Estos datos han sido constatados con la generación de dos mapas (1987-2016). La superficie de retención de excesos de precipitación por cobertura vegetal para el año 1987 es significativamente mayor que la superficie que aún queda en el año 2016 para la misma cuenca. Estos mapas fueron generados a los efectos de identificar zonas críticas en términos de protección y preservación de las capacidades del sistema. La generación de esta información estuvo relacionada a los mapas de riesgo generados por el Instituto Superior de Estudios Ambientales que fueron generados posterior al último evento de lluvias extraordinarias registrado en Sierras Chicas. la conclusión a la que arribamos es que ambos productos son complementarios: mientras que los mapas de riesgo determinan una cota máxima de urbanización menor a una pendiente del 28\%, los mapas de retención de excesos de precipitación por cobertura vegetal aportan superficie crítica que debería ser protegida por ser las "últimas áreas que aportan al sistema esta función ecosistémica". Estos datos, junto con la generación de otros relativos a otras funciones que brinda el ecosistema bosque constituyen la lectura de las dinámicas del territorio no como una fotografía -a los efectos de un plan-sino como funcionamiento de la interacción de sistemas para un determinado momento. Los mapas generados de esta función ecosistémica deben ser complementados como se ha dicho con otras funciones para obtener no sólo la vulnerabilidad del sistema en general en términos de provisión de servicios ecosistémicos sino, en una escala menor la definición de áreas buffer o de amortiguamiento de las áreas críticas definidas de provisión de funciones ecosistémicas. Este estudio deberá quedar para una instancia posterior de profundización del tema. 


\section{Debate}

El proceso de planificación tradicional, especialmente en los países latinoamericanos ha estado digitado en la mayor parte de su desarrollo por agentes externos. Todas las etapas analizadas han estado determinadas por modelos de ordenamiento territorial, tanto europeos como norteamericanos, que hasta hoy siguen marcando las bases de la normativa local. Incorporar las dinámicas propias y articularlas con las bases de planes rígidos y modelos abstractos ha resultado en el mejor de los casos en copias de experiencias exitosas con alguna variante local. Sin embargo, y a pesar de estos factores estas propuestas aún siguen siendo zonificaciones estáticas que no contemplan las variables que afectan al territorio y sus actores en términos de procesos.

El ambiente no es un enfoque específico ni una dimensión más en una lista de variables de un plan o una estructura urbana -si pensamos a escala de urbanismo-, el ambiente es todo cuanto interactua en el territorio, incluye los procesos biofísicos y los asentamientos humanos, tanto como las interacciones entre ambos. Este simple razonamiento invita a pensar cuál es el lugar que ocupa a la hora de pensar "ordenar" tanto la ciudad como el periurbano 0 las áreas naturales.

Esta tesis demostró que las transformaciones territoriales realizadas por los asentamientos humanos tienen una incidencia decisiva en los procesos que involucran al sistema natural. Ambos sistemas se encuentran en un estado constante de interacción y de intercambio de flujos que los determinan. El sistema natural es alterado y responde de manera crítica a distintos procesos biofísicos que antes podía desarrollar de manera equilibrada. El sistema de Ios asentamientos humanos aumenta su vulnerabilidad frente a estos acontecimientos extraordinarios. Estas interacciones no son tenidas en cuenta en la planificación, esto puede deberse a la complejidad que presentan, a la falta de articulación entre disciplinas e incluso a la falta de información base con que se cuenta sobre determinados territorios y procesos.

Los resultados obtenidos en términos cuantitativos son significativos en cuánto a disminución de capacidades del sistema de llevar acabo determinadas funciones. Esto si bien constituye un dato cuantitativo innovador no es ajeno a las consecuencias experimentadas por los habitantes de Sierras Chicas que han sufrido inundaciones, incendios

y otros eventos extremos que se han visto intensificados a medida que lo hacia la superficie urbanizada en entornos que se percibían, hasta no hace mucho tiempo como naturales y hoy presentan un perfil casi urbano. Si bien estos resultados sólo constituyen una primera aproximación a una temática sumamente compleja como es identificar las dinámicas biofísicas de transformaciones en territorios de interfase urbano-natural, constituyen un elemento de valor empírico para marcos teóricos internacionales como el de los servicios ecosistémicos que son ampliamente cuestionados por ser, en la mayoría de los casos enfoques elegidos para valoración económica de bienes y servicios ambientales. No siendo este caso el de la valoración económica de servicios ecosistémicos, las herramientas 
disponibles que han sido abordadas desde estos marcos teórico-metodológicos han aportado la posibilidad de avanzar en ejemplos concretos de pérdida de condiciones anteriores a impulsores de cambios del sistema, en este caso: el avance de la urbanización de baja densidad en interfases críticas.

Una de las líneas de investigación que propone abrir esta tesis es la de los impulsores de cambios del paisaje -los cuales serán abordados en una instancia de investigación doctoral-, dado que la obtención de datos de esta etapa confirmo la alteración condiciones específicas del territorio de la cuenca, sin embargo, aún existen interrogantes respecto a la urbanización. Las hipótesis que se abren están relacionadas con el valor del suelo periurbano en relación con el suelo urbano y el efecto de migración por amenidades, que si bien fueron planteados en el marco teórico y muchas de las características que describe el proceso pueden leerse en el caso de estudio no han sido comprobadas empíricamente.

Las limitaciones que fueron encontradas durante el proceso se relacionan a la profundidad del marco metodológico específico de la generación de modelos. Si bien es posible identificar un proceso evolutivo en el entendimiento y manejo del software, nuevos interrogantes son planteados a partir del proceso de aprendizaje. Estos se relacionan con la información específica que permite generar los modelos y con el margen de error que estos pueden ocasionar. Es de suma importancia constatar que la utilización del software eco-ser estuvo dada por la posibilidad de realizar consultas y salvar dudas en el proceso con aquellos expertos en el área de manejo de imágenes satelitales y software, pero también con quienes desarrollaron y realizaron modelos de eco-ser y que han brindado toda su experiencia desinteresadamente. La propuesta ahora es, avanzar en el entendimiento de esta herramienta y de cuáles son los condicionantes preestablecidos, por un lado, y por el otro indagar en otras herramientas disponibles para el mapeo y valoración de servicios ecosistémicos.

Es importante destacar que el proceso que implicó el desarrollo de este trabajo -y no en términos de agradecimientos-contó con el apoyo y asesoramiento de profesionales de diversas disciplinas lo que no sólo implicó el enriquecimiento del proceso en sí sino que, implicó también la posibilidad de realizar una pequeña pero significante aproximación al territorio desde miradas ajenas a la arquitectura y el urbanismo. Esto en términos de un debate implica, la necesidad de pensar el territorio desde varias miradas fuera de la oficina.

Incorporar la transdisciplina a la planificación del territorio, permite abordar problemas tan complejos como la evaluación de servicios ecosistémicos en áreas de interfase no desde "la forma correcta", sino desde la pluralidad que implica reducir un margen de error, una lectura dimensional, un enfoque único. La complejidad del territorio exige, tal seriedad para leerlo. 


\section{Una reflexión sobre la complejidad}

A modo de cerrar el debate sobre los resultados de este proceso de investigación, y atendiendo a la inquietud con que se inicia este proceso y que tiene que ver con la teoría de los sistemas complejos y el desafío de incorporar los proceso y herramientas que definen y construyen esta teoría al proceso de diagnóstico territorial como primera instancia de articulación transciciplinar.

El principal problema teórico está asociado a la barrera que existe entre las incumbencias y el campo de acción de cada disciplina del territorio. Esto, fundamentado en la especialización de cada área y generando una desconexión en la construcción de conocimiento de base sobre los procesos que se llevan adelante en el mismo territorio fragmentado por el foco disciplinar.

Este trabajo se definió como un ejercicio de articulación disciplinar complejo tanto en términos teóricos como metodológicos.

La interfase planteada como objeto de estudio trasciende el hecho fijo durante el proceso y se ubica en la misma teoría que la determina. La interfase es teórica, es metodológica, es diciplinar, es física, es el campo y la ciudad. Es el campo de batalla del nuevo urbanismo de Ascher desde la mirada metropolitana, pero también es el nuevo desafío de la ruralidad en estas megaciudades-expandidas.

Este ejercicio no hubiese sido posible sin contar con actores y herramientas fuera de la arquitectura y el urbanismo. Si bien como en un laboratorio es necesario acotar el experimento, en este caso ocurre algo similar ya que han quedado abiertas nuevas posibilidades de profundizar la transdiciplina.

Es preciso dejar en claro que no se trata de abarcar todo como una mirada holística, sino que al contrario se trató de demostrar cuán necesario es incorporar otras miradas a la investigación urbana y del ordenamiento territorial. Quedan entonces abiertas las siguientes cuestiones:

¿Qué pasa cuando se abordan los procesos biofísicos del territorio? Además de una instrumentalización de un marco teórico difundido y criticado como los servicios ecosistémicos, ¿es posible cuantificar el territorio en términos de pérdidas o modificaciones críticas? ¿Solamente son afectados los servicios ecosistémicos cuando el impacto antrópico es urbano?

Todas las respuestas merecen una construcción transdiciplinar y sin embargo responderían solo a una parte de la problemática territorial. Esto nos ubica nuevamente en el bucle tetralógico de Ciurana, en donde la alimentación y la retroalimentación no sólo construye nuevos objetos de estudio, sino que decanta respuestas que no son posibles de obtener desde una mirada única y por lo tanto sesgada del proceso complejo que es la ciudad como ecosistema social por excelencia. 


\section{Bibliografía}

Abramo, Pedro. 2012. "La Ciudad Com-Fusa: Mercado y Producción de La Estructura Urbana En Las Grandes Metrópolis Latinoamericanas." Eure 38(114): 35-69.

ADEC. 2014. Prospectiva Territorial Para El Área Metropolitana de Córdoba. Informe Descriptivo Del Sistema Del AMC. Córdoba.

Aizpuru, Maite Zapiain. 2003. Los Límites Del Crecimiento: Informe Al Club de Roma Sobre El Predicamento de La Humanidad.

Ambrosino, Silvio et al. 2004. Inundaciones Urbanas En Argentina. 1ra ed. ed. Juan Carlos Bertoni. Córdoba: Estudio Tríptico.

Ascher, François. 2004. Los Nuevos Principios Del Urbanismo. El Fin de Las Ciudades No Está a La Orden Del Día. Madrid: Alianza.

Ávila Sánchez, Héctor. 2001. "Ideas y Planteamientos Teóricos Sobre Los Territorios Periurbanos. Las Relaciones Campo-Ciudad En Algunos Países de Europa y América." Investigaciones Geográficas 1(45): 108-27.

Bahr, Jurgen, and Ricardo Riesco. 1981. "Estructura Urbana de Las Metrópolis Latinoamericanas. El Caso de La Ciudad de Santiago." Revista de Geografía Norte Grande 8: 27-55.

Banco Mundial. $2016 . \quad$ "Datos de Población Urbana." https://datos.bancomundial.org/indicador/SP.URB.TOTL.IN.ZS (May 29, 2018).

Barchuk, Alicia. 2016. "Riesgos En Sierras Chicas Ante Los Cambios de Uso Del Suelo." Tecyt. Taller de estudios de la ciudad y el territorio (2): 26-31. https://revistas.unc.edu.ar/index. php/tecyt/article/view/15293.

Barral, María Paula. 2016. 1 Tutorial Mapeo ECOSER. Protocolo Colaborativo de Evaluación y Mapeo de Servicios Ecosistémicos y Vulnerabilidad Socio-Ecológica Para El Ordenamiento Territorial. Buenos Aires.

Barros, Vicente, Hernán Carlino, Eugenia Magnasco, and Graciela O. Magrin. 2015. Secretaria de Ambiente y Desarrollo Sustentable de la Nación Tercera Comunicación Nacional de La República Argentina a La Convención Marco de Las Naciones Unidas Sobre El Cambio Climático. Buenos Aires.

Barsky, Andrés. 2005. "El Periurbano Productivo, Un Espacio En Constante Transformación. Introduccín Al Estado de Debate, Con Referencias Al Caso de Buenos Aires." Scripta Nova. Revista electrónica de Geografía y Clencias Sociales 9(194): 1-13.

Bauman, Zygmunt. 1999. La Globalización. Consecuencias Humanas. 2da ed. México D.F.: Fondo de Cultura Económica.

Benedetti, Alejandro, and Patricia Souto. 2011. Territorio , Lugar, Paisaje. Prácticas y Conceptos Básicos En Geografía. ed. Patricia Souto. Buenos Aires: Editorial de la Facultad de Filosofía y Letras. Universidad de Buenos Aires.

Bengoetxea Urizu, Juán Antonio. 2001. "Principios Jurídicos Para La Ordenación Del Territorio." BIBLID (8): 79-101.

Berkes, Fikret, and Carl Folke. 1998a. Linking Social and Ecological System. Management Practices and Social Mechanisms for Building Resilience. first publ. eds. Fikret Berkes and Carl Folke. New York: Cambridge University Press.

- - - 1998b. Linking Social and Ecological Systems. Managment Practices and Social Mechanisms for 
Building Resilience. Cambridge: Press Syndicate of the University of Cambridge.

Bolstad, Paul V, and T M Lillesand. 1991. "Rapid Maximum Likelihood Classification." Photogrammetric Engineering \& Remote Sensing 57(1): 67-74.

Boyd, James, and Spencer Banzhaf. 2007. "What Are Ecosystem Services? The Need for Standardized Environmental Accounting Units w." 3.

Browder, John O, James R Bohland, and Joseph L Scarpaci. 1995. "Patterns of Development on the Metropolitan Fringe: Urban Fringe Expansion in Bangkok, Jakarta and Santiago." APA Journal 3(61): 310.

Bryant, C. R, L.H Russwurm, and A.G McLellan. 1982. The City's Countryside. Land and Its Management in the Rural-Urban Fringe. first edit. New York: Longman.

Buller, Henry. 1991. "Péri-Urbanisation» ( France ) : Deux Modèles de Retour à La Campagne." Économie rurale (202-203): 40-43.

Busquets, Jaume, and Albert Cortina. 2009. Gestión Del Paisaje. 1a ed. eds. J Busquets and A Cortina. Barcelona: Editorial Ariel S.A.

Cárdenas Jirón, Luz. 2005. "Enfoques Metodológicos de La Planificación Urbana y Del Transporte. 19801999." Urbano 8(11): 4-14.

Cardoso, María Mercedes, and Blanca A Fritschy. 2012. "Revisión Del Espacio Rururbano y Sus Criterios de Delimitación." Contribuciones Científicas GAEA 24: 27-39.

Carreño, L, F.C Frank, and E.F Viglizzo. 2012. "Agriculture, Ecosystems and Environment Tradeoffs between Economic and Ecosystem Services in Argentina during 50 Years of Land-Use Change." Agriculture, Ecosystems and Environment 154: 68-77.

Castells, Manuel. 1989. La Ciudad Informacional. Tecnologías de La Información, Reestructuración Económica y Proceso Urbano-Regional. Madrid: Alianza.

Castronovo, R. 1998. "Dinámica Del Crecimiento Urbano En La Ciudad de Tandil: Análisis de Los Sectores Periurbanos o Rururbanos y Sus Implicancias Ambientales." In Actas de VIII Jornadas Cuyanas de Geografía, Mendoza, Mendoza, 561-66.

CEMAT. 1999. Comisión Europea Estrategia Territorial Europea. Hacia Un Desarrollo Equilibrado y Sostenible Del Territorio de La UE. https://ec.europa.eu/regional_policy/sources/docoffic/official/reports/pdf/sum_es.pdf.

CEPAL. 2010. "La Urbanización Presenta Oportunidades y Desafíos Para Avanzar Hacia El Desarrollo Sostenible." https://www.cepal.org/notas/73/Titulares2.html (May 29, 2018).

Chocat, B. 1997. Encyclopł̇die de l'hydrologie Urbaine et de l'assainissement. ed. B Chocat. Paris: Ed. Lavoisier.

Ciccolella, Pablo. 1999. "Globalización y Dualización En La Región Metropolitana de Buenos Aires . Grandes Inversiones y Reestructuración Socioterritorial En Los Años Noventa." EURE 25(76): 1-15.

- - - . 2006. "Metropolis Latinoamericanas: Territorios Subregulados, ¿espacios Del Capital?" In Las Grandes Aglomeraciones y Su Periferia Regional Experiencias En Latinoamericas, eds. H. CÁMARA DE DIPUTADOS et al. México D.F.: Universidad Autónoma de Méxio. Instituto de Geografía, 378.

- - - . 2012. "Revisitando La Metrópolis Latinoamericana Más Allá de La Globalización." riURB (8): 9-21.

Clements, Frederic Eduard. 1905. Research Methods in Ecology. eds. F Clements and Irvin S Cutter. Lincoln: Press of Jacob Hortb \& Company.

CMNUCC. 1992. 62301 Convención Marco de Las Naciones Unidas Sobre El Cambio Climático. 
Collado, A et al. 2009. Monitoreo de La Cobertura y Uso Del Suelo a Partir de Sensores Remotos. Resultados 2006-2009.

Collin, Delavaud Anne. 1993. "Moteurs et Dynamismes de La Périurbanisation En Amérique Latine." Cahiers du CREPIF (Centre de recherches et d'études sur Paris et l'île-de-France): 103-20.

Consejo de Europa. 1983. Carta Europea de Ordenación Del Territorio. Torremolinos. http://cope.sanmartindelosandes.gov.ar/wp-content/uploads/2012/09/Carta_Europea_OT.pdf.

_- - . 2000. 47 Anuario Jurídico y Económico Escurialense Convenio Europeo Del Paisaje. Italia.

Corboz, André. 1980. El Territorio Como Palimpsesto.

COTBN. 2009. Programa de Ordenamiento Territorial de los Bosques Nativos de la provincia de Córdoba Proyecto de Ley de Ordenamiento Territorial de Bosques Nativos de La Provincia de Córdoba. Córdoba.

Daily, G. D. 1997. Nature's Services: Societal Dependence on Natural Ecosystems. Washington DC: Island Press.

Dematteis, Giuseppe. 1998. "Suburbanización y Periurbanización. Ciudades Anglosajonas y Ciudades Latinas." In La Ciudad Dispersa. Suburbanización y Nuevas Periferias, ed. F.J. Monclús. Barcelona: CCCB, 1-8.

van Dijk, Albert I.J.M. et al. 2009. "Forest-Flood Relation Still Tenuous - Comment on 'Global Evidence That Deforestation Amplifies Flood Risk and Severity in the Developing World'by C. J. A. Bradshaw, N.S. Sodi, K. S.-H. Peh and B.W. Brook." Global Change Biology 15(1): 110-15.

Dilley, Max et al. 2005. Natural Disaster Hotspots. A Global Risk. Washington DC: The World Bank and Columbia University.

Escribano, R, A Encinas, and M A Martin. 1997. Ecotonos: Importancia de La Transición Entre Agrupaciones Arbóreas y El Matorral En La Gestión Forestal. Estudio de Casos. Madrid.

FAO. 2005. 2 Forests and Floods: Drowning in Fiction or Thriving on Facts? ed. FAO \& CIFOR. Situ Gede, Sidang Barang, Bogor Barat: CIFOR- The Center for International Forestry Reserch. FAO. citeulikearticle-

id:349739\%5Cnhttp://uww. cifor.cgiar.org/scripts/newscripts/publications/detail.asp?pid=1849.

Fernández, Roberto. 2000. La Ciudad Verde. Teoría de La Gestión Ambiental Urbana. 1ra ed. ed. Ana Olszewski. Buenos Aires: Espacio Editorial.

Garay, ALfredo M. 2013. "Líneas de Borde y Franjas de Transición." In Cien Cafés, 100 Textos Nuevos, 100 Autores, 100 Notas de Café de Las Ciudades, 100 Datos Sobre La Ciudad Futura, ed. Marcelo Corti. Buenos Aires: Editorial Café de las Ciudades, 38-40.

García, Rolando. 2006. Agora Philosophica Sistemas Complejos. Conceptos, Método y Fundamentación Epistemológica de La Investigación Interdisciplinaria. Barcelona: Gedisa S.A.

García Vázquez, Carlos. 2008. Ciudad Hojaldre. Visiones Urbanas Del Siglo XXI. Barcelona: Gustavo Gill.

Gavier, Gregorio I, and Enrique H. Bucher. 2004. "Deforestación de Las Sierras Chicas de Córdoba (Argentina) En El Período 1970-1997." Academina Nacional de Ciencias. MIscelánea 101: 4-27.

Giobellina, Beatriz. 2011. "La Defensa Del Suelo Agrícola de Calidad Como Recurso Finito y Estratégico Para La Soberanía Alimentaria y La Sustentabilidad Local y Global." Universitat Polotécnica de Valencia.

Giunta, Juan Domingo. 2014. Córdoba Una Ciudad En Cifras. Guía Estadística de La Ciudad de Córdoba. Córdoba. 
De Groot, R. et al. 2012. "Integrating the Ecological and Economic Dimensions in Biodiversity and Ecosystem Service Valuation." The Economics of Ecosystems and Biodiversity:Ecological and Economic Foundations: 9-40.

Haesbaert, Rogério. 2004. "Dos Múltiplos Territórios á Multiterritorialidade." : 1-20.

- - - . 2010. "Regional-Global, Dilemas Da Região e Da Regionalização Na Geografía Contemporânea." Betrand Brasil: 208.

Haines-Young, Roy, and Marion Potschin. 2010. "The Links between Biodiversity , Ecosystem Services and Human Well-Being." In Ecosystem Ecology: A New Synthesis, eds. David G Raffaelo and Christopher J J Frid. Cambridge University Press.

- - - 2013. Report to the European Environment Agency Common International Classification of Ecosystem Services (CICES): Consultation on Version 4. August-December 2012. Nottingham. uww.cices.eu.

Halffter, Gonzalo. 1994. "¿Qué Es La Biodiversidad?" Lletres de Batalla (62): 5-14.

Holland, Marjorie M, and Paul G Risser. 1991. "The Role of Landscape Boundaries in the Management and Restoration of Changing Environments." In Ecotones, eds. M.M Holland, P.G Risser, and R.J Naiman. Boston: Springer.

IPCC. 2013. "Glosario." In Cambio Climático. Bases Físicas. Contribución Del Grupo de Trabajo I Al Quinto Informe de Evaluación Del Grupo Intergubernamental de Expertos Sobre El Cambio Climático, eds. T.F Stocker et al. Cambridge, Reino Unido y Nueva York, Estados Unidos de América: Cambridge University Press.

IPLAM. 2016. Plan Director Sierras Chicas. Córdoba.

Irós, Guillermo, Enrique Moiso, César Alonso, and Augusto Bravo. 2014. Urbanización y Movilidad En El Área Metropolitana de Córdoba. Córdoba.

Jacobs, Jane. 1962. The Death and Life of Great American Cities, Reading in Planning Theory. 1st ed. ed. Jonathan Cape. London.

Jaillet, Marie-christine, and Guy Jalabert. 1982. "La Production de I ' Espace Urbain Périphérique." Revue géographique des Pyrénées et du Sud-Ouest 53(1): 7-26.

Janoschka, Michael. 2002. "El Nuevo Modelo de La Ciudad Latinoamericana: Fragmentación y Privatización." EURE (Santiago) 28(85): 1-14.

Jiménez Guerrero, Luis M. 2016. Hacia Ciudades y Territorios Inteligentes, Resilientes y Sostenibles. Gestión y Gobernanza Para La Gran Transición Urbana. 1ra ed. ed. Comité editorial ASYPS. Madrid: ASYPS. Asociación para la Sostenibilidad y el Progreso de las Sociedades.

Juillard, Etienne. 1961. "L ' Urbanisation Des Campagnes En Europe Occidentale." Études rurales (1): 1833.

Koolhaas, Rem. 1995. "La Ciudad Genérica." OMA, S,M,L,XL: 1247-54.

Kremen, Claire. 2005. "Managing Ecosystem Services: What Do We Need to Know about Their Ecology?" Ecology letters (8): 468-79.

Laterra, Pedro, María Paula Barral, Alejandra Carmona, and Laura Nahuelhual. 2015. "ECOSER: Protocolo Colaborativo de Evaluación y Mapeo de Servicios Ecosistémicos y Vulnerabilidad Socio-Ecológica Para El Ordenamiento Territorial." (October): 58. http://eco-ser.com.ar/.

Laterra, Pedro, Esteban G Jobbágy, and J. M Paruelo, eds. 2011. Valoración de Servicios Ecosistémicos: Conceptos, Herramientas y Aplicaciones Para El Ordenamiento Territorial. 1ra ed. Buenos Aires: 
Imprenta ErrGé \& Asociados.

Laterra, Pedro, Esteban G Jobbágy, and J M Paruelo. 2010. Servicios Ecosistémicos En Argentina.

Liu, Jianguo et al. 2007. "Coupled Human and Natural Systems Coupled Human and Natural Systems." Ambio 36(8): 639-49.

Lopes de Sousa, Marcelo. 2003. "Território: Sobre Espaço e Poder, Autonomia e Desenvolvimento." In Geografia: Conceitos e Temas, eds. Iná Elias Castro, Paulo César da Costa Gomes, and Roberto Lobato Corréa. Rio de Janeiro: Bertrand.

Luhmann, Niklas. 1998. Sistemas Sociales. Lineamientos Para Una Teoría General. ed. Rubí. Barcelona: Anthropos.

Maceira, Nestor. 2015. "Talleres Pre-Congreso." In Cuarto Congreso Internacional de Servicios Ecosistémicos En Los Neotrópicos: De La Investigación a La Acción, Mar del Plata: Geap. Grupo de estudio de agroecosistemas y paisajes rurales.

Mari, Nicolas, and Diego Pons. 2015. "La Observación Remota y Sus Aplicaciones a La Planificación Del Territorio Urbano-Rural." In Perspectivas de La Agricultura Urbana y Periurbana En Córdoba. Aportes Del Programa Pro Huerta a La Producción Agroecológica de Los Alimentos, eds. Beatriz Giobellina and Mario Quinteros. Córdoba: Ediciones INTA, 29-31.

Maris, Virginie. 2011. "De La Naturaleza a Los Servicios EcosistémicosU. Na Mercantilización de La Biodiversidad." EcoRev: 27-32.

Martínez, Mauricio, and Ana M. Suárez. 2015. "Percepción Ambiental de Una Comunidad Aledaña Al Río Pontezuelo, Mayarí, Noroeste de Cuba." Revista de investigaciones marinas 35(1): 58-68.

Massiris Cabeza, Ángel. 2002. "Ordenación Del Territorio En América Latina." Scripta Nova. Revista electrónica de Geografía y Clencias Sociales VI(125): 1-28.

de Mattos, Carlos A. 1984. CEPAL. Estudios e investigaciones Paradigmas, Moelos y Estrategias En La Práctica Latinoamericana de Planificación Regional. Santiago.

- - - . 2006. "Modernización Capitalista y Transformación Metropolitana En América Latina: Cinco Tendencias Constitutivas." In América Latina: Cidade, Campo e Turismo, eds. Amalia Inés Geraiges de Lemos, Arroyo Mónica, and María Laura Silveira. San Pablo: CLACSO, 36. http://bibliotecavirtual.clacso.org.ar/ar/libros/edicion/lemos/03mattos. pdf.

Maturana, Humberto R, and Francisco G Varela. 2003. De Máquinas y Seres Vivos. Autopoiesis: La Organización de Lo Vivo. 1ra ed. ed. Francisco Varela. Buenos Aires: Lumen.

Meadows, Donella H, Dennis L Meadows, Jorgen Randers, and William W Behrens III. 1972. The Limits to Growth. New York: Universe Books.

Millennium Ecosystem Assessment. 2005. Ecosystems and Human Well-Being: A Framework for Assessment. Washington DC.

Monclús, Francisco Javier. 1999. "Ciudad Dispersa y Ciudad Compacta. Perspectivas Urbanísticas Sobre Las Ciudades Mediterráneas." D'Humanitats (7): 95-110.

Morello, Jorge. 2000. "Funciones Del Sistema Periurbano : El Caso de Buenos Aires." : 49.

Morin, Edgar. 1997. Introducción Al Pensamiento Complejo. Valladolid: Gedisa. http://www.pensamientocomplejo.com.ar/docs/files/MorinEdgar_Introduccion-al-pensamientocomplejo_Parte1.pdf.

- - - 2005. "Complejidad Restringida, Complejidad General." In Intelligence de La Complexité: Épistémologie et Pragmatique, Cerisy-La-Salle, 26. 
Moulaert, Frank, Arantxa Rodríguez, and Erik Achille Marie Swyngedouw. 2003. The Globalized City: Economic Restructuring and Social Polarization in European Cities. eds. Frank Moulaert, Arantxa Rodríguez, and Erik Swyngedouw. Oxford: Oxford university press.

Muñoz, Jesús Montosa. 1999. "Población, Urbanización y Uso Del Suelo En La Franja Periurbana de Málaga." Baetica. Estudios de Arte Geografía e Historia (21): 131-36.

Odum, Eugene. 1971. Fundamentals of Ecology. 3ra ed. Philadelphia: W.B. Saunders.

Paasi, Anssi. 1986. "The Institutionalization of Regions: A Theoretical Framework for Understanding the Emergence of Regions and the Constitution of Regional Identity." Fennia 164(1): 1-42.

- - - . 2003. "Region and Place : Regional Identity in Question." Progess in Human Geography 4(27): 47585.

- - - . 2012. "Border Studies Reanimated: Going beyond the Territorial/Relational Divide." Environment and Planning 44: 2303-9.

Parisi, Daniel, and María Isabel Vargas. 2014. Análisis Del Área Metropolitana de Córdoba Mediante Un Enfoque Prospectivo Territorial.

Paruelo, J M. 2008. "La Caracterización Funcional de Ecosistemas Mediante Sensores Remotos." Ecosistemas 17(3): 4-22.

Paruelo, José M et al. 2004. "Regional Scale Relationships between Ecosystem Structure and Functioning : The Case of the Patagonian Steppes." Global Ecology and Biogeography (13): 385-95.

Peralta, Carolina. 1997. "Medioambiente \& Urbanización. El Caso Del Corredor nor-Oeste Del Área Metropolitana de Córdoba." Universidad Nacional de Córdoba. http://hdl.handle.net/11086/4583.

Pérez Andrés, Antonio Alfonso. 1998. "La Ordenación Del Territorio, Una Encrucijada de Competencias Planificadoras." Revista de la Administración Pública 147: 97-138.

Poggiese, Héctor. 2011. Planificación Participativa y Gestión Asociada (PPGA). 1a ed. Ciudad Autónoma de Buenos Aires: Espacio Editorial.

Pons, Diego, and Yuliana Céliz. 2018. "Escenarios de Cambio Climático: Hacia Líneas Estratégicas Para El Cinturón Verde de Córdoba." In La Alimentación de Las Ciudades. Transformaciones Territoriales y Cambio Climático En El Cinturón Verde de Córdoba, ed. Beatriz Giobellina. Buenos Aires: Ediciones INTA, 229-58.

Pradilla Cobos, Emilio. 2015. "De La Ciudad Compacta a La Periferia Dispersa." Ciudades (106).

Prados, Ma José. 2011. "Naturbanización. Algunos Ejemplos En Áreas de Montaña y Periurbanas." Treballs de la Societat Catalana de Geografia 71-72: 179-200.

Prados, María José. 2009. Naturbanization: New Identities and Processes for Rural-Natural Areas. ed. María José Prados. Leiden: Taylor \& Francis.

Precedo Ledo, Andrés. 2004. Nuevas Realidades Territoriales Para El Siglo XXI : Desarrollo Local, Identidad Territorial y Ciudad Difusa. Madrid: Editorial Síntesis.

Precedo Ledo, Andrés, José Javier Orosa González, and Alberto Míguez Iglesias. 2010. "De La Planificación Estratégica Al Marketing Urbano : Hacia La Ciudad Inmaterial." EURE 36(108): 5-27.

Pryor, R. J. 1937. "Defining the Rural..Urban Fringe*." Social Forces 293(November): 202-15.

Quiéter, F et al. 2007. "Servicios Ecosistémicos y Actores Sociales. Aspectos Conceptuales y Metodológicos Para Un Estudio Interdisciplinario." Gaceta Ecológica 84(85): 17-26.

Quijas, Sandra, B Schmid, and Patricia Balvanera. 2010. "Plant Diversity Enhances Provision of Ecosystem 
Services: A New Synthesis." Basic and Applied Ecology 11: 582-93.

Radeloff, V C, and J E Mckeefry. 2005. "THE WILDLAND-URBAN INTERFACE IN THE UNITED STATES." 15(3): 799-805.

Raffestin, Claude. 1980. Por Una Geografía Del Poder. El Colegio de Michoacan.

Reboratti, Carlos. 2000. Ambiente y sociedad: conceptos y relaciones Ambiente y Sociedad. Conceptos y Relaciones. Buenos Aires: Ariel.

Rees, William E. 1992. "Ecological Footprints and Appropiated Carrying Capacity: What Urban Economics Leaves Out." Environment \& Urbanization 4(121).

Rodríguez, Norberto, and Luciana Ghermandi. 2016. "Análisis General de La Interface Natural-Urbana y de La Terminología Que La Describe." Vivienda \& Ciudad (3): 67-76.

Sack, Robert David. 1986. Human Territoriality: Its Theory and History. 1st ed. Cambridge: Press Syndicate of the University of Cambridge.

Schröter, Matthias et al. 2014. "Ecosystem Services as a Contested Concept: A Synthesis of Critique and Counter-Arguments." Conservation Letters 7(6): 514-23.

Soja, Edward W. 2008. Postmetrópolis. Primera ed. ed. Traficante de Sueños. Madrid.

Steuteville, Robert. 2017. "Great Idea : Pedestrian Shed and the 5-Minute Walk." PSQ. Public square a CNU Journal: 1-10. https://www.cnu.org/.

Stocker, T.F et al. 2013. Cambio Climático 2013 Bases Físicas. Resumen Para Responsables de Políticas, Resumen Técnico y Preguntas Frecuentes. Ginebra.

Terzaga, Alfredo. 1963. Geografía de Córdoba. Buenos Aires: Editorial Assandri.

Von Thunen, J.H., and P.J Hall. 1966. "Von Thunen's Isolated State: An English Edition of Der Isolierte Staat." Pergamon Press.

Tucci, Carlos E M. 2007. Gestión de Inundaciones Urbanas. Córdoba.

Viglizzo, Ernesto F, Lorena V Carreño, José Volante, and María J Mosciaro. 2011. "Valuación de Bienes y Servicios Ecosistémicos: ¿verdad Objetiva o Cuento de La Buena Pipa?" In Valoración de Servicios Ecosistémicos: Conceptos, Herramientas y Aplicaciones Para El Ordenamiento Territorial, eds. Pedro Laterra, Esteban G Jobbágy, and J. M Paruelo. Ediciones INTA, 17-33.

Waibel, Leo. 1979. "La Teoría de von Thünen Sobre La Influencia de La Distancia Al Mercado En Relación a La Utilización de La Tierra. Su Aplicación a Costa Rica." Revista Geográfica de América Central 1(910): 119-36. http://wnw.revistas.una.ac.cr/index. php/geografica/article/view/2926. 